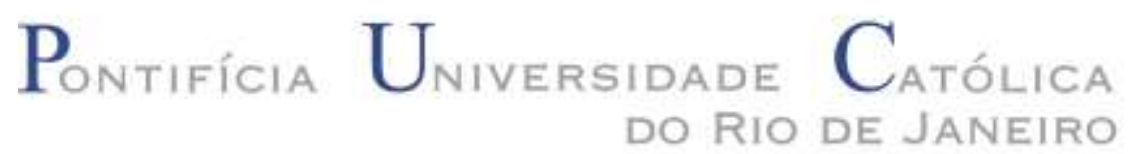

Gilvania Terto Alves

Comportamento de Aço Estrutural API 5L X65 após Exposição ao Hidrogênio: Uma Abordagem Baseada na Fratura Dúctil

Tese de Doutorado

Tese apresentada como requisito parcial para obtenção do grau de Doutor pelo Programa de PósGraduação em Engenharia de Materiais e de Processos Químicos e Metalúrgicos do Departamento de Engenha Química e de Materiais do Centro Técnico Científico da PUC-Rio.

Orientador: Prof. Marcos Venícius Soares Pereira

Rio de Janeiro

Dezembro de 2014 


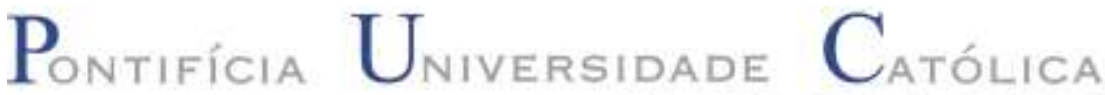

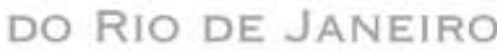

Gilvania Terto Alves

\section{Comportamento de Aço Estrutural API 5L X65 após Exposição ao Hidrogênio: Uma Abordagem Baseada na Fratura Dúctil}

\begin{abstract}
Tese apresentada como requisito parcial para obtenção do grau de Doutor pelo Programa de Pós-Graduação em Engenharia de Materiais e de Processos Químicos e Metalúrgicos do Departamento de Engenhada Química e de Materiais do Centro Técnico Científico PUC-Rio. Aprovada pela Comissão Examinadora abaixo assinada.
\end{abstract}

Prof. Marcos Venícius Soares Pereira Orientador e Presidente Departamento de Engenharia de Materiais - PUC Rio

Prof.a Ana Rosa Fonseca de Aguiar Martins Departamento de Engenharia de Materiais - PUC Rio

Prof. Fathi Aref Ibrahim Darwish Universidade Federal Fluminense - UFF

Prof. José Luiz Fernandes CEFET/RJ

Dr. Marcelo Alexandre Tirelli General Motors do Brasil

Prof. José Eugênio Leal Coordenador Setorial de Pós-Graduação do Centro Técnico Científico da PUC-Rio 
Todos os direitos reservados. É proibida a reprodução total ou parcial do trabalho sem autorização da universidade, da autora e do orientador.

\section{Gilvania Terto Alves}

Graduou-se em Engenharia Mecanica pelo Centro Federal de Educação Tecnológica do Rio de Janeiro CEFET - RJ em 2003. Especialista em Eng.a do Petróleo pela UNESA em 2005. Professora do Ensino Básico técnico e tecnológico do CEFET-RJ em 2008. Mestre em Engenharia Mecânica pela PUC-Rio em 2009.

Ficha Catalográfica

Alves, Gilvania Terto

Comportamento de aço estrutural API 5L X65 após exposição ao hidrogênio : uma abordagem baseada na fratura dúctil / Gilvania Terto Alves ; orientador: Marcos Venícius Soares Pereira. -2014.

250 f. : il. (color.) ; $30 \mathrm{~cm}$

Tese (doutorado)-Pontifícia Universidade Católica do Rio de Janeiro, Departamento de Engenharia de Materiais, 2014.

Inclui bibliografia

1. Engenharia de materiais - Teses. 2. Indústria offshore. 3. Hidrogenação. 4. Ensaios de tenacidade. 5. Propagação de trincas. I. Pereira, Marcos Venícius Soares. II. Pontifícia Universidade Católica do Rio de Janeiro. Departamento de Engenharia de Materiais. III. Título. 
Aos meus pais, Osvaldo e Maria José, e ao meu esposo Marcio de Melo Monteiro, pelo apoio, incentivo e confiança. 


\section{Agradecimentos}

A Deus, por ter me permitido vivenciar esta etapa da vida com saúde.

Aos meus pais e meu esposo Marcio de Melo Monteiro pelo incentivo.

Ao professor Marcos Venícius Soares Pereira por ter me aceitado como aluna, pela orientação e constante incentivo nos momentos difíceis.

Aos Professores participantes da Comissão examinadora.

À PUC-Rio, pelos auxílios concedidos, sem os quais este trabalho não poderia ter sido realizado.

Aos professores do DEMa, pelos conhecimentos transmitidos e funcionários PUC, em especial ao Sr. Marques pela paciência nos momentos de usinagem de corpos de prova.

Aos meus colegas da PUC-Rio, Roberta Amorim, Marcio Jardim, José Paolucci e José Alex de Galiza pela apoio nos momentos difíceis, e pelos momentos de descontração vividos nas aulas de Mecânica da Fratura.

Ao Eng. Francis de Souza e Eng. Sylvestre Scarano da Silva, ambos da Vallourec S.A., que apoiaram a realização deste trabalho e ao analista de laboratório Rondinelle Dores pela atenção durante os ensaios realizados e paciência.

A Vallourec S.A. pelo apoio financeiro essencial a realização deste trabalho.

Ao IFRJ - Paracambi, principalmente André Rocha Pimenta pela ajuda durante o andamento do trabalho. 


\section{Resumo}

Alves, Gilvania Terto; Pereira, Marcos Venícius Soares (Orientador). Comportamento do Aço Estrutural API 5L X65 após Exposição ao Hidrogênio: Uma Abordagem Baseada na Fratura Dúctil. Rio de Janeiro, 2014. 250p. Tese de Doutorado - Departamento de Engenharia Química e de Materiais, Pontifícia Universidade Católica do Rio de Janeiro.

Aços ARBL são cada vez utilizados na construção de linhas de dutos (pipelines) devido aos benefícios de pressões de linha mais elevadas, redução de peso do tubo, e, principalmente, diminuição dos riscos de falhas estruturais. Entretanto, tais tubos, em serviço offshore, podem ser fragilizados pela presença de $\mathrm{H}_{2} \mathrm{~S}$ no fluido transportado. Sendo assim, esta pesquisa estudou a influência do hidrogênio no comportamento à fratura do aço API 5L X65 por ensaios de tenacidade à fratura (CTOD e Integral $\mathrm{J}$ ) no aço com e sem hidrogênio $\mathrm{a}-30{ }^{\circ} \mathrm{C}$, o que possibilitou uma análise comparativa das duas condições. Pelos parâmetros CTOD e Integral J, se verificou ausência de redução da tenacidade à fratura do aço X65, uma vez que os valores dos parâmetros citados para a condição mais severa de hidrogenação foram similares àqueles encontrados na condição de referência. O efeito degradante provocado pelo hidrogênio foi associado a uma maior propagação de trinca durante os ensaios de tenacidade. Isto indica que o hidrogênio pode causar efeitos contraditórios no comportamento à fratura do material que estão relacionados ao tipo de investigação realizada para análise do comportamento mecânico do material (macroscópica ou microscópica), da microestrutura e às variáveis experimentais adotadas nos ensaios, tais como taxa de deformação, concentração de hidrogênio e nível de tensões.

\section{Palavras-chave}

Indústria offshore; hidrogenação; ensaios de tenacidade; propagação de trincas. 


\section{Abstract}

Gilvania Terto Alves; Pereira, Marcos Venícius Soares (Advisor). Behavior of Structural Steel API 5L X65 after Exposure to Hydrogen: An Approach Based on Ductile Fracture. Rio de Janeiro, 2014. 250p. These - Departamento de Engenharia Química e de Materiais, Pontifícia Universidade Católica do Rio de Janeiro.

HSLA steels are increasingly used in the construction of pipelines due to its excellent mechanical properties, resulting in adjustments to higher line pressures, weight reduction of the tube, and mainly risk decrease of structural failure. However, such pipes, when in offshore operation, can be embrittled by the presence of $\mathrm{H}_{2} \mathrm{~S}$ in the transported fluid. So that, this research aimed to study the influence of hydrogen on the fracture behavior of API 5L X65 steel with and without hydrogen at $-30{ }^{\circ} \mathrm{C}$, which enabled a comparative analysis of the two conditions. Based on the CTOD and J Integral parameters, it was found that there was no reduction in the toughness of the X65 steel, since the CTOD and J related to the most severe hydrogenation conditions were similar to those found in the reference condition. The degrading effect caused by hydrogen was associated with a higher crack propagation during the toughness tests. This indicates that hydrogen can cause contradictory effects on the fracture behavior of the material. The discrepant effects are related to the type of research undertaken to analyze the mechanical behavior of the material (macroscopic or microscopic), microstructure and experimental variables adopted during the tests, such as strain rate, hydrogen concentration, stress levels.

\section{Keywords}

offshore industry; hydrogenation; toughness tests; crack propagation. 


\section{Sumário}

1. Introdução

2 . Revisão Bibliográfica

34

2.1. Tubos de Aço para Dutos 34

2.1.1. Processo de Fabricação de Tubos 36

2.2. Mecânica da Fratura 36

2.2.1. Mecânica da Fratura Linear Elástica (MFLE) 39

2.2.1.1. Fator Concentração de Tensão 39

2.2.1.2. Teoria de Griffith 42

2.2.1.3. Campo de Tensões na Ponta da Trinca 46

2.2.1.4. Fator Intensificador de Tensões 49

2.2.2. Fator Intensificador de Tensões - Critério de Fratura 53

2.2.3. Influência da Espessura Sobre a Tenacidade à Fratura 54

2.2.4. Tamanho da Zona Plástica a Frente da Ponta da Trinca 55

2.3. Mecânica da Fratura Elasto-Plástica (MFEP) 60

2.3.1. Modelo de Wells para CTOD 62

2.3.2. Modelo de Dugdale, Burdekin e Stone "Strip Model" 64

2.3.2.1. Contribuição de Dawes a Determinação do CTOD (ס) 66

2.4. Determinação Experimental do CTOD $(\delta) \quad 69$

2.4.1. CTOD $(\delta)$ pela BS 7448:1 70

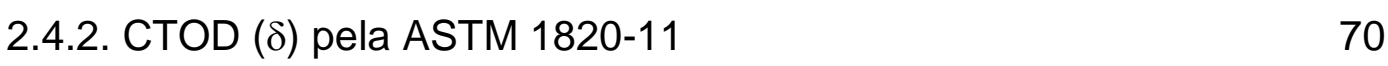

2.5. Ensaios de Tenacidade à Fratura 74

2.5.1. Etapas de Ensaio de Tenacidade à Fratura 75

2.5.1.1. Seleção de Corpos de Prova 75

2.5.1.2. Orientação do corpo de prova 78

2.5.1.3. Pré-Trincamento 79

2.5.1.4. Instrumentação do Corpo de Prova 82

2.5.1.5. Descrição do Ensaio 82

2.5.1.6. Análise do registro carga-deslocamento para determinação do 
CTOD $(\delta)$

2.5.2. Validação do ensaio 85

2.6. Abordagem Macroscópica e Microscópica da Fratura 86

2.6.1. Micromecanismos de Fratura dos Materiais Metálicos 89

2.6.1.1. Micromecanismo da Fratura Dúctil 90

2.6.1.2. Micromecanismo da Fratura Frágil 96

2.7. Difusão do Hidrogênio 98

2.8. Ensaio de Permeação 104

2.9. Fragilização por Hidrogênio 106

2.9.1. Entrada do Hidrogênio no Interior dos Metais 109

2.9.1.1. Entrada por Hidrogênio na Fase Líquida 109

2.9.1.2. Entrada por Hidrogênio na Fase Gasosa 110

2.10. Métodos de Avaliação da Susceptibilidade à Fragilização por Hidrogênio 111

2.11. Mecanismos de Atuação do Hidrogênio 117

2.11.1. Teoria da Pressão Interna 118

2.11.2. Decoesão Reforçada Pelo Hidrogênio (HEDE) 119

2.11.3. Plasticidade Localizada Reforçada pelo Hidrogênio (HELP) $\quad 121$

2.11.4. Fragilização Induzida pela Formação de Hidretos (HIE) 127

2.12. Influência dos parâmetros metalúrgicos na fratura assistida pelo hidrogênio 129

2.13. Efeito do Hidrogênio nas Propriedades Mecânicas dos Aços 136

2.13.1. Influência sobre as propriedades trativas 137

2.13.2. Influência na resistência à fratura 148

2.13.3. Influência a resistência à fadiga 158

3. Metodologia Experimental 162

3.1. Especificação do Material 162

3.2. Caracterização microestrutural do material 164

3.2.1. Análise metalográfica 164

3.2.2. Análise de Inclusões 165

3.3. Caracterização de Propriedades Mecânicas 166

3.3.1. Ensaio de Dureza 166 
3.3.3. Ensaio de Impacto 168

3.4. Avaliação de Tenacidade à Fratura 170

3.4.1. Retirada dos Corpos de Prova 172

3.4.2. Pré-trincamento 173

3.4.3. Hidrogenação 175

3.5. Ensaio de Tenacidade à Fratura 178

3.5.1. Validade do Entalhe Lateral 181

3.5.2. Preparação dos Corpos de Prova 181

3.5.3. Ensaios 182

3.5.4. Medição do Comprimento Real da Pré-Trinca 182

3.6. Fractografia 183

4. Resultados e Discussões 184

4.1. Composição Química 184

4.2. Caracterização Microestrutural 185

4.2.1. Análise Metalográfica 185

4.2.2. Análise de Inclusões 186

4.3. Propriedades Mecânicas 187

4.3.1. Ensaio de Dureza $\quad 187$

4.3.2. Ensaio de Tração 189

4.3.3. Ensaio de Impacto 191

4.3.4. Ensaios de Tenacidade à Fratura 194

4.3.4.1. Corpos de prova na condição não hidrogenada 195

4.3.4.2. Corpos de prova hidrogenados por $168 \mathrm{~h}$ - Grupo B 198

4.3.4.2.1. Corpos de Prova Hidrogenados por $168 \mathrm{~h}$ - Grupo C 200

4.3.4.3. Corpos de Prova Hidrogenados por $96 \mathrm{~h}-$ Grupo D 203

4.3.4.4. Corpos de prova hidrogenados por $48 \mathrm{~h}$ - Grupo E 205

4.3.5. Análise dos Valores de CTOD para as Condições de Ensaio 207

4.3.5.1. Hidrogenação por $168 \mathrm{~h}$

4.3.5.2. Ensaios a Velocidade de $1,0 \mathrm{~mm} / \mathrm{min}$

4.3.5.3. Ensaios a velocidade de $0,5 \mathrm{~mm} / \mathrm{min} 213$ 
4.3.5.4. Influência da Velocidade de Ensaio para $168 \mathrm{~h}$ de Hidrogenação

4.3.5.5. Influência da Velocidade de Ensaio para $48 \mathrm{~h}$ de Hidrogenação

218

4.3.6. Corpos de Prova com Entalhe Lateral 219

4.3.6.1. Corpos de Prova com 50\% de Redução de Espessura Hidrogenados por $168 \mathrm{~h}$

4.3.6.2. Corpos de Prova com $70 \%$ de Redução de Espessura Hidrogenados por $168 \mathrm{~h}$

4.4. Análise dos métodos usados na determinação da tenacidade à fratura.

5 . Conclusões e Sugestões de Trabalhos Futuros 


\section{Lista de Figuras}

Figura 1 - Perfuração do tarugo de aço em laminador ...........................36

Figura 2 - Triângulo da mecânica da fratura

Figura 3 - Etapas de avaliação de integridade estrutural de elemento trincado

Figura 4 - Chapa infinita de Inglis com furo elíptico

Figura 5 - Concentração de tensão nas proximidades de uma descontinuidade

Figura 6 - Chapa infinita de Griffth com trinca passante por toda espessura.....

Figura 7 - Curva A: aumento da energia superficial, curva B: queda da energia potencial e curva $\mathrm{C}$ : energia total

Figura 8 - Curva de resistência à propagação de trinca vs força motriz ...46

Figura 9 - Deformações devido a ação de carregamento

Figura 10 - Influência da espessura no estado de deformação de chapa plana

Figura 11 - Distribuição de tensões em elemento infinitesimal na ponta da trinca.

Figura 12 - Modos de carregamento em uma trinca: (a) abertura, (b) cisalhamento no plano e (c) cisalhamento fora do plano

Figura 13 - Tensão normal no plano da trinca em função da distância à ponta da trinca.

Figura 14 - Variação do fator intensificador de tensões em função da espessura.

Figura 15 - Tamanho da zona plástica: (a) Em estado plano de tensão.

(b) Em estado plano de deformação

Figura 16 - Corpo de prova de flexão em três apoios. B: espessura, W: largura e S: espaçamento entre os apoios 
Figura 17 - Campo de aplicação da mecânica da fratura 61

Figura 18 - Blunting da ponta da trinca devido acarregamento trativo .....62

Figura 19 - Trinca de Wells, após incorporação da zona plástica ao tamanho real da trinca

Figura 20 - Modelo de CTOD elaborado por Burdekin e Stone.

Figura 21 - Curva carga $(\mathrm{P})$ vs deslocamento de abertura da boca da trinca (CMOD).

Figura 22 - Conversão do deslocamento obtido da boca do entalhe para deslocamento na ponta da trinca

Figura 23 - Contorno arbitrário de Integral ao redor da ponta de trinca

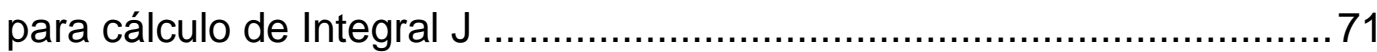

Figura 24 - Sequência de propagação de trinca com aplicação de carregamento

Figura 25 - Tipos de corpos de prova: (a) Compacto a tração. (b) Disco compacto a tração. (c) Flexão por três apoios. (d) Trinca central por tração. (e) Arco.

Figura 26 - Entalhe lateral em corpo de prova, onde B: espessura nominal e $B_{N}$ : espessura remanescente.

Figura 27 - Geometrias de entalhes laterai. (a) Tipo U, (b) Tipo V e (c) Tipo fenda .77

Figura 28 - Notação ASTM para orientação de corpos de prova extraídos de materiais planos.

Figura 29 - Notação ASTM para orientação de corpos de prova extraídos de materiais cilíndricos

Figura 30 - Pré-trinca de fadiga na ponta do entalhe usinado .80

Figura 31 - Extensômetro de fratura no entalhe do corpo de prova 82

Figura 32 - Tipos de curvas carga vs deslocamento da boca da trinca...83

Figura 33 - Demonstração de pop-in em curva de ensaio de CTOD em decorrência da existência de uma LBZ.

Figura 34 - Procedimento para medição do tamanho real da pré-trinca de fadiga e da propagação da trinca 
Figura 35 - Corpos de prova Charpy rompidos. (a) Fratura dúctil.

(b) Fratura frágil

Figura 36 - (a) Curva $\sigma$ vs $\varepsilon$ : material com comportamento plástico com apreciável deformação plástica. (b) Superfície de fratura com estricção característica da significativa deformação plástica

Figura 37 - (a) Curva $\sigma$ vs $\varepsilon$ : material com comportamento linear elástico. (b) Superfície de fratura de com deformação plástica desprezível.

Figura 38 - Forma dos dimples em função do modo de carregamento ....91

Figura 39 - (a) "Dimples" devido a modo I de carregamento e (b)"dimples" devido a modo II/III de carregamento

Figura 40 - Superfície de fratura com "dimples" cônicos equiaxiais (a) e "Dimples" rasos (b)

Figura 41 - Superfície de fratura de aço com dimples e suas respectivas inclusões

Figura 42 - Fractografia de corpo de prova de aço tracionado:

(a) dimples alongados nas laterais (cisalhamento) e (b) dimples equiaxiais no centro submetido a tensão normal.

Figura 43 - Efeito da assimetria existente no tamanho dos "dimples" na propagação da trinca.

Figura 44 - Micromecanismo de clivagem em aço liga. 96

Figura 45 - Facetas de clivagem em superfície fraturada de trilho

Figura 46 - Micromecanismo misto de fratura verificado na falha de um vaso de pressão

Figura 47 - Hidrogênio nos sítios intersticiais das estruturas cristalinas CCC e CFC do ferro.

Figura 48 - EL: energia de ligação par hidrogênio e sítio aprisionador, $E_{s}$ : energia de ponto de sela, $E_{a T}$ : energia de ativação do sítio aprisionador, $\mathrm{E}_{\mathrm{aD}}$ : energia de ativação para difusão do hidrogênio na rede cristalina, $S_{A}$ : sítio aprisionador e $S_{n}$ : sítio normal da rede cristalina.

Figura 49 - (a) Movimento da discordância após captação do hidrogênio externo em direção a descontinuidade. (b) Perda de hidrogênio para sítio irreversível. (c) Discordância indo ao encontro da descontinuidade após ceder hidrogênio ao sítio reversível. 
Figura 50 - Fonte interna de hidrogênio. (a) Movimento da discordância com hidrogênio em direção a descontinuidade. (b) Perda de hidrogênio para sítio irreversível. (c) Discordância indo ao encontro da descontinuidade após receber hidrogênio do sítio reversível para alcance do equilíbrio

Figura 51 - Esquema do ensaio de permeação

Figura 52 - Descrição global da interação de aspectos necessário a fragilização por hidrogênio

Figura 53 - Esquema de interface metálica em contato com solução aquosa para entrada de hidrogênio.

Figura 54 - Absorção de átomos de hidrogênio por metais expostos a atmosfera hidrogenada gasosa

Figura 55 - Desenho esquemático do corpo de prova e as variáveis envolvidas nos cálculos dos parâmetros CSR, CLR e CTR

Figura 56 - Aumento da distância entre os átomos de ferro devido ao hidrogênio reduzindo a força de ligação entre os átomos de ferro. 119

Figura 57 - (a) Redução da energia de coesão entre átomos devido ao hidrogênio $\left(\mathrm{U}^{\circ}>\mathrm{U}^{\mathrm{H}}\right)$. (b) Maior distância interatômica com o hidrogênio após deformação da estrutura cristalina

Figura 58 - Maior abertura da ponta da trinca em monocristais de $\mathrm{Fe}-3 \%$ Si na ausência de hidrogênio (a) e com hidrogênio (b).

Figura 59 - Visualização do movimento das discordâncias com o aumento da pressão de hidrogênio por MET

Figura 60 - Sobreposição de discordâncias nas condições com hidrogênio (brancas) e sem hidrogênio (pretas)

Figura 61 - Efeito de fixação (pinning effect) provocado pela atmosfera de hidrogênio ao redor das discordâncias (a) e liberação das discordâncias. deixando átomos de hidrogênio.

Figura 62 - Observação macroscópica em aço inoxidável 304.

(a) Bandas de deslizamento ao redor da trinca de fadiga na condição não hidrogenada. (b) Bandas de deslizamento apenas nas proximidades da trinca de fadiga na presença do hidrogênio 126

Figura 63 - Baixa quantidade de banda de deslizamento em grãos mais afastados da trinca de fadiga em amostras de aço inoxidável 304 na condição não hidrogenada (a) e com hidrogênio (b) 
Figura 64 -Amaciamento e endurecimento em grãos hidrogenados de aço. (a), (b) e (c): concentração de hidrogênio na ponta da trinca de fadiga. (d): grãos amaciados, próximos a ponta da trinca de fadiga e grãos endurecidos, afastados da ponta da trinca.

Figura 65 - Microestrutura bandeada de ferrita e perlita em aço carbono - manganês.

Figura 66 - Curvas $\sigma$ vs \& para material ensaiado ao ar e em atmosfera hidrogenada

Figura 67 - (a) Curvas tensão vs deformação de aço baixo carbono (a) e de aço maraging (b) com e sem hidrogênio.

Figura 68 - Variação da resistência à fratura a partir da densidade de corrente crítica de $25 \mathrm{~mA} / \mathrm{cm}^{2}$ em carregamento estático

Figura 69 - Variação da resistência à fratura para condição de carregamento dinâmico

Figura 70 - Influência da concentração de hidrogênio associado ao concentrador de tensão no comportamento trativo de corpos de prova.

(a) Liso (b) Entalhado com diferentes concentradores de tensão 142

Figura 71 - (a) Seção transversal de corpo de prova não hidrogenado tracionado. (b) Micromecanismo de dimples na região central b.

(c) e (d). Dimples reduzidos nos lábios de cisalhamento. (e) Seção transversal de corpo de prova tracionado após hidrogenação. (f) Micromecanismo de clivagem na região central $\mathbf{f}$.

Figura 72 - Curvas tensão vs deformação de um aço X100 submetido a vários tempos de hidrogenação.

Figura 73 - Curvas do ensaio de tração obtidas em atmosfera hidrogenada, nitrogenada e em atmosfera submetida a mudança de gás $\left(\mathrm{N}_{2} \rightarrow \mathrm{H}_{2}\right)$ (a) e mudança de gás $\left(\mathrm{H}_{2} \rightarrow \mathrm{N}_{2}\right)(b)$

Figura 74 - Influência da pressão do hidrogênio no comportamento mecânico em tração do aço API X80

Figura 75 - Influência da taxa de deformação no ensaio de tração na fragilização do X80.

Figura 76 - Deformação subsuperficial de amostra não hidrogenada (a). Refino do subgrão a $1 \mu \mathrm{m}$ da superfície (b). Maior tamanho do subgrão em maiores profundidades da superfície da fratura (c) e (d)...148 
Figura 77 - Influência da velocidade do ensaio sobre valor do CTOD crítico.

Figura 78 - Curva Carga $x V_{p}$ de corpos de prova hidrogenados

Figura 79 - Curva P vs LLD de aço hidrogenado e não hidrogenado a $-70{ }^{\circ} \mathrm{C}$.

Figura 80 - Redução de ductilidade do metal base com o aumento da densidade de corrente

Figura 81 - Redução de ductilidade da ZTA do X70 com o aumento da densidade de corrente.

Figura 82 - Redução da tenacidade à fratura aparente $\left(K_{Q}\right)$ em função do tempo de hidrogenação

Figura 83 - a) Superfície de fratura com micromecanismo de dimples.

(b) Superfície de fratura com micromecanismo de clivagem.

Figura 84 - Influência da temperatura e da frequencia de carga na taxa de crescimento da trinca de fadiga com hidrogênio

Figura 85 - Influência do hidrogênio e frequência de teste no crescimento da trinca de fadiga do aço inoxidável tipo 304.

Figura 86 - Taxa de crescimento da trinca em função da frequência de carregamento de fadiga

Figura 87 - Morfologia de inclusões em aço. A: tipo sulfeto. B: tipo alumina. C: tipo silicato e D: tipo óxido globular.

Figura 88- (a) Pontos de medição para o ensaio de dureza Vickers.

(b) Medições na espessura de parede

Figura 89 - Esquema da usinagem do corpo de prova para ensaio de tração a partir do tubo sem costura.

Figura 90 - Orientação para extração do corpo de prova tipo Charpy ...168

Figura 91 - Dimensões finais do corpo de prova para ensaio Charpy. .. 168

Figura 92- Corpo de prova Charpy segundo norma API 5L(2007) e

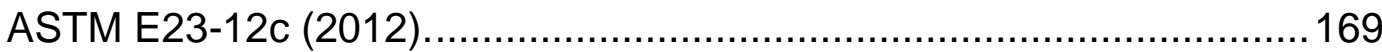

Figura 93 - Máquina de ensaio Charpy para ensaio de impacto ............169

Figura 94 - Fluxograma de avaliação de tenacidade à fratura................171

Figura 95 - Dimensões finais do corpo de prova. ................................172 
Figura 96 - Fresamento do entalhe do corpo de prova

Figura 97 - (a) Disposição dos corpos de prova na cuba segundo NACE TM0284-2003 (2003). (b) Corpos de prova posicionados para hidrogenação no laboratório de corrosão.

Figura 98 - Instalação para hidrogenação dos corpos de prova de acordo com NACE TM 0284-2003

Figura 99 - Divisão dos corpos de prova para hidrogenação.

Figura 100 - Corpo de prova na máquina para ensaio de CTOD 178

Figura 101 - Máquina de ensaio de CTOD do laboratório de pesquisa e desenvolvimento da Vallourec.

Figura 102 - Corpo de prova SENB com entalhe lateral. 180

Figura 103 - Usinagem de entalhe lateral nos corpos de prova no laboratório do ITUC-RJ.

Figura 104 - Esquema para medição do comprimento real da pré-trinca de fadiga.

Figura 105 - Microestrutura martensítica revenida do aço API 5L X65. Aumento: 500x.

Figura 106 - Perfil de inclusões na amostra de aços API 5L X65 186

Figura 107 - Amostra utilizada para levantamento de dureza do aço API $5 \mathrm{~L}$ X65

Figura 108 - Variação da dureza ao longo da espessura de parede do tubo.

Figura 109 - Curva carga vs CMOD de corpo de prova não hidrogenado.

Figura 110 - Componente plástica $\left(V_{p}\right)$ do deslocamento de abertura da boca da trinca.

Figura 111 - Comprimento real da pré-trinca de fadiga. 196

Figura 112 - Curva carga vs CMOD de corpo de prova hidrogenado por $168 \mathrm{~h}$ e ensaiado a $0,5 \mathrm{~mm} / \mathrm{min}$.

Figura 113 - Curva carga vs CMOD de corpo de prova hidrogenado por $168 \mathrm{~h}$ 
Figura 114 - Curva carga vs CMOD de corpo de prova hidrogenado por $96 \mathrm{~h}$ e ensaiado a $1,0 \mathrm{~mm} / \mathrm{min}$.

Figura 115 - Curva $P$ vs CMOD de corpo de prova hidrogenado por $48 \mathrm{~h}$ e ensaiado a $1,0 \mathrm{~mm} / \mathrm{min}$.

Figura 116 - Valores de $\operatorname{CTOD}^{(1)}$ em função da velocidade de ensaio para hidrogenação de $168 \mathrm{~h}$.

Figura 117 - Propagação estável da trinca após 168 h de hidrogenação. Aumento de $8 \mathrm{x}$

Figura 118- Fractografia de superfície hidrogenada por 168 h oriunda de ensaio de CTOD 210

Figura 119- Micromecanismo de quase clivagem na região de propagação estável da pré-trinca. Aumento: 500X.

Figura 120- Partícula de $2 .^{a}$ fase iniciadora da quase clivagem. Aumento: 4000X.

Figura 121- Influência do tempo de hidrogenação para velocidade de ensaio de $1,0 \mathrm{~mm} / \mathrm{min}$.

Figura 122- Propagação estável da trinca a $1,0 \mathrm{~mm} / \mathrm{min}$. Tempos de hidrogenação: (a) 48 h, (b) $96 \mathrm{~h}$ e (c) $168 \mathrm{~h}$.

Figura 123- Influência do tempo de hidrogenação na tenacidade à fratura para velocidade de ensaio de $0,5 \mathrm{~mm} / \mathrm{min}$.

Figura 124- Macroscopia da superfície de fratura de corpos de prova ensaiados a $0,5 \mathrm{~mm} / \mathrm{min}$ não hidrogenados (a) e após $168 \mathrm{~h}$ de hidrogenação (b).

Figura 125 - Regiões da superfície de fratura para a condição não hidrogenada. As setas indicam a direção de propagação da trinca. Aumento: 120X.

Figura 126 - Fractografia da região de propagação estável da trinca obtida por microscopia eletrônica de varredura de corpo prova não hidrogenado. Aumento: 600X.

Figura 127 - Influência da velocidade de ensaio na tenacidade a fratura para 168 h de hidrogenação. 218

Figura 128 - Influência da velocidade de ensaio na tenacidade a fratura para carga de hidrogênio de $48 \mathrm{~h}$. 
Figura 129 - Curvas Carga vs CMOD dos corpos de prova entalhados lateralmente em relação aos sem entalhe a $0,5 \mathrm{~mm} / \mathrm{min}$.

Figura 130 - Carga vs CMOD para corpos de prova com 50\% de redução lateral na espessura ensaiados a $0,5 \mathrm{~mm} / \mathrm{min}$.

Figura 131 - Carga vs CMOD para corpos de prova com $70 \%$ de redução lateral na espessura ensaiados a $0,5 \mathrm{~mm} / \mathrm{min}$. 224

Figura 132 - Distribuição de tensões na espessura em corpos de prova sem entalhe lateral (a) e com entalhe lateral (b) 226

Figura 133 - Relação entre termos $2 \sigma_{y s}$ e m $\sigma_{f}$ para as condições de ensaio realizadas. 


\section{Lista de Tabelas}

Tabela 1 - Composição química ( $\%$ em peso) de aços grau API $5 \mathrm{~L}$.......35

Tabela 2 - Aplicações dos aços API utilizados no Brasil. ..........................35

Tabela 3 - Energias de ativação necessárias para saída do hidrogênio do sítio aprisionador.

Tabela 4 - Variação das propriedades mecânicas do aço carbono na presença de concentrador de tensões e hidrogênio.

Tabela 5 - Variação das propriedades mecânicas de aços para dutos

hidrogenados por carregamento catódico.

Tabela 6 - Influência da taxa de deformação no efeito do hidrogênio sobre os valores do CTOD.

Tabela 7 - Resultados eperimentais para condição hidrogenada e não hidrogenada $\mathrm{a}-70{ }^{\circ} \mathrm{C}$ para aço API $5 \mathrm{~L}$ X65.

Tabela 8 - Redução dos valores da Integral J do metal de base e da ZTA com aumento da densidade de corrente

Tabela 9 - Distribuição de corpos de prova extraídos de flange.

Tabela 10 - Composição química do aço estrutural escolhido para este estudo.

Tabela 11 - Propriedades mecânicas especificadas para o aço estrutural proposto.

Tabela 12 - Composição química do aço API 5L X65. 184

Tabela 13 - Análise de inclusões no aço API 5L X65. 186

Tabela 14 - Valores de dureza Vickers para aço API 5L X65 188

Tabela 15- Propriedades mecânicas obtidas do ensaio de tração a temperatura ambiente $\left(25^{\circ} \mathrm{C}\right)$.

Tabela 16 - Propriedades mecânicas analíticas para temperatura de $-30 \stackrel{\circ}{\circ}$ do aço API 5 L X65

Tabela 17 - Energias absorvidas obtidas por ensaio de impacto tipo Charpy em baixas temperaturas. 
Tabela 18 - Energias de absorção por impacto em aço de mesmo grau ao adotado neste estudo

Tabela 19 - Valores de CTOD obtidos a partir de ensaio realizado no laboratório de pesquisa e desenvolvimento da Vallourec.

Tabela 20 - Valores de Integral J obtidos a partir de ensaio realizado no laboratório de pesquisa e desenvolvimento da Vallourec.

Tabela 21 - Parâmetros do ensaio CTOD dos corpos de prova não hidrogenados.

Tabela 22 - Parâmetros do ensaio CTOD dos corpos de prova não hidrogenados

Tabela 23 - Especificação da solução de hidrogenação para tempo de $168 \mathrm{~h}$.

Tabela 24 - Valores de CTOD para corpos de prova hidrogenados por $168 \mathrm{~h}$

Tabela 25- Valores de Integral J para corpos de prova hidrogenados por $168 \mathrm{~h}$.

Tabela 26 - Especificação da solução de hidrogenação para tempo de $168 \mathrm{~h}$.

Tabela 27 - Valores de CTOD para corpos de prova hidrogenados por $168 \mathrm{~h}$ para velocidade de $0,25 \mathrm{~mm} / \mathrm{min}$ e $1,0 \mathrm{~mm} / \mathrm{min}$. 202

Tabela 28 - Valores de Integral J para corpos de prova hidrogenados por $168 \mathrm{~h}$ para velocidade de $0,25 \mathrm{~mm} / \mathrm{min}$ e $1,0 \mathrm{~mm} / \mathrm{min}$. 202 Tabela 29 - Especificação da solução de hidrogenação para tempo de $168 \mathrm{~h}$

Tabela 30- Valores de CTOD para condição hidrogenada por 96 h......204 Tabela 31- Valores de Integral J para corpos de prova hidrogenados por $96 \mathrm{~h}$ 204

Tabela 32 - Especificação da solução de hidrogenação para tempo de $48 \mathrm{~h}$ 205

Tabela 33- Valores de CTOD para condição hidrogenada por 48 h......206 Tabela 34 - Valores de Integral J para corpos de prova hidrogenados por $48 \mathrm{~h}$.

Tabela 35- Valores parciais e totais de propagação da trinca das superfícies de fratura hidrogenadas por $168 \mathrm{~h}$. 
Tabela 36 - Valores de CTOD para condição não hidrogenada. 220

Tabela 37 - Valores de Integral J para corpos de prova com entalhe lateral condição não hidrogenada.

Tabela 38 - Valores de CTOD de carga máxima para condição de $168 \mathrm{~h}$ de hidrogenação para corpos de prova com $50 \%$ de redução de espessura.

Tabela 39 - Valores da Integral J de carga máxima para condição de $168 \mathrm{~h}$ de hidrogenação para corpos de prova com $50 \%$ de redução de espessura.

Tabela 40- Valores de CTOD de carga máxima para condição de $168 \mathrm{~h}$ de hidrogenação para corpos de prova com $50 \%$ de redução de espessura.

Tabela 41- Valores de Integral J de carga máxima para condição de $168 \mathrm{~h}$ de hidrogenação para corpos de prova com $70 \%$ de redução de espessura. 


\section{Lista de Siglas}

AIE - Agencia Internacional de Energia

AISI - American Iron and Steel Institute

API - American Petroleum Institute

ARBL - Alta resistência e baixa liga

ASTM - American Society Testing and Material

BSI - British Standard Institute

CLR - Cracking length ratio

CMOD - Crack mouth opening displacement

$\mathrm{CP}$ - Corpo de prova

CSR - Cracking sensitivity ratio

CT - Compact testing

CTOD - Crack tip opening displacement

CTR - Cracking thickness ratio

DP - Desvio padrão

EAC - Environmentally assisted cracking

HEDE - Hydrogen enhanced decohesion

HELP - Hydrogen enhanced localized plasticity

HIC - Hydrogen induced cracking

HSC - Hydrogen stress sracking

HSLA - High strength low-alloy

LBZ - Local Brittle Zone

LLD - Load line displacement

MET - Microscopia eletrônica de transmissão

MFEP - Mecânica da fratura elasto-plástica

MFLE - Mecânica da fratura linear elástica

SENB - Single edge notched bend

SSC - Sulfide stress cracking 


\section{Lista de Símbolos}

A - Área exposta de corpo de prova de ensaio de permeação

$a_{0}$ - comprimento da pré-trinca

a - metade do comprimento da descontinuidade

$\mathrm{a}_{\mathrm{c}}$ - tamanho crítico da trinca

$a_{r}$ - comprimento real da pré-trinca de fadiga

$A_{p l}$ - Área plástica sob curva P x CMOD ou LLD

B - Espessura do corpo de prova

b - metade da largura da descontinuidade

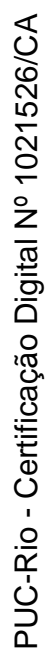

$\mathrm{C}_{\text {app }}$ - solubilidade aparente

$\mathrm{C}_{\mathrm{H}}$ - concentração de hidrogênio

CTOD $^{(1)}$ - Valores de CTOD obtidos experimentalmente

CTOD $^{(2)}$ - Valores de CTOD calculados pela norma BS 7448:1

CTOD $^{(3)}$ - Valores de CTOD calculados pela norma ASTM 1820-11

$D_{\text {app }}$ - Coeficiente de difusão aparente

ds - incremento do comprimento ao longo do contorno

E - Módulo de elasticidade

F - constante de Faraday

$f(a / W)$ - fator geométrico do componente trincado

$F_{f}-$ Força máxima de fadiga

$F_{\text {max }}$ - Carga máxima de fadiga

$\mathrm{F}_{\min }$ - Carga mínima de fadiga

$G$ - Taxa de liberação de energia

i- densidade de corrente

$I_{\infty}$ - Densidade de corrente em estado estacionário 
$J$ - Integral J

$J_{\infty}$ - Fluxo de hidrogênio através de membrana de aço

$J^{(1)}-$ Valores de Integral $\mathrm{J}$ obtidos experimentalmente

$J^{(2)}-$ Valores de Integral $\mathbf{J}$ calculados pela norma BS 7448:1

$J^{(3)}-$ Valores de Integral J calculados pela norma ASTM 1820-11

$J_{c}-$ Integral J crítico

K - Fator intensificador de Tensão

$\mathrm{K}_{\mathrm{c}}$ - Fator intensificador de tensões dependente da espessura

$\mathrm{K}_{\mathrm{f}}$ - máximo fator intensificador de tensões durante a fadiga

$K_{I}-$ Fator intensificador de tensões

$\mathrm{K}_{\mathrm{Ic}}-$ Fator intensificador de tensões crítico

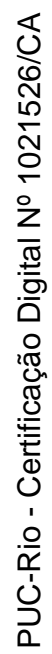

$\mathrm{K}_{\mathrm{t}}-$ fator concentrador de tensão

$L$ - Espessura de corpo de prova de ensaio de permeação

$m$ - fator de restrição plástica

P - Carga aplicada

$q$ - constante experimental

$r$ - distância do ponto analisado a ponta da trinca

R - Razão entre carga mínima e máxima de fadiga

$\mathrm{R}$ - Resistência à fratura

$r_{p}$ - distância do centro de rotação aparente a extremidade da trinca

$r_{p l}$ - raio da zona plástica

S - Distância entre apoios do dispositivo de fixação no corpo de prova

$\mathrm{T}_{i}-$ componentes do vetor tração

$\mathrm{u}_{\mathrm{i}}$ - componentes do vetor deslocamento

$\mathrm{V}$ - Afastamento de uma das faces da trinca

$v$ - velocidade do ensaio de tenacidade à fratura

$V_{p}$ - componente plástica do deslocamento de abertura da boca da trinca 
w - densidade de energia de deformação

W - Largura do corpo de prova

$\mathrm{W}-\mathrm{a}_{0}$ - ligamento (parte não trincada) do corpo de prova

$x$ - Distância do centro da trinca até sua ponta

z - altura do apoio para extensômetro de medição de abertura da boca da trinca.

$\sigma-$ Tensão nominal

$v$ - coeficiente de Poisson

$\eta$ - constante plástica

$\Gamma$ - contorno arbitrário da integral ao redor da ponta da trinca

$\rho$ - raio de curvatura da extremidade da descontinuidade

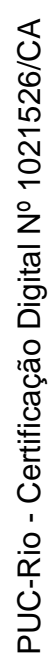

$\delta$ - Valor de abertura da ponta da trinca - CTOD

$\sigma_{A}-$ Tensão na ponta da descontinuidade $(A)$

$\Delta \mathrm{a}$ - propagação de trinca

$\delta_{c}-$ CTOD crítico

$\sigma_{\mathrm{fr}}-$ Tensão de fratura

$\Delta K$ - Variação do fator intensificador de tensão

$\tau_{\llcorner}-$Tempo até atingir condição estacionária

$\gamma_{p}-$ Trabalho plástico

$\gamma_{s}-$ Energia de superfície

$\Delta U$ - variação de energia entre corpo trincado e não trincado

$\Delta U_{e}-$ variação de energia elástica entre corpo trincado e não trincado

$\sigma_{\text {us }}-$ Limite de resistência mecânica do material

$\Delta U_{s}$ - variação de energia de superfície entre corpo trincado e não trincado

$\varepsilon_{x}$ - Componente de deformação na direção $x$

$\sigma_{x}-$ Componente de tensão na direção $x$ 
$\varepsilon_{y}$ - Componente de deformação na direção y

$\sigma_{y}-$ Componente de tensão na direção y

$\sigma_{y}-$ Tensão de escoamento do material

$\sigma_{y s}-$ Limite de escoamento do material

$\sigma_{y s 0,5}-$ limite de escoamento em deformação de referência de $0,5 \%$.

$\sigma_{y s T P}-$ limite de escoamento na temperatura de pré-trincamento

$\varepsilon_{z}$ - Componente de deformação na direção $z$

$\sigma_{z}-$ Componente de tensão na direção y 


\section{Introdução}

Com o crescente desenvolvimento da economia mundial, a necessidade por energia aumentará significativamente devido ao consumo impulsionado pela maior demanda dos setores industrial, geração de eletricidade, de transporte e comercial e crescimento acelerado de países emergentes que compõem o BRICS (Brasil, Rússia, Índia, China e África do Sul).

Segundo a Agência Internacional de Energia (AIE), o consumo de petróleo aumentará em 900 mil barris diários em 2015 para alcance do valor de aproximadamente 94 milhões de barris diários. (G1, 2015).

A contínua demanda por energia fez com que constantes pesquisas fossem desenvolvidas para descobertas de novos campos petrolíferos. Uma descoberta recente é o petróleo da camada do pré-sal, localizada em uma extensão de $800 \mathrm{~km}$ entre o litoral do estado de Santa Catarina e o Espírito Santo, compreendendo as bacias de Santos, Espírito Santo e Campos. Estudos geológicos apontam que a camada de petróleo encontram-se em profundidades bem elevadas, estimadas em 7000 m em relação ao nível do mar (Folha Online, 2009). Com o advento do présal, investimentos tecnológicos voltados para a área de exploração e transporte de petróleo e derivados serão realizados com o intuito de suprir a necessidade energética de modo mais econômico e mais seguro.

Com o aumento do consumo mundial de energia é necessário uma ampliação da malha dutoviária gerando assim uma constante atualização tecnológica de setores relacionados ao projeto, construção, instalação e manutenção para garantia da integridade dos mesmos. O desenvolvimento de tubos de aço de alta resistência tem possibilitado a indústria petrolífera uma economia significativa no custo total do transporte de óleo/gás à alta pressão, e obedecendo atendendo os requisitos de órgãos normalizadores como, por exemplo, o American Petroleum Institute (API) obtém-se material com propriedades mecânicas satisfatórias de resistência mecânica, resistência à corrosão e tenacidade por adequadas especificações metalúrgicas e processamento de material (Dong et al., 2009). 
Os tubos de aço utilizados na indústria petrolífera para transporte de petróleo e/ou gás podem ser do tipo com costura (soldados) ou sem costura. Os tubos sem costura da API são utilizados na malha dutoviária, ou seja, são os que tem a função de conduzir os fluidos petrolíferos dos poços até os meios de armazenamento como navios petroleiros, plataformas e refinarias.

Aços ARBL são cada vez mais utilizados na construção de linhas de duto por seus maiores limites de resistência mecânica que proporcionam tubos com menores espessuras de parede obtendo desta forma melhor relação custo/limite de escoamento e resistência mecânica, baixo teor de carbono que contribui para melhora da tenacidade, soldabilidade e custos de instalação. Além da utilização dos aços API para fabricação de pipelines, os aços API 5L - grau X podem também ser usados na construção de risers que tem a função de fazer a ligação entre os poços de petróleo, no fundo do mar, e as plataformas ou navios, na superfície (Souza, 2011).

\section{Análise do Problema}

Uma das preocupações relacionada à integridade estrutural das linhas dutoviárias consiste na ocorrência de compostos, a base de enxofre, prejudiciais ao aço durante o transporte de petróleo e/ou gás natural.

A composição do petróleo depende do local de sua extração porém, pode-se afirmar que este é composto essencialmente por carbono, hidrogênio e enxofre . O hidrogênio por sua vez, quando reage com outros elementos como, por exemplo, o enxofre, forma o sulfeto de hidrogênio $\left(\mathrm{H}_{2} \mathrm{~S}\right)$ que pode contribuir para a degradação das propriedades mecânicas do aço. Este efeito é conhecido mundialmente como fragilização por hidrogênio

Além disso, com o cenário tecnológico atual apontando para produção e transporte de óleo e gás em temperaturas de operação superiores a atuais, há uma tendência a problemas associados a existência de hidrogênio na estrutura cristalina do material devido a maior difusão do mesmo. O hidrogênio na sua forma atômica entra na rede cristalina do aço por meio de reações químicas entre o sulfeto de hidrogênio $\left(\mathrm{H}_{2} \mathrm{~S}\right)$, presente no fluido, e o metal do duto (Santos, 2011). Por possuir um diâmetro atômico pequeno, o hidrogênio tem a capacidade de se difundir rapidamente pelos sítios intersticiais da rede cristalina. Sendo assim, a 
intensidade dos efeitos do hidrogênio sobre o comportamento mecânico do material depende de sua concentração, da temperatura, do estado de tensão no componente e da interação do hidrogênio com os defeitos da estrutura cristalina.

Os efeitos do hidrogênio sobre os aços podem ser verificados através de parâmetros de caracterização de materiais. Um efeito bem perceptível, em alguns aços, é a redução de ductilidade (parâmetro macroscópico), facilmente verificada através de ensaios de tração (Tiwari et al., 2000 e Moro, 2010). O comportamento das trincas também pode ser influenciado pelo hidrogênio na estrutura dos aços. Verifica-se que o parâmetro da/dN, taxa de crescimento da trinca sob carregamento cíclico de fadiga, aumenta com a presença do hidrogênio (Murakami, 2010).

A tenacidade à fratura dos materiais também pode ser afetada pelo hidrogênio. Ultimamente a mecânica da fratura vem sendo bastante utilizada nos projetos estruturais. Parâmetros como, por exemplo, CTOD - Crack Tip Opening Displacement são bastante divulgados na avaliação da capacidade de materiais de alta ductilidade em conviver com descontinuidades do tipo trincas mediante a ação de carregamentos.

Sabendo-se que é impossível garantir a inexistência de trincas em um componente estrutural, uma redução da ductilidade macroscópica no material pode interferir no modo de propagação da trinca. O modo de propagação estável é desejável uma vez que há alto consumo de energia na forma de deformação. Como o hidrogênio pode induzir a propagação de trincas, o foco do problema reside em avaliar a influência do hidrogênio sobre o comportamento à fratura de material usado na fabricação de tubos para dutos submarinos, buscando analisar o nível de influência sobre os micromecanismos de deformação decorrentes de carregamentos mecânicos. 


\section{Objetivo}

Esta tese tem como objetivo os seguintes itens:

- Determinar o grau de degradação na tenacidade à fratura, provocado pelo hidrogênio no aço API 5L grau X65 na condição de temperado e revenido por levantamento dos parâmetros CTOD e Integral J;

- Caracterizar as superfícies de fratura buscando identificar o micromecanismo envolvido na ação do hidrogênio, assim como outros parâmetros que confirmem a ação deletéria do hidrogênio sobre o material como, por exemplo, a extensão da propagação da trinca;

- Verificar se há mudança do micromecanismo de fratura com a ação do hidrogênio na estrutura cristalina ao aço mencionado.

- Mostrar a correlação entre os parâmetros de tenacidade à fratura CTOD e Integral J;

\section{Descrição da Tese}

O presente trabalho está formatado em seis capítulos, conforme descrito a seguir. No Capítulo I, Introdução, apresenta-se alguns tópicos relevantes que explicitam o cenário mundial de exploração e produção de petróleo em função da grande demanda energética afomentada pelo crescimento de países emergentes formadores do BRICS e a importância de conhecer o comportamento em fratura dos materiais usados na expansão da malha dutoviária, expostos a condições agressivas como, por exemplo a presença de hidrogênio nos fluidos transportados. Neste capítulo também consta a análise do problema e, os objetivos desta tese.

No Capítulo II, Revisão Bibliográfica, encontra-se um estado da arte fundamental para o entendimento do tema proposto e de suma importância na realização desta tese.

Ainda no Capítulo II, se relata conceitos relacionados a mecânica da fratura, e suas ramificações, assim como os parâmetros de tenacidade à fratura utilizados para caracterização de material, os respectivos ensaios para determinação de tais parâmetros e a correlação existente entre os mesmos e os micromecanismos envolvidos na deformação seguido de fratura dos materiais. 
Ainda no Capítulo II, se encontra um estado da arte fundamental para o entendimento do tema proposto e de suma importância na realização desta tese. Descreve-se os aspectos associados a difusão do hidrogênio na estrutura cristalina do material e os procedimentos estabelecidos para avaliação da susceptibilidade do material a ação do hidrogênio. Também é relatado os mecanismos de atuação do hidrogênio nos metais, assim como a influência do mesmo sobre as propriedades mecânicas dos aços.

No Capítulo III, Metodologia Experimental, parte central do trabalho, explica-se as metodologias desenvolvidas para a análise do comportamento em fratura do aço usado na fabricação de tubos e expostos e a meio hidrogenado, apresentando os procedimentos para obtenção dos parâmetros de tenacidade à fratura e análise da influência do hidrogênio sobre a tenacidade à fratura do material nas condições de ensaios estabelecidas.

No Capítulo IV, Resultados e Discussões, apresenta os resultados de tenacidade à fratura (CTOD e Integral $\mathrm{J}$ ) obtidos nos experimentos e outros calculados, assim como as fractografias das superfícies dos corpos de prova após os ensaios realizados em diferentes condições. Neste capítulo encontra-se uma comparação entre os valores de CTOD e Integral J para análise da influência do tempo de hidrogenação e velocidade de ensaio no comportamento à fratura do aço.

No Capítulo V, Conclusões e Sugestões, são apresentadas as conclusões e recomendações visando a continuidade deste trabalho a partir de outros temas de pesquisa correlatos.

O Capítulo VI, Referências Bibliográficas, são apresentadas as referência das informações citadas no desenvolvimento deste trabalho. 


\section{Revisão Bibliográfica}

\subsection{Tubos de Aço para Dutos}

Atualmente os aços das linhas de dutos seguem as especificações da API e são conhecidos por aços API 5L. Estes aços são classificados em graus (A, B ou $\mathrm{X}$ ) e os de grau $\mathrm{X}$ são considerados de alta resistência e baixa liga (ARBL). Possuem teores, em peso, de carbono entre 0,06 a $0,25 \%$ e somatório de elementos de liga inferior a $8 \%$.

Segundo a especificação API 5L (2007) o grau do aço indica o valor mínimo de seu limite de escoamento, em ksi. Por exemplo, o aço API 5L X65 tem 65 ksi de limite mínimo de escoamento, o que corresponde aproximadamente a $450 \mathrm{MPa}$. Com a iminente exploração de petróleo em águas ultraprofundas, necessita-se de materiais com maior nível de resistência mecânica. Sendo assim, a adição de elementos de liga nobres (cobre, níquel e molibdênio, entre outros) associado a processamentos térmicos, tem proporcionado o desenvolvimento do aço grau X100 e X120 com maior limite de resistência e menor espessura de parede capazes de suportar elevadas pressões, o que contribui para menor custo de instalação pela redução do peso.

A Tabela 1 informa a composição química dos aços de alta resistência e baixa liga para utilização em dutos estabelecidos pela API, enquanto a Tabela 2 mostra as principais aplicações dos respectivos graus de aço API. 
Tabela 1 - Composição química ( \% em peso) de aços grau API 5L (API 5L Specification, 2007).

\begin{tabular}{|c|c|c|c|c|c|c|c|c|c|}
\hline \multirow[t]{2}{*}{ Grau } & \multicolumn{9}{|c|}{ \% em peso } \\
\hline & $\mathrm{C}$ & $\mathrm{Si}$ & $\mathrm{Mn}$ & $\mathrm{P}$ & $S$ & $\mathrm{~V}$ & $\mathrm{Nb}$ & $\mathrm{Ti}$ & $\mathrm{C}_{\mathrm{eq}}$ \\
\hline \multirow{2}{*}{$\mathrm{X} 42 \mathrm{~N}$} & $\leq$ & $\leq$ & $\leq$ & $\leq$ & $\leq$ & $\leq$ & $\leq$ & $\leq$ & $\leq$ \\
\hline & 0,24 & 0,40 & 1,20 & 0,025 & 0,015 & 0,0 & 0,05 & 0,04 & 0,43 \\
\hline \multirow{2}{*}{$\mathrm{X} 52 \mathrm{~N}$} & $\leq$ & $\leq$ & $\leq$ & $\leq$ & $\leq$ & \multirow{2}{*}{$\begin{array}{c}\leq \\
0,10\end{array}$} & $\leq$ & $\leq$ & $\leq$ \\
\hline & 0,24 & 0,45 & 1,40 & 0,025 & 0,015 & & 0,05 & 0,04 & 0,43 \\
\hline $60 N$ & $\begin{array}{c}\leq \\
0,24\end{array}$ & $\begin{array}{c}\leq \\
0,45\end{array}$ & $\begin{array}{c}\leq \\
1,40\end{array}$ & $\begin{array}{c}\leq \\
0,025\end{array}$ & $\begin{array}{c}\leq \\
0,015\end{array}$ & 0,10 & 0,05 & 0,04 & (2) \\
\hline \multirow{2}{*}{ X65Q } & $\leq$ & $\leq$ & $\leq$ & $\leq$ & $\leq$ & \multirow{2}{*}{ (1) } & \multirow{2}{*}{ (1) } & \multirow{2}{*}{ (1) } & $\leq$ \\
\hline & 0,18 & 0,45 & 1,70 & 0,025 & 0,015 & & & & 0,43 \\
\hline \multirow{2}{*}{ X70Q } & $\leq$ & $\leq$ & $\leq$ & $\leq$ & $\leq$ & \multirow[t]{2}{*}{ (1) } & \multirow[t]{2}{*}{ (1) } & \multirow[t]{2}{*}{ (1) } & $\leq$ \\
\hline & 0,18 & 0,45 & 1,80 & 0,025 & 0,015 & & & & 0,43 \\
\hline \multirow{2}{*}{ X80Q } & $\leq$ & $\leq$ & $\leq$ & $\leq$ & $\leq$ & \multirow{2}{*}{ (1) } & \multirow[t]{2}{*}{ (1) } & \multirow[t]{2}{*}{ (1) } & \multirow{2}{*}{ (2) } \\
\hline & 0,18 & 0,45 & 1,90 & 0,025 & 0,015 & & & & \\
\hline \multirow{2}{*}{ X100Q } & $\leq$ & $\leq$ & $\leq$ & $\leq$ & $\leq$ & \multirow[t]{2}{*}{ (1) } & \multirow[t]{2}{*}{ (1) } & \multirow[t]{2}{*}{ (1) } & \multirow[t]{2}{*}{ (2) } \\
\hline & 0,16 & 0,45 & 1,90 & 0,020 & 0,010 & & & & \\
\hline \multirow{2}{*}{\multicolumn{10}{|c|}{$\begin{array}{l}\text { (1) - A menos que combinado a soma de } \mathrm{Nb}, \mathrm{V} \text { e } \mathrm{Ti} \text { deve } \mathrm{ser} \leq 0,15 \text {. } \\
\text { (2) - Conforme combinado pelas partes interessadas. } \\
\mathrm{N}, \mathrm{Q} \text { - Condição de normalizado, e temperado e revenido respectivamente. }\end{array}$}} \\
\hline & & & & & & & & & \\
\hline \multicolumn{3}{|c|}{$\begin{array}{l}\text { Limite de escoamento } \\
\text { mínimo (MPa) }\end{array}$} & \multicolumn{4}{|c|}{ Grau } & \multicolumn{3}{|c|}{ Aplicação } \\
\hline & 20 & & $\mathrm{X} 4$ & / X46 & $\mathrm{X} 52 / 2$ & & Linhas $\mathrm{c}$ & bsaixa & essão \\
\hline & $/ 450$ & & & X60/ & X65 & & Linhas & média & alta \\
\hline & 185 & & & $\mathrm{X}^{\prime}$ & & & Linhas & alta & ธรกิด \\
\hline & 555 & & & $X$ & & & Linhas & alta $p$ & ssão \\
\hline & 590 & & & $\mathrm{X} 1$ & & & com requ & ito de & dução \\
\hline & 330 & & & $\mathrm{X} 1$ & & & & peso & \\
\hline
\end{tabular}




\subsubsection{Processo de Fabricação de Tubos}

Os tubos fabricados para montagem das linhas de duto podem ser classificados como com ou sem costura. Os que possuem costura são fabricados a partir de chapas que terão suas extremidades unidas por um cordão de solda ao longo de seu comprimento (Tenaris Confab, 2008).

Em contrapartida os tubos sem costura são fabricados a partir de tarugos maciços de aço com diâmetro de 180 a 230 mm de diâmetro e comprimento de 6 m devidamente aquecidos, através do processo Mannesmann, onde o tarugo maciço em movimento rotatório em um sentido é perfurado por um mandril em movimento de translação em sentido contrário.

Como este processo de fabricação proporciona a conservação de massa do tarugo, durante a perfuração ocorre uma extensa deformação plástica no sentido do seu comprimento, sendo assim o tubo perfurado possui maior comprimento que na condição inicial. A Figura 1 ilustra etapa de prefuração do tarugo maciço de aço em um laminador automático existente na Vallourec.

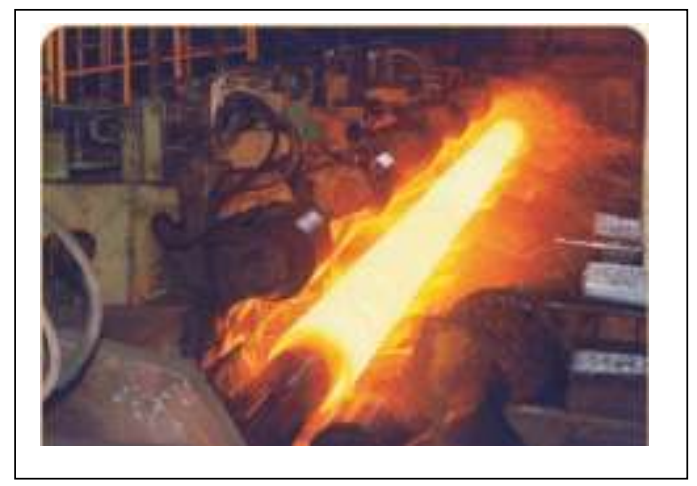

Figura 1 - Perfuração do tarugo de aço em laminador (Vallourec, 2010).

\subsection{Mecânica da Fratura}

A mecânica da fratura surgiu com o intuito de suprir insuficiencias deixadas pela mecanica clássica na abordagem da resistência dos materiais. Inicialmente os projetos estruturais eram baseados na mecânica clássica, especificamente na abordagem da resistência dos materiais, na qual a tensão aplicada ao componente mecânico era inferior a tensão limite de escoamento do material. Esta abordagem 
não considera a existência de descontinuidades/defeitos no interior do material, e por isso não evitava falhas repentinas e catastróficas em componentes estruturais (Anderson, 2005).

Atualmente sabe-se que muitas das falhas em componentes estruturais são associadas a presença de trincas que podem causar a fratura quando submetidos a tensão. Sabendo-se que é impossível garantir a inexistência de trincas em um componente estrutural, estabeleceu-se a abordagem da mecânica da fratura com o intuito de conhecer o comportamento dos materiais frente a existência deste tipo de descontinuidade.

A mecânica da fratura estuda a capacidade de um material em conviver com uma descontinuidade/defeito mediante a ação de tensões, ou seja, avalia a tenacidade à fratura do material. O princípio da mecânica da fratura é estabelecido pelo triângulo da fratura ilustrado na Figura 2.

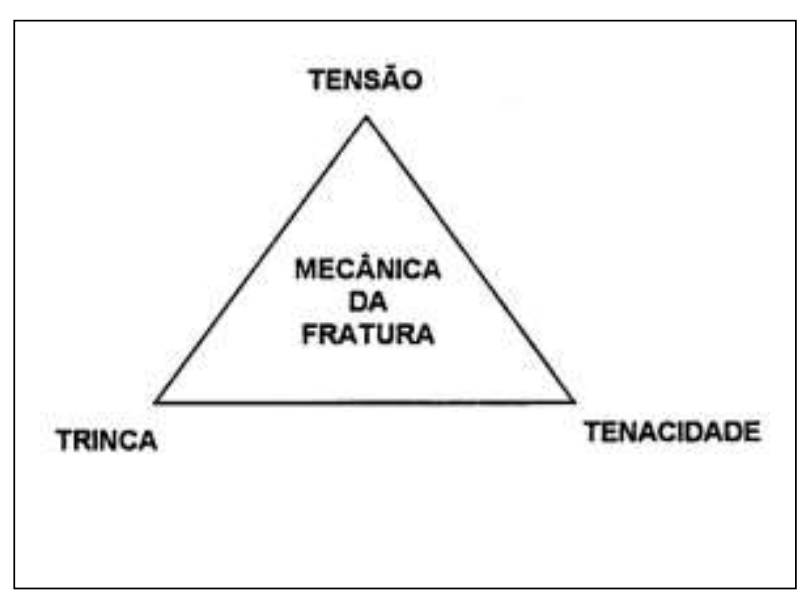

Figura 2 - Triângulo da mecânica da fratura (Anderson, 2005).

O triângulo da mecânica da fratura retrata bem como uma avaliação da tenacidade à fratura de um componente deve ser conduzida. A tenacidade à fratura do material deve ser capaz de sobrepor os efeitos causados pela tensão (Anderson, 2005). Caso isto não aconteça, haverá fratura. A Figura 3 ilustra o procedimento de avaliação de integridade estrutural aplicada para componentes trincados (Zerbst, 2007). 


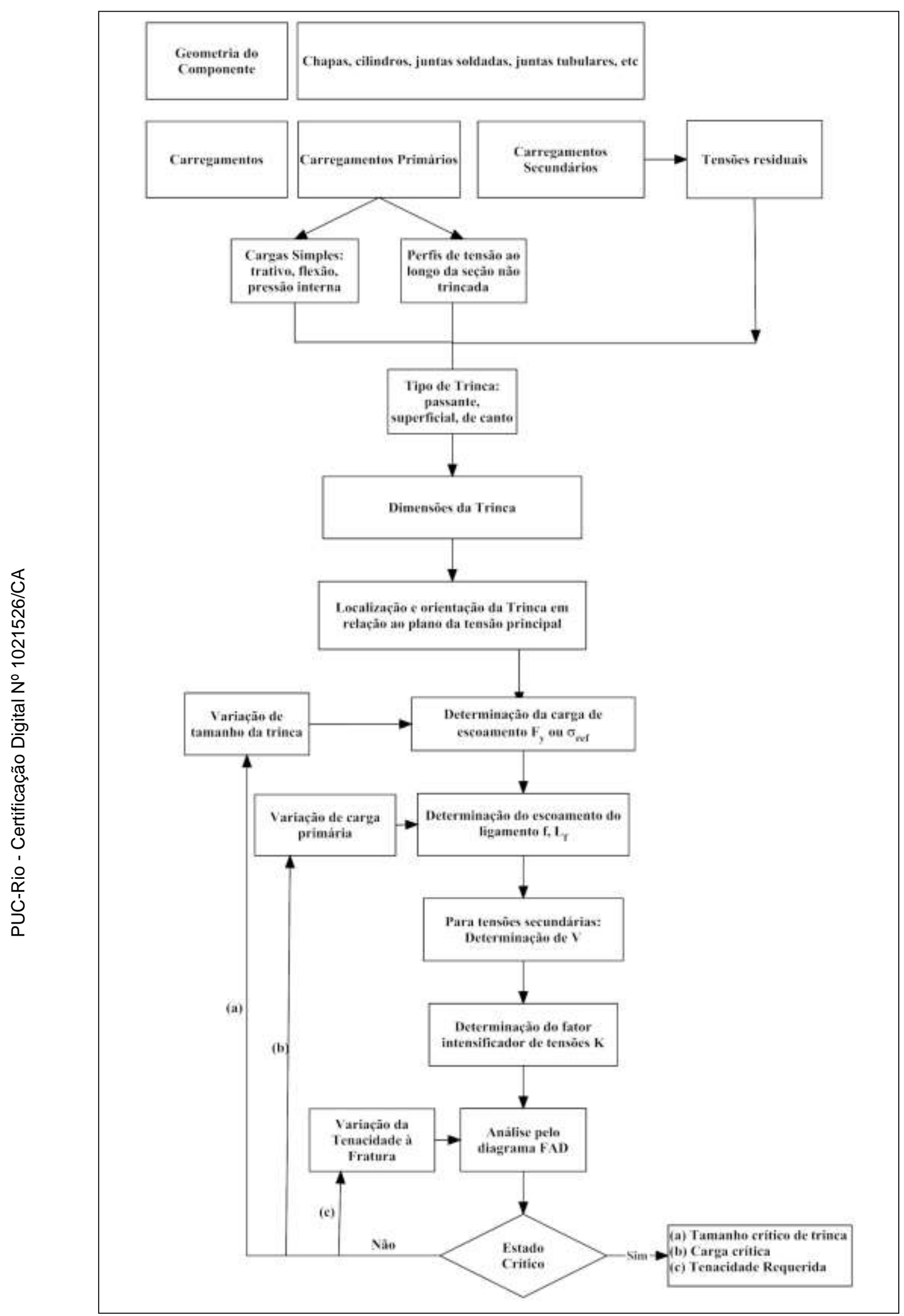

Figura 3 - Etapas de avaliação de integridade estrutural de elemento trincado (Zerbst, 2007). 
A mecânica da fratura tem como principal objetivo determinar se um defeito pré-existente, tipo trinca, irá ou não levar o componente à fratura catastrófica para tensões normais de serviço permitindo, ainda, determinar o grau de segurança efetivo de um componente trincado (Anderson, 2005). Além disso, é importante determinar a taxa com que a trinca se propaga. Uma vez determinado o tamanho crítico da trinca e, também, a sua taxa de propagação, podem ser programadas inspeções com técnicas não destrutivas, para verificar se o tamanho real da trinca não está próximo do tamanho crítico, o que significa fim da vida útil do componente.

A mecânica da fratura por meios de projetos mais confiáveis e programas de inspeções, possibilita uma utilização segura de componentes com trincas, sem a necessidade de fatores de segurança elevados e com a confiança de que não ocorrerá uma falha imprevista. Esta tem dois ramos: a mecânica da fratura linear elástica (MFLE) e a mecânica da fratura elastoplástica (MFEP).

\subsubsection{Mecânica da Fratura Linear Elástica (MFLE)}

A mecânica da fratura linear elástica é restrita ao estudo de componentes trincados em materiais com pouca ou nenhuma deformação plástica, isto é, materiais frágeis, através do parâmetro $\mathrm{K}$, denominado fator intensificador de tensões. O fator intensificador de tensões surgiu do estudo do comportamento das tensões no interior do material a partir do fator de concentração de tensões.

\subsubsection{Fator Concentração de Tensão}

Componentes mecânicos podem conter descontinuidades do tipo trincas e/ou miro-trincas oriundas de falhas em procedimentos de fabricação como, por exemplo, usinagem, soldagem, e/ou fundição. As descontinuidades também podem ser oriundas de carregamento cíclico ou exposição do componente à atmosfera corrosiva (Roesler, Harders e Baeker, 2007).

Estudos de fratura sob o ponto de vista atômico demonstram que a resistência coesiva de um material com descontinuidades internas é da ordem de 3 
a 4 vezes menor que a de um material considerado perfeito. Sendo assim as descontinuidades reduzem a resistência global do material, concentrando assim as tensões localmente a nível atômico causando a fratura.

As primeiras pesquisas sobre o efeito concentrador de tensões foram realizadas por Inglis em 1913 através de descontinuidades elípticas em chapa plana considerada infinita ${ }^{(1)}$ submetida a tensões remotas. Uma chapa é considerada infinita quando o comprimento da descontinuidade. A Figura 4 ilustra a chapa utilizada nos estudos de Inglis.

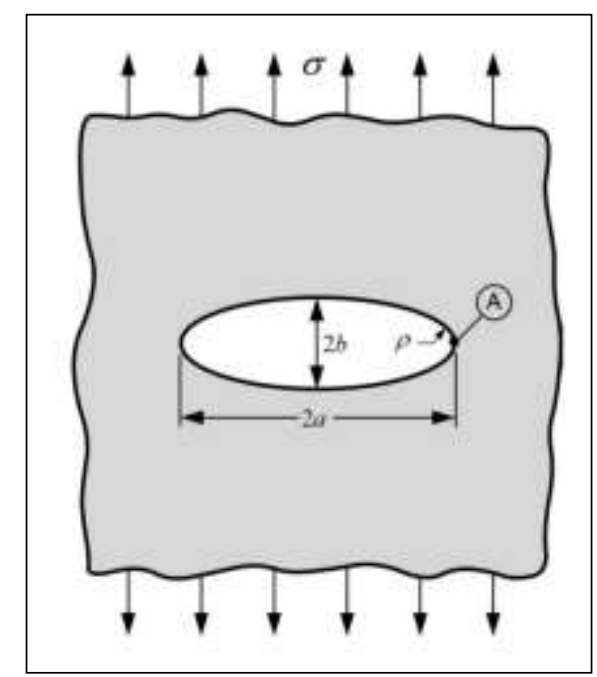

Figura 4 - Chapa infinita de Inglis com furo elíptico (Anderson, 2005).

A introdução de descontinuidades em chapas tensionadas elasticamente, onde o $2^{\mathrm{a}}$ é muito menor que a largura da chapa, provoca uma redistribuição do campo de tensões ao seu redor. A tensão na ponta da descontinuidade (ponto A) é dada pela Equação (1):

$$
\sigma_{A}=\sigma\left(1+\frac{2 a}{b}\right)
$$

na qual,

$\sigma_{\mathrm{A}}=$ tensão na ponta da descontinuidade $(\mathrm{MPa})$;

$\sigma=$ tensão nominal remota aplicada $(\mathrm{MPa})$;

$\mathrm{a}=$ metade do comprimento da descontinuidade $(\mathrm{mm})$;

$\mathrm{b}=$ metade da largura da descontinuidade $(\mathrm{mm})$; 
Observando a Equação (1) acima percebe-se que a tensão nas proximidades da descontinuidade aumenta devido ao efeito de concentração de tensão representado pela razão $\sigma_{A} / \sigma$ na ponta, denominado fator concentrador de tensão, $\mathrm{K}_{\mathrm{t}}$ (Anderson, 2005; Broek, 1988). Este efeito é devido às tensões se propagarem apenas em meio contínuo. Sendo assim qualquer descontinuidade interior ao material interrompe o fluxo concentrando as tensões nas vizinhanças da descontinuidade, conforme visualizado na Figura 5.

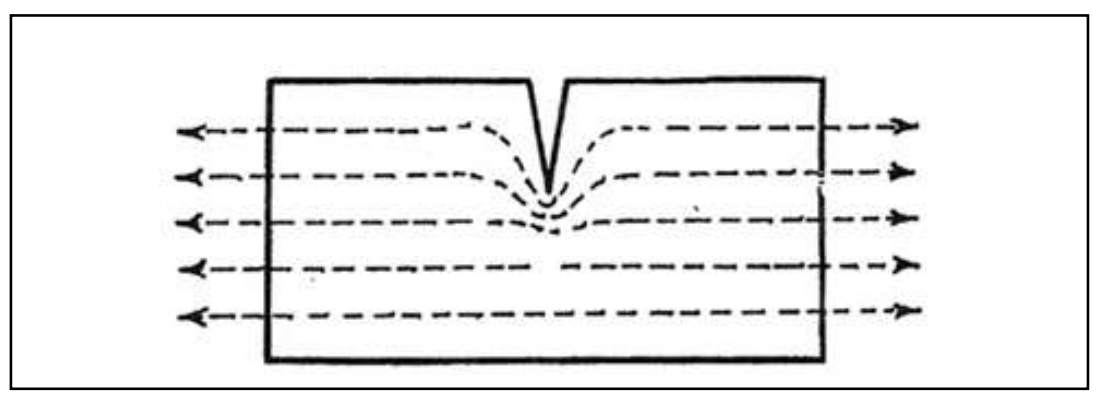

Figura 5 - Concentração de tensão nas proximidades de uma descontinuidade (Shukla, 2004).

A concentração de tensões é dependente apenas da geometria da descontinuidade, conforme pode ser verificado na Equaçãodo fator de concentração de tensões $\left(\mathrm{K}_{\mathrm{t}}\right)$. Considerando um aumento significativo do comprimento da descontinuidade em relação a largura (vide Figura 4), a descontinuidade elíptica se torna uma trinca pontiaguda e o fator concentrador de tensões aumenta consideravelmente levando a existência de tensões infinitas na ponta da trinca. A Equação (2) de Inglis abaixo representa o efeito mais geral da concentração de tensão em função do raio de curvatura da descontinuidade (Anderson, 2005; Broek, 1988; Shukla, 2004).

$$
K_{t}=1+\sqrt{\frac{a}{\rho}}
$$

na qual,

$\mathrm{K}_{\mathrm{t}}=$ fator de concentração de tensão;

$\mathrm{a}=$ metade do comprimento da descontinuidade $(\mathrm{mm})$;

$\rho=$ raio de curvatura da descontinuidade em sua extremidade $(\mathrm{mm})$. 
O conceito de fator de concentração de tensões não se aplica a componentes trincados. O raio da ponta de uma trinca $(\rho)$ tende a zero, levando a fatores concentradores de tensão extremamente elevados e tensões infinitas no interior do material. Um campo de tensões infinitas na ponta de uma descontinuidade é impossível, pois nenhum material é capaz de resistir a tensões infinitas. Sendo assim foi necessário um ajuste dos efeitos causados pela presença de uma descontinuidade no interior de um componente mecânico. Desta forma Griffith em 1920 aprimorou os estudos sobre a teoria da fratura adotando uma base energética em vez de análise local de tensões (Anderson, 2005; Broek, 1988).

\subsubsection{Teoria de Griffith}

Apesar de toda a formulação teórica, Inglis não conseguiu explicar o motivo pelo qual peças com entalhes afiados não quebravam e concluiu que o fator de concentração de tensões não abrange a maior parte das situações de engenharia, já que as estruturas e/ou componentes estruturais raramente estão livres de descontinuidades do tipo trincas. Desta forma Griffith (1920) a partir dos estudos iniciados por Inglis estabeleceu uma nova análise sobre a fratura de materiais adotando uma abordagem energética.

O estudo de Griffith adotou como modelo de material o vidro, material de comportamento linear elástico, ou seja, com pouca capacidade de deformação plástica, e foi baseado em uma abordagem energética, na qual verificou a variação de energia em um corpo, considerado perfeito, após a inserção de uma descontinuidade tipo trinca. Griffith assumiu que a fratura somente vai ocorrer se a energia armazenada no material for igual ou maior que a energia necesária para geração de novas superfícies de fratura (Shukla, 2004).

O estudo foi realizado em uma chapa plana infinita submetida a tensões trativas remotas. A condição de chapa infinita indica que as dimensões da descontinuidade são muito pequenas em relação às dimensões da chapa. A Figura 6 ilustra a chapa usada por Griffith. 


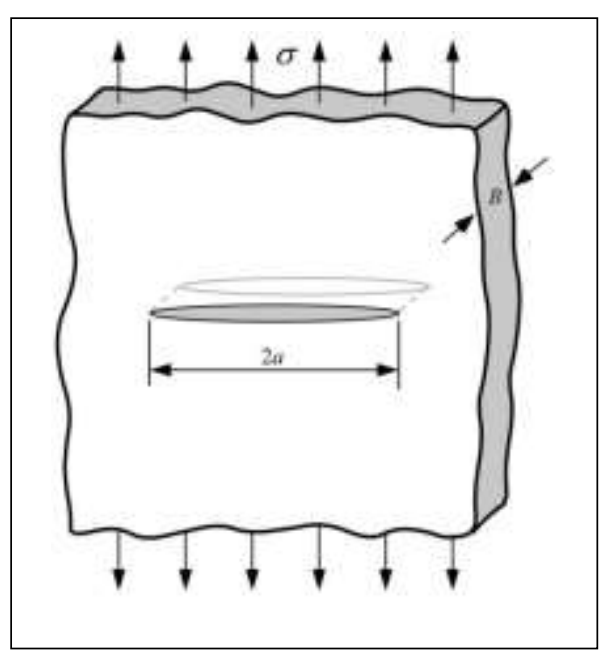

Figura 6 - Chapa infinita de Griffth com trinca passante por toda espessura (Anderson, 2005).

O modelo da trinca de Griffith em chapa com estado plano de tensão considera que a energia potencial oriunda do carregamento, cedida ao material é armazenada sob a forma de energia elástica. Se a energia elástica no sistema (chapa) for suficiente para romper as ligações atômica, novas superfícies serão criadas no material devido a transformação da energia elástica em energia de superfície. Em outras palavras, segundo Griffith, a fratura no material é oriunda de um balanço energético no qual há um aumento da energia de superfície em detrimento da energia potencial (Anderson, 2005; Shukla, 2004). O gráfico ilustrado na Figura 7 representa o balanço termodinâmico envolvido durante a propagação de uma trinca pelo modelo de Griffith.

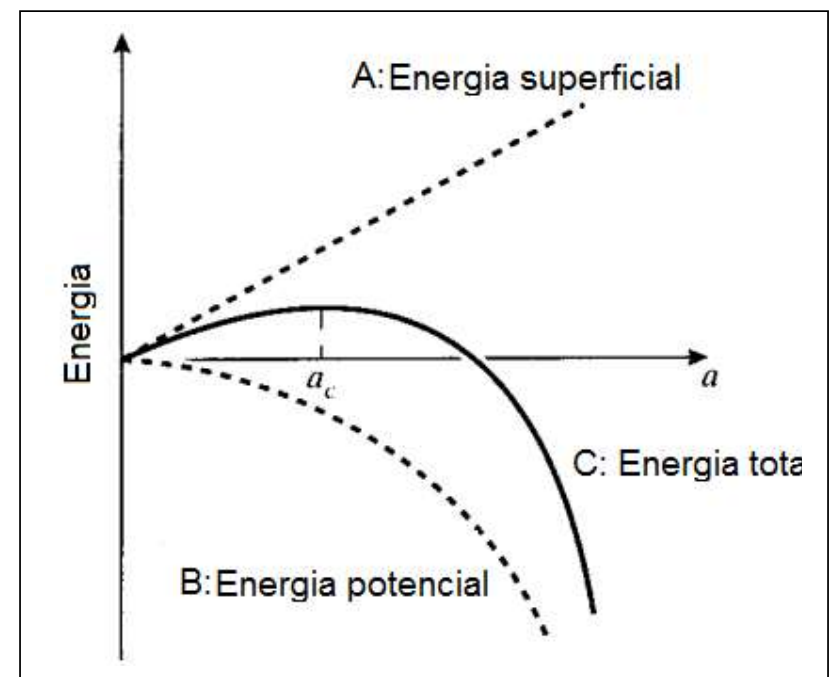

Figura 7 - Curva A: aumento da energia superficial, curva B: queda da energia potencial e curva C: energia total (Roylance, 2001). 
A partir de um equacionamento termodinâmico que considera a variação de energia existente entre o corpo sem trinca e um corpo trincado, obtém-se a Equação (3) abaixo para a tensão de fratura:

$$
\begin{gathered}
\Delta U=\Delta U_{e}+\Delta U_{s} \\
\frac{d \Delta U}{d a}=\frac{d}{d a}\left(-\frac{\pi a^{2} \sigma^{2}}{E}+4 a \gamma_{s}\right)=0 \\
4 a \gamma_{s}-\frac{2 \pi a \sigma^{2}}{E}=0 \\
\sigma_{f r}=\left(\frac{2 E \gamma_{s}}{\pi a}\right)^{1 / 2}
\end{gathered}
$$

na qual,

$\Delta \mathrm{U}=$ Variação de energia entre corpo com trinca e sem trinca;

$\Delta \mathrm{U}_{\mathrm{e}}=$ Variação de energia elástica;

$\Delta \mathrm{U}_{\mathrm{s}}=$ variação de energia de superfície;

$\sigma_{\mathrm{fr}}=$ tensão de fratura;

$\mathrm{E}=$ módulo de elasticidade;

$\gamma_{\mathrm{s}}=$ energia de superfície;

$\mathrm{a}=$ metade do comprimento da trinca.

A teoria de Griffith aplica-se somente a materiais frágeis como por exemplo, vidro, cerâmicos e por conta disto Orowan e Irwin buscaram estender a teoria para materiais de engenharia que possuem significativa capacidade de deformação plástica (Cotterell, 2002; Anderson, 2005). Desta forma, foi inserido o trabalho plástico $\left(\gamma_{p}\right)$ devido ao movimento das discordâncias na região ao redor da trinca em crescimento. Para facilitar, a partir de agora o somatório $\gamma_{p}+\gamma_{s}$ será denominado de $\mathrm{w}_{\mathrm{f}}$. Sendo assim, a Equação (4) de Griffith modificada para materiais dúcteis é: 


$$
\sigma_{f}=\left[\frac{2 E\left(\gamma_{s}+\gamma_{P}\right)}{\pi a}\right]^{1 / 2}
$$

Analisando em termos de energia, haverá propagação da trinca quando a energia disponível no material for suficiente para superar sua resistência à fratura. Em relação a este aspecto Irwin definiu um critério de fratura, similar ao de Griffith, estabelecido como taxa de liberação de energia $(G)$ ou força motriz para fratura. A taxa de liberação de energia é definida como a variação de energia potencial (elástica) em relação à área da trinca, que vai aumentando durante a fratura (propagação estável da trinca). A partir das Equações (3) e (4) mencionadas acima tem-se a taxa de liberação de energia para uma chapa larga em estado plano de tensão com trinca de comprimento 2a, conforme Equação (5):

$$
G=\frac{\pi \sigma^{2} a}{E}
$$

A propagação da trinca, que pode ser estável ou instável, vai ocorrer quando a taxa de liberação de energia da chapa $(\mathrm{G})$ for igual a $2 \mathrm{w}_{\mathrm{f}}$ que a partir de agora será denominada de resistência à fratura $(\mathrm{R})$.

A resistência do material a propagação de trinca vai reduzindo em função do nível de tensão aplicada (taxa de liberação de energia) pois o aumento de tensão faz com a que a trinca se aproxime mais de seu tamanho crítico, ou seja, de sua propagação instável. Quando a taxa de liberação de energia é igual a resistência à propagação da trinca $(\mathrm{G}=\mathrm{R})$, se tem a taxa de liberação de energia crítica e se está no limite para instabilidade da trinca (Anderson, 2005). A curva de resistência ilustrada na Figura 8 mostra o comportamento estável ou instável da trinca, em função da variação da taxa de liberação de energia em relação ao comprimento da trinca. 


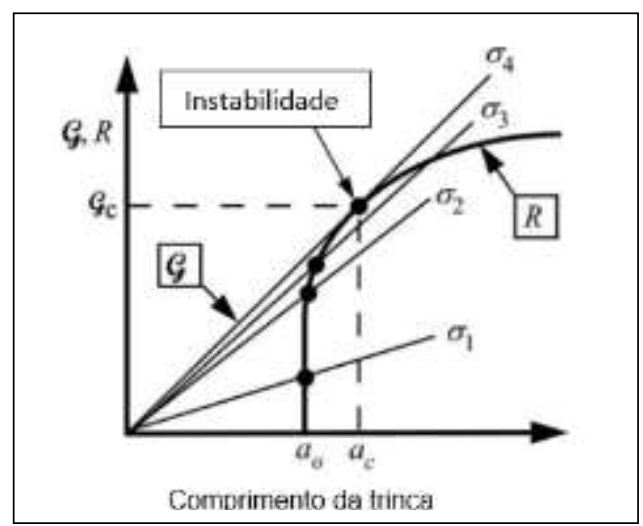

Figura 8 - Curva de resistência à propagação de trinca vs força motriz (Anderson, 2005).

Em resumo pode-se dizer que para propagação estável da trinca deve-se ter a seguinte condiçõe representada na Equação (6):

$$
\frac{d G}{d a} \leq \frac{d R}{d a}
$$

Enquanto que para ocorrência da propagação instável da trinca deve-se atender a Equação (7):

$$
\frac{d G}{d a}>\frac{d R}{d a}
$$

\subsubsection{Campo de Tensões na Ponta da Trinca}

Uma chapa de forma arbitrária com uma trinca de tamanho aleatório possui um estado tensões diferenciado na ponta da trinca. Considerando um material de comportamento elástico, o campo de tensões na extremidade da trinca é pelo menos biaxial (estado plano de tensão) e pode ser triaxial se as condições de restrição forem atendidas (Anderson, 2005). As superfícies livres de uma chapa não são submetidas a tensões. Desta forma as superfícies livres da trinca possuem tensão $\sigma_{\mathrm{x}}$ igual a zero. Porém, afastando-se uma pequena distância da raiz da trinca tem-se $\sigma_{\mathrm{x}}$ e $\sigma_{\mathrm{y}}$ diferente de zero, e $\sigma_{\mathrm{z}}$ ainda igual a zero pois é uma superfície livre e sem ação de carga externa. Esta condição é típica de chapa com espessura reduzida em relação às outras dimensões (chapa fina) e caracteriza o 
estado plano de tensão. No que concerne a deformação, se tem um estado triaxial de deformação representado pelas seguintes Equações (8), (9) e (10) e Figura 9:

$$
\begin{aligned}
& \varepsilon_{x}=\frac{1}{E}\left(\sigma_{x}-v \sigma_{y}\right) \\
& \varepsilon_{y}=\frac{1}{E}\left(\sigma_{y}-v \sigma_{x}\right) \\
& \varepsilon_{z}=-\frac{v}{E}\left(\sigma_{x}+v \sigma_{y}\right)
\end{aligned}
$$

na qual,

$\sigma_{\mathrm{x}}=$ componente de tensão na direção $\mathrm{x}[\mathrm{MPa}]$;

$\sigma_{\mathrm{y}}=$ componente de tensão na direção y $[\mathrm{MPa}]$;

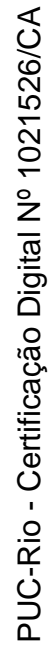

$v=$ coeficiente de Poisson;

$\mathrm{E}=$ módulo de elasticidade $[\mathrm{MPa}]$;

$\varepsilon_{\mathrm{x}}=$ componente da deformação na direção x;

$\varepsilon_{\mathrm{y}}=$ componente da deformação na direção y;

$\varepsilon_{\mathrm{z}}=$ componente da deformação na direção $\mathrm{z}$.

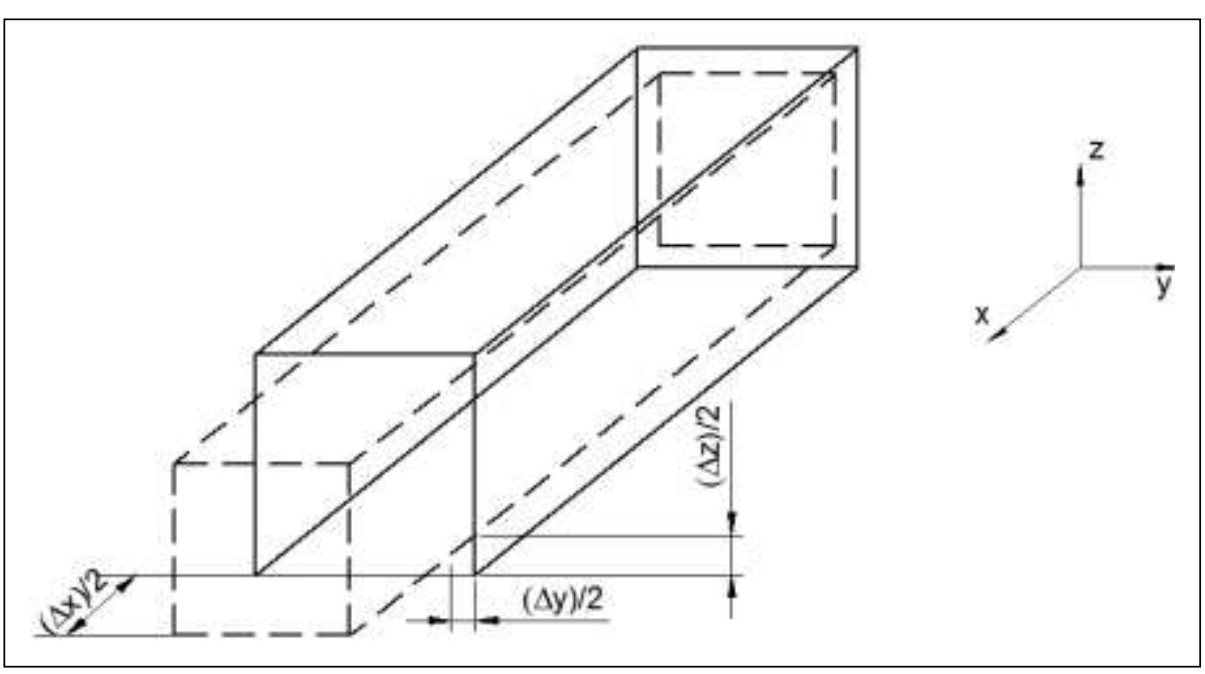

Figura 9 - Deformações devido a ação de carregamento. Adaptado de (Hearn, 1997). 
A condição de triaxialidade de tensões será verificada na ponta da trinca quando a deformação $\varepsilon_{\mathrm{z}}$ for suprimida, ou seja, impedida de ocorrer. Esta situação ocorre em chapas de grandes dimensões, geralmente denominada de chapa grossa. As superfícies da trinca são livres de tensão e possuem $\varepsilon_{\mathrm{z}}=0$. Porém, imediatamente a frente da ponta da trinca existe uma região com possibilidade de deformação $\varepsilon_{\mathrm{z}}$ que pode ser comparada com um cilindro de comprimento igual a espessura da chapa. A Figura 10 ilustra a porção de material com possibilidade de deformação.

A contração do material anexado a ponta da trinca do (cilindro) não ocorre devido à grande quantidade de material ao redor que se opõe à deformação, exceto em uma pequena parte lateral da chapa. A restrição da contração lateral, ou seja, a inibição do escoamento plástico, provoca no componente trincado uma tensão na direção $\mathrm{z}, \sigma_{\mathrm{z}}$, especificamente no material junto a trinca, conforme a Figura 10. O grau de inibição da restrição está relacionado ao nível de triaxialidade de tensões. Quanto mais próximo a tensão na direção do carregamento estiver de $\sigma_{\mathrm{x}} \mathrm{e} \sigma_{\mathrm{z}}$, maior o nível de restrição plástica nos arredores da trinca.

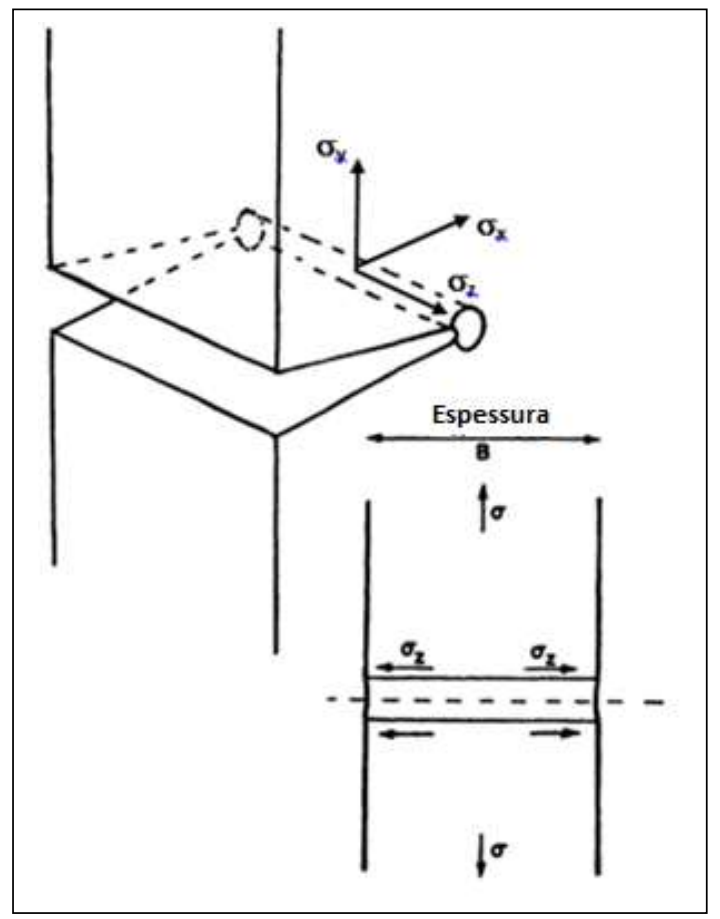

Figura 10 - Influência da espessura no estado de deformação de chapa plana (Broek, 1988). 


\subsubsection{Fator Intensificador de Tensões}

Conforme mencionado no item 2.2.1.1 o fator concentrador de tensões depende apenas de parâmetros geométricos da trinca e não permite calcular como a tensão diminui a medida que se afasta da descontinuidade (trinca). O fator concentrador de tensões não é adequado para um descontinuidade tipo trinca. O raio da ponta da trinca $(\rho)$ tende a zero e com isto as tensões tendem ao infinito, por menor que seja a tensão nominal aplicada remotamente ao componente. Desta forma, houve a necessidade da definição de um novo critério para analisar como é a sensibilidade da flutuação da tensão nos arredores da trinca. Este critério é denominado fator intensificador de tensões.

A distribuição de tensões ao redor da vizinhança da trinca é função da localização do ponto de análise no material elástico linear, denominado elemento infinitesimal, em relação a ponta da trinca, definido por um eixo de coordenada polar, de acordo com a Figura 11.

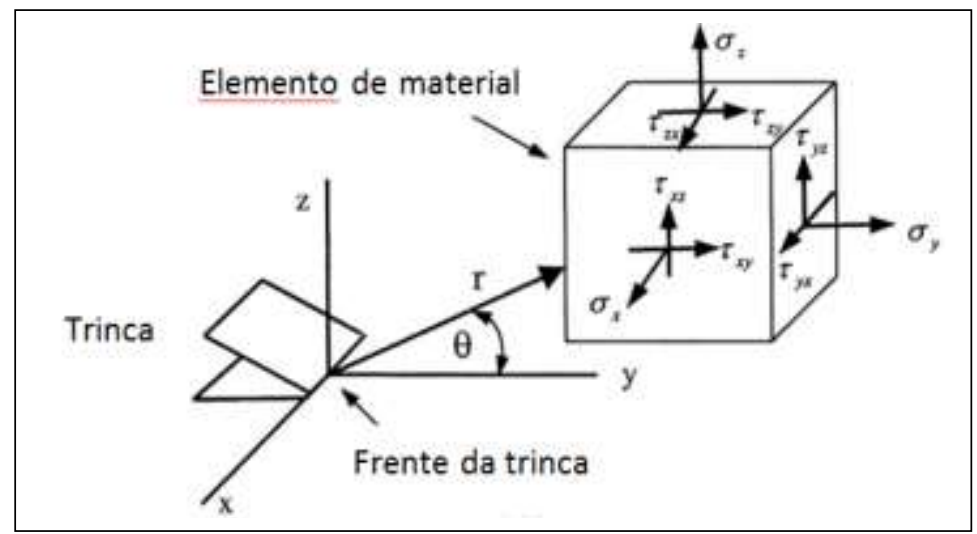

Figura 11 - Distribuição de tensões em elemento infinitesimal na ponta da trinca (Perez, 2004).

Segundo Shukla (2004), Anderson (2005) e Roesler, Harders e Baeker (2007), o fator intensificador de tensões depende do modo de carregamento ao qual a trinca está submetida. Sun e Jin (2012) relatam que cargas externas aplicadas em corpos trincados, provocam movimento das superfícies da trinca, uma em relação à outra, descrito pelos deslocamentos $u_{x}, u_{y}$ e $u_{z}$ definidos de acordo com um sistema de coordenadas cartesiano posicionado na ponta da trinca.

Existem três modos de carregamento: modo I, II e III. O modo I está associado a tensões trativas na qual as superfícies da trinca são abertas. Já os 
modos II e III são carregamentos cisalhantes, no qual no modo II as tensões cisalhantes estão no plano de propagação da trinca e são paralelas ao mesmo. Enquanto que no modo III as tensões cisalhantes são paralelas ao plano de propagação, porém estão fora do plano de propagação (Sun e Jin, 2012). A Figura 12 demonstra os três modos de carregamento em uma trinca.

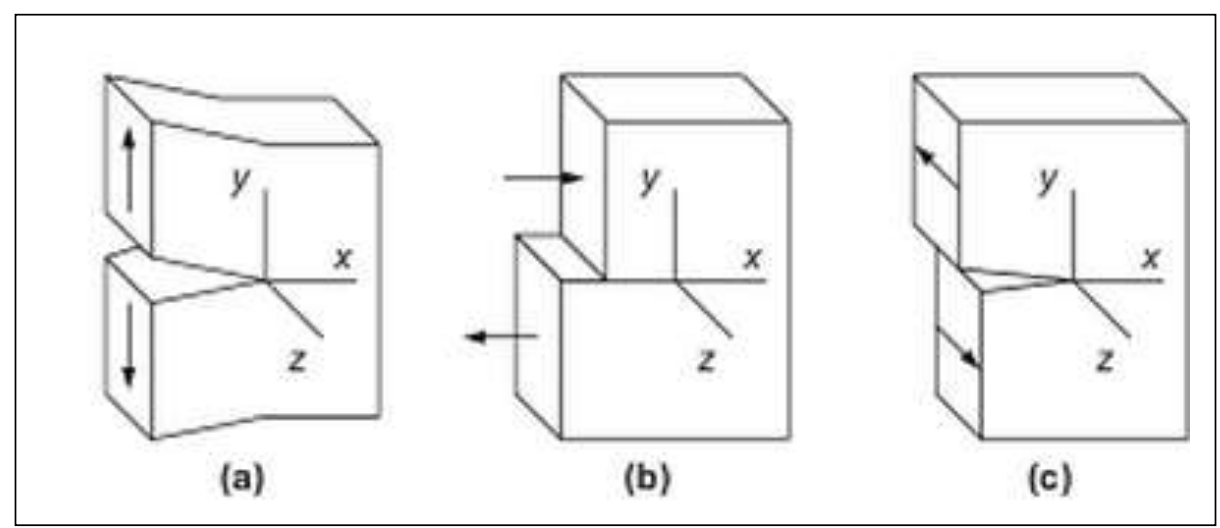

Figura 12 - Modos de carregamento em uma trinca: (a) abertura, (b) cisalhamento no plano e (c) cisalhamento fora do plano (Sun e Jin, 2012).

Um componente trincado pode sofrer qualquer um dos carregamentos ilustrados acima ou até uma combinação dos mesmos, porém o modo I de carregamento é o mais importante pois é predominante na maioria das situações práticas.

O campo de tensões na ponta da trinca é função da distância $r$ e do ângulo $\theta$ do plano de propagação da trinca. Estas análise foram conduzidas por Irwin e Weestergaard em material isotrópico linear elástico e forneceram soluções para as tensões e deformações em uma chapa infinita em estado plano de tensões.

Segundo Irwin (1957), Anderson (2005) e Zhu e Joyce (2012), Irwin observou que o campo de tensões nas proximidades da trinca sempre se comporta da mesma forma: as soluções são sempre singulares na ponta da trinca, quando r é igual a zero, e o termo que lidera essa condição de singularidade é sempre proporcional a um fator, designado de fator de intensidade de tensões (K).

Nas vizinhanças da ponta da trinca foi verificado que as componentes da tensão $\sigma_{\mathrm{ij}}$ no ponto de coordenada $(r, \theta)$, Figura 11, é dada por Equação (11):

$$
\sigma_{i j}=\left[\frac{K}{(2 \pi r)^{1 / 2}}\right] f(\theta)
$$


+ termos de ordem superior

Quanto mais r se aproxima de zero, ou seja, quanto mais perto da ponta da trinca, maior o valor da primeira parcela e se pode desprezar os termos de ordem superior.

Segundo Anderson (2005), no modo I de carregamento o fator intensificador de tensões é designado por $\mathrm{K}_{\mathrm{I}} \mathrm{e}$ as tensões na ponta da trinca são dadas pelas seguintes Equações (12), (13) e (14) para o estado plano de tensão e (15), (16) e (17) para estado plano de deformação:

Estado Plano de Tensão

$$
\begin{gathered}
\sigma_{x}=\left[\frac{K}{(2 \pi r)^{1 / 2}}\right] \cos \left(\frac{\theta}{2}\right)\left(1-\operatorname{sen}\left(\frac{\theta}{2}\right) \operatorname{sen}\left(\frac{3 \theta}{2}\right)\right) \\
\sigma_{y}=\left[\frac{K}{(2 \pi r)^{1 / 2}}\right] \cos \left(\frac{\theta}{2}\right)\left(1+\operatorname{sen}\left(\frac{\theta}{2}\right) \operatorname{sen}\left(\frac{3 \theta}{2}\right)\right) \\
\sigma_{z}=0
\end{gathered}
$$

Estado Plano de Deformação

$$
\begin{gathered}
\sigma_{x}=\left[\frac{K}{(2 \pi r)^{1 / 2}}\right] \cos \left(\frac{\theta}{2}\right)\left(1-\operatorname{sen}\left(\frac{\theta}{2}\right) \operatorname{sen}\left(\frac{3 \theta}{2}\right)\right) \\
\sigma_{y}=\left[\frac{K}{(2 \pi r)^{1 / 2}}\right] \cos \left(\frac{\theta}{2}\right)\left(1+\operatorname{sen}\left(\frac{\theta}{2}\right) \operatorname{sen}\left(\frac{3 \theta}{2}\right)\right) \\
\sigma_{z}=v\left(\sigma_{x}+\sigma_{y}\right)
\end{gathered}
$$

O campo de tensão na ponta da trinca é dominado pela condição de singularidade $1 / \sqrt{r}$. Nos arredores da zona de singularidade, a tensão trativa aplicada remotamente aumenta para níveis consideráveis. A Figura 13 mostra a 
variação da tensão normal ao plano da trinca $(\theta=0)$ em função da distância da ponta da trinca $(r)$.

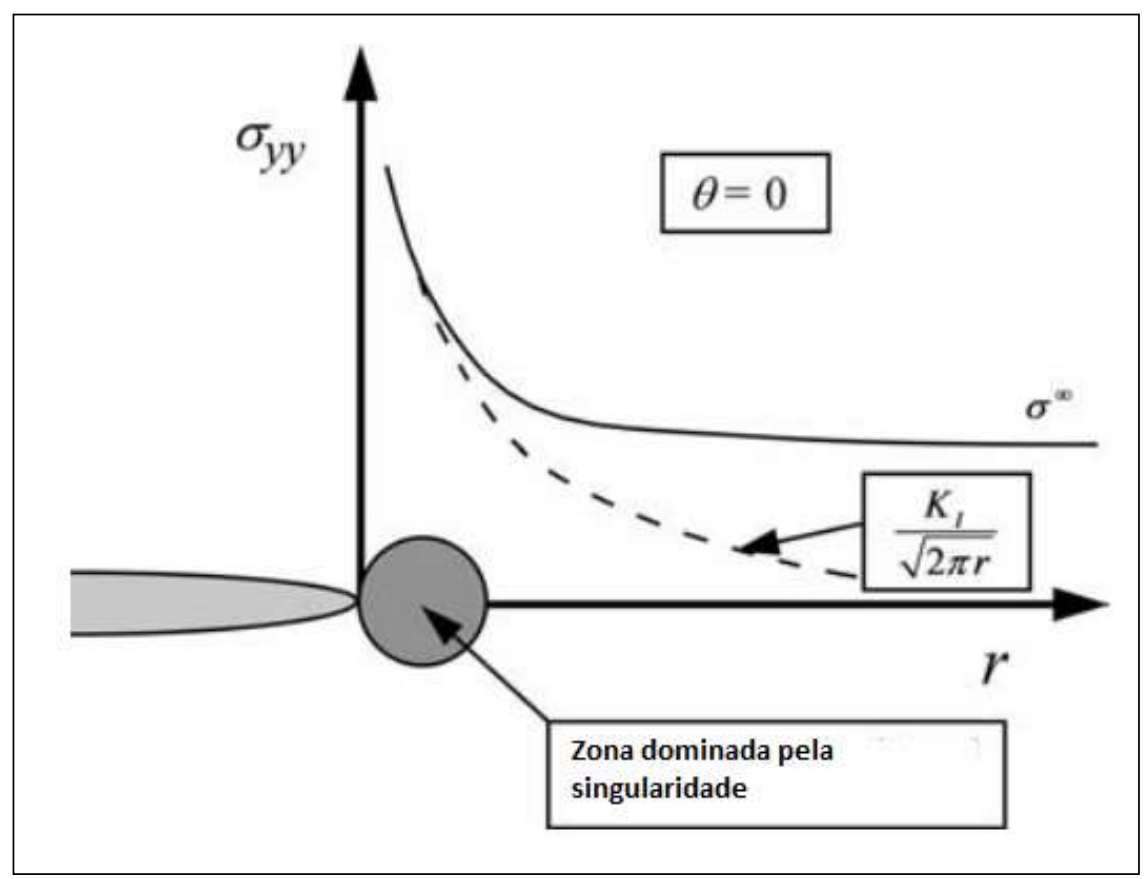

Figura 13 - Tensão normal no plano da trinca em função da distância à ponta da trinca (Anderson, 2005).

$\mathrm{O}$ fator intensificador de tensões $\left(\mathrm{K}_{\mathrm{I}}\right)$ define o grau de singularidade na ponta da trinca. Isto é, as tensões perto da ponta da trinca aumentam proporcionalmente a $\mathrm{K}_{\mathrm{I}}$.

O fator intensificador de tensões $(K)$ depende da forma e tamanho da trinca, modo de carregamento e geometria do componente estrutural. Sabe-se que nos materiais de comportamento linear elástico, as componentes de tensões são proporcionais à força remotamente aplicada e, consequentemente, a tensão. Sendo assim, $\mathrm{K} \propto \sigma$. Para uma trinca passante central em uma chapa infinita submetida a tensão trativa remota, perpendicular ao plano da trinca, $\mathrm{K}_{\mathrm{I}}$ pode ser obtido pela Equação (18) mais simples mostrada a abaixo:

$$
K_{I}=Y \sigma \sqrt{\pi a}
$$

na qual,

$\sigma=$ tensão nominal remota $[\mathrm{MPa}]$; 
$\mathrm{a}=$ metade do comprimento da trinca $[\mathrm{m}]$;

$\mathrm{Y}=$ função adimensional dependente da geometria do componente [adimensional];

\subsubsection{Fator Intensificador de Tensões - Critério de Fratura}

O valor da carga aplicada a trinca, e consequentemente a tensão influencia no fator intensificador de tensões $(\mathrm{K})$. As tensões localizadas em ponto próximo a região dominada pela singularidade se relaciona com o fator intensificador de tensões (K) através da Equação (19) abaixo:

$$
\sigma_{i j}=\left[\frac{K}{(2 \pi r)^{1 / 2}}\right] f(\theta)
$$

na qual $\mathrm{f}(\theta)$ é função geométrica do componente.

O fator intensificador de tensões $(\mathrm{K})$ fornece o campo de tensões localizado nos arredores da trinca. Porém, nenhum material pode suportar tensões infinitas, desta forma, o material a frente da trinca vai fraturar quando a tensão local atingir um valor limite da ordem de 25 a $30 \%$ da resistência coesiva do material. Conhecendo a tensão limite, se determina o fator intensificador de tensões limite para início da propagação da trinca.

O fator intensificador de tensões limite para propagação da trinca é designado na literatura específica como tenacidade à fratura e é representado pelo parâmetro $\mathrm{K}_{\mathrm{Ic}}$ no modo I de carregamento, denominado fator intensificador de tensões crítico. Em resumo, quando o carregamento aplicado ao componente trincado for suficiente para produzir um fator intensificador de tensões igual ao fator crítico se tem a fratura (Broek, 1988; Shukla, 2004 e Anderson, 2005).

A tenacidade à fratura é inerente ao material, pois é uma propriedade mecânica. Porém a tenacidade à fratura do material depende do estado de tensão existente no componente trincado. Ou seja, é necessário critério para se utilizar o parâmetro $\mathrm{K}_{\mathrm{Ic}}$ na especificação de tenacidade à fratura do material. $\mathrm{O}$ critério para uso do $\mathrm{K}_{\mathrm{Ic}}$ está relacionado a espessura. 


\subsubsection{Influência da Espessura Sobre a Tenacidade à Fratura}

A tenacidade à fratura em materiais lineares elásticos é dependente da geometria. A espessura exerce influência sobre o estado de tensão de um componente trincado, que pode estar sob a condição de tensão plana ou deformação plana.

É comum na mecânica da fratura encontrar o parâmetro $\mathrm{K}$ na forma $\mathrm{K}_{\mathrm{c}}$ ou $\mathrm{K}_{\mathrm{Ic}}$. Ambos definem a tenacidade à fratura do material porém o $\mathrm{K}_{\mathrm{c}}$ não é um valor constante, já que o mesmo se altera com o aumento da espessura. Um componente trincado de pouca espessura (chapa fina) encontra-se sob estado de tensão plana, e sob esta condição o parâmetro $\mathrm{K}$ passa a ser $\mathrm{K}_{\mathrm{c}}$, que reduz com o aumento da espessura do componente.

Porém a mudança no estado plano de tensão para plano de deformação ocorre para uma determinada espessura. Após uma faixa de espessura de transição, o valor de $K_{c}$ se torna constante e nesse momento se atingiu o parâmetro $\mathrm{K}_{\mathrm{Ic}}$, denominado tenacidade à fratura no estado plano de deformação no modo I de carregamento. A Figura 14 mostra a variação do parâmetro K com a espessura do material.

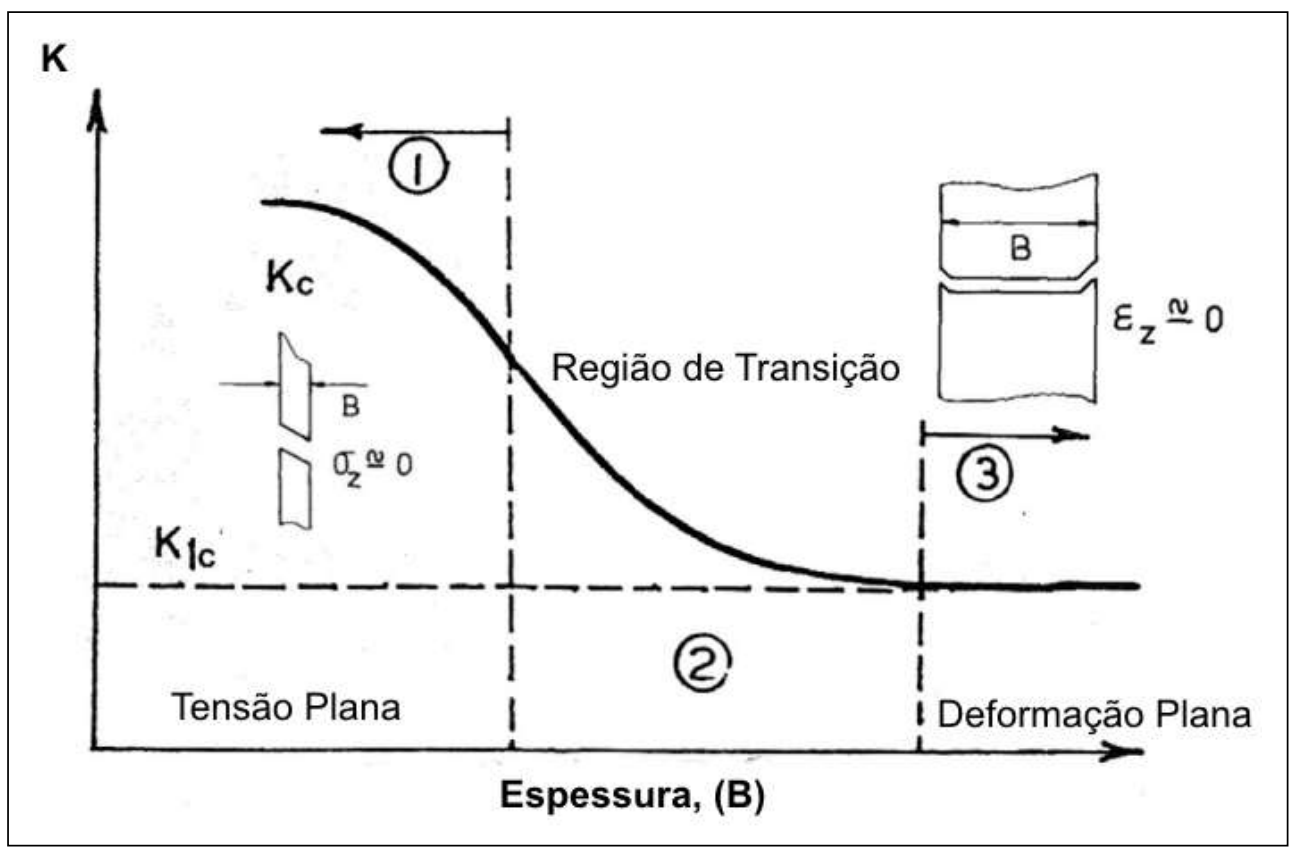

Figura 14 - Variação do fator intensificador de tensões em função da espessura. Adaptado de Anderson, 2005 e Shukla, 2004. 
Em resumo, tem-se: quando a denotação $\mathrm{K}_{\mathrm{c}}$ estiver sendo usada, a análise refere-se a uma fratura em tensão plana ou em estado de transição. Já a denotação $\mathrm{K}_{\mathrm{Ic}}$ refere-se à análise de fratura em situação de completa restrição à deformação, o que caracteriza o estado plano de deformação.

A interação da propriedade do material com o carregamento e o tamanho da trinca controla todo o processo de fratura do componente trincado. Em conformidade com esta situação, a condição de fratura para um componente sob o estado de deformação plana pode ser expresso pela Equação (20):

$$
K_{I c}=Y \sigma_{f} \sqrt{\pi a_{c}}
$$

na qual, $\mathrm{K}_{\mathrm{Ic}}$ é propriedade que vai definir o material a ser utilizado na fabricação do componente, $\sigma_{\mathrm{f}}$ é tensão de falha oriunda da etapa de projeto e $\underline{\mathbf{a}}_{\mathbf{c}}$ é o tamanho crítico da trinca detectável por técnica não destrutiva. Ao atingir a condição acima a fratura do componente ocorrerá por meio de propagação instável da trinca.

\subsubsection{Tamanho da Zona Plástica a Frente da Ponta da Trinca}

Tensões acima do limite de escoamento do material na ponta da trinca $\left(\theta=0^{\circ}\right)$ causadas pelo modo I de carregamento provocam uma região de deformação, denominada zona plástica (Hertzberg, 2012). Sabe-se que em materiais estudados pela mecânica da fratura linear elástica, esta zona plástica é pequena, porém pode-se estimar seu tamanho pela Equação (21)

$$
\sigma_{y}=\frac{K_{I}}{\sqrt{2 \pi r}}
$$

na qual (r) é a distância do ponto analisado a ponta da trinca. $\mathrm{O}$ tamanho da zona plástica a frente da ponta da trinca é função do nível de triaxialidade encontrado no material nos arredores da trinca. Para o estado plano de tensão, o início do escoamento se dá quando a tensão $\left(\sigma_{\mathrm{y}}\right)$ for igual ao limite de escoamento do material $\left(\sigma_{\mathrm{ys}}\right)$. Reescrevendo a Equação (21) em função da distância de 
afastamento até a ponta da trinca, se tem o raio da zona plástica $\left(\mathrm{r}_{\mathrm{pl}}\right)$ na Equação 22:

$$
r_{p l}=\frac{1}{2 \pi}\left(\frac{K_{I}}{\sigma_{y s}}\right)^{2}
$$

Por Broek (1988) nas condições de deformação plana, onde o campo triaxial de tensões restringe a deformação na direção da espessura, o tamanho da zona plástica é estimado pela análise da tensão transversal $\left(\sigma_{\mathrm{x}}\right)$ e longitudinal $\left(\sigma_{\mathrm{y}}\right)$. Como a deformação na direção da espessura $\varepsilon_{\mathrm{z}}$ é igual a zero se tem a relação entre $\sigma_{z}$ e $\sigma_{y}$ pela Equação (23) e (24) a seguir:

$$
\begin{aligned}
& \varepsilon_{z}=\frac{\sigma_{z}}{E}-v \frac{\sigma_{x}}{E}-v \frac{\sigma_{y}}{E}=0 \\
& \sigma_{z}=v\left(\sigma_{x}+\sigma_{y}\right)
\end{aligned}
$$

omo $\sigma_{\mathrm{x}}$ e $\sigma_{\mathrm{y}}$ são iguais conforme mencionado na seção 2.2.1.3 e considerando o coeficiente de Poisson (v) igual a 0,33 se tem a Equação (25):

$$
\sigma_{z}=0,33\left(2 \sigma_{y}\right)=0,66 \sigma_{y}
$$

Segundo o critério de falha de Tresca, o início do escoamento ocorre quando a diferença entre as tensões principais máxima e mínima do material é igual ao seu limite de escoamento, $\sigma_{\mathrm{ys}}$. Equacionando o exposto acima e utilizando a relação entre $\sigma_{y}$ e $\sigma_{z}$ se tem Equação (26) e Equação (27):

$$
\begin{gathered}
\sigma_{y s}=\sigma_{y}-\sigma_{z}=\sigma_{y}-0,66 \sigma_{y} \\
\sigma_{y}=3 \sigma_{y s}
\end{gathered}
$$

na qual se verifica que a tensão $\left(\sigma_{y}\right)$ para o escoamento na ponta da trinca deve ser três vezes maior que o limite de escoamento do material, devido a maior condição 
de restrição plástica. Substituindo a Equação (27) na Equação (21) tem-se a estimativa do raio da zona plástica $\left(\mathrm{r}_{\mathrm{pl}}\right)$ em deformação plana:

$$
r_{p l}=\frac{K_{I}^{2}}{2 \pi\left(3 \sigma_{y s}\right)^{2}}=\frac{K_{I}^{2}}{18 \pi\left(\sigma_{y s}\right)^{2}}
$$

$\mathrm{Na}$ prática, a condição de deformação plana não existe na superfície do componente. Sendo assim, a restrição plástica faz com que a tensão necessária ao escoamento na ponta da trinca se aumentada de um fator menor que 3. Irwin, segundo Broek (1982), sugeriu o fator 1,68. Desta forma a Equação (28) se modifica resultando na Equação (29):

$$
r_{p l}=\frac{K_{I}^{2}}{2 \pi\left(1,68 \sigma_{y s}\right)^{2}}=\frac{K_{I}^{2}}{6 \pi\left(\sigma_{y s}\right)^{2}}
$$

Pelos tamanhos da zona plástica em tensão plana e deformação plana representados respectivamente pelas Equações (22) e (29), se conclui que a zona plástica em deformação plana é três vezes menor quando comparada a zona plástica em tensão plana, o que está de acordo com o conceito de deformação plana. A Figura 15 ilustra a diferença entre as zonas plásticas no estado plano de tensão e no estado plano de deformação.

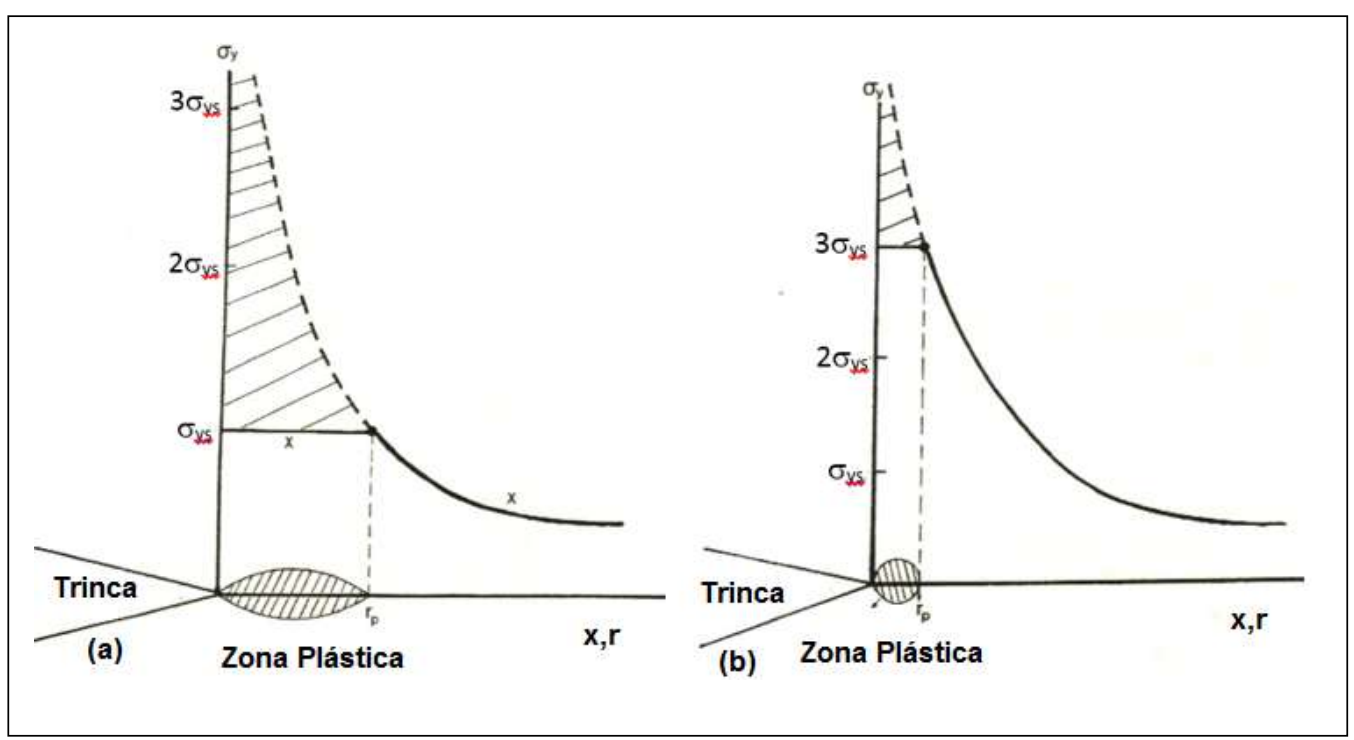

Figura 15 - Tamanho da zona plástica: (a) Em estado plano de tensão. (b) Em estado plano de deformação (Broek, 1988). 
Como a existência da zona plástica faz a trinca aparentar maior comprimento do que ela realmente tem, Irwin (1961) incorporou o raio da zona plástica (r) definido anteriormente pelas Equações (22) e (28) ao tamanho real da trinca. Então o tamanho efetivo da trinca é $\left(a+r_{p}\right)$, onde a é a metade do comprimento medido da trinca e $r_{p}=r$ é o raio da zona plástica (Hertzberg, 2012).

É necessário enfatizar que o parâmetro $\mathrm{K}_{\mathrm{Ic}}$ de um material linear elástico somente pode ser determinado através de ensaio padronizado pela American Society of Testing and Materials (ASTM). Esta instituição descreve os procedimentos experimentais e a geometria do corpo de prova para medição da tenacidade à fratura em deformação plana nos materiais metálicos. Tais procedimentos encontram-se na norma E399.

O ensaio consiste em carregar monotonicamente um corpo de prova, entalhado e pré trincado por fadiga, até se obter a propagação instável da trinca. Quando se tem a propagação instável da trinca, se conhece o $\mathrm{K}_{\mathrm{Ic}}$, e esta propriedade de material é dependente apenas da temperatura e taxa de deformação. Existe uma variedade de tipos de geometrias de corpos de prova, porém um dos mais utilizados devido a facilidade de aplicação do carregamento é o do tipo flexão por três apoios, ilustrado na Figura 16.

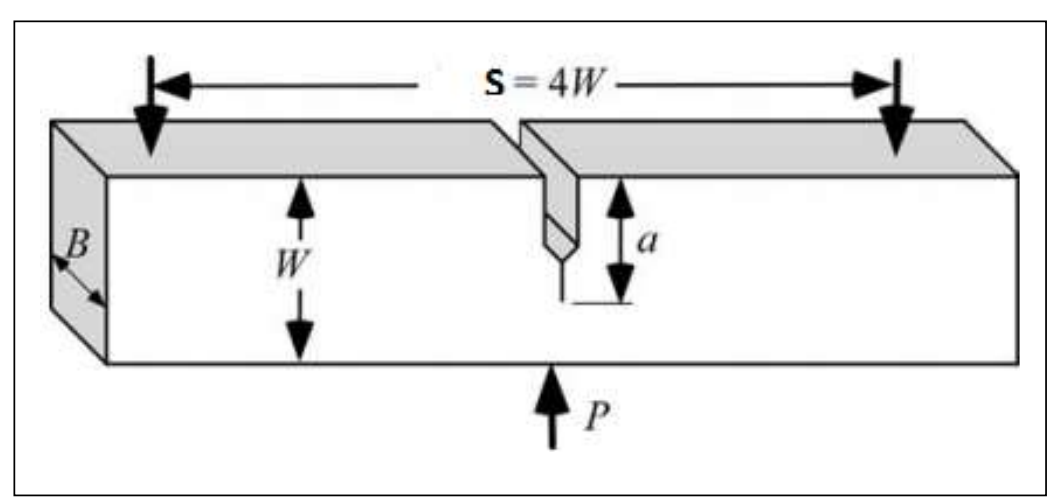

Figura 16 - Corpo de prova de flexão em três apoios. B: espessura, W: largura e S: espaçamento entre os apoios (Anderson, 2005).

O procedimento de ensaio definido pela ASTM é específico para determinação de $\mathrm{K}_{\mathrm{Ic}}$, que não depende da espessura. Isto significa que a ponta da trinca no corpo de prova, durante o ensaio, deve estar sob o estado plano de 
deformação, e para isso o mesmo deve satisfazer requisitos associados à geometria, para que o grau de restrição à deformação plástica seja alcançado e por conseguinte a zona plástica na ponta da trinca seja bem pequena em relação às dimensões do corpo de prova (Broek, 1988; Gdoutos 2005).

O estado plano de deformação é alcançado no corpo de prova quando a porção de material na ponta da trinca na forma de cilindro é longa e de pequeno diâmetro. Em situações de trinca passante pela espessura pode-se afirmar que o comprimento (L) do cilindro é a própria espessura do corpo de prova e o diâmetro (D) pode ser tomado como o tamanho da zona plástica. Em Broek (1988), encontra-se uma relação L/D expressa na Equação (30) onde se tem:

$$
\frac{L}{D}=\frac{B}{K_{I c}^{2} / \sigma_{y s}^{2}}>q
$$

na qual,

$\mathrm{B}=$ espessura do corpo de prova;

$\mathrm{K}_{\mathrm{Ic}}=$ tenacidade à fratura em deformação plana;

$\sigma_{\mathrm{ys}}=$ limite de escoamento do material;

$\mathrm{q}=$ constante experimental igual a 2,5.

Pelo exposto acima se sabe que a espessura mínima do corpo de prova para assegurar a condição de estado plano de deformação é expresso pela Equação (31):

$$
B \geq 2,5\left(\frac{K_{I c}}{\sigma_{y s}}\right)^{2}
$$

Como não se conhece o valor de $\mathrm{K}_{\mathrm{Ic}}$ já que o ensaio ainda não foi realizado, se deve adotar um valor inicial, baseado em dados da literatura específica para determinação da espessura. Após a determinação de $\mathrm{K}_{\mathrm{Ic}}$, é necessário verificar se a razão $\left(\mathrm{K}_{\mathrm{Ic}} / \sigma_{\mathrm{ys}}\right)^{2}$ é menor que a espessura (B) do corpo de prova. Caso negativo, outro ensaio com corpo de prova de maior espessura deve ser realizado (Broek, 1988). 
Além da espessura mínima, deve-se determinar o tamanho da trinca (a). De acordo com a ASTM E 399, estas dimensões são obtidas pelas Equações (32) e (33) a seguir:

$$
\begin{aligned}
& B \geq 2,5\left(\frac{K_{I c}}{\sigma_{y s}}\right)^{2} \\
& a \geq 2,5\left(\frac{K_{I c}}{\sigma_{y s}}\right)^{2}
\end{aligned}
$$

\subsection{Mecânica da Fratura Elasto-Plástica (MFEP)}

A mecânica da fratura linear elástica (MFLE) é restrita ao estudo de componentes trincados em materiais de comportamento linear com plasticidade limitada na ponta da trinca. Porém, é fato que para os chamados materiais de engenharia, ou seja, aqueles cujo o comportamento em deformação é não linear, não se pode mais utilizar o parâmetro $\mathrm{K}_{\mathrm{Ic}}$ da MFLE para determinação da tenacidade à fratura, pois a fratura nestes materiais é precedida de extensa deformação plástica.

Anderson (2005), Gdoutos (2005), Gross e Selig (2011) e Shukla (2004) destacam que materiais com significativa plasticidade como, por exemplo, os aços estruturais, a zona plástica a frente da ponta da trinca não é desprezível em relação as dimensões do corpo de prova, o que invalida o uso da mecânica da fratura linear elástica. Desta forma a mecânica da fratura elasto-plástica (MFEP) estuda fratura caracterizada por propagação estável de trinca, responsável pela deformação plástica. A Figura 17 mostra a seguir a aplicabilidade da mecânica da fratura linear elástica e elasto-plástica em função do tamanho da zona plástica causada pelo escoamento nas proximidades da ponta da trinca. 


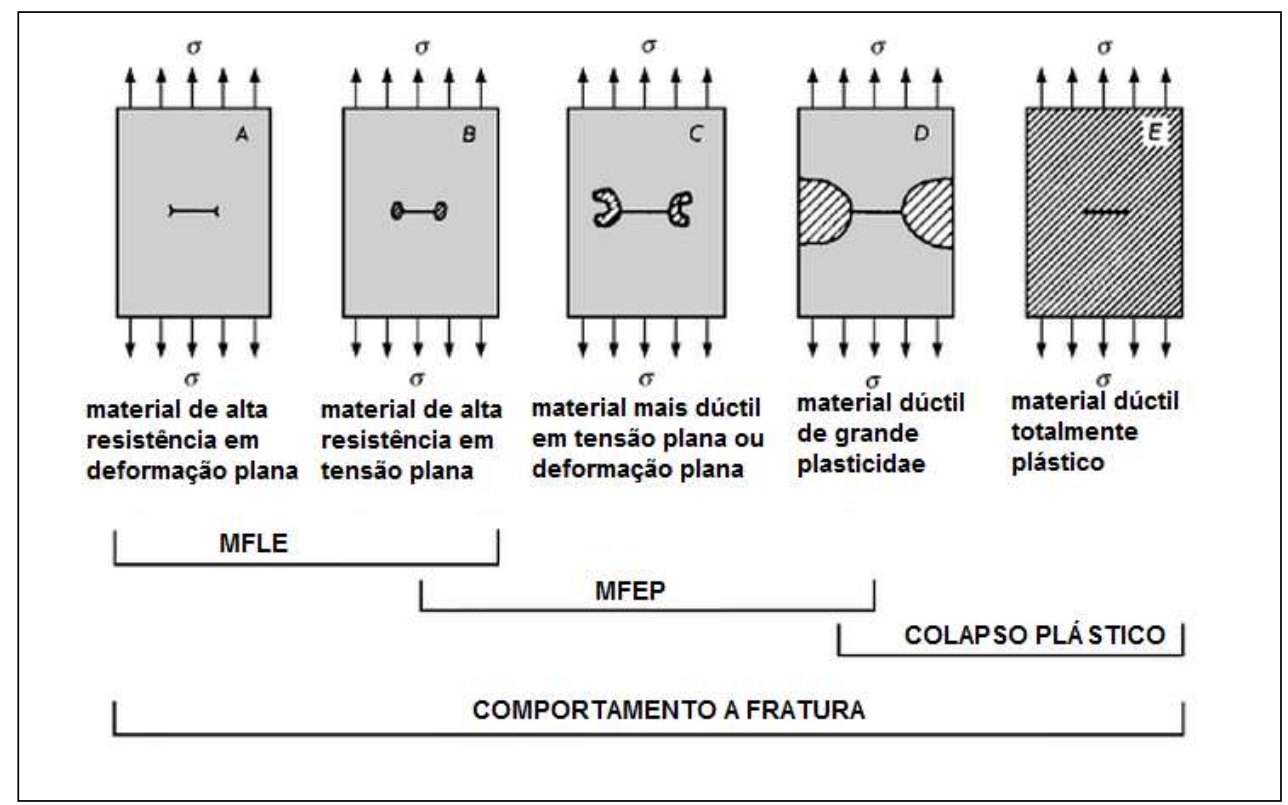

Figura 17 - Campo de aplicação da mecânica da fratura (Janssen, Zuidema e Wanhill, 2006).

A impossibilidade de se utilizar o parâmetro da MFLE é também devido a necessidade de grande espessura para se garantir a condição de deformação plana (estado triaxial de tensões) na ponta da trinca, o que acarreta em corpos de prova de grandes dimensões elevadas, inviabilizando tecnicamente e economicamente a realização do ensaio (Shukla, 2004).

Sendo assim, segundo Anderson (2005), Janssen, Zuidema e Wanhill (2006) e outros colaboradores do assunto, para a análise do comportamento à fratura de materiais com boa ductilidade é realizada através das técnicas da mecânica da fratura elasto-plástica através dos parâmetros CTOD e a Integral J .

Um dos primeiros parâmetros da mecânica da fratura elasto-plástica, o CTOD foi desenvolvido por Wells na década de 60. Este percebeu que os flancos de uma trinca inicialmente aguda, em materiais elasto-plásticos são abertos quando a trinca é submetida a um carregamento trativo. Como o material possui alta ductilidade, a ponta da trinca se deforma plasticamente antes de ocorrer a propagação da trinca pois as tensões nesta região excedem o limite de escoamento do material (Janssen, Zuidema e Wanhill, 2006). Com esta deformação, a ponta antes aguda se torna arredondada (trinca embotada) e este fenômeno é conhecido como "blunting" ilustrado na Figura 18. 


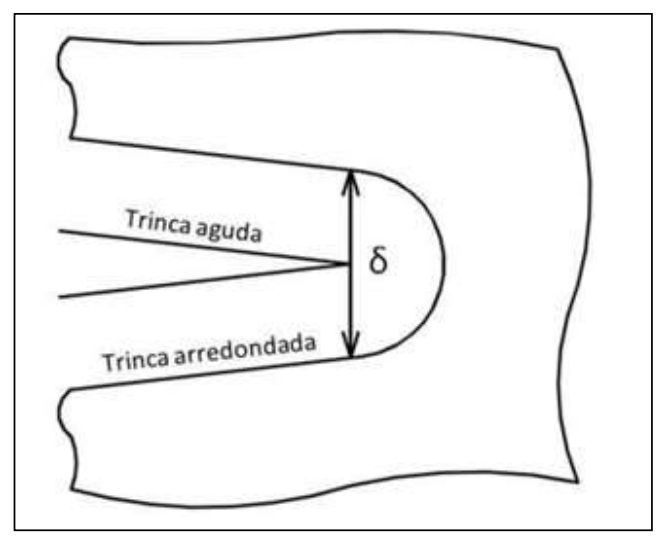

Figura 18 - Blunting da ponta da trinca devido acarregamento trativo (Donato, 2009).

Wells, a partir do CTOD, estabeleceu uma análise do campo de tensões e deformações ao redor da trinca desenvolvido pela intensificação de tensões através da medição do deslocamento causado pelo arredondamento da ponta da trinca, utilizada posteriormente como critério de fratura. Cotterell (2002), Anderson (2005) e Janssen, Zuidema e Wanhill (2006) relatam que o critério do CTOD, proposto por Wells, assume que para ocorrer a fratura a ponta da trinca deve atingir um valor de abertura crítica, tomado como o valor da tenacidade à fratura do material. A partir desta abertura crítica inicia-se a geração de novas superfícies e consequentemente o processo de fratura propriamente dito.

O grau de abertura dos flancos da trinca (arredondamento de sua ponta) é diretamente proporcional a tenacidade à fratura do material, quanto mais os flancos da trinca se abrem maior o arredondamento da trinca mostrando assim a ductilidade do material (Moore e Pisarski, 2013).

\subsubsection{Modelo de Wells para CTOD}

O modelo de Wells (1961) consiste de uma chapa plana infinita com trinca de comprimento $2 \mathrm{a}$, passante ao longo da espessura, submetida a tensão remota.

A deformação plástica a frente da ponta da trinca provocada pela intensificação das tensões oriundas do carregamento trativo proporciona um crescimento virtual da trinca. Sendo assim, Wells (1961) considerou a incorporação da zona plástica ao tamanho real da trinca, sugerida por Irwin, e passou a adotar o tamanho virtual da trinca $\left(a+r_{p}\right)$ representado na Figura 19. 


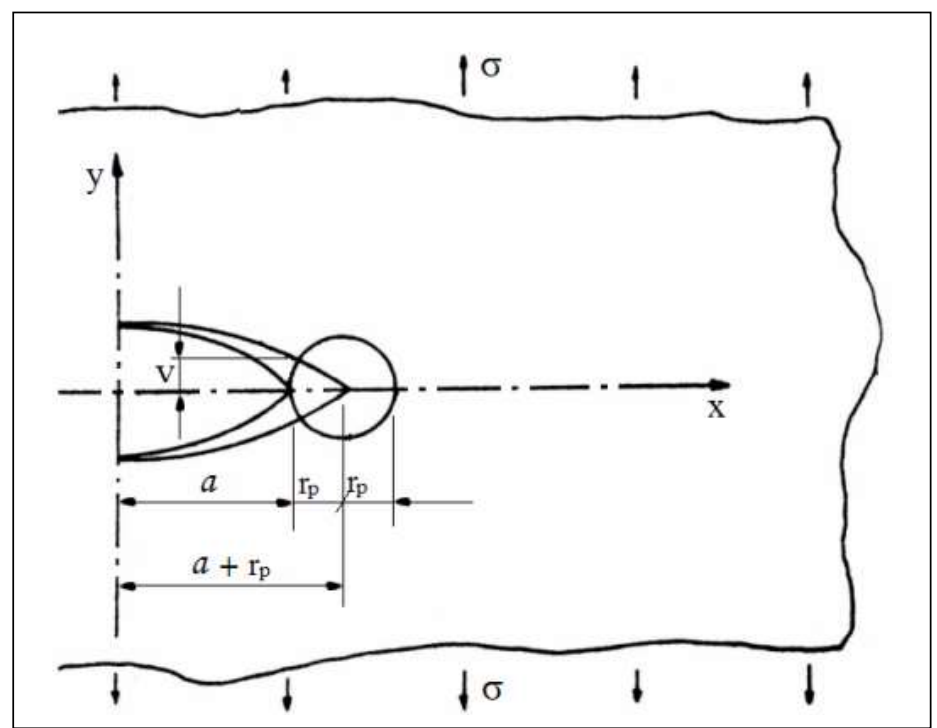

Figura 19 - Trinca de Wells, após incorporação da zona plástica ao tamanho real da trinca (Wells, 1961).

Desta forma a abertura de uma das superfícies da trinca para materiais elásticos, onde a coordenada do ponto de análise $\mathrm{x} \leq \mathrm{a}$, é dada pela Equação (34):

$$
V=\frac{2 \sigma}{E} \sqrt{a^{2}-x^{2}}
$$

na qual,

$\mathrm{V}=$ afastamento de uma das faces da trinca em relação ao centro da mesma [mm]; $\sigma=$ tensão remota aplicada $[\mathrm{MPa}]$

$\mathrm{E}=$ Módulo de elasticidade $[\mathrm{MPa}]$

$\mathrm{a}=$ metade do comprimento da trinca $[\mathrm{mm}]$;

$\mathrm{x}=$ distância do centro a ponta da trinca $[\mathrm{mm}]$.

Analisando a ponta da trinca, ou seja, $\mathrm{x}=\mathrm{a}$ e utilizando o tamanho virtual da trinca $\left(a+r_{p}\right)$, a Equação (34) passa a ter a seguinte forma:

$$
V=\frac{2 \sigma}{E} \sqrt{2 a r_{p}+r_{p}^{2}}
$$


Como o modelo de Wells considera pequenos níveis de deformação plástica, $\mathrm{a} \geq \mathrm{r}_{\mathrm{p}}$, o afastamento de uma das faces da trinca (V) para o estado plano de tensão, assume a seguinte forma expressa na Equação (36):

$$
\begin{aligned}
& V=\frac{2 \sigma}{E} \sqrt{2 a r_{p}} \\
& V=\frac{2 \sigma}{E} \sqrt{2 a \times \frac{1}{2 \pi}\left(\frac{K_{I}}{\sigma y s}\right)^{2}}
\end{aligned}
$$

Substituindo a definição de $K_{I}=\sigma \sqrt{\pi a}$ na Equação (36), tem-se a Equação (37):

$$
V=\frac{2 K_{I}{ }^{2}}{\pi E \sigma_{y s}}
$$

Como o CTOD que é denominado $\delta$, é igual a $2 \mathrm{~V}$, o que corresponde ao deslocamento de abertura na ponta da trinca tem-se a Equação (38):

$$
\delta=2 V=\frac{4 K_{I}{ }^{2}}{\pi E \sigma_{y s}}
$$

\subsubsection{Modelo de Dugdale, Burdekin e Stone "Strip Model"}

Baseado em um modelo inicialmente estabelecido por Dugdale e Barenblatt para materiais não endurecíveis, Burdekin e Stone em 1966 desenvolveram uma outra abordagem para o conceito de CTOD, através da análise de uma chapa infinita com uma trinca de comprimento 2a, em estado plano de tensão (Anderson, 2004; Perez, 2004).

A chapa submetida a um carregamento trativo uniforme, aplicado de forma remota e perpendicular ao plano da trinca apresentou uma zona plástica de comprimento $\rho$, na forma de uma estreita faixa, devido às tensões ao limite de escoamento do material apresentado na ponta da trinca. Este modelo considera que a extensão da trinca na direção da tensão aplicada é menor quando comparado 
a extensão do comprimento (Seelig, 2011). A Figura 20 ilustra o modelo de zona plástica desenvolvida por Burdekin e Stone.

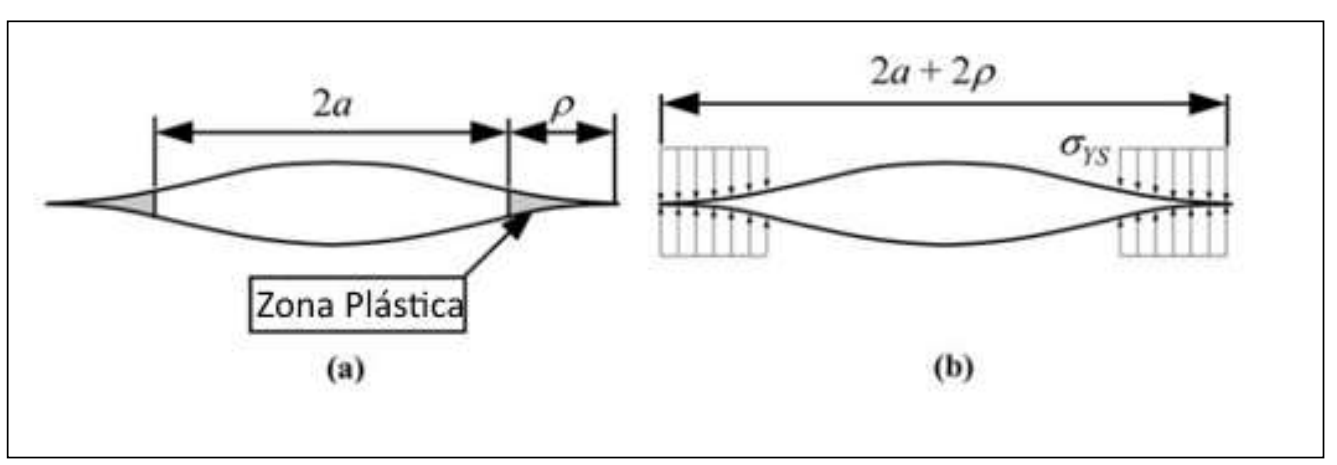

Figura 20 -Modelo de CTOD por Burdekin e Stone ( Seelig, 2011).

Pela Figura 20 o deslocamento de abertura das faces da trinca $(\delta)$ ao longo do crescimento virtual da trinca atinge um valor $\delta_{\mathrm{t}}$ na ponta física da trinca e desaparece na ponta da zona plástica formada. $\mathrm{Se} \delta$ é indicativo da deformação plástica na ponta da trinca, este pode ser tomado como um critério elasto-plástico para início do crescimento da trinca, ou seja, o início da propagação da trinca ocorrerá quando o deslocamento da abertura atingir um valor crítico $\left(\delta_{\mathrm{t}}=\delta_{\mathrm{tc}}\right)$. Desta forma pode-se afirmar que $\delta_{\mathrm{tc}}$ é uma propriedade de material.

Além do mais, por Perez (2004) e Gross e Seelig (2011), neste modelo não existe mais a condição de singularidade, $(1 / \sqrt{r})$, na zona plástica, já que as tensões atuantes neste local são finitas (tensão limite de escoamento do material). Consequentemente o fator intensificador de tensões pela tensão externa anula o fator intensificador devido ao escoamento a frente da trinca $\left(\mathrm{K}_{\mathrm{I}(\sigma)}=-\mathrm{K}_{\mathrm{I}(\sigma \mathrm{ys})}\right)$. A partir dessa condição e da aplicação do princípio da superposição para cálculo do fator intensificador de tensões efetivo, Burdekin e Stone deduziram a Equação (39):

$$
\delta=\frac{8 \sigma_{y s} a}{\pi E} \ln \left(\sec \frac{\pi \sigma}{2 \sigma_{y s}}\right)
$$

Pela expansão do termo entre parênteses a Equação (39) assume a forma da Equação (40): 


$$
\delta=\frac{8 \sigma_{y s} a}{\pi E}\left[\frac{1}{2}\left(\frac{\pi \sigma}{2 \sigma_{y s}}\right)^{2}+\frac{1}{12}\left(\frac{\pi \sigma}{2 \sigma_{y s}}\right)^{4}+\frac{1}{45}\left(\frac{\pi \sigma}{2 \sigma_{y s}}\right)^{6}+\ldots\right]
$$

Considerando que o carregamento externo submete a trinca a um campo elástico de tensões $\left(\sigma / \sigma_{\mathrm{ys}}<1\right)$, pode-se desprezar do segundo termo em diante do da parcela entre colchetes (Zhu e Joyce, 2012), resultando na Equação (41):

$$
\delta=\frac{\sigma^{2} \pi a}{E \sigma_{y s}}
$$

Substituindo a definição de $K_{I}$ na Equação (41), tem-se a Equação (42):

$$
\delta=\frac{K_{I}^{2}}{E \sigma_{y s}}
$$

\subsubsection{Contribuição de Dawes a Determinação do CTOD (ס)}

Dawes (1979), a partir do modelo de Burdekin e Stone e de uma série de experimentos estabeleceu uma maneira de se determinar o valor do deslocamento de abertura da ponta da trinca por procedimento experimental. Dawes verificou que o deslocamento da abertura da boca do entalhe em conexão com o monitoramento da carga aplicada era capaz de fornecer o valor do CTOD $(\delta)$ na posição original da ponta da trinca. A partir de um corpo de prova instrumentado por um extensômetro de fratura, denominado "clip gage", posicionado na abertura do entalhe é possível estabelecer uma relação com a ponta da trinca original pela medida do deslocamento da boca do entalhe (CMOD). A Figura 21 ilustra uma típica curva obtida de um ensaio de CTOD. 


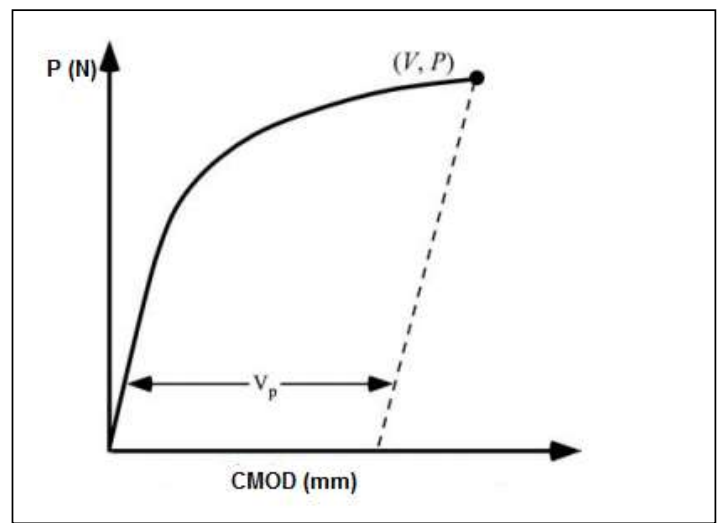

Figura 21 - Curva carga (P) vs deslocamento de abertura da boca da trinca (CMOD) (Anderson, 2005).

A conversão da medida $\mathrm{V}_{\mathrm{p}}$ para deslocamento da abertura da ponta da trinca

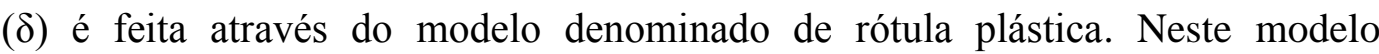
considera-se que as metades do corpo de prova rotacionam ao redor de um centro fixo, denominado centro de rotação aparente, localizado abaixo da ponta da trinca. O centro de rotação aparente marca o ponto ao redor do qual ocorre a deformação plástica devido ao carregamento aplicado. A Figura 22 ilustra o mencionado acima. O modelo da rótula plástica atualmente ainda é utilizado nos ensaios de tenacidade à fratura elaborados pelas normas disponíveis.

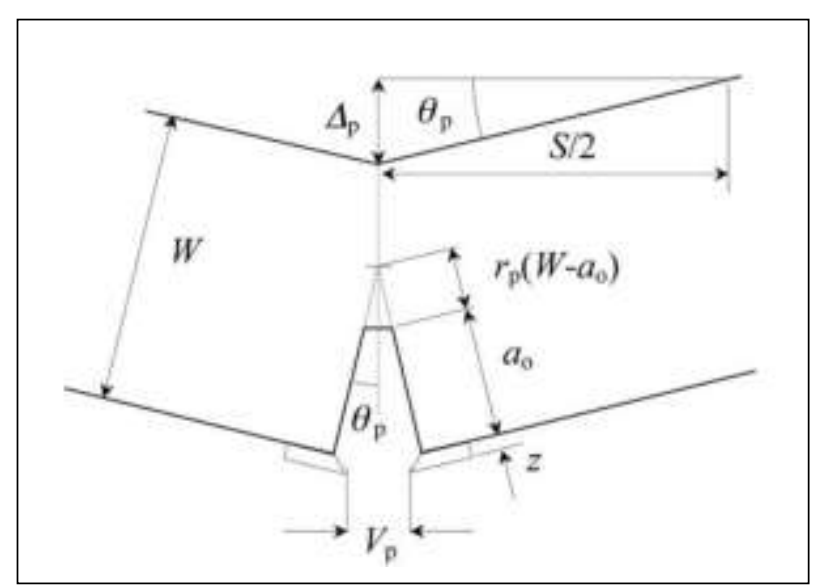

Figura 22 - Conversão do deslocamento obtido da boca do entalhe para deslocamento na ponta da trinca (Tagawa et al., 2010).

Através de uma relação geométrica com a abertura da boca da trinca $\left(\mathrm{V}_{\mathrm{p}}\right)$ tem-se o valor do CTOD $(\delta)$ a partir de uma semelhança entre triângulos, demonstrada pela Equação (43): 


$$
\frac{\delta}{r_{p}\left(W-a_{0}\right)}=\frac{V_{p}}{r_{p}\left(W-a_{0}\right)+a_{0}}
$$

Segundo Anderson (2005), este modelo foi submetido a alguns ajustes, e atualmente, o valor de CTOD é fornecido de forma experimental através de uma Equaçãocomposta por duas parcelas que representam a parcela elástica e plástica do CTOD. A parcela elástica do CTOD $\left(\delta_{\mathrm{el}}\right)$ representa a força motriz necessária para propagação da trinca e a intensificação de tensões causada por tal propagação. $\mathrm{O} \delta_{\mathrm{el}}$ é obtido a partir da Equação (44):

$$
\delta_{e l}=\frac{K^{2}\left(1-v^{2}\right)}{2 \sigma_{y s} E}
$$

Já para a parcela plástica do CTOD $\left(\delta_{\mathrm{pl}}\right)$ considera-se que as metades do corpo de prova se assemelham a braços rígidos que rotacionam ao redor de uma rótula plástica localizada na parte íntegra (ligamento) do corpo de prova. Desta forma segundo o exposto na Equação (42), o $\delta_{\mathrm{pl}}$ é representado pela Equação (45):

$$
\delta_{p l}=\frac{r_{p}\left(W-a_{0}\right) V_{p}}{r_{p}\left(W-a_{0}\right)+a_{0}}
$$

Assim o CTOD total ( $\delta$ ) é fornecido pela Equação (46):

$$
\delta=\frac{K^{2}\left(1-v^{2}\right)}{2 E \sigma_{y s}}+\frac{r_{p}\left(W-a_{0}\right) V_{p}}{r_{p}\left(W-a_{0}\right)+a_{0}}
$$

na qual,

$\mathrm{K}=$ fator intensificador de tensões para carga em questão $\left[\mathrm{MPa}(\mathrm{mm})^{1 / 2}\right]$;

$\mathrm{E}=$ Módulo de Elasticidade [MPa];

$v=$ coeficiente de Poisson [adimensional];

$\sigma_{\mathrm{ys}}=$ limite de escoamento [MPa]; 
$\mathrm{z}=$ altura do apoio para extensômetro de medição de abertura da boca da trinca $[\mathrm{mm}]$

$\mathrm{W}=$ largura do corpo de prova $[\mathrm{mm}]$;

$\mathrm{a}_{0}=$ comprimento da pré-trinca $[\mathrm{mm}]$;

$\mathrm{V}_{\mathrm{p}}=$ componente plástica da abertura da boca da trinca do corpo de prova [mm];

$\mathrm{r}_{\mathrm{p}}=$ distância do centro de rotação aparente à extremidade da trinca [mm].

Vale ressaltar que o parâmetro CTOD tem como objetivo caracterizar a capacidade do material de ser deformar antes do processo de fratura através da medição da abertura da boca da trinca em corpo de prova usinado. Este valor indica o máximo que as faces da trinca se afastam antes de sua propagação, ou seja, o valor de iniciação. E este pode ser tratado como uma propriedade do material de tenacidade à fratura.

\subsection{Determinação Experimental do CTOD ( $\delta)$}

O parâmetro CTOD é obtido após a realização de um experimento regido por normas específicas desenvolvidas por institutos especializados em pesquisa. Como exemplo de institutos se pode citar o Instituto Inglês de Normas - Bristish Standards Institution (BSI), a Sociedade Japonesa de Engenheiros Mecânicos Japan Society of Mechanical Engineers (JSME) e a Sociedade Americana de Testes e Materiais - American Society for Testing and Materials (ASTM).

Atualmente entre as normas disponíveis para avaliação de tenacidade à fratura, recomendadas por códigos de integridade estrutural que avaliam a criticidade de defeitos, as mais usadas para determinação do CTOD são as normas BS 7448:1 (1991) e a ASTM 1820-11 (2011). Ambas as normas definem o procedimento experimental porém, estas possuem diferenças em relação à forma de cálculo do parâmetro CTOD. 


\subsubsection{CTOD ( $\delta)$ pela BS $7448: 1$}

A norma inglesa BS 7448:1 (1991) utiliza o mesmo método de cálculo estabelecido originalmente pela BS 5762 publicada em 1979. O modelo atual é denominado modelo da rótula plástica, onde se considera que a deformação na ponta da trinca é consequência da rotação dos flancos da trinca ao redor de um ponto fixo a frente da ponta da trinca denominado centro de rotação aparente $\left(r_{p}\right)$. $\mathrm{O}$ valor do centro de rotação $r_{p}$ tem valor igual a 0,4 para corpos de prova de flexão em 3 apoios (SENB) ou 0,46 para corpos de prova do tipo compacto em tração (CT). Sendo assim, o cálculo do CTOD para corpos de prova do tipo flexão por 3 apoios e compacto são dados pelas Equações (47) e (48), respectivamente:

$$
\begin{gathered}
\delta=\frac{K^{2}\left(1-v^{2}\right)}{2 E \sigma_{y s}}+\frac{0,4\left(W-a_{0}\right) V_{p}}{0,4\left(W-a_{0}\right)+0,6 a_{0}+z} \\
\delta=\frac{K^{2}\left(1-v^{2}\right)}{2 E \sigma_{y s}}+\frac{0,46\left(W-a_{0}\right) V_{p}}{0,46 W+0,54 a_{0}+(C-W)+z}
\end{gathered}
$$

na qual C é a largura total e W é a largura a partir do centro dos furos do corpo de prova do tipo compacto.

\subsubsection{CTOD ( $\delta)$ pela ASTM 1820-11}

A forma de cálculo do CTOD pela norma americana não é baseado em um ensaio de CTOD propriamente dito e sim no ensaio para determinação do parâmetro Integral J.

O conceito da Integral J foi desenvolvido inicialmente por Rice em 1968. Baseado em uma abordagem energética, este parâmetro é válido para materiais com comportamento elástico não linear e elasto-plásticos e tem o objetivo de medir a taxa de liberação de energia devido a propagação da trinca, ou seja, pela variação (aumento) da área de fratura. A Integral J é uma Integral de linha que pode ser vista como uma medida da intensidade do campo de tensões e 
deformações na ponta da trinca, conforme indicado na Figura 23 (Anderson, 2005).

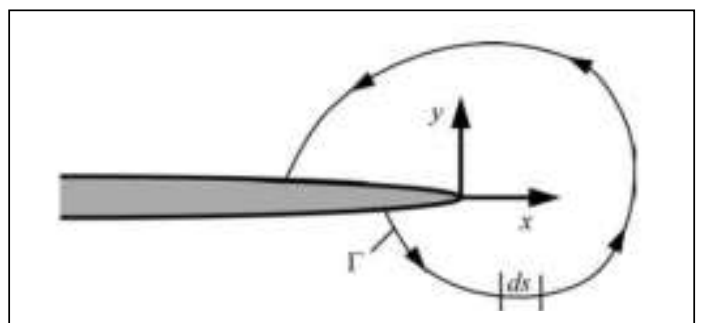

Figura 23 - Contorno arbitrário de Integral ao redor da ponta de trinca para cálculo de Integral J (Anderson, 2005).

A Integral J é representada pela Equação (49):

$$
J=\int_{\Gamma}\left(w d y-\vec{T}_{i} \frac{\partial \vec{u}_{i}}{\partial x} d s\right)
$$

na qual,

$\mathrm{w}=$ densidade de energia de deformação

$\Gamma=$ contorno arbitrário, no sentido anti-horário em torno da ponta da trinca, o qual se inicia na face inferior da trinca e termina na face superior;

$\mathrm{T}_{\mathrm{i}}=$ componentes do vetor tração;

$\mathrm{u}_{\mathrm{i}}=$ componentes do vetor deslocamento;

ds $=$ incremento de comprimento ao longo do contorno

A Integral J pode ser usada como um parâmetro de critério de fratura a partir de um modelo de processo de fratura que se inicia quando uma trinca aguda existente no componente é submetida a carregamento. À medida que a trinca é submetida a carregamento sua ponta é deformada (embotada). O grau de embotamento aumenta com o carregamento até que o material ao redor não tenha mais capacidade de se deformar e a trinca se propague para posição a frente da trinca originalmente embotada, formando assim uma nova trinca (Landes e Begley, 1977). A medição da Integral J, como parâmetro de tenacidade à fratura é realizada no ponto onde ocorre a primeira propagação e o mesmo é definido como J crítico. A Figura 24 ilustra o processo de fratura comentado acima. 


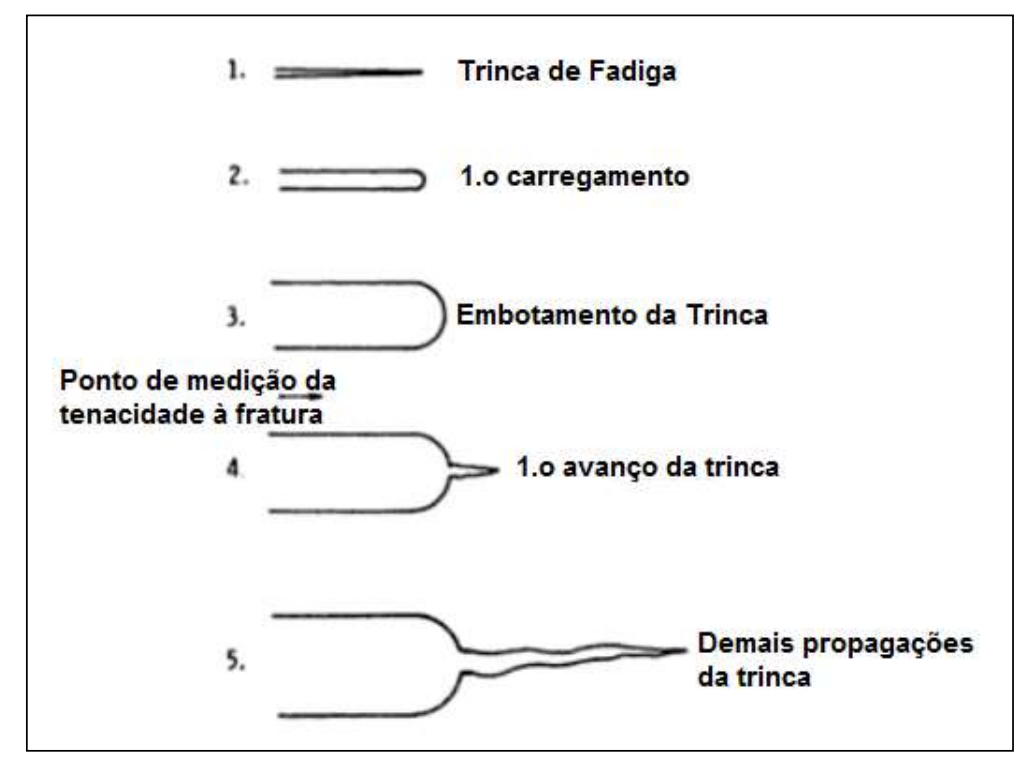

Figura 24 - Sequência de propagação de trinca com aplicação de carregamento (Landes e Begley,1977).

A Integral $\mathbf{J}$ é determinada experimentalmente a partir da monitoração da carga e do deslocamento de aplicação da linha da carga (LLD) ou do deslocamento de abertura da boca da trinca (CMOD). Desta forma a ASTM 182011 (2011) estabelece todas as etapas para obtenção da Integral J que é composta por duas parcelas, a elástica e a plástica. A Equação (50) fornece o valor da Integral J para corpo de prova do tipo flexão por três apoios:

$$
J=\frac{K^{2}\left(1-v^{2}\right)}{E}+\frac{\eta A_{p l}}{B\left(W-a_{0}\right)}
$$

$$
\text { I II }
$$

na qual,

$\mathrm{I}$ = componente elástica de $\mathrm{J}$;

II = componente plástica de J;

$\mathrm{A}_{\mathrm{pl}}=$ área plástica sob a curva carga $\mathrm{x}$ deslocamento (LLD ou CMOD);

$\eta=1,9 ;{ }^{(1)}$

$$
3,667-2,199(\mathrm{a} / \mathrm{W})+0,437(\mathrm{a} / \mathrm{W})^{2}{ }^{(2)}
$$


Sendo a Integral J e CTOD, parâmetros de tenacidade à fratura da mecânica da fratura elasto-plástica, ao longo dos anos estudos vem sendo realizados com o intuito de desenvolver equações que relacionem os dois parâmetros (Pereira, Darwish e Campelo, 2013). Desta forma, obteve-se uma relação entre a Integral J e o CTOD $(\delta)$ representado pela Equação (51).

$$
J=m \sigma_{y} \delta
$$

na qual,

$\mathrm{J}=$ Integral $\mathrm{J}$;

$\mathrm{m}=$ fator de restrição;

$$
\begin{aligned}
& m=3,018-0,22(a / W)-\left[4,32-2,23(a / W)\left(\sigma_{y s} / \sigma_{T S}\right)\right]+\left[4,44-2,29(a / W)\left(\sigma_{y s} / \sigma_{T S}\right)^{2}\right]- \\
& \left.-[2,05-1,06)(a / W)\left(\sigma_{y s} / \sigma_{T S}\right)^{3}\right]-A S T M 1820-11(2011)
\end{aligned}
$$

$\sigma_{\mathrm{f}}=$ tensão de escoamento do material;

$\delta=\mathrm{CTOD}$

Notas: (1) Se área plástica é calculada usando deslocamento da linha de aplicação de carga (LLD);

(2) Se a área plástica é calculada pelo deslocamento de abertura da boca da trinca (CMOD);

A restrição plástica, representada pelo fator m, pode ser definida como um obstáculo estrutural a ser vencido para início da deformação plástica no material. Tal obstáculo é imposto principalmente pelas condições de geometria e condiçoes físicas, mas também pode ser causado devido a incompatibilidade existente nas propriedades de materiais, como por exemplo, as heterogeneidades existentes em juntas soldadas (Kozak e Ivandic, 2002).

A triaxilidade de tensões indica a facilidade com que a deformação plástica vai ocorrer no material, ou seja, quanto maior a triaxialidade de tensões, maior a condição de restrição plástica e mais próximo o estado de tensões está da condição de deformação plana (Shan e Kolednick, 1994).

Segundo Pereira, Darwish e Campelo (2013), o fator de restrição plástica (m) é uma constante de material assume valores dependentes do estado de tensão na ponta da trinca. De uma forma geral para a condição de tensão plana, assume 
valor igual a 1, enquanto que para condição de deformação plana, o valor é igual a m é igual a 2 (Gordon, Neale e Wang, 1995).

Porém, estudos realizados por Pereira, Darwish e Campelo (2013) provam que o fator de restrição plástica, além de depender do estado de tensão na ponta da trinca, também depende de propriedades do material tal como o limite de escoamento e coeficiente de encruamento. Tal conclusão foi obtida após comparação entre os fatores de restrição plástica obtidos experimentalmente, a partir dos valores de CTOD e Integral $\mathbf{J}$, e analiticamente pela norma ASTM 1820-11 (2011) e dos modelos de por Shih, Tracey, McMeeking e Schwalbe em função do coeficiente de encruamento dos aços de alta e média resistência testados.

As comparações mostraram que os fatores de restrição plástica experimentais e os previstos pelos modelos de Shih, Tracey, McMeeking e Schwalbe tendem a aumentar com o aumento do coeficiente de encruamento dos aços ensaiados (Shih, 1981; McMeeking, 1977; Tracey, 1973 e Schwalbe et al., 1986). Também foi verificado que em função do método de cálculo do fator de restrição plástica $(\mathrm{m})$, pode-se ter valores mais conservadores de tenacidade à fratura (modelo de McMeeking, Tracey). Em se tratando dos aços de média resistência, o modelo de Schwalbe e Shih são conservadores, o que proporciona menores valores de CTOD. Já os fatores de restrição plástica obtidos com estes modelos são maiores em relação aos valores experimentais ou aos calculados segundo a norma ASTM 1820-11 (2011).

\subsection{Ensaios de Tenacidade à Fratura}

Com o objetivo de quantificar a tenacidade à fratura e fornecer melhor interação entre a mecânica da fratura e as avaliações de integridade estrutural de componentes, os ensaios de tenacidade à fratura fornecem valores críticos dos parâmetros de tenacidade à fratura nos quais ocorre a falha do corpo de prova por propagação instável da trinca (Anderson, 2005). A tenacidade a fratura pode ser avaliada através da determinação dos seguintes parâmetros: 
- Fator intensificador de tensões crítico $\left(\mathrm{K}_{\mathrm{Ic}}\right)$ em condições de deformação plana para materiais de comportamento linear elástico;

- Deslocamento crítico da abertura da ponta da trinca $\left(\delta_{c}\right)$ e valor crítico da Integral $\mathbf{J}\left(\mathbf{J}_{\mathrm{c}}\right)$ para materiais elasto-plásticos;

Conforme mencionado, os ensaios para avaliação da tenacidade à fratura de um material são estabelecidos por normas que explicitam todas as etapas envolvidas para a sua realização. Algumas destas normas, mencionadas na seção anterior, apesar de elaboradas por instituições diferentes, compartilham as mesmas etapas envolvidas na realização do ensaio. Vale ressaltar que as etapas descritas a seguir são relativas as normas americana (ASTM) e inglesa (BSI), que são as mais utilizadas para caracterização da tenacidade a fratura.

\subsubsection{Etapas de Ensaio de Tenacidade à Fratura}

\subsubsection{Seleção de Corpos de Prova}

Segundo Roesler, Harders e Baeker (2007), Anderson (2005) os corpos de prova mais utilizados para avaliação de tenacidade à fratura são os do tipo flexão por três apoios - (SENB) e o compacto por tração - (CT). Porém a norma ASTM 1820-11 (2011) possibilita a utilização com geometrias menos usuais tais como o tipo arco, disco e trinca central por tração.

Ainda é possível, em função do comportamento mecânico do material, a utilização de corpos de prova com side grooves (entalhes laterais), com a finalidade de manter uma propagação de trinca reta durante o ensaio (Anderson, 2005). Estes restringem ou eliminam o estado de tensão plana através da remoção das superfícies livres de baixa triaxilidade de tensões e com isso se obtém frentes de trinca relativamente mais retas (Imai e Matake, 1982; Anderson, 2005).

A Figura 25 e 26 respectivamente ilustra as possíveis geometrias para corpos de prova e a geometria do entalhe lateral. 


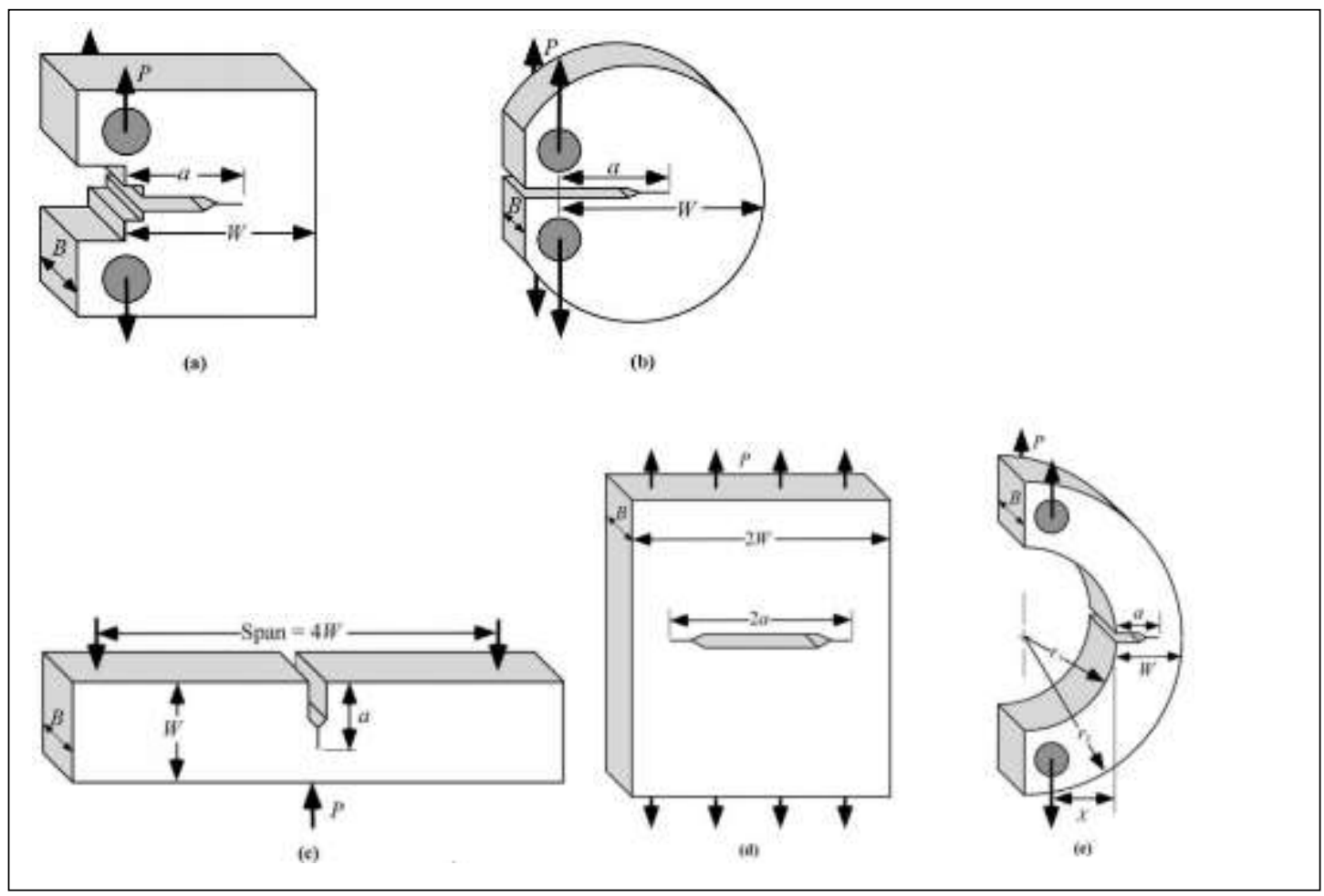

Figura 25 - Tipos de corpos de prova: (a) Compacto a tração. (b) Disco compacto a tração. (c) Flexão por três apoios. (d) Trinca central por tração. (e) Arco ( Anderson, 2005).

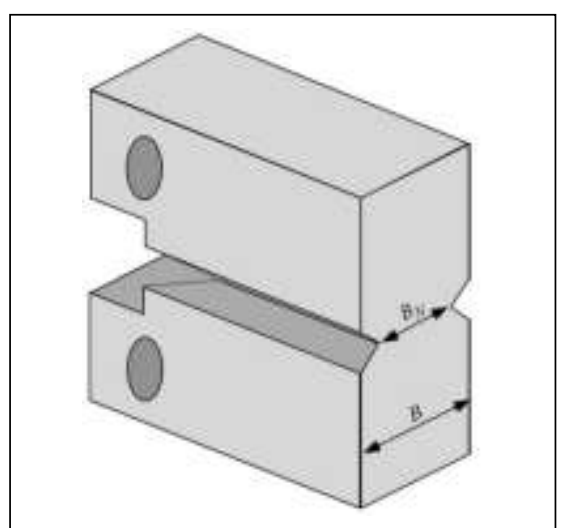

Figura 26 - Entalhe lateral em corpo de prova, onde B: espessura nominal e $\mathrm{B}_{\mathrm{N}}$ : espessura remanescente ( Anderson, 2005).

Um corpo de prova sem entalhe lateral exibe uma grande deformação em suas superfícies laterais (livres) devido ao baixo estado triaxial de tensão, o que provoca um tunelamento (tunneling) da trinca na porção central do corpo de prova fazendo com que a mesma se propague mais rápido nesta região. Imai e Matake (1982), relatam que corpos de prova sem side groove ou com side groove na forma de U tiveram maior propagação de trinca na porção central da espessura 
enquanto que os corpos de prova com side groove tipo $\mathrm{V}$ e tipo fenda obtiveram propagação de trinca mais uniforme ao longo de toda a espessura. A Figura 27 ilustra algumas geometrias de side-grooves utilizadas no estudo citado.

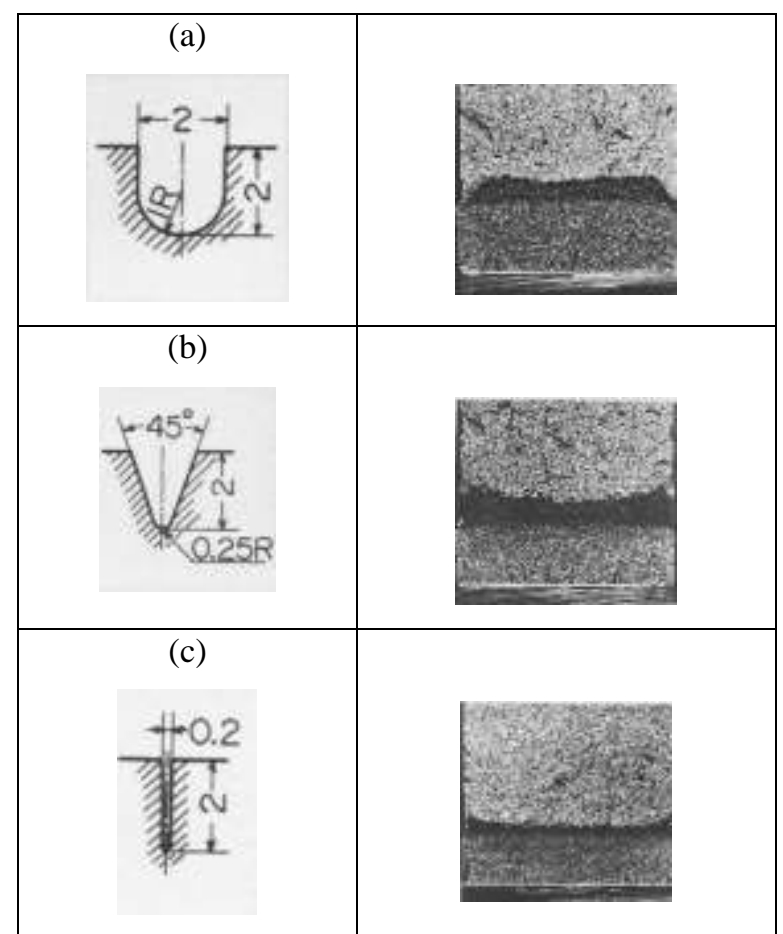

Figura 27 - Geometrias de entalhes laterai. (a) Tipo U, (b) Tipo V e (c) Tipo fenda ( Imai e Matake, 1982).

A norma BS 7448-1 (1991) não estabelece diretrizes quanto às dimensões do entalhe lateral, porém não proíbe sua utilização desde que relatada na documentação do ensaio. Já a norma ASTM 1820-11 (2011) determina que o entalhe lateral deve causar uma redução máxima de $25 \%$ da espessura original, ter ângulo entre as superfícies do entalhe menor que $90^{\circ}$, raio da raiz do entalhe de $0,5 \pm 0,2 \mathrm{~mm}$ e deve ser feito após o pré-trincamento do corpo de prova.

Sabe-se que o side groove modifica a forma como a trinca se propaga, influenciando o comportamento à fratura do material. Zhang e Shi(1992) estudou a influência da profundidade do entalhe lateral sobre o valor de iniciação da Integral $\mathbf{J}\left(\mathrm{J}_{\mathrm{i}}\right)$ e da energia absorvida durante o ensaio de impacto charpy. Também foi verificado que a profundidade de tais entalhes influencia diretamente o valor de Integral J de carga máxima $\left(\mathrm{J}_{\mathrm{m}}\right)$, quanto maior a profundidade, menor a Integral $\mathrm{J}$ de carga máxima $\left(\mathrm{J}_{\mathrm{m}}\right)$, até um limite onde se verifica que o $\mathrm{J}_{\mathrm{m}}$ permanece constante. Neste momento é observado que o valor da Integral de carga máxima $\left(\mathrm{J}_{\mathrm{m}}\right)$ se iguala ao valor de iniciação da Integral $\mathbf{J}\left(\mathrm{J}_{\mathrm{i}}\right)$ do material. 


\subsubsection{Orientação do corpo de prova}

Materiais de engenharia raramente são homogêneos e isotrópicos, pois sua microestrutura e consequentemente suas propriedades mecânicas podem variar de acordo com a orientação em que as medições são efetuadas (Anderson, 2005). Este fenômeno é conhecido como anisotropia.

No que concerne o comportamento associado à fratura, a anisotropia tem interferência significativa nas avaliações de tenacidade à fratura. Desta forma, a orientação do corpo de prova é uma variável importante às medições de tenacidade.

Com o objetivo de padronizar a orientação de corpos de prova, extraídos de matéria prima, foi elaborada uma notação válida para chapas e discos, ilustrada na Figura 28 e 29, de modo a facilitar o relato de tal informação no relatório de ensaio.

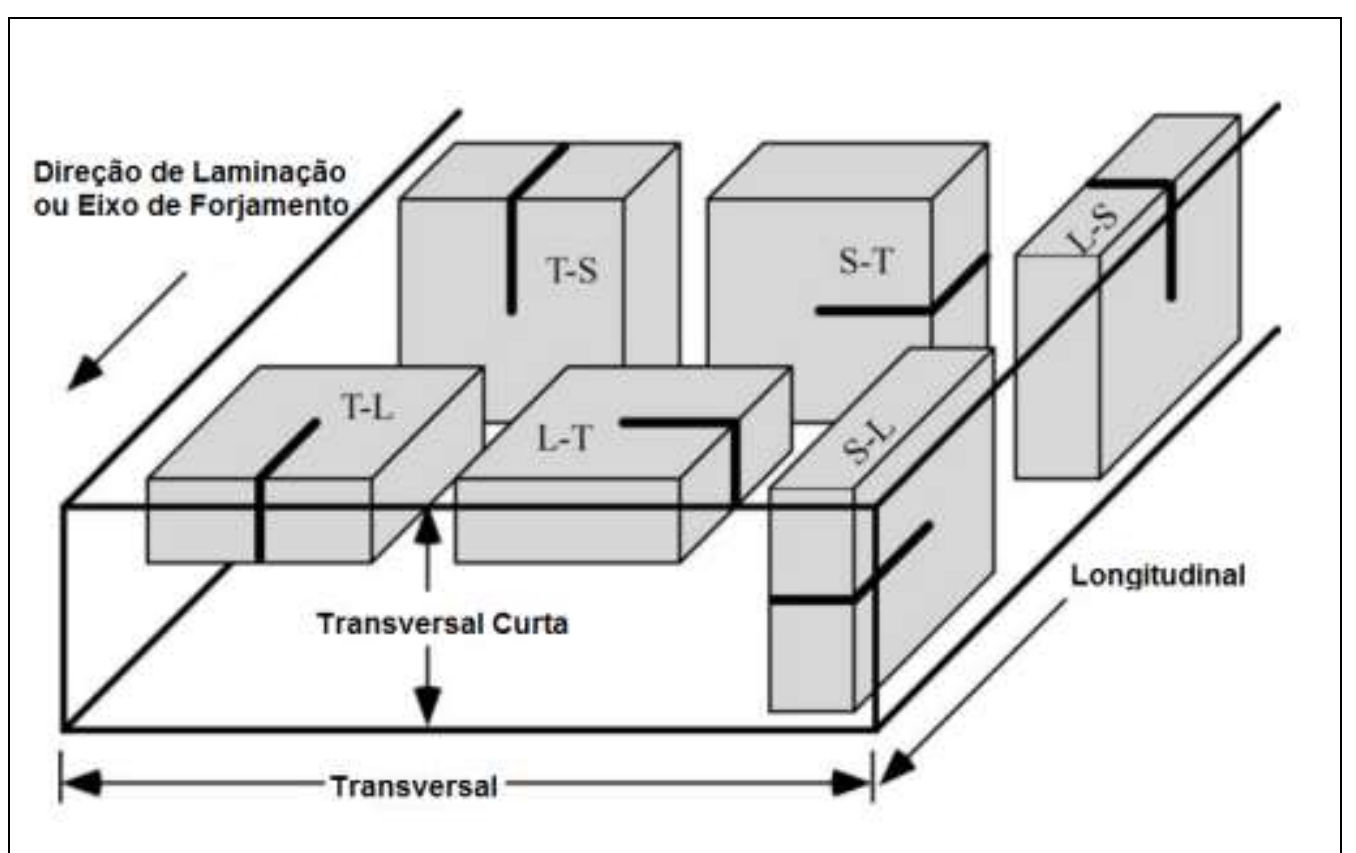

Figura 28 - Notação ASTM para orientação de corpos de prova extraídos de materiais planos (Anderson, 2005). 


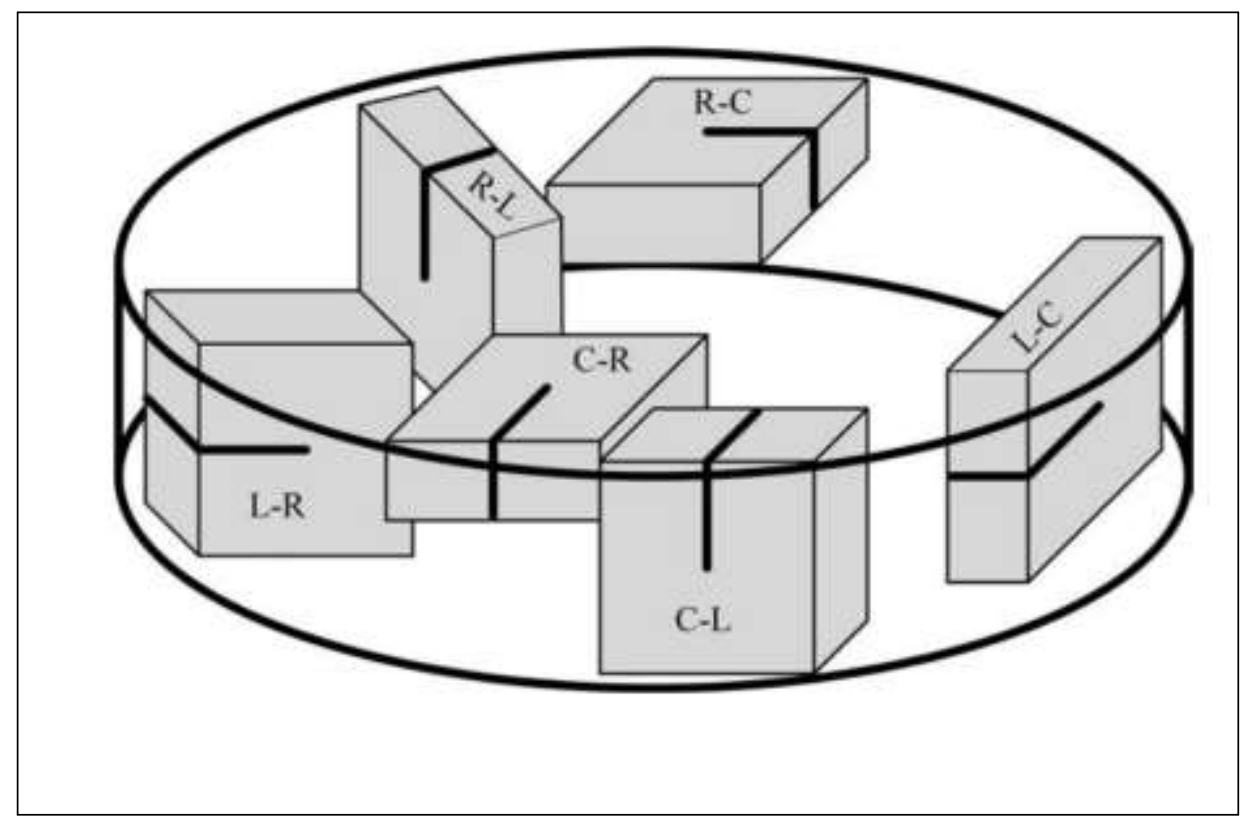

Figura 29 - Notação ASTM para orientação de corpos de prova extraídos de materiais cilíndricos (Anderson, 2005).

Segundo a ASTM, existem seis possíveis orientações para extração dos corpos de prova. As letras $\mathrm{L}, \mathrm{T}$ e $\mathrm{S}$ significam longitudinal, transversal e transversal curta, respectivamente. A notação consiste em uma combinação de duas letras, onde a primeira representa a direção do carregamento aplicado e a segunda indica a direção de propagação da trinca.

\subsubsection{Pré-Trincamento}

A introdução de um defeito com a severidade da trinca nos corpos de provas através de processos convencionais de usinagem é inviável, devido as pequenas dimensões do defeito e principalmente a necessidade de se garantir uma ponta aguda. Sendo assim, a operação de pré-trincamento do corpo de prova é indispensável ao ensaio de tenacidade à fratura.

Com o material na microestrutura desejada, a norma BS 7448-1 (1991) estabelece que o pré-trincamento deve ser realizado a temperatura ambiente, a partir de um entalhe usinado por fresamento ou eletro-erosão. Sendo assim, a finalidade do entalhe é atingir um nível de concentração de tensões em sua ponta para que seja possível iniciar a pré-trinca através de rigoroso controle do 
carregamento cíclico (fadiga). A Figura 30 ilustra a trinca de fadiga iniciada a partir a ponta do entalhe mecânico.

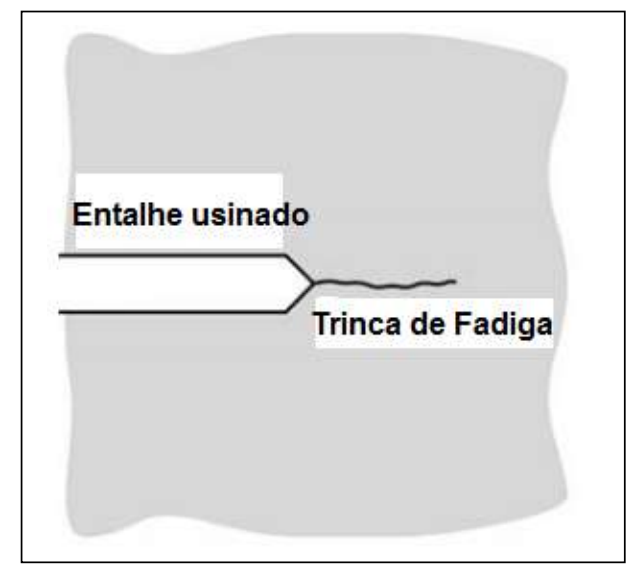

Figura 30 - Pré-trinca de fadiga na ponta do entalhe usinado (Anderson, 2005).

O comprimento total da trinca de fadiga (comprimento do entalhe mais o comprimento da trinca de fadiga), introduzida no corpo de prova, deve estar na faixa de valores que compreende a relação 0,45 a $0,55 \mathrm{~W}$, tanto para corpos de prova tipo compacto como para os de flexão por três apoios (BS 7448-1 (1991)). Por uma questão de facilitar o processo de pre-trincamento, a relação de $0,5 \mathrm{~W}$ é preferida em relação às demais.

Para garantir a ausência de embotamento na ponta da trinca de fadiga (embotamento) e consequentemente uma ponta aguda, deve-se controlar a carga necessária a fadiga. Desta forma, para corpos de prova do tipo flexao por três apoios, a carga máxima de fadiga $\left(\mathrm{F}_{\mathrm{f}}\right)$ deve ser o menor valor entre as três opções Equações (52), (53) e (54):

$$
F_{f}=\frac{B\left(W-a_{0}\right)^{2}\left(\sigma_{y s}+\sigma_{u s}\right)}{4 S}
$$

na qual,

$\mathrm{B}=$ espessura do corpo de prova $[\mathrm{mm}]$;

$\mathrm{W}-\mathrm{a}_{0}=$ ligamento (parte não trincada) do corpo de prova $[\mathrm{mm}]$;

$\mathrm{S}=$ distância entre apoios do dispositivo de fixação do corpo de prova [mm];

$\sigma_{\mathrm{ys}}=$ limite de escoamento do material $[\mathrm{MPa}]$;

$\sigma_{\mathrm{us}}=$ limite de resistência mecânica do material [MPa]. 
Força correspondente a

$$
\frac{\Delta K}{E}=3,2 \times 10^{-4} \mathrm{~m}^{0,5}
$$

na qual,

$\Delta \mathrm{K}=$ variação do fator intensificador de tensões $\left[\mathrm{MPa} \cdot \mathrm{m}^{1 / 2}\right]$;

$\mathrm{E}=$ módulo de elasticidade do material $[\mathrm{MPa}] ;$

ou

$$
F_{f}=\frac{K_{f} \times B W^{1,5}}{S \times f(a / W)}
$$

na qual,

$\mathrm{K}_{\mathrm{f}}=$ máximo fator intensificador de tensões de fadiga aplicado durante os estágios finais do processo.

$$
K_{f}=0,6\left(\frac{\sigma_{y s}}{\sigma_{y s}}\right) K_{Q}
$$

na qual,

$\sigma_{\mathrm{ysTP}}=$ limite de escoamento do material na temperatura do pré trincamento (temperatura ambiente)

$\sigma_{\mathrm{ys}}=$ limite de escoamento do material na temperatura de ensaio de tenacidade à fratura.

$\mathrm{f}(\mathrm{a} / \mathrm{W})=$ função que relaciona comprimento da trinca e largura do corpo de prova.

$$
K_{Q}=\frac{F_{Q} \times S}{B W^{1,5}} \times f(a / W)
$$

na qual $\mathrm{K}_{\mathrm{Q}}$ na Equação (56) é o valor provisório de $\mathrm{K}_{\mathrm{Ic}}$

A partir da determinação da carga máxima de fadiga para início da prétrinca, se estabelece a carga mínima a partir da razão (R), entre a carga mínima máxima $\left(\mathrm{F}_{\text {fmín }}\right)$ e máxima $\left(\mathrm{F}_{\mathrm{f}}\right)$ que é igual a 0,1 . 
Além da determinação da carga de fadiga para a pré trinca, deve-se atentar ao comprimento mínimo da trinca de fadiga que deve ser maior que 1,3 $\mathrm{mm}$ ou $2,5 \% \mathrm{~W}$ e ao plano de propagação da pré-trinca de fadiga que deve estar dentro de $10^{\circ}$ do seu plano de propagação.

\subsubsection{Instrumentação do Corpo de Prova}

$\mathrm{O}$ resultado dos ensaios de tenacidade à fratura dependem do registro da carga aplicada e do deslocamento de abertura da boca da trinca.

A monitoração da carga é feita diretamente pela máquina de ensaio através de uma célula de carga. $\mathrm{O}$ deslocamento de abertura da boca da trinca é realizada por um transdutor, denominado extensômetro de fratura, mais usualmente conhecido por clip gage (Anderson, 2005). A Figura 31 ilustra o extensômetro de fratura posicionado no corpo de prova.

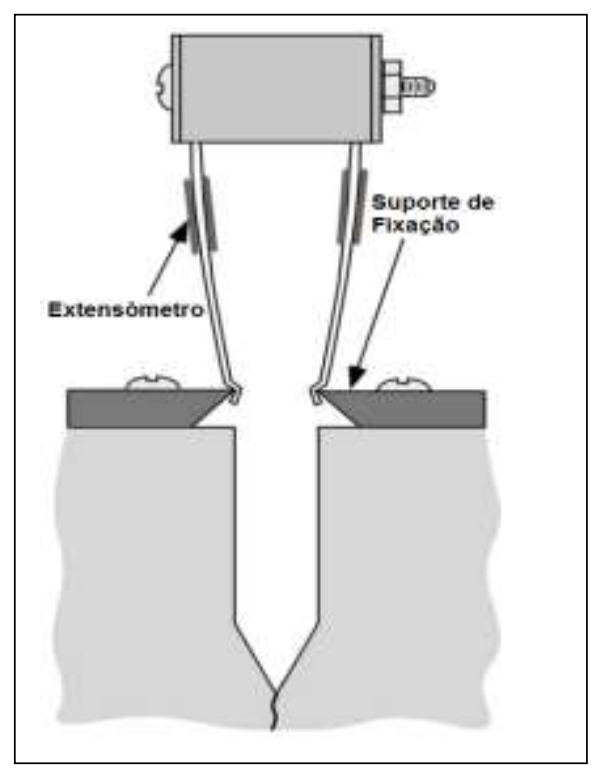

Figura 31 - Extensômetro de fratura no entalhe do corpo de prova (Anderson, 2005).

\subsubsection{Descrição do Ensaio}

Segundo a norma BS 7448-1 (1991), a taxa de carregamento imposta ao corpo de prova no ensaio de CTOD deve permitir aumento no fator intensificador de tensão $\left(\mathrm{K}_{\mathrm{I}}\right)$ entre 0,5 e 3,0 $\mathrm{MPa}(\mathrm{m})^{1 / 2}$. 
Em relação a temperatura do ensaio, a mesma deve ser controlada com uma exatidão de $\pm 2{ }^{\circ} \mathrm{C}$. Antes do início do ensaio a temperatura do corpo de prova deve estar estabilizada e tal fato depende do tempo de permanência na atmosfera do ensaio após a superfície do corpo de prova alcançar a temperatura de teste. Para ensaios em meio líquido deve-se manter o corpo de prova por pelo menos 30 s para cada $1 \mathrm{~mm}$ de espessura, enquanto que para ensaios em atmosferas gasosas a BS 7448-1 (1991) estabelece a permanência de pelo menos 1 minuto para cada 1 mm de espessura.

Vale ressaltar que durante o ensaio a variação de temperatura não deve ultrapassar a $2{ }^{\circ} \mathrm{C}$.

\subsubsection{Análise do registro carga-deslocamento para determinação do CTOD ( $\delta)$}

A Figura 32 ilustra as possíveis curvas características obtidas durante um ensaio para determinação do CTOD.

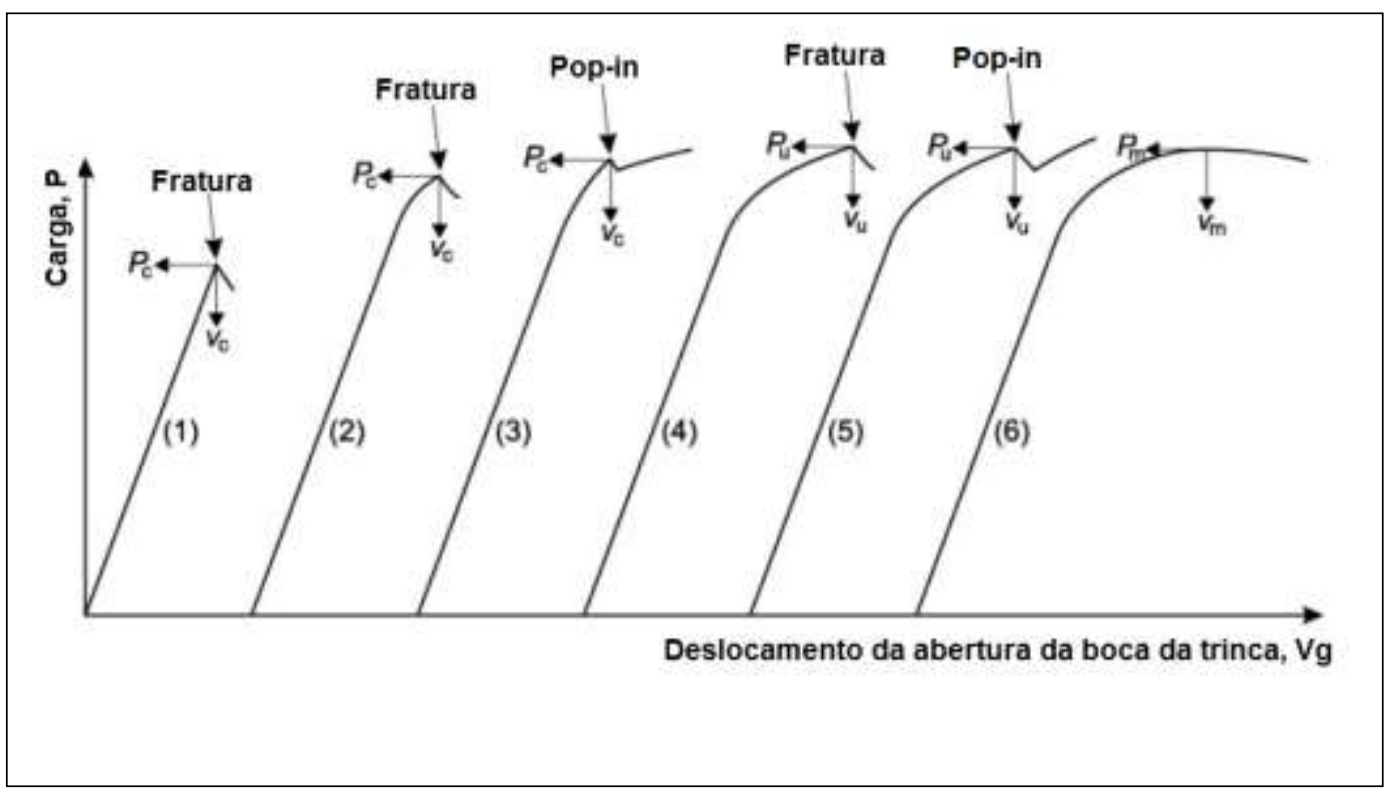

Figura 32 - Tipos de curvas carga vs deslocamento da boca da trinca (Janssen, Zuidema e Wanhill, 2006). 
A curva 1 corresponde a um ensaio onde não houve propagação estável da trinca e a propagação instável da trinca ocorreu com pouco ou nenhum escoamento plástico a frente da ponta da trinca. Desta forma, não há componente plástica do deslocamento da abertura da ponta da trinca $\left(\mathrm{V}_{\mathrm{p}}\right)$ e sendo assim o CTOD é composto apenas da parcela elástica.

As curva 2 e 3 possuem desvio da linearidade o que indica a presença de plastificação a frente da ponta da trinca de tamanho significativo em relação ao ligamento do corpo de prova. Em muitos casos, há uma rápida propagação instável da trinca denominado "pop-in". "Pop-ins" aparecem como descontinuidades na curva obtida durante o ensaio (curva 3), associadas ao rápido aumento do deslocamento e geralmente a uma queda no valor da carga (Janssen, Zuidema e Wanhill, 2006). De acordo com Berejnoi, Ipiña e Llorente (2000) o pop-in é bem comum, principalmente em ensaios de tenacidade à fratura de juntas soldadas e é resultante da rápida propagação da trinca por encontrar uma microregião de maior fragilidade em relação ao restante do material, conhecida como "local brittle zone" (LBZ), seguida de aprisionamento da trinca, ou seja, uma interrupção na propagação estável devido a existência de maior ductilidade ao redor da LBZ. A Figura 33 correlaciona o pop-in causado por uma LBZ com a curva carga $v s$ deslocamento de abertura da boca da trinca.

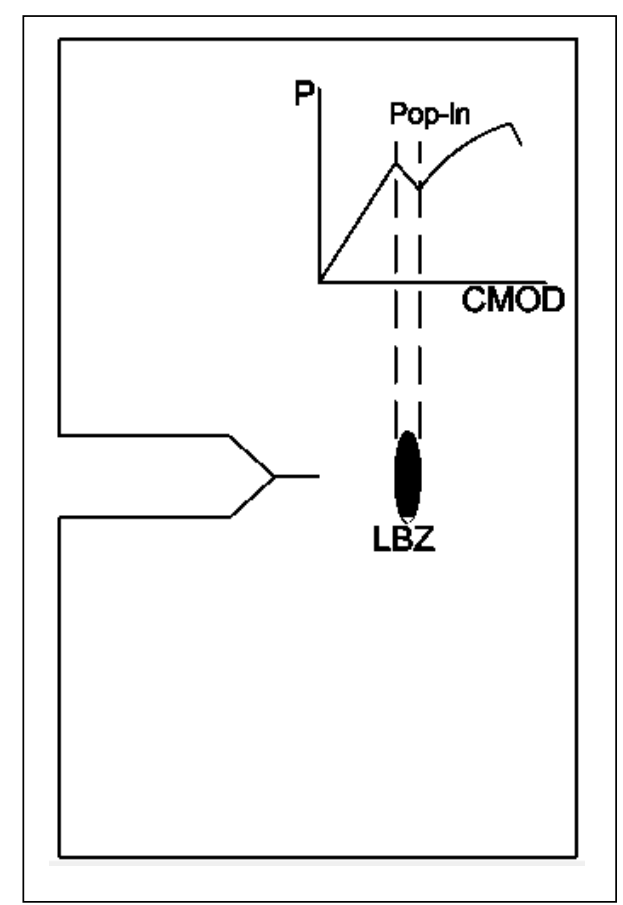

Figura 33 - Demonstração de pop-in em curva de ensaio de CTOD em decorrência da existência de uma LBZ. 
Em ambas as curvas, o CTOD calculado é denominado CTOD crítico $\left(\delta_{\mathrm{c}}\right)$. O valor de $\delta_{\mathrm{c}}$ é o valor do CTOD no início da propagação instável, ou seja, quando se tem propagação estável de trinca $\Delta \mathrm{a}<0,2 \mathrm{~mm}$.

As curvas 4 e 5 são características de materiais de maior tenacidade à fratura, já que a região não linear da curva é maior em relação às curvas da situação anterior, o que indica maior propagação estável da trinca antes da fratura do mater. Nesta situação, também é possível a ocorrência de pop-ins (curva 5). Neste caso, se calcula o CTOD último $\left(\delta_{\mathrm{u}}\right)$ na qual se tem propagação estável da trinca $\Delta \mathrm{a}>0,2 \mathrm{~mm}$, antes do início da propagação instável da trinca.

Em se tratando de materiais dúcteis, durante o ensaio há significativa propagação estável da trinca antes do material perder a capacidade de resisitir a propagação da trinca. Este fato é evidenciado na curva 6 onde se verifica que a carga permanece constate (patamar de carga máxima) antes do início da propagação instável de trinca, ou seja, antes do material não ser mais capaz de resistir a carregamentos. O valor de CTOD calculado nestas condições é conhecido como CTOD de carga máxima $\left(\delta_{\mathrm{m}}\right)$.

\subsubsection{Validação do ensaio}

Após os ensaio, deve-se examinar a superfície de fratura, obtida por ruptura do corpo de prova após imersão em nitrogênio líquido, de modo a verificar se os requisito associados ao tamanho real da pré-trinca de fadiga e a propagação da trinca foram atendidos, garantindo assim a validade do ensaio.

Segundo BS 7448:1 (1991), a medição do comprimento real da pré-trinca de fadiga consiste em medir 9 pontos equidistantes, Figura 34, onde os pontos mais externos estão localizados a $1 \%$ da espessura do corpo de prova. Para a medição da propagação da trinca, segue-se o mesmo procedimento descrito acima para se conhecer o avanço da trinca durante o ensaio. 


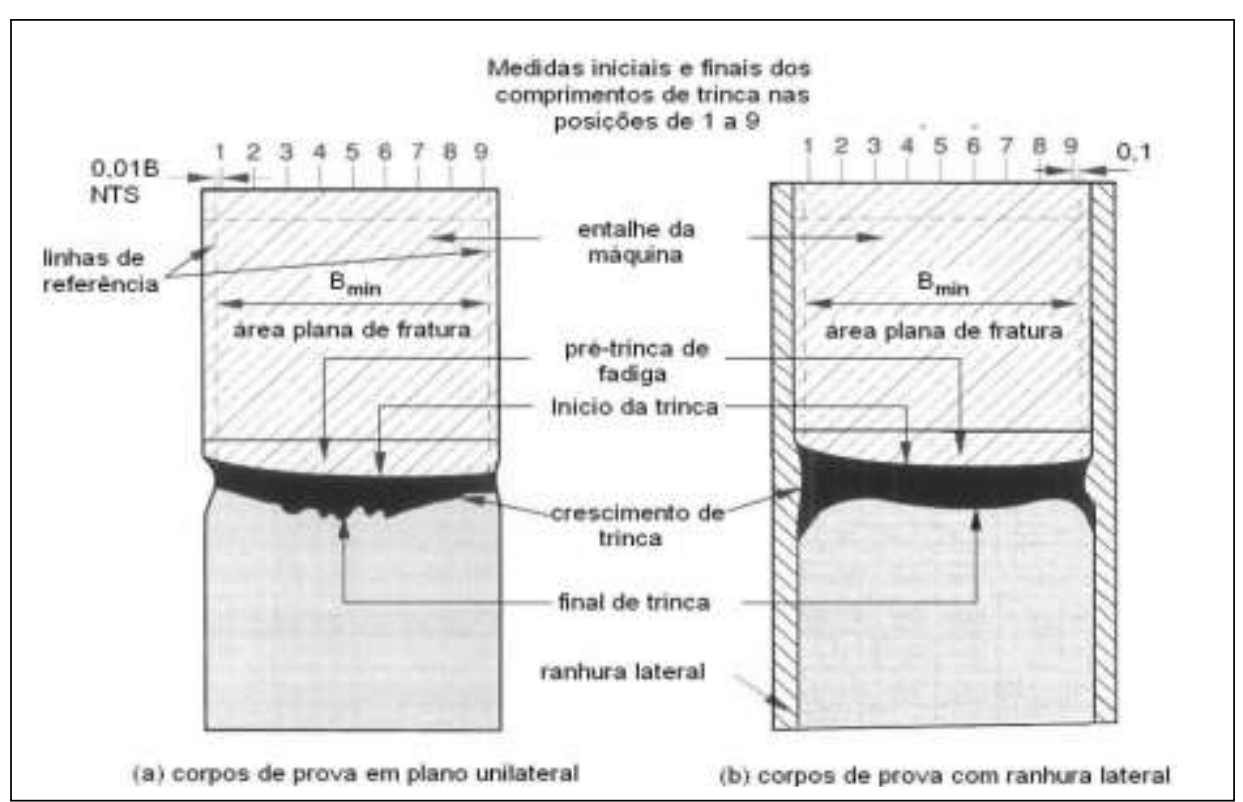

Figura 34 - Procedimento para medição do tamanho real da pré-trinca de fadiga e da propagação da trinca. (BS 7448:4, 1997).

O tamanho real da pré-trinca de fadiga $\left(\mathrm{a}_{\mathrm{r}}\right)$ é obtido,a partir da Equação (57)

$$
a_{r}=\frac{a_{19}+\sum_{2}^{9} a_{2}+\ldots+a_{9}}{8}
$$

na qual, $a_{19}=\frac{a_{1}+a_{9}}{2}$

Considerando que a razão a/W está na faixa entre 0,45 e 0,55 , o ensaio será válido se os seguintes requisitos forem atendidos:

- A diferença entre qualquer duas das nove medições do comprimento da pré trinca não deve exceder $10 \%$ de seu comprimento nominal;

- O comprimento mínimo da trinca de fadiga deve ser maior que 1,3 $\mathrm{mm}$ ou $2,5 \% \mathrm{~W}$;

\subsection{Abordagem Macroscópica e Microscópica da Fratura}

A deformação plástica durante o serviço é geralmente considerada um critério de falha pois as deformações são significativamente intoleráveis o que 
leva o componente estrutural a operar de forma insegura (Roesler, Harders e Baeker, 2007). Um outro critério de falha a ser considerado nas avaliações de integridade estrutural é a fratura.

A fratura de um componente mecânico ou estrutural é caracterizada pela geração de novas superfícies em seu interior, o que resulta na separação do componente em duas ou mais partes quando submetido a tensões oriundas de carregamento monotônico (Gross e Seelig, 2011). Sendo assim, a fratura no sentido denotativo da palavra é o evento final no componente, e este é precedido de alguns estágios que ocorreram no interior material e que determinaram o tipo de fratura no material metálico. Desta forma, o conhecimento de tais estágios, que estão associados aos aspectos microscópicos da fratura é importante para a avaliação da fratura.

De uma forma geral, a fratura dos materiais metálicos são classificadas em: fratura dúctil e fratura frágil. Pokluda e Sandera (2012), baseia esta classificação em uma abordagem macroscópica, onde considera-se a existência ou ausência de deformação plástica nos componentes fraturados.

A fratura dúctil está associada a significativa deformação plástica e é dependente do grau de restrição imposto ao componente estrutural. Em casos de pouca restrição, o componente será submetido a grandes níveis de deformação plástica, ou seja, em se tratando de carregamento trativo, o corpo de prova sofrerá grande redução de seção transversal. Porém, em condições de alta restrição (componentes de grandes dimensões), a fratura dúctil ocorre com discreta contração (Janssen, Zuidema e Wanhill, 2006).

A Figura 35 ilustra dois corpos de prova fraturados submetidos a ensaio de impacto tipo Charpy. Nota-se que o corpo de prova (a) exibiu maior contração lateral na região tracionada do entalhe tipo $\mathrm{V}$ e, consequentemente maior expansão lateral no lado oposto onde ocorreu compressão do material. Tais evidências confirmam a fratura dúctil no corpo de prova (a) e fratura frágil no corpo de prova (b). 


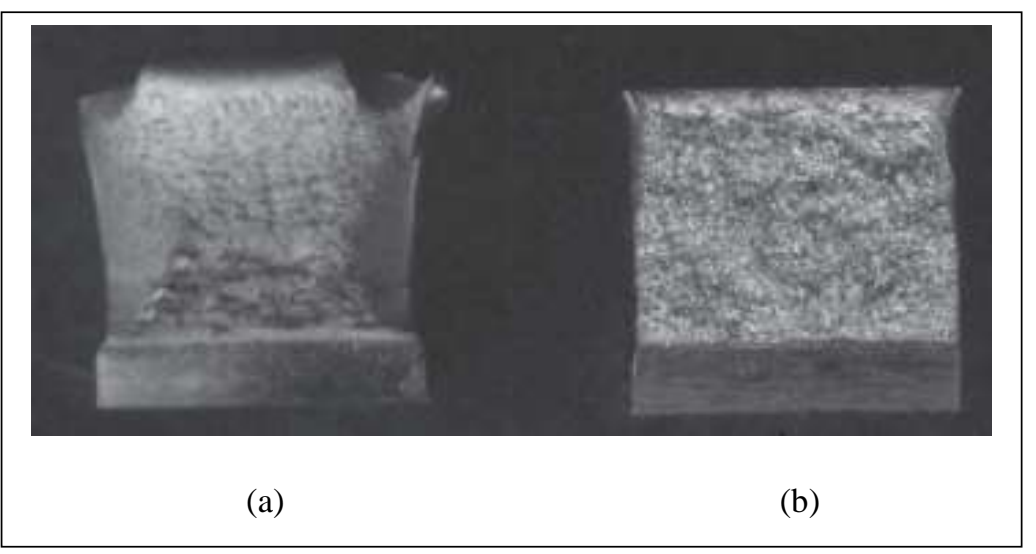

Figura 35 - Corpos de prova Charpy rompidos. (a) Fratura dúctil. (b) Fratura frágil (Janssen, Zuidema e Wanhill, 2006).

A fratura frágil exibe pequena ou desprezível deformação plástica e está associada a uma baixa absorção de energia. A probabilidade de material fraturar de modo frágil aumenta com a redução da temperatura e/ou aumento da taxa de deformação aplicada durante o carregamento.

A fratura frágil ocorre pela ruptura das ligações atômicas, sendo este o motivo pela aparência superficial brilhante e plana da superfície de fratura. Este tipo de fratura é verificada em materiais de comportamento linear elástico como, por exemplo, materiais cerâmicos.

Considerando o comportamento mecânico de um material sob ensaio de tração monotônico uniaxial, o tipo de fratura macroscópica pode ser determinada a partir de uma análise da curva tensão $(\sigma) v s$ deformação $(\varepsilon)$. Em se tratando de fratura macroscopicamente fragil, tal curva possui aspecto linear enquanto que a fratura macroscopicamente dúctil possui curva $\sigma v s \varepsilon$ não linear.

Além da análise da curva $\sigma v s \varepsilon$, a avaliação do comportamento mecânico do material pode ser complementada pela inspeção das partes rompidas do corpo de prova. A Figura 36 e 37 mostram a associação da curva $\sigma v s \varepsilon$ com análise das partes rompidas de um corpo de prova cilíndrico ensaiado a tração para fratura dúctil e fratura frágil, respectivamente. 


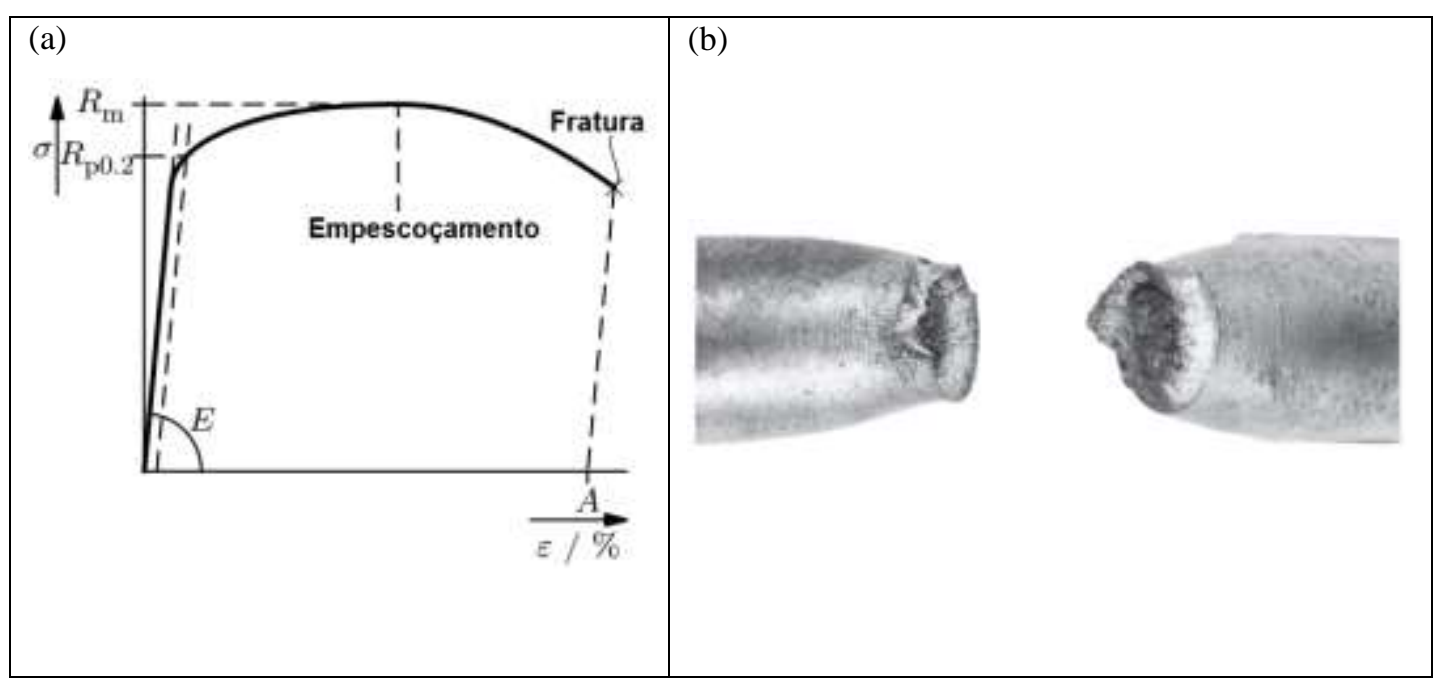

Figura 36 - (a) Curva $\sigma$ vs $\varepsilon$ : material com comportamento plástico com apreciável deformação plástica (Roesler, Harders e Baeker, 2007). (b) Superfície de fratura com estricção característica da significativa deformação plástica (Askeland, Fulay e Wright, 2010).

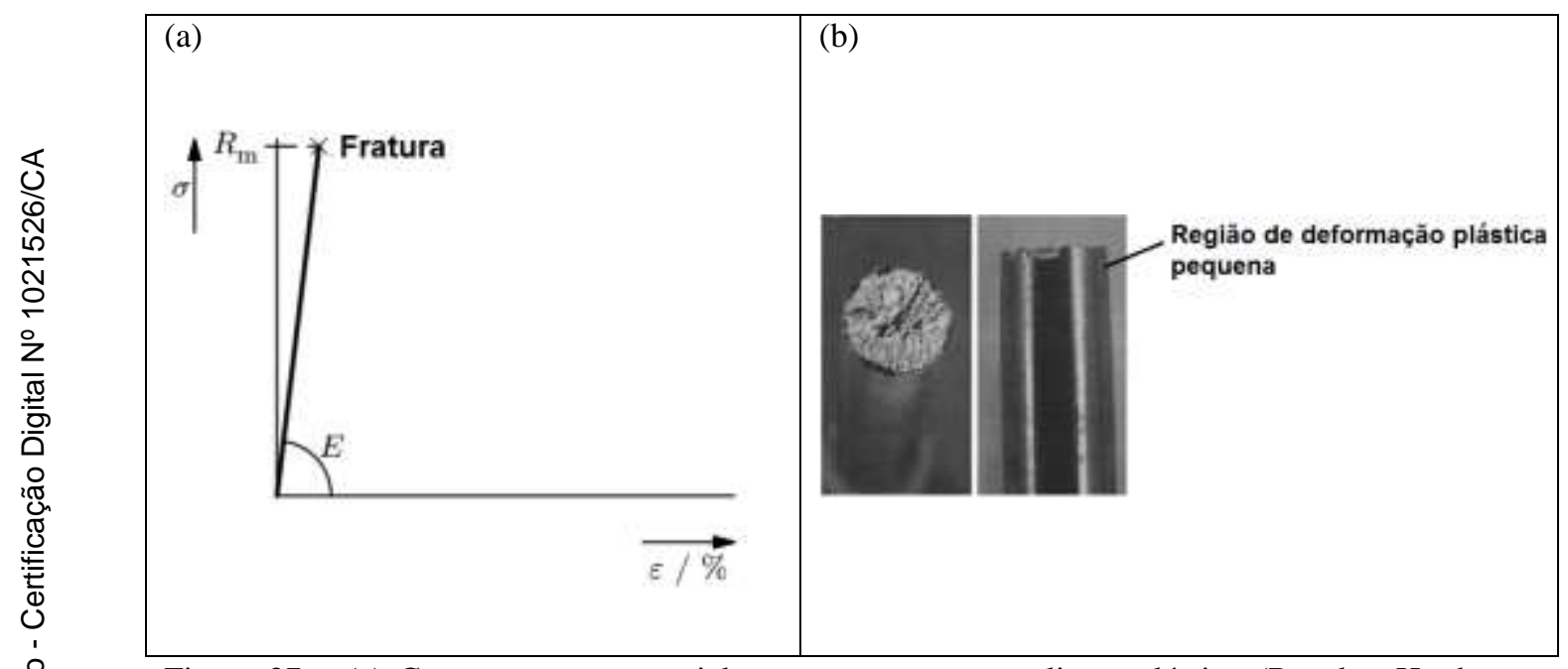

Figura 37 - (a) Curva $\sigma$ vs $\varepsilon$ : material com comportamento linear elástico (Roesler, Harders e Baeker, 2007). (b) Superfície de fratura de com deformação plástica desprezível (Liu, 2005).

\subsubsection{Micromecanismos de Fratura dos Materiais Metálicos}

O processo de fratura consiste na geração contínua de novas superfícies em virtude da existência de micromecanismos de fratura que atuam sob o ponto de vista microscópico durante a deformação plástica no interior do material, favorecendo a propagação de trincas. Os micromecanismos de fratura dependem do tipo de fratura macroscópica verificada no componente mecânico/estrutural. Se a fratura for dúctil, o micromecanismo atuante é o MVC - micro-void coalescence, mas usualmente conhecido por micromecanismo por dimples. Por 
outro lado, se a fratura for frágil, o micromecanismo predominante é o da clivagem.

\subsubsection{Micromecanismo da Fratura Dúctil}

A deformação plástica macroscópica característica de fratura dúctil é consequência do movimento das discordâncias em ligas metálicas. As discordâncias são defeitos lineares que integram o mecanismo de deformação dos materiais, auxiliando no deslizamento dos planos cristalinos. Porém, o movimento das discordâncias pode ser dificultado por barreiras encontradas na rede cristalina como, por exemplo, partículas de segunda fase, contorno de grão, impurezas.

Maioria dos materiais de engenharia possui em sua microestrutura partículas de segunda fase e/ou inclusões não metálicas que podem fraturar ou se destacar da matriz ao seu redor durante a deformação plástica, dependendo da resistência da partícula e de sua interface com a matriz. Partículas duras preferencialmente fraturam em níveis altos de tensão como, por exemplo, em estado triaxial de tensão. Já a separação da partícula da matriz ocorre principalmente se a deformação na matriz for em grande escala (Roesler, Harders e Baeker, 2007; Meyers e Chawla, 2008).

Em se tratando da falha dúctil de materiais estruturais de engenharia, quando estes falham por excesso de carregamento o micromecanismo atuante é composto por nucleação, crescimento e coalescimento de microcavidades (Anderson, 2005; Meyers e Chawla, 2008). Este processo é oriundo da interação das discordâncias com as partículas de segunda fase. Por uma ação cisalhante se abre interfaces e com o aumento da deformação plástica a cavidade começa a crescer. As microcavidades nucleiam em regiões não uniformes de deformação plástica, tais como as regiões associadas a existência de partículas de segunda fase, inclusões não metálicas, contornos de grão e empilhamento de discordâncias. Quando a deformação no material aumenta, a microcavidade cresce, coalesce, e eventualmente origina uma superfície de fratura contínua (Figura 38). Este tipo de micromecanismo exibe várias depressões com formato tipo xícara que são resultado direto da coalescencia de microcavidades. Tais depressões são denominadas "dimples" ou alvéolos. 
Segundo Janssen, Zuidema e Wanhill (2006), Tawancy, Ul-hamid e Abbas (2004), o formato do dimple é governado pelo estado de tensão dentro do material no momento em que as microcavidades se formam e coalescem. Estado uniaxial de tensões formam "dimples" essencialmente equiaxiais.

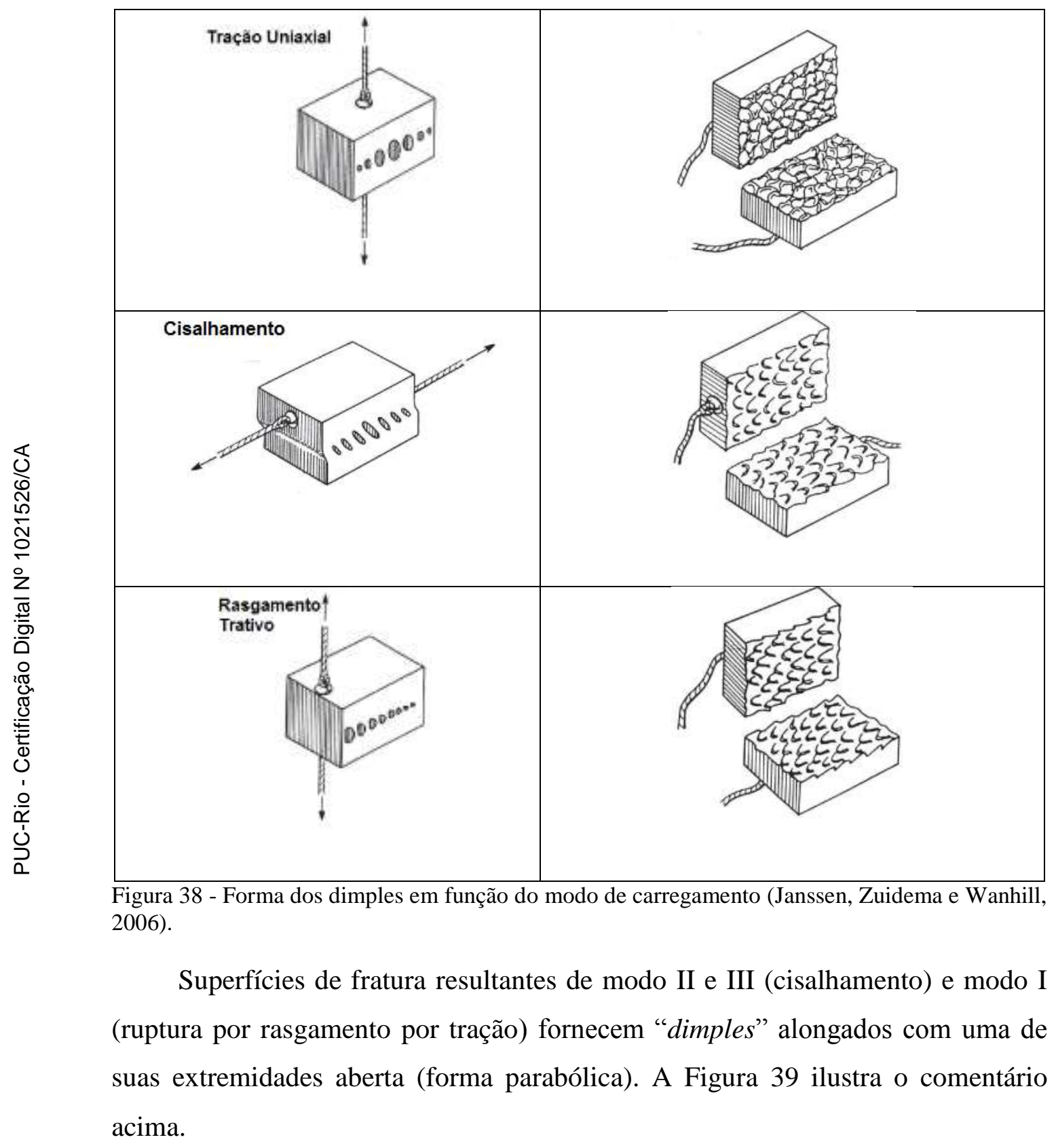




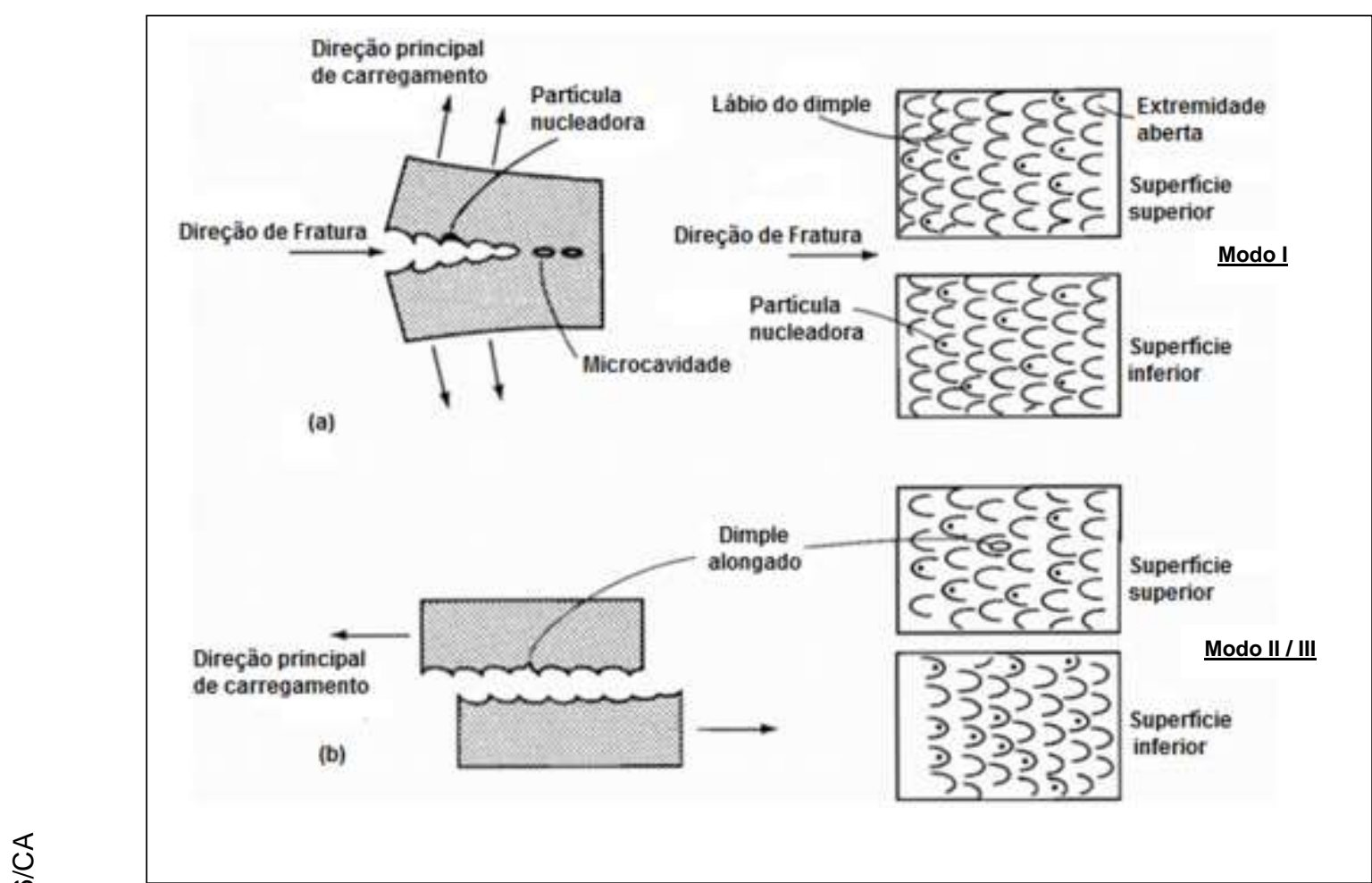

Figura 39 - (a) "Dimples" devido a modo I de carregamento e (b)"dimples" devido a modo II/III de carregamento (Mills, 1987).

Além de uma de suas extremidades abertas, se pode notar que dimples possuem orientações diferentes em função do modo de carregamento. No Modo II / III de carregamento cisalhante, os "dimples da superfície de fratura superior apontam para um sentido, enquanto que os dimples da superfície inferior estão orientados em sentido oposto. Já a superfície de fratura obtida por rasgamento trativo (Modo I) possui “dimples” orientados no mesmo sentido.

Dependendo da microestrutura e plasticidade do material, os "dimples" podem exibir uma forma cônica profunda ou pode ser raso, conforme ilustra a Figura 40. 


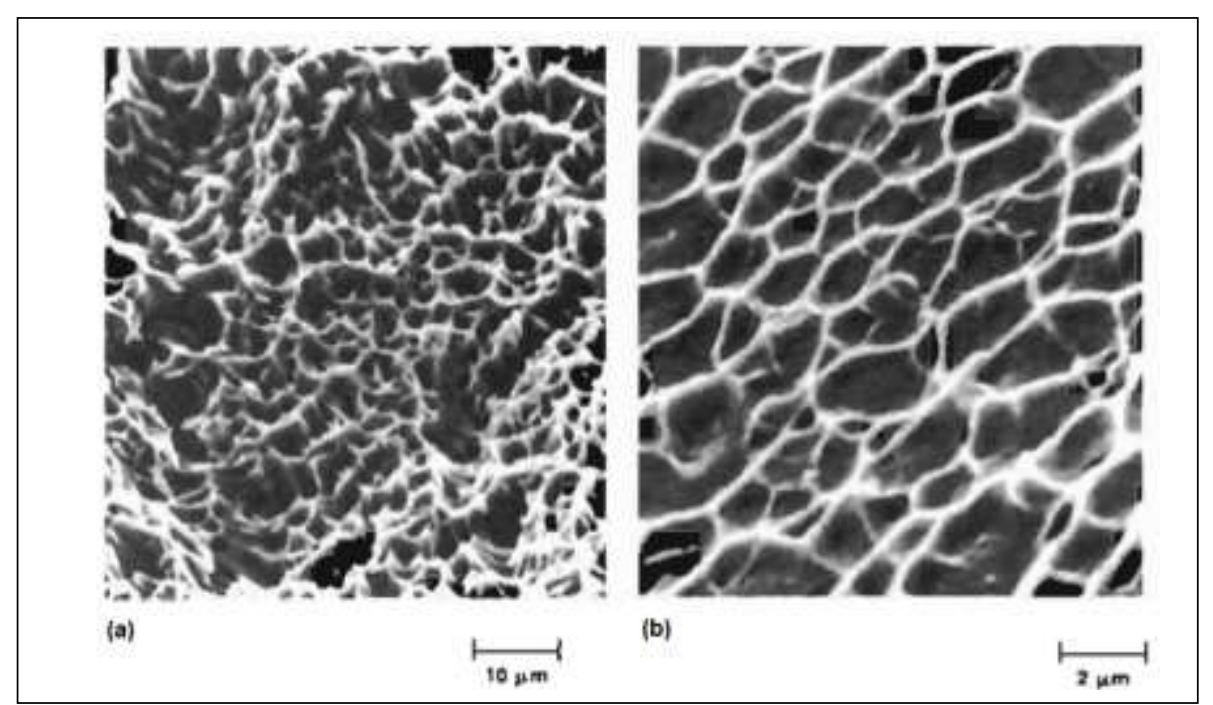

Figura 40 - Superfície de fratura com "dimples"cônicos equiaxiais (a) e "Dimples" rasos (b) (Mills, 1987).

Conforme mencionado, a fratura da partícula ou sua decoesão da interface da matriz causa no material microcavidades que se deformam com o carregamento atuante sobre o componente. A matriz existente entre as partículas de segunda fase é monofásica, sendo assim, possui maior ductilidade. Desta forma, as cavidades crescem através do deslizamento das discordâncias existentes na matriz nos planos de máxima tensão de cisalhamento. Como exemplo, se pode citar o ensaio de tração, onde se verifica um estado uniaxial de tensão com deformações ocorrendo a $45^{\circ}$ em relação a direção de carregamento. A Figura 41 mostra a superfície de fratura de aço com microestrutura ferrítica com dimples, alguns com suas respectivas partículas de segunda fase. Observa-se que a superfície de fratura obtida por microscopia eletrônica de varredura está de acordo com o padrão de fractografia (dimples equiaxiais) para carregamento trativo ilustrado na Figura 38.

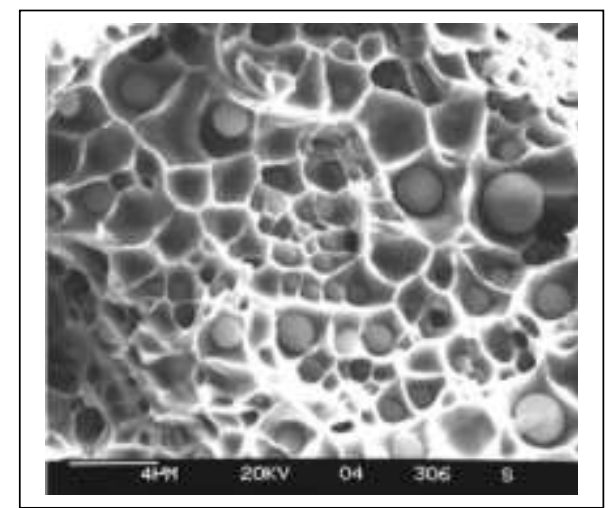

Figura 41 - Superfície de fratura de aço com dimples e suas respectivas inclusões (Roesler, Harders e Baeker, 2007). 
Em um ensaio de tração uniaxial, os dimples são inicialmente equiaxiais. Porém, ao decorrer do ensaio ocorre alteração do estado de tensão no interior do corpo de prova e consequentemente mudança da forma do "dimple".

Com a separação da porção central do corpo de prova, a fratura ocorre em direção a superfície externa. Com as mudanças nas condições de restrição, ocorre um favorecimento a deformação nos planos de máxima tensão de cisalhamento (aproximadamente $45^{\circ}$ em relação a direção de carregamento) e portanto os dimples crescem em forma alongada, dando forma a fratura do tipo taça-cone.

A Figura 42 mostra os dimples na porção central e na porção periférica de um corpo de prova submetido a ensaio de tração com carregamento monotônico.

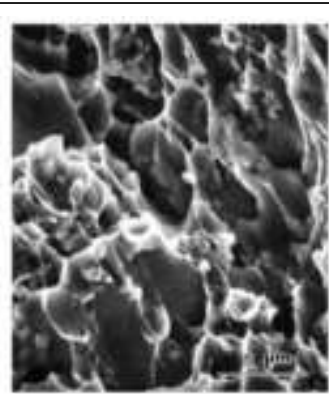

(a)

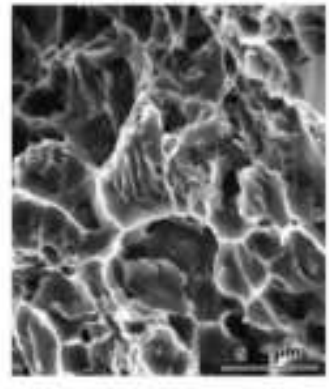

(b)

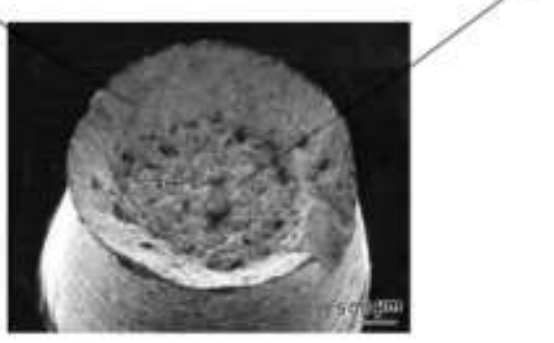

Figura 42 - Fractografia de corpo de prova de aço tracionado: (a) dimples alongados nas laterais (cisalhamento) e (b) dimples equiaxiais no centro submetido a tensão normal (Meyers e Chawla, 2008).

O tamanho do "dimple" na superfície de fratura é governado pelo número e distribuição das microcavidades que são nucleadas.

Quando existem poucos sítios nucleadores ou estes são largamente espaçados, as microcavidades crescem antes de coalescer e o resultado final é a criação de uma superfície de fratura com grandes "dimples". Pequenos "dimples" são formados quando numerosos sítios nucleadores são ativados e microcavidades adjacentes se unem (coalescem) antes de seu crescimento para um tamanho maior. 
"Dimples" muito pequenos são normalmente encontrados em materiais endurecidos por dispersão de óxidos.

Vale ressaltar que os "dimples" correspondentes as superficies de fratura raramente possuem o mesmo tamanho devido as fraturas raramente ocorrem por ação pura de tração ou cisalhamento. As várias combinações dos modos I, II e III, assim como a mudança constante na orientação dos planos de fratura quando a trinca se propaga resulta em uma deformação assimétrica nas superfícies de fratura correspondentes. A Figura 43 mostra o efeito da assimetria no tamanho do "dimple". A superfície B que é deformada após a fratura exibe "dimples" mais longos que seu "dimple" correspondente na superfície A.

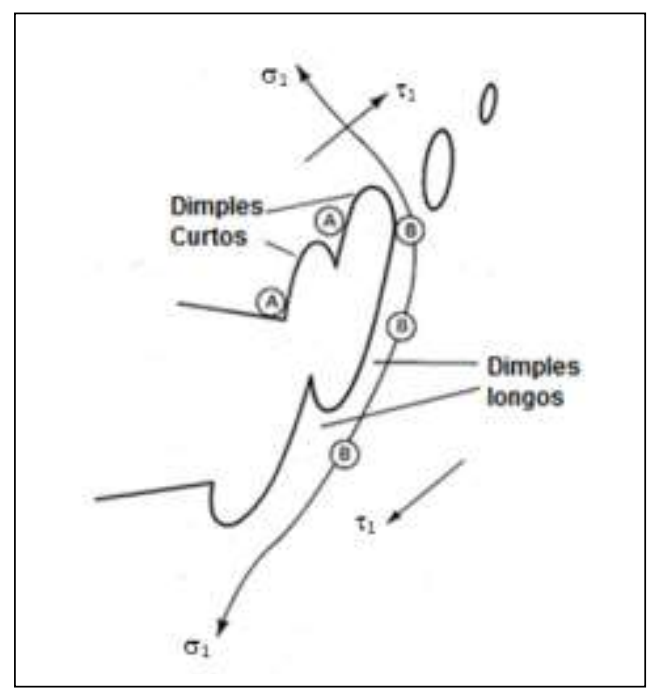

Figura 43 - Efeito da assimetria existente no tamanho dos "dimples" na propagação da trinca (Mills, 1987).

Quando a fratura ocorre por combinação do Modo I e II, é possível saber a direção da fratura local. Como ilustrado, o plano de fratura contendo os "dimples" mais longos encontra a região a partir da qual a trinca se propagou, enquanto o plano de fratura correspondente com os "dimples" mais curtos encontra-se fora da região. Com as diferentes combinações dos Modos I, II e III de carregamento, poderia haver até 14 variações de forma e orientação de dimples nas superfícies de fratura correspondentes. 


\subsubsection{Micromecanismo da Fratura Frágil}

Em escala macroscópica, a fratura frágil tem um aspecto plano normal a direção da carga aplicada, conforme ilustrado na Figura 40. Segundo Hütter, Zybell e Kuna (2014) e Roesler, Harders e Baeker (2007), o processo envolvido nesta fratura é de baixo consumo de energia. Por isto a deformação plástica existente no processo de fratura é considerada nula ou muito pequena.

Em escala microscópica, a fratura frágil ocorre por uma rápida e gradual separação de átomos da estrutura cristalina, devido a ruptura das ligações atômicas, ao longo do plano de fratura de baixos índices cristalográficos. O micromecanismo que rege este processo é conhecido como clivagem e é caracterizado por superfícies planas, denominadas facetas de clivagem. A Figura 44 exemplifica uma superfície de fratura obtida pelo micromecanismo de clivagem.

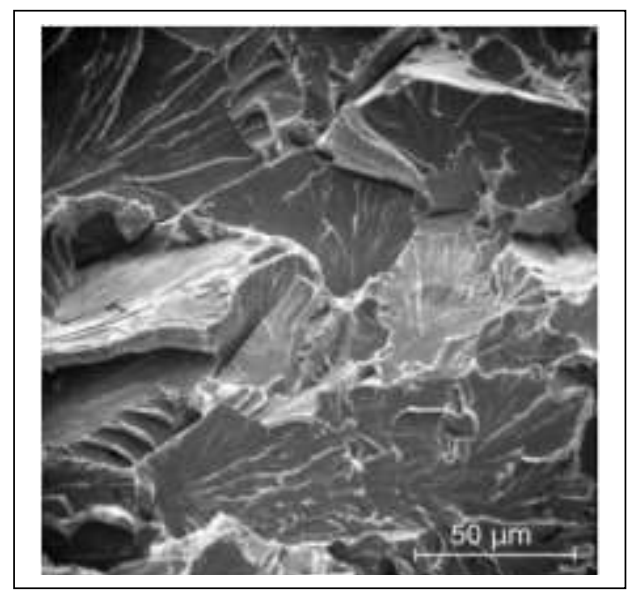

Figura 44 - Micromecanismo de clivagem visualizado em aço liga (Roesler, Harders e Baeker, 2007).

Alguns materiais de engenharia exibem mudança no micromecanismo de fratura com a redução da temperatura e/ou tipo de carregamento. Em geral, materiais de engenharia, de microestrutura cúbica de corpo centrado, que operam em condições de baixa temperatura e/ou são submetidos a carregamentos típicos de fadiga sofrem fratura por clivagem. Li et al. (2013) verificaram o micromecanismo da clivagem na falha de um trilho de rodovia destinada ao tráfego de cargueiros. Inspeções macroscópicas na superfície fraturada do trilho mostram que a causa da falha do componente mencionado foi a fadiga. A 
iniciação da trinca se deu na extremidade das marcas de sargento (área 1) e sua propagação foi em direção divergente as marcas de sargento.

Análises fractográficas da superfície de fratura do trilho corroboraram o micromecanismo de clivagem presente na fratura do trilho. A Figura 45 mostra a área 1 inspecionada e o micromecanismo de clivagem associado.

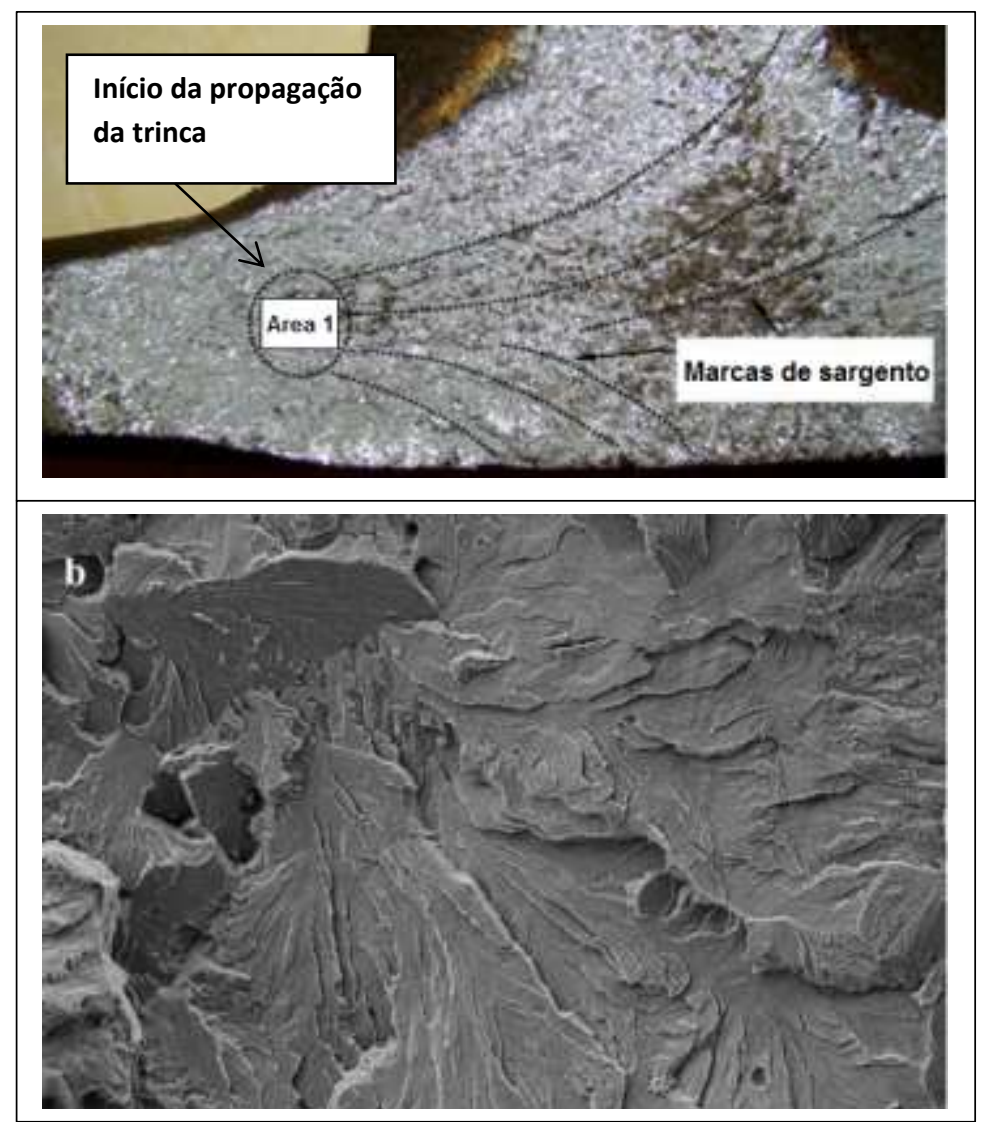

Figura 45 - Facetas de clivagem em superfície fraturada do trilho (Li et al., 2013).

Liu (2005) relata dois termos associados a clivagem: clivagem pura ou ideal e quase-clivagem. A clivagem pura somente ocorre sob condições bem definidas associadas a microestrutura e condições de operação, como por exemplo, a exposição do componente a ambientes ácidos (Jha et al., 2013). Quando é observado frações variadas de deformação plástica junto com facetas de clivagem se tem a quase-clivagem.

Jha et al. (2013), verificou a presença de quase-clivagem na investigação da superfície de fratura de vaso de pressão soldado, construído em aço de alta resistência e baixa liga, que falhou após teste hidrostático de rotina para qualificação. As análises por microscopia eletrônica de varredura identificaram 
falha no cordão de solda longitudinal devido a falta de fusão e também confirmaram o micromecanismo misto de fratura (quasi-clivagem) caracterizado pela presença de facetas rodeadas de dimples. A Figura 46 mostra a fractografia da superfície do vaso de pressão.

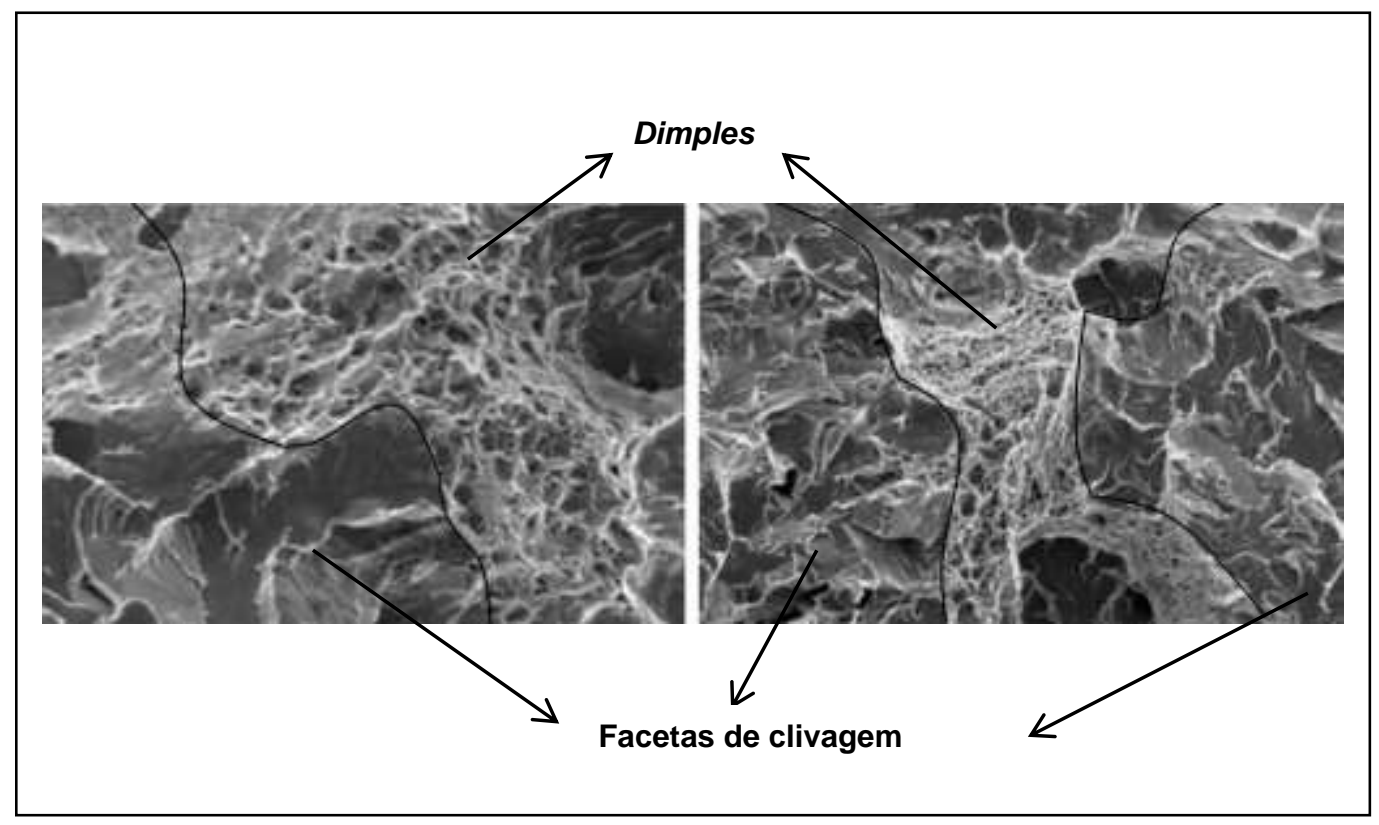

Figura 46 - Micromecanismo misto de fratura verificado na falha de um vaso de pressão (Jha et al., 2013).

\subsection{Difusão do Hidrogênio}

Segundo Crank (1980) e Mehrer (2007), a difusão consiste no transporte de matéria de um ponto para outro por movimentação de átomos devido a energia térmica.

O hidrogênio, na sua forma atômica, possui um diâmetro muito pequeno $(0,074 \mathrm{~nm})$ em relação ao Ferro $(0,286 \mathrm{~nm})$ e se difunde com facilidade pelos sítios interstiticiais da estrutura cristalina do aço (Jiang e Carter, 2004).

Após a absorção do hidrogênio na rede cristalina do ferro, o mesmo devido a sua baixa solubilidade e alta mobilidade vai se difundir e ocupar os sítios intersticiais da rede do ferro. Os sítios intersticiais preferenciais do ferro ocupados pelo hidrogenio são os sítios octaédricos e tetraédricos (Mehrer, 2007). A Figura 47 ilustra os sítios octaétricos e tetraédricos existentes em uma estrutura cristalina do ferro. 


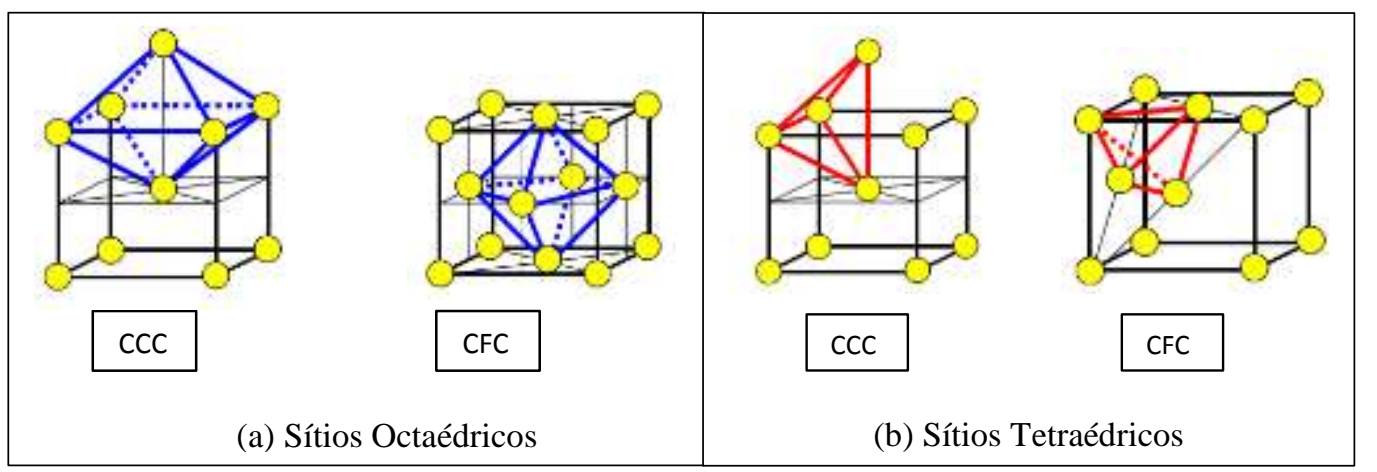

Figura 47 - Hidrogênio nos sítios intersticiais das estruturas cristalinas CCC e CFC do ferro. Adaptada de Miranda, Rodrigues, 1994.

Porém, segundo Jiang e Carter (2004), existem estudos contraditórios em relação a posição intersticial do hidrogênio. Estudos relatam que a preferência do átomo de hidrogênio é pelo sítio tetraédrico (Norskov, 1982) enquanto que outros (Gong, Zeng e Zheng, 1989) afirmam que o sítio preferencial é o octaédrico.

Por análises do tamanho dos parâmetros de rede da estrutura cristalina cúbica de corpo centrado (CCC) conclui-se que o raio dos sítios tetraédricos e octaédricos são $0,36 \AA$ e $0,19 \AA$, respectivamente. Admitindo que o raio do átomo de hidrogênio $0,37 \AA$, se percebe que o hidrogênio se ajusta melhor no sítio tetraédrico. A ocupação de sítios octaédricos pelo hidrogênio submete a rede cristalina cúbica de corpo centrado (CCC) do ferro a uma grande distorção tetragonal devido a alteração no comprimento das ligações entre o hidrogênio e os átomos de ferro. Esta alteração fortalece a análise das dimensões dos sítios tetraédricos confirmando que estes são preferenciais pelos átomos de hidrogênio (Jiang e Carter, 2004).

Em condições ideais, tem-se a difusão do hidrogênio pelos interstícios preferenciais da estrutura cristalina do aços. Porém, na realidade a estrutura cristalina do material não é perfeita. Devido a existência de defeitos metalúrgicos tais como lacunas, contorno de grão, discordâncias, partículas de segunda fase, entre outros que agem como sítios aprisionadores de hidrogênio (Stroe, 2006; Micheler e Naumann, 2010). Uma boa análise sobre a ação dos aprisionadores no hidrogênio requer o conhecimento dos seguintes fatores: a energia de ativação $\left(\mathrm{E}_{\mathrm{aT}}\right)$, para o escape do hidrogênio, a energia de ligação do hidrogênio $\left(\mathrm{E}_{\mathrm{L}}\right)$, a densidade do aprisionador e a fração de ocupação do aprisionador (Vianna, 2005). 
A Figura 48 abaixo representa os níveis energéticos associados a um sítio aprisionador.

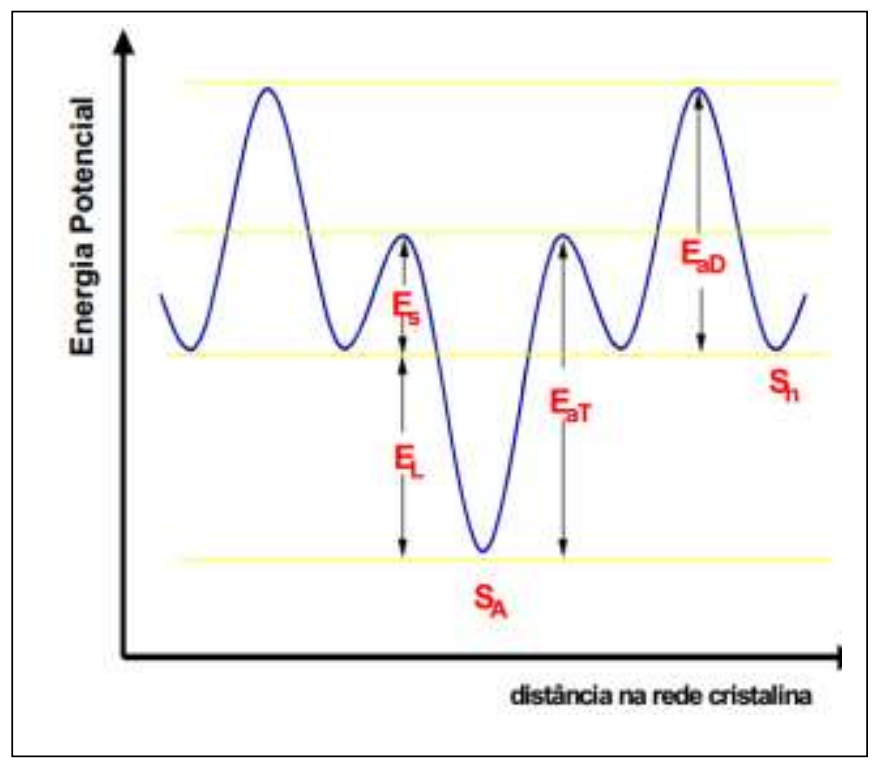

Figura 48 - EL: energia de ligação par hidrogênio e sítio aprisionador, $\mathrm{E}_{\mathrm{s}}$ : energia de ponto de sela, $\mathrm{E}_{\mathrm{aT}}$ : energia de ativação do sítio aprisionador, $\mathrm{E}_{\mathrm{aD}}$ : energia de ativação para difusão do hidrogênio na rede cristalina, $\mathrm{S}_{\mathrm{A}}$ : sítio aprisionador e $\mathrm{S}_{\mathrm{n}}$ : sítio normal da rede cristalina (Vianna, 2005).

Em função da energia de ligação existente entre o sítio aprisionador e o hidrogênio, a uma determinada temperatura, Micheler e Naumann (2010) e Micheler e Bologh (2010) classificam os sítios em reversíveis e irreversíveis. Os sítios reversíveis possuem baixa energia de ligação, aproximadamente $60 \mathrm{~kJ} / \mathrm{mol}$, tornando mais fácil o retorno do hidrogênio para difusão na estrutura cristalina. As discordâncias, contornos de grão e microcavidade são exemplos de sítios reversíveis.

Os sítios irreversíveis que tem maior energia de ligação, valores superiores a $60 \mathrm{~kJ} / \mathrm{mol}$, aprisionam mais fortemente o hidrogênio, necessitando assim que se forneça maior quantidade de energia térmica para sua liberação e posterior difusão na estrutura cristalina. Como exemplos de sítios irreversíveis se pode citar as partículas de segunda fase como os carbonetos, nitretos, inclusões de MnS, entre outros.

Lee e Lee (1984) e Cho e Lee (1982) apresentam estudos realizados por análises térmicas onde se tem as energias de ativação necessárias para o escape dos átomos de hidrogênio dos sítios aprisionadores. Segue abaixo Tabela 4 com 
resumo dos tipos de sítios aprisionadores com suas respectivas energias de ativação.

Tabela 3 - Energias de ativação necessárias para saída do hidrogênio do sítio aprisionador. Adaptado de Cho e Lee (1982) e Lee e Lee (1984).

\begin{tabular}{|c|c|c|c|}
\hline Sítio Aprisionador & Classificação & $\begin{array}{c}\text { Energia de Ativação } \\
\text { (kJ/mol) }\end{array}$ & Material \\
\hline Contorno de grão & Reversível & 17,20 & $\mathrm{Fe}$ \\
\hline Discordância & Reversível & 26,80 & $\mathrm{Fe}$ \\
\hline Microcavidades & Reversível & 35,30 & $\mathrm{Fe}$ \\
\hline $\begin{array}{c}\text { Interface das } \\
\text { inclusões de MnS }\end{array}$ & Irreversível & 76,20 & $\mathrm{Fe}$ \\
\hline $\begin{array}{c}\text { Interface inclusões } \\
\text { de TiC }\end{array}$ & Irreversível & 86,90 & $\mathrm{Fe}$ \\
\hline
\end{tabular}

A existência de sítios aprisionadores na estrutura cristalina influencia na taxa de transporte de hidrogênio no metal, pois reduz o número de átomos em difusão pelos sítios intersticiais (tetraédricos e octaédricos) da rede.

É assumido que a difusão do hidrogênio pelos sítios intersticiais da rede cristalina é controlado pela taxa de liberação dos átomos pelos sítios aprisionadores, ou seja, depende da quantidade de átomos em uma unidade de tempo que conseguem vencer a barreira de energia de ativação do sítio aprisionador (Lee e Lee, 1986).

Os sítios aprisionadores atraem os átomos de hidrogênio para si e o tempo de permanência nestes vai depender da capacidade de aprisionamento de cada tipo de aprisionador, que está associado a sua energia de ligação e também a quantidade de hidrogênio armazenada, isto é, da concentração crítica (Pressouyre, 1979). Os sítios aprisionadores no interior do metal podem agir como fontes ou sumidouros de hidrogênio. Em situações onde se tem energia térmica suficiente para superar a energia de ativação do aprisionador alguns sítios serão fontes, pois trocarão hidrogênio de forma reversível com locais da rede ou com outros sítios mais fortes (irreversíveis). Em contrapartida, os sítios serão sumidouros quando aprisionarem mais fortemente os átomos de hidrogênio.

Além disso, alguns sítios aprisionadores podem ser descontinuidades em potencial, pois se a capacidade de átomos de hidrogênio armazenada, durante a 
exposição em ambientes hidrogenados, exceder a concentração crítica haverá a nucleação de trincas no material. As Figuras 49 e 50 ilustram o modelo qualitativo de interação do hidrogênio com sítios aprisionadores reversíveis e irreversíveis (Pressouyre, 1979). São consideradas duas situações para fonte de hidrogênio: hidrogênio externo e hidrogênio interno e em ambas se tem uma análise da interação de discordâncias ao encontrar consecutivamente um sítio aprisionador irreversível e outro reversível.

$\mathrm{Na}$ condição de hidrogênio externo, considera-se que o material está livre de hidrogênio. Assim as discordâncias existentes na estrutura cristalina do material captam o hidrogenio adsorvido e posteriormente absorvido e estas durante seu movimento encontram os sítios aprisionadores e fornecem átomos de hidrogênio já que estão livres. Desta forma, as chances de uma descontinuidade nuclear uma trinca é reduzida porque a quantidade de hidrogênio na discordância é reduzida devido a perda para os sítios aprisionadores durante o movimento.

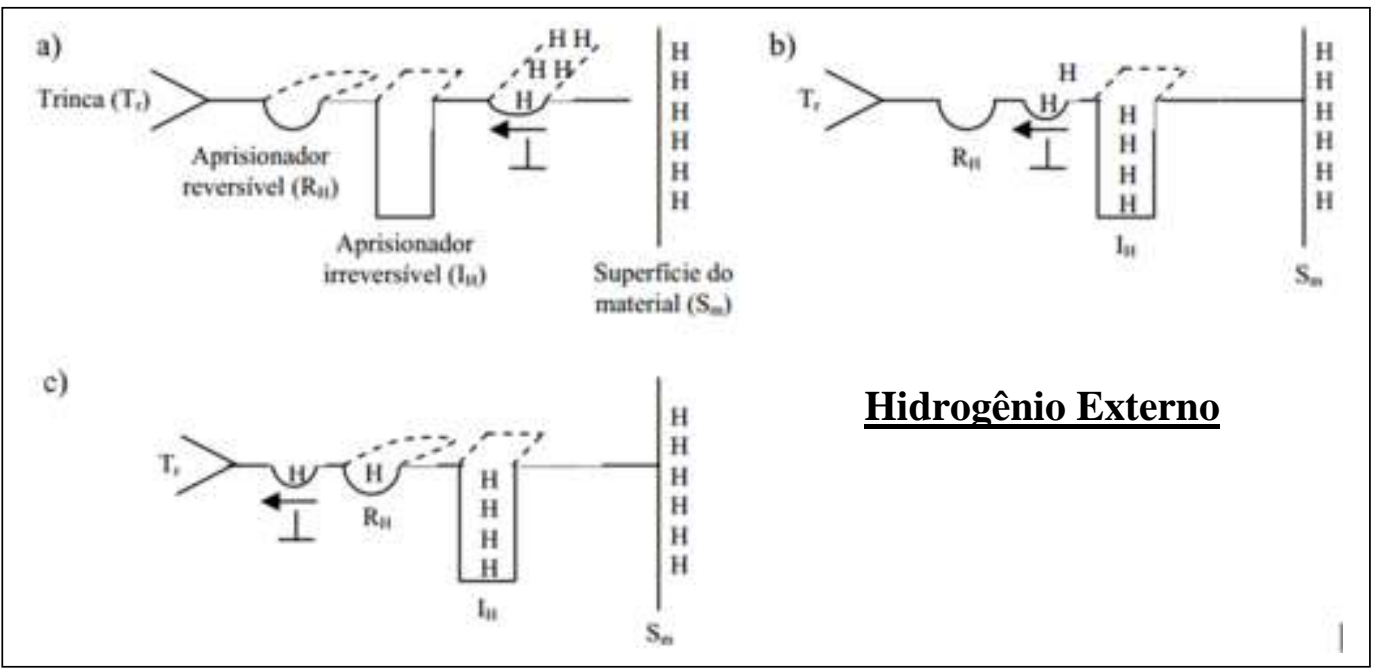

Figura 49 - (a) Movimento da discordância após captação do hidrogênio externo em direção a descontinuidade. (b) Perda de hidrogênio para sítio irreversível. (c) Discordância indo ao encontro da descontinuidade após ceder hidrogênio ao sítio reversível (Pressouyre, 1979).

Nas situações onde a fonte de hidrogênio é interna, o comportamento interativo entre discordância/sítios é um pouco diferenciado pois o movimento desta ocorre em material que já possui hidrogênio na sua estrutura cristalina e por isso as trocas de átomos de hidrogênio entre sítios aprisionadores e discordâncias são necessárias para se atingir a condição de equilíbrio. 
As discordâncias transportam o hidrogênio captado dos interstícios da rede e ao encontrar o sítio irreversível perde átomos de hidrogênio. Ao continuar o movimento a discordância com uma quantidade de hidrogênio menor que o necessário para condição de equilíbrio recebe hidrogenio do sítio aprisionador reversível. Ao alcançar a descontinuidade a discordância tem maior quantidade de hidrogênio do que no caso de hidrogênio externo, aumentando as chances de nucleação de uma trinca a partir da descontinuidade.

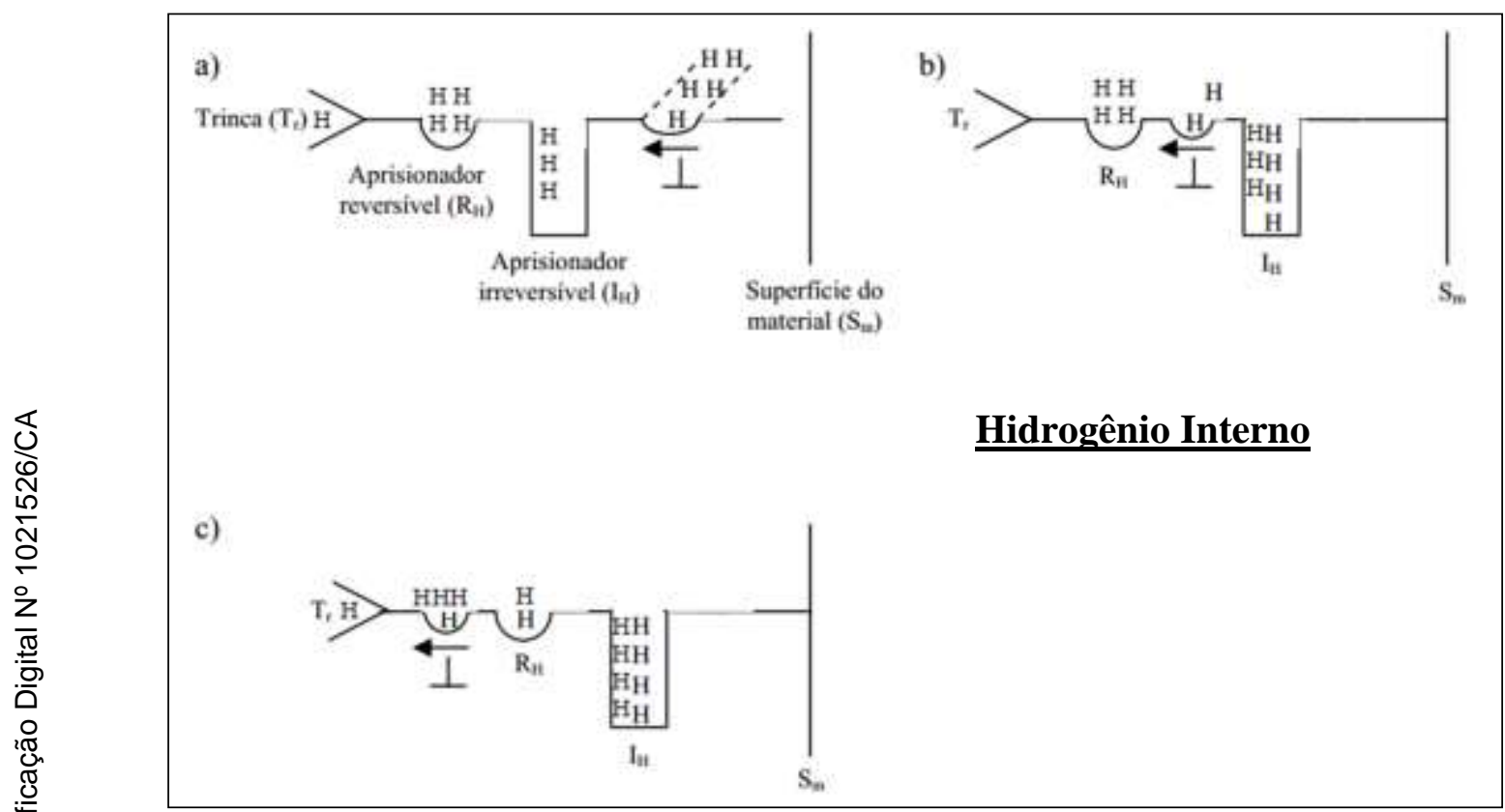

Figura 50 - Fonte interna de hidrogênio. (a) Movimento da discordância com hidrogênio em direção a descontinuidade. (b) Perda de hidrogênio para sítio irreversível. (c) Discordância indo ao encontro da descontinuidade após receber hidrogênio do sítio reversível para alcance do equilíbrio (Pressouyre, 1979).

Em situações de exposição ao hidrogênio, o efeito de aprisionamento provocado pelas heterogeneidades existentes na estrutura cristalina do material tem sido avaliadas por técnicas experimentais, a citar como exemplo o ensaio de permeação e o método de análises térmicas. Como o aprisionamento interfere nas características de difusão, as técnicas experimentais citadas permite a avaliação do coeficiente de difusão aparente do material. 


\subsection{Ensaio de Permeação}

Permeação é definido como a quantidade de hidrogênio afluente na saída da membrana por unidade de tempo, por unidade de espessura da membrana. Segundo Huang et al. (2010) e Fallahmohammadi, Bolzoni e Lazzari, (2013) a técnica de permeação de hidrogênio consiste em impor um gradiente de concentração de hidrogênio entre duas faces de uma membrana metálica. Isso é realizado em uma célula formada por dois compartimentos, conhecida como célula de Devanathan, conforme procedimento estabelecido por norma ISO 17081 (2004).

O corpo de prova na forma de chapa com espessura de aproximadamente $1 \mathrm{~mm}$ deve ser montado entre os dois compartimentos da célula, construídos em vidro e preenchidos com solução, com no mínimo $1 \mathrm{~cm}^{2}$ de área exposto para cada célula eletrolítica. A célula de carregamento de hidrogênio e a de detecção de hidrogênio são preenchida por solução $0,1 \mathrm{~mol} / \mathrm{L} \mathrm{NaOH}$ e solução NACE TM0284 saturada por $\mathrm{H}_{2} \mathrm{~S}$, respectivamente, conforme Figura 51.

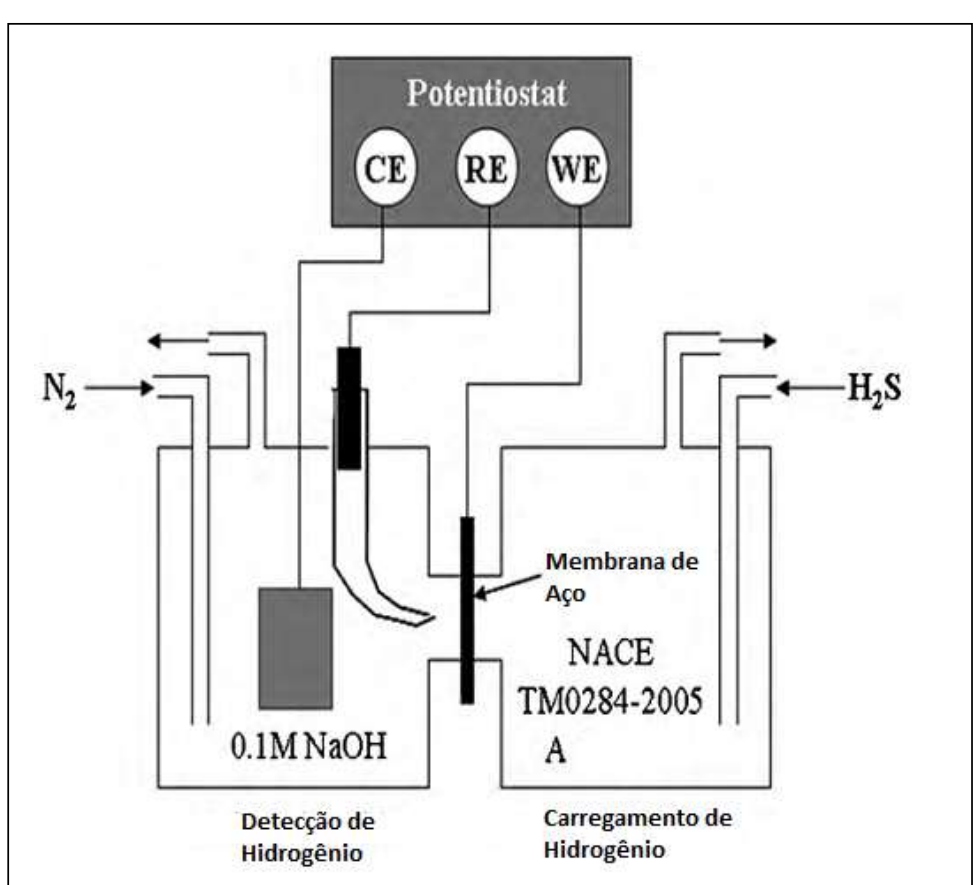

Figura 51 - Esquema do ensaio de permeação (Huang et al., 2010).

Pelo ensaio de permeação é possível calcular as variáveis relacionadas à difusão. A difusividade aparente, ou seja, a difusão desconsiderando os efeitos do aprisionamento, é obtida da curva de permeação do hidrogênio pelo tempo de 
relaxação. Desta forma, a permeabilida, de $\left(J_{\infty} L\right)$ o coeficiente de difusividade aparente assim como a solubilidade $\left(\mathrm{c}_{\mathrm{app}}\right)$ aparente do hidrogênio são calculados pelas Equações (58), (59) e (60), respectivamente:

$$
J_{\infty} L=\frac{I_{\infty} L}{F A}
$$

na qual,

$\mathrm{J}_{\infty}=$ Fluxo de hidrogênio através da membrana de aço $\left[\mathrm{mol} \mathrm{H} \mathrm{m} \mathrm{m}^{-2} \mathrm{~s}^{-1}\right.$;

$\mathrm{I}_{\infty}=$ Densidade de corrente em estado estacionário;

$\mathrm{L}=$ Espessura do corpo de prova $[\mathrm{mm}]$;

$\mathrm{F}=$ constante de Faraday;

$\mathrm{A}=$ área do corpo de prova exposta para cada célula eletrolítica.

$$
D_{a p p}=\frac{L_{2}}{6 \tau_{L}}
$$

na qual

$\mathrm{D}_{\mathrm{app}}=$ Coeficiente de difusão aparente $\left[\mathrm{m}^{2} / \mathrm{s}\right]$;

$\tau_{\mathrm{L}}=$ tempo para alcance da condição estacionária (s).

$$
c_{a p p}=\frac{J_{\infty} L}{D_{a p p}}
$$

Como já mencionado, a presença dos sítios aprisionadores influenciam no processo de difusão do hidrogênio. Para comprovar tal influência Fallahmohammadi, Bolzoni e Lazzari (2013) obtiveram o coeficiente de difusão de rede e o aparente do hidrogênio a partir de ensaios de permeação do aço API 5L X65. O coeficiente aparente e o coeficiente de rede do aço mencionado se encontraram na faixa de $1,5-2 \times 10^{-11} \mathrm{~m}^{2} / \mathrm{s}$ e $1-3 \times 10^{-10} \mathrm{~m}^{2} / \mathrm{s}$, respectivamente. Os resultados obtidos confirmam que os sítios aprisionadores reduzem o transporte de átomos de hidrogênio, pois o coeficiente de difusão de rede (sem aprisionamento) é maior que o coeficiente de difusão aparente. 


\subsection{Fragilização por Hidrogênio}

O "termo "fragilização por hidrogênio" é genérico, pois indica qualquer processo de degradação mecânica assistida pelo hidrogênio, que resulta na redução de propriedades como, por exemplo, ductilidade, resistência à fadiga, tenacidade à fratura, entre outras do material. O processo de degradação é manifestado em diversas maneiras como, por exemplo, fratura catastrófica em componentes de aços de alta resistência, contribuição para o fenômeno de trincamento por corrosão sob tensão, falha em reatores nucleares em zircaloy devido a formação de hidretos, trincamento em dutos entre outros

Segundo Thompson (1985) apud Strohaecker (1989), o termo fratura assistida pelo hidrogênio parece ser mais apropriado do que fragilização por hidrogênio, pois não inclui apenas a fratura em tensões/deformações abaixo da especificação do projeto na existência de hidrogênio, mas também a possibilidade da fratura não ser necessariamente frágil.

Os danos provocados às propriedades mecânicas dos materiais metálicos, especialmente os aços já vem sendo estudado há muito tempo. Segundo a Sociedade Real Inglesa, Johnson (1874) verificou redução da capacidade de deformação em arames de aço após poucos minutos de imersão em solução de ácido clorídrico ou sulfúrico. Após a exposição a solução os arames se romperam após carregamento de flexão. Antes do banho com os ácidos, estes eram capazes de suportar duas a três vezes a mesma carga de flexão antes de se romper.

Desde os primeiros indícios verificados por Johnson (1874), vários mecanismos vem sendo estudados para explicar o fenômeno e atualmente existe uma vasta nomenclatura para descrever as interações entre o hidrogênio e o metal. Entre os termos atualmente encontrados na literatura que se referem a fragilização por hidrogênio, se pode citar, trincamento induzido pelo hidrogênio (HIC Hydrogen Induced Cracking), e trincamento sob tensão induzido pelo hidrogenio (HSC - Hydrogen Stress Cracking) (Vieira, 2004).

A ocorrência do processo de fragilização está primeiramente associada à exposição do material a uma fonte de hidrogênio. Por Perng e Wu (2003), operações de soldagem, processos de decapagem, deposição eletrolítica e/ou condições de serviço podem ser fontes de hidrogênio. A interação do hidrogênio 
com uma parcela significativa dos metais inicia-se a partir da penetração do mesmo na estrutura cristalina do material. Devido ao pequeno raio atômico, o hidrogênio, na forma atômica $\left(\mathrm{H}_{0}\right)$, possui grande mobilidade e por isso se difunde rapidamente na malha cristalina.

Sendo assim, segundo Vieira (2004) e Ferreira (2003), qualquer processo capaz de produzir hidrogênio na sua forma atômica pode contribuir para sua absorção pela estrutura cristalina. Parte do hidrogênio absorvido ao se combinar na sua forma molecular $\left(\mathrm{H}_{2}\right)$, tende a escapar da estrutura cristalina devido a formação de bolhas. Já a fração que penetra no metal é determinado pela concentração de substâncias que se combinam com o hidrogênio e evitam desta forma a formação do hidrogênio molecular como, por exemplo, cianeto e sulfeto e pela extensão da superfície metálica em contato com a fonte de hidrogênio.

$\mathrm{Na}$ indústria petrolífera uma possível fonte de hidrogênio é o petróleo. $\mathrm{Na}$ composição do petróleo existe enxofre $(\mathrm{S})$ e água $\left(\mathrm{H}_{2} \mathrm{O}\right)$ e devido às reações químicas há formação de sulfeto de hidrogênio $\left(\mathrm{H}_{2} \mathrm{~S}\right)$ que é altamente fragilizante. O metal do duto exposto ao sulfeto de hidrogênio é submetido a um processo interno de corrosão. As reações de corrosão desenvolvidas na presença de $\mathrm{H}_{2} \mathrm{~S}$ em solução são apresentadas a seguir:

$$
\begin{array}{ll}
\text { Reação anódica: } & \mathrm{Fe} \rightarrow \mathrm{Fe}^{+2}+2 \mathrm{e}^{-} \\
\text {Reações de dissociação: } & \mathrm{H}_{2} \mathrm{~S} \rightarrow \mathrm{H}^{+}+\mathrm{HS}^{-} \\
\text {Reações Catódicas: } & 2 \mathrm{H}^{+}+2 \mathrm{e}^{-} \rightarrow 2 \mathrm{H}^{0}
\end{array}
$$

Os íons $\mathrm{H}^{+}$existentes nos fluidos ácidos oriundos de reação de dissociação de solução neutra ou básica combinam-se com os elétrons perdidos da superfície do tubo (reação catódica), formando assim o hidrogênio atômico. A tendência do hidrogênio atômico é de se combinar na sua forma molecular gasosa $\left(\mathrm{H}_{2}\right)$, porém a existência de $\mathrm{H}_{2} \mathrm{~S}$ inibem a taxa de formação de hidrogênio molecular, deixando o hidrogênio atômico livre para difusão para o interior da estrutura cristalina.

O processo degradante das propriedades mecânicas dos metais, incentivado pelo hidrogênio, envolve muitas faces com grandes implicações em sua análise. Para fins de compreensão das complexas interações entre o hidrogênio e o material, deve-se considerar um número significativo de aspectos relativos a 
atmosfera onde se encontra o material, propriedades intrínsecas do material e a aspectos exclusivamente relacionados ao estado de tensão imposto ao componente mecânico (Barnoush, 2011). De um modo geral, para ocorrência da fragilização por hidrogênio, as circunstâncias envolvidas na análise do comportamento do material (numérica ou experimental) perante a ação do hidrogênio devem considerar a existência de três fatores:

- concentração mínima de hidrogênio para difusão na estrutura cristalina do material;

- estado de tensão suficiente ao material;

- microestrutura do material susceptível a ação do hidrogênio.

A Figura 52 ilustra a interação dos fatores responsáveis pela fragilização por hidrogênio.

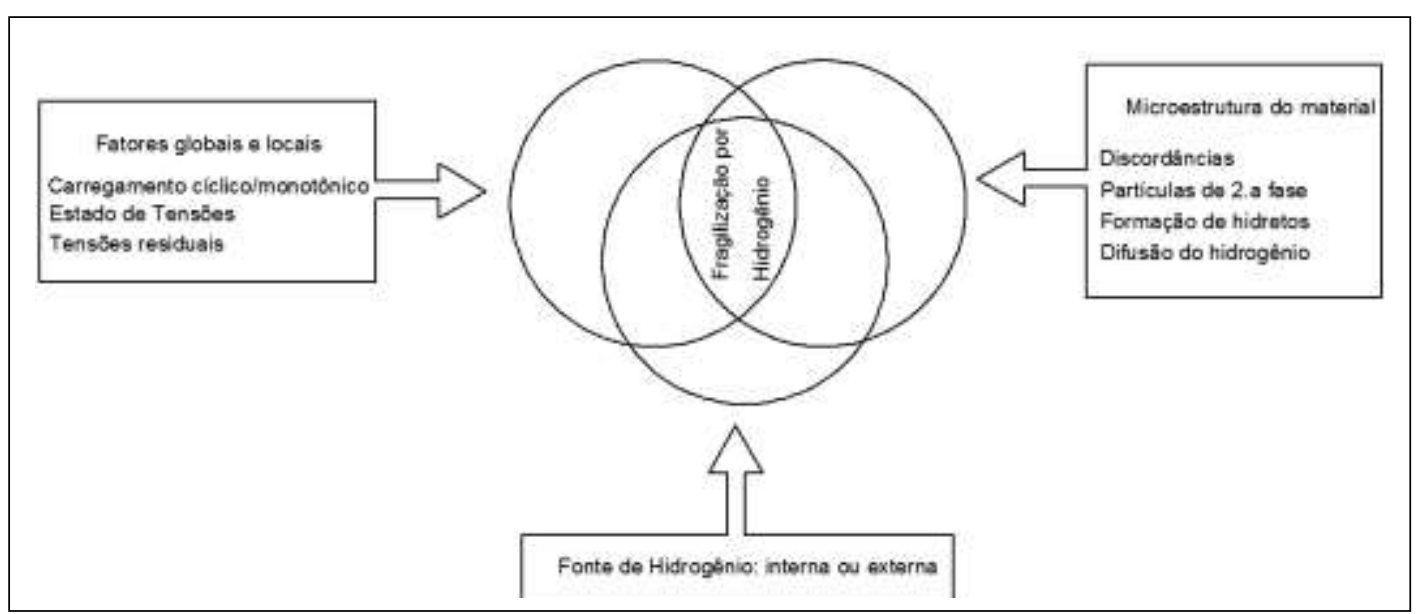

Figura 52 - Descrição global da interação de aspectos necessário a fragilização por hidrogênio. (Adaptado de Barnoush, 2011).

Diversos mecanismos foram propostos desde os indícios que os metais sofriam algum grau de fragilização quando expostos ao hidrogênio até as décadas atuais. Os mecanismos da fragilização por hidrogênio aceitos pela comunidade acadêmica, segundo Chatzidouros et al. (2011) são: a teoria da pressão de hidrogênio, decoesão induzida por hidrogênio, plasticidade localizada induzida pelo hidrogênio, fragilização pela formação de hidretos.

Porém, é fato que apenas um mecanismo não é suficiente para descrever, de maneira clara e completa, o fenômeno de fragilização (Barnoush, 2011). Sendo assim, para uma abordagem mais realística do fenômeno deve-se considerar que a 
fragilização pode ser governada por múltiplos mecanismos, o que vem às vezes proporcionando descobertas contraditórias.

\subsubsection{Entrada do Hidrogênio no Interior dos Metais}

A entrada do hidrogênio para sua difusão no interior da estrutura cristalina é um fenômeno complexo que envolve muitos parâmetros. Esta pode ser realizada através de hidrogênio na forma líquida ou gasosa.

\subsubsection{Entrada por Hidrogênio na Fase Líquida}

As situações nas quais pode-se ter a entrada do hidrogênio na fase líquida são muitas, quando se considera que o hidrogênio é proveniente de meios aquosos. Uma das formas de entrada do hidrogênio mais conhecida é através da dissociação dos átomos em soluções ácidas (Barnoush, 2011).

A região de fronteira entre a superfície metálica e a solução aquosa (eletrólito) é uma uma interface complexa devido a existência de uma densa rede de dipolos de moléculas de água no eletrólito e também a competição que ocorre durante a absorção de diferentes espécies da superfície do metal. A Figura 53 ilustra um esquema representativo da interface metálica/eletrólito com os átomos dissolvidos.

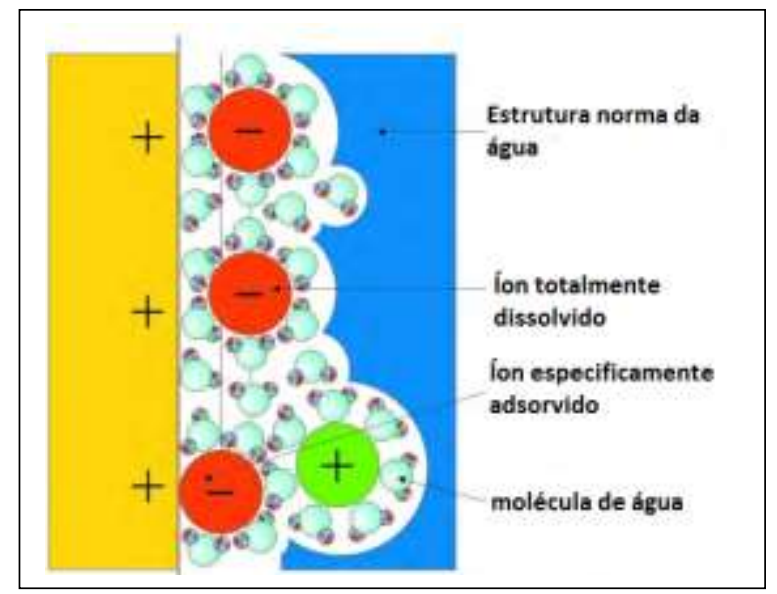

Figura 53 - Esquema de interface metálica em contato com solução aquosa para entrada de hidrogênio (Barnoush, 2011). 


\subsubsection{Entrada por Hidrogênio na Fase Gasosa}

De uma forma geral, pode-se considerar que a interação entre superfície metálica e gás hidrogênio é definida em termos de 3 etapas: fisissorção, quimissorção e absorção (Barnoush,2011 e Moro, 2009).

A fisissorção é a adesão da molécula de hidrogênio (adsorvido) na superfície (adsorvente) do metal que ocorrem em níveis de baixa energia devido a ligações de Van der Walls formando um filme composto de multicamadas na superfície metálica.

A etapa de quimissorção envolve reações químicas entre os átomos de hidrogênio adsorvidos na superfície e átomos da superfície metálica, ocorrendo assim a dissociação dos átomos de hidrogênio. Como a quimissorção envolve a transferência e compartilhamento de elétrons entre o hidrogênio e a superfície metálica (nuvem eletrônica), esta etapa ocorre com maiores níveis de energia. A quimissorção envolve ligações químicas de curto alcance, esta é limitada a formação de uma única camada de produtos pós reação na superfície metálica.

A absorção é a última etapa no sistema interativo gás-superfície metálica. Envolve a penetração dos produtos das reações químicas (quimissorção) na estrutura cristalina do metal. $O$ processo de entrada do hidrogênio gasoso na superfície metálica pode ser representada pela Equação (61):

$$
H_{2}+2 M \rightarrow 2 M H_{a d s}
$$

A Equação (61) descreve a absorção dos átomos de hidrogênio após processo de dissociação da molécula $\mathrm{H}_{2}$, esquematizado na Figura 54.

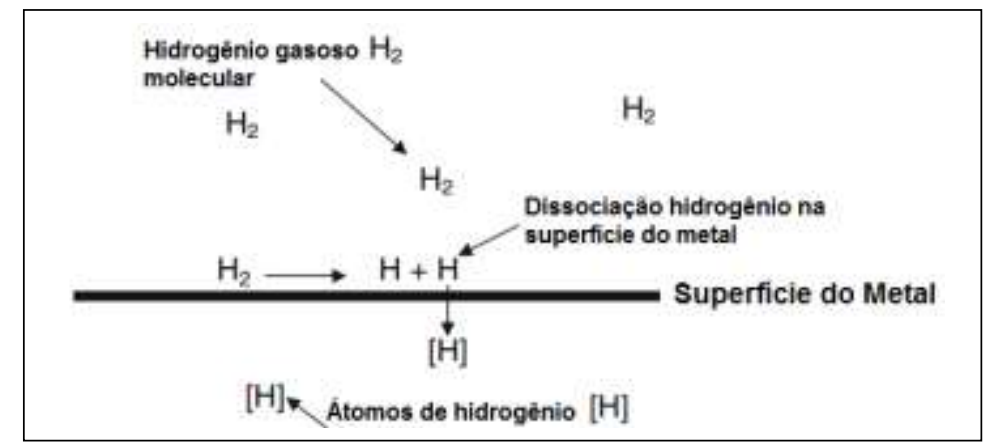

Figura 54 - Absorção de átomos de hidrogênio por metais expostos a atmosfera hidrogenada gasosa (Louthan Jr., 2008). 


\subsection{Métodos de Avaliação da Susceptibilidade à Fragilização por Hidrogênio}

Para determinação da susceptibilidade à fragilização pelo hidrogênio de materiais metálicos são realizados procedimentos experimentais em laboratórios orientados por normas específicas para tal finalidade.

Os métodos de avaliação estabelecidos pelas normas disponíveis são complexos quando comparados a outros métodos para caracterização mecânica de propriedades de tração, dureza, resistência ao impacto e resistência à fadiga. A complexidade dos métodos está principalmente associada a forma de se fornecer hidrogênio ao material (hidrogenação interna ou externa).

As normas existentes para verificação da susceptibilidade à fragilização diferenciam-se pelo meio de hidrogenação (líquida ou gasosa), método de carregamento, se houver, (trativo, flexão, entre outros), e tempo de duração do ensaio. Entre as normas acessíveis, abaixo segue uma relação das principais com uma breve descrição de seus objetivos:

ASTM G129-00 (2013) - Standard Practice for Slow Strain Rate Testing to Evaluate the Susceptibility of Metallic Materials to Environmentally Assisted Cracking.

Esta prática descreve o uso de corpos de prova de tração e de fadiga pré trincados, para determinação da resistência ao trincamento auxiliado pelo ambiente de serviço $(E A C)$ em baixas taxas de deformação.

O procedimento envolve a aplicação de cargas em corpos de prova fixados em célula para confinamento do fluido de teste (fluido inerte ou corrosivo) da máquina de ensaio. O ensaio é conduzido até a fratura do corpo de prova, em fluido inerte e também em fluido corrosivo, e durante toda a duração do ensaio, o corpo de prova é monitorado em relação à carga aplicada e seu alongamento. Para fins de determinação da resistência do material ao trincamento, os resultados conduzidos em ambientes de teste corrosivos devem ser comparados com os resultados correspondentes para o mesmo material em ambiente inerte.

A resistência do material ao trincamento em ambiente predisposto para tal finalidade é determinado a partir do cálculo das seguintes razões: tempo decorrido 
até a falha $\left(\mathrm{t}_{\mathrm{FEAC}} / \mathrm{t}_{\mathrm{f}}\right)$, alongamento plástico $\left(\Delta \mathrm{L}_{\mathrm{EAC}} / \Delta \mathrm{L}\right)$, redução de área da seção transversal (R.A $\mathrm{EAC}_{\mathrm{C}}$ / R.A), resistência a tração com entalhe (LRE $\mathrm{EAC}_{\mathrm{C}} / \mathrm{LRE}$ ), limiar do fator intensificador de tensões em condição em deformação plana $\left(\mathrm{K}_{\mathrm{I}(\mathrm{EAC})} / \mathrm{K}_{\mathrm{I}}\right)$.

A resistência do material é avaliada pela análise dos parâmetros mencionados acima. Quanto menor o valor do parâmetro, em relação a unidade, menor a resistência do material ao trincamento auxiliado pelo ambiente.

ASTM G142-98 (2011) - Standard Test Method for Determination of Susceptibility of Metals to Embrittlement in Hydrogen Containing Environments at High Pressure, High Temperature, or Both.

Estabelece os procedimentos confiáveis para determinar propriedades de tração de metais expostos a alta pressão de hidrogênio gasoso, em alta temperatura ou não. Os ensaios são feitos em corpos de prova com ou sem entalhe, e podem ser realizados em todos os metais independente de seu processo de fabricação. É aplicável a uma ampla faixa de pressões, temperaturas e atmosferas gasosas.

ASTM F1940-07a (2014) - Standard Test Method for Process Control Verification to Prevent Hydrogen Embrittlement in Plated or Coated Fasteners.

Norma limitada a avaliar a fragilização induzida pelo hidrogênio devido apenas a processamento de galvanização / revestimentos (hidrogenação interna IHE) e não devido a exposição ambiental (hidrogenação externa EHE). Este método de teste é destinado a avaliar processos de galvanização e revestimentos de parafusos ferrosos.

ASTM F519-13 (2013) - Standard Test Method for Mechanical Hydrogen Embrittlement Evaluation of Plating/Coating Processes and Service Environments.

Este método de teste descreve testes mecânicos e define critérios de aceitação para processos de revestimento e galvanização que pode causar 
fragilização por hidrogênio nos aços. Exposições subsequentes a substâncias quimicas encontrados em ambientes de serviço tais como fluidos, tratamentos de limpeza ou manutenção que entre em contato com a superfície limpa ou revestida/galvanizada do aço, também pode ser avaliado.

ASTM F1459 - 06 (2012) - Standard Test Method for Determination of the Susceptibility of Metallic Materials to Hydrogen Gas Embrittlement (HGE).

Enfoca a determinação quantitativa da susceptibilidade de materiais metálicos a fragilização por $\mathrm{H}$, quando exposto a altas pressões de gás hidrogênio.

A avaliação tem como base a ruptura de um corpo de prova na forma de um disco de pequena espessura, submetido a pressões idênticas tanto de gás hidrogênio quanto de gás inerte, como, por exemplo, hélio ou argônio. O teste é conduzido até a falha do disco. $\mathrm{O}$ valor da razão entre as pressões de falha $\left(\mathrm{P}_{\mathrm{He}} /\right.$ $\mathrm{P}_{\mathrm{H}}$ ) fornece uma indicação relativa do nível de degradação da resistência do material na presença do gás hidrogênio.

ASTM F1624-12 (2012) - Standard Test Method for Measurement of Hydrogen Embrittlement Threshold in Steel by the Incremental Step Loading Technique.

Estabelece procedimento para medir susceptibilidade do aço a falha causada pelo hidrogênio. Utiliza corpos de prova da mecânica da fratura e pela medição do limiar para início da propagação subcrítica da trinca avalia quantitativamente a susceptibilidade de aços de diferentes composições químicas e/ou com diferentes tratamentos térmicos.

Também avalia o efeito residual do hidrogênio resultante de tratamentos termomecânico, tratamento superficial, revestimentos, e eletrogalvanização, assim como o efeito do hidrogênio introduzido no aço por fontes externas como fluidos e substancias quimicas de limpeza e manutenção, produtos petroquímicos, e pares galvânicos em ambientes aquosos.

O teste é feito ou no ar, para medição do efeito do hidrogênio residual, ou em ambiente controlado, para medir o efeito do hidrogênio introduzido no aço como resultado de fontes externas de hidrogênio. 
NACE MR0175 / ISO 15156 (2009) - Petroleum and Natural Gas Industries Materials for Use in $\mathrm{H}_{2} \mathrm{~S}$-Containing Environments in Oil and Gas Production.

A partir de dados experimentais e de experiência de campo, esta norma fornece orientações para seleção de materiais e ligas resistentes a corrosão a serem usados em ambientes ácidos encontrados em sistemas de produção de óleo e gás (árvore de natal). Pelo estabelecimento de requisitos mínimos relacionados a propriedades mecânicas, tratamentos térmicos, condições de soldagem tem-se o objetivo de minimizar os riscos de trincamento sob tensão na presença de sulfetos de hidrogênio $\left(\mathrm{H}_{2} \mathrm{~S}\right)$. É dividida em três partes. Parte 1 possui orientações gerais para seleção dos materiais, parte 2 orienta na seleção de aços carbono e aços liga, e parte 3 é voltada para escolha de ligas resistentes a corrosão e outras ligas.

Part 1: General principles for selections of cracking-resistant materials.

Part 2: Cracking-resistant carbon and low alloy steels, and the use of cast irons.

Part 3: Cracking-resistant CRAs (corrosion-resistant alloys) and other alloys.

NACE MR0103 (2003) - Materials Resistant to Sulfide Stress Cracking in Corrosive Petroleum Refining Environments.

Similar a NACE MR0175, porém é destinada a seleção de materiais e ligas resistentes a corrosão a serem usados nos processos de refino.

NACE TM0284 (2003) - Evaluation of Pipeline and Pressure vessels for Resistance to Hydrogen-Induced Cracking.

Estabelece método para avaliar a resistência ao trincamento de aços para dutos e chapas destinadas a vasos de pressão causado pela absorção de hidrogênio a partir de corrosão aquosa por sulfeto. Consiste em submeter corpos de prova de espessura igual a $20 \mathrm{~mm}$, sem aplicação de carga, a exposição a uma das duas soluções de teste (A ou B) por no mínimo 96 h.

A resistência de tais aços é avaliada com base nos parâmetros CSR Cracking Sensitivity Ratio (razão de sensibilidade ao trincamento), CLR Cracking Length Ratio (razão do comprimento da trinca) e CTR (Cracking 
Thickness Ratio). O cálculo dos parâmetros acima é previsto pelas Equações (62), (63) e (64), respectivamente. E a Figura 55 ilustra as variáveis envolvidas:

$$
\begin{gathered}
C S R=\left[\frac{\Sigma(a \times b)}{(W \times T)}\right] \times 100 \% \\
C S R=\frac{\Sigma a}{W} \times 100 \% \\
C T R=\frac{\Sigma b}{W} \times 100 \%
\end{gathered}
$$

nas quais,

$\mathrm{W}=$ largura da seção dos corpos de prova $[\mathrm{mm}]$;

$\mathrm{a}=$ comprimento da trinca $[\mathrm{mm}]$;

$\mathrm{b}=$ espessura da trinca $[\mathrm{mm}]$;

$\mathrm{T}=$ espessura do corpo de prova $[\mathrm{mm}]$.

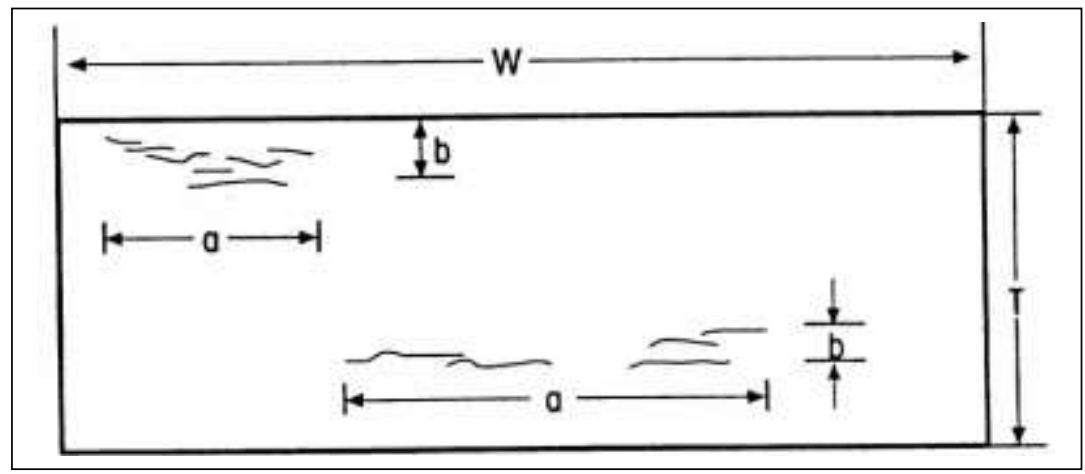

Figura 55 - Desenho esquemático do corpo de prova e as variáveis envolvidas nos cálculos dos parâmetros CSR, CLR e CTR (NACE TM0284, 2003).

NACE TM0177 (2005) - Laboratory Testing of Metals for Resistance to Sulfide Stress Cracking and Stress Corrosion Cracking in $\mathrm{H}_{2} \mathrm{~S}$ Environments. 
Cobre a avaliação da resistência ao trincamento por tensão induzido por sulfeto e ao trincamento por corrosão sob tensão em ambientes aquosos de baixo $\mathrm{pH}$ contendo $\mathrm{H}_{2} \mathrm{~S}$.

O teste é realizado com o corpo de prova montado em um recipiente selado e anti-vazamento onde é colocado a solução de teste. Esta norma estabelece quatro métodos de teste:

- método A (Standard Tensile Test);

- método B (Standard Bent-Beam Test);

- método C (Standard C-Ring Test);

- método D (Standard Double-Cantilever-Beam DCB).

O método A consiste em submeter um corpo de prova a tensões trativas por um período de $720 \mathrm{~h}$ ou até a fratura, o que ocorrer primeiro. A reprovação do corpo de prova ocorre pela separação completa do mesmo ou pela existência de trincas superficiais na seção monitorada do corpo de prova. A inexistência de trincas após decorridas $720 \mathrm{~h}$ de teste inferem na aprovação do corpo de prova, indicando que o material possui resistência ao trincamento em ambiente com $\mathrm{H}_{2} \mathrm{~S}$.

O método B envolve tensões de flexão no corpo de prova pela aplicação de diferentes carregamentos. Os corpos de prova após tensionados são expostos a solução de teste. A falha por trincamento, se houver, é determinada pela inspeção visual com auxílio de um microscópio de baixa ampliação (lupa), quanto a existência de trincas superficiais. A duração do teste é de $720 \mathrm{~h}$ ou até a ruptura do corpo de prova, o que ocorrer primeiro.

No método C, um corpo de prova na forma de anel, imerso em solução de teste, é tensionado por $720 \mathrm{~h}$ ou até a ruptura completa do corpo de prova, o que ocorrrer primeiro.

Para avaliação da resistência ao trincamento deve-se inspecionar o corpo de prova quanto à existência de trincas superficiais. Se desejável, pode-se adotar como critério de falha a visualização da primeira trinca em ampliações de 10X.

O método D, a partir de ensaios com corpos de prova do tipo compacto da mecânica da fratura, submetidos a carregamento trativo, fornece a medição da resistência dos materiais metálicos ao trincamento induzido por ambientes ácidos com $\mathrm{H}_{2} \mathrm{~S}$. A avaliação se dá em termos do fator intensificador de tensões crítico 
para ambientes com $\mathrm{H}_{2} \mathrm{~S}$. Como o método fornece o valor direto da resistência à propagação da trinca, este não depende da inspeção visual em busca de trincas superficiais.

ISO 11114-4 (2005) - Test Methods for Selecting Metallic Materials Resistant to Hydrogen Embrittlement.

Define dois métodos de avaliação: método A e método $\mathrm{B}$. O método A consiste em submeter um corpo de prova na forma de disco a pressão constante de gás a taxa constante até romper ou trincar. $\mathrm{O}$ efeito fragilizante do hidrogênio é evidenciado comparando a pressão de ruptura do $\mathrm{H}_{2}$ com a pressão de ruptura do gás inertte (gás hélio - $1 \mathrm{He}$ ). Com o cálculo da razão $\mathrm{P}_{\mathrm{H} 2} / \mathrm{P}_{\mathrm{He}}$ tem-se a avaliação da resistência do material. Quanto mais baixa a razão, pior o comportamento do aço frente a ação do hidrogênio.

O método B utiliza corpo de prova tipo compacto submetido a carregamento para determinar o fator intensificador de tensões limite (threshold stress intensity factor) para susceptibilidade ao trincamento de materiais metalicos em atmosfera hidrogenada gasosa.

\subsection{Mecanismos de Atuação do Hidrogênio}

Como já citado, a literatura acadêmica (Wang, 2009; Chatzidouros el al., 2011; Barnoush, 2011; Robertson et al., 2015) considera os seguintes mecanismos para a atuação do hidrogênio: Teoria da Pressão Interna, Decoesão Reforçada por Hidrogênio (HEDE - Hydrogen Enhanced Decohesion), Plasticidade Localizada Reforçada pelo Hidrogênio (HELP - Hydrogen Enhanced Localized Plasticity) $e$ Fragilização Induzida por Hidretos (HIE - Hydride-Induced Embrittlment). Porém, é fato que não existe um mecanismo universal para explicar a degradação causada pelo hidrogênio. Este efeito é provavelmente causado por uma combinação de vários fatores referentes a mecanismos diferentes (Dayal e Parvathavarthini, 2003; Barnoush, 2011). Sendo assim, para uma abordagem mais realística do fenômeno, deve-se considerar que a fragilização pode ser governada por múltiplos mecanismos, sendo um deles dominante, o que vem proporcionando descobertas as vezes contraditórias. 


\subsubsection{Teoria da Pressão Interna}

Qualquer processo que produza hidrogênio atômico na superfície de um metal pode ocasionar absorção dos átomos para o interior da estrutura cristalina (Chicot; Vianna; Miranda, 2002). A fração de hidrogênio absorvida pelo metal é determinada pela presença de substâncias que reduzem a taxa de combinação de átomos de hidrogênio para sua forma molecular como, por exemplo, sulfeto de hidrogênio $\left(\mathrm{H}_{2} \mathrm{~S}\right)$, impedindo que os átomos de hidrogênio escapem do material na forma de bolha de gás. Como o hidrogênio molecular $\left(\mathrm{H}_{2}\right)$ é um composto de grande diâmetro atômico, quando comparado ao hidrogênio atômico, e não se difunde no interior da estrutura cristalina, este se acumula em armadilhas existentes como lacunas, discordâncias, interfaces entre matriz e partículas de segunda fase, sulfetos, entre outros, resulta no aumento da pressão interna. O aumento da pressão interna em determinadas regiões da estrutura cristalina associada a tensões aplicadas favorece a nucleação e propagação de trincas (Dayal e Parvathavarthini, 2003; Chatzidouros et al., 2011).

A teoria da pressão interna também é conhecida como teoria da redução da energia superficial. Petch e Stables (1952) verificaram que a fragilização está essencialmente ligada à redução da energia superficial causada pela adsorção de hidrogênio molecular nas faces de uma trinca existente. Devido a concentração de tensão na ponta da trinca há uma redução de energia superficial por conta do acúmulo de hidrogênio. Desta forma, ocorre diminuição da tensão de ruptura do material, favorecendo a propagação da trinca. A Equação (65), de Griffiths, descreve matematicamente a redução da energia superficial.

$$
\sigma_{f}=\sqrt{\frac{2 \times E \times \gamma}{\pi \times a}}
$$

na qual,

$\mathrm{E}=$ módulo de elasticidade $[\mathrm{MPa}]$

$\mathrm{a}=$ comprimento da trinca $[\mathrm{mm}]$; 
$\gamma=$ energia superficial $[\mathrm{N} / \mathrm{mm}]$.

\subsubsection{Decoesão Reforçada Pelo Hidrogênio (HEDE)}

Este mecanismo foi proposto por Troiano (1960), posteriormente aprimorado por Oriani (1970). Neste modelo, aplicável para fratura frágeis com micromecanismo de clivagem intergranular, o hidrogênio se acumula dentro da estrutura cristalina e reduz a resistência de ligação coesiva entre os átomos (Barnoush, 2011). O acúmulo de hidrogênio aumenta a distância interatômica entre os átomos, reduzindo sua resistência de coesão como ilustrado na Figura 56.

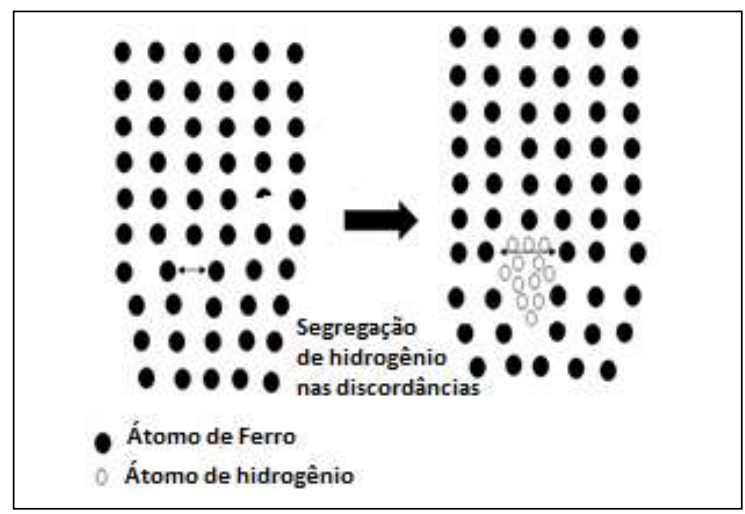

Figura 56 - Aumento da distância entre os átomos de ferro devido ao hidrogênio reduzindo a força de ligação entre os átomos de ferro (Leal, 2007).

A redução da energia de coesão entre os átomos pode ser verificada através da análise da curva de energia de coesão. Quanto maior a profundidade do poço da curva de energia, maior a temperatura de fusão do metal e maior a tensão necessária para separação dos átomos (Figura 57). Estudos de Oriani e colaboradores mostram a curva da energia de coesão na presença de hidrogênio comparada com a curva sem hidrogênio Oriani (1960) apud Stroe (2006). 


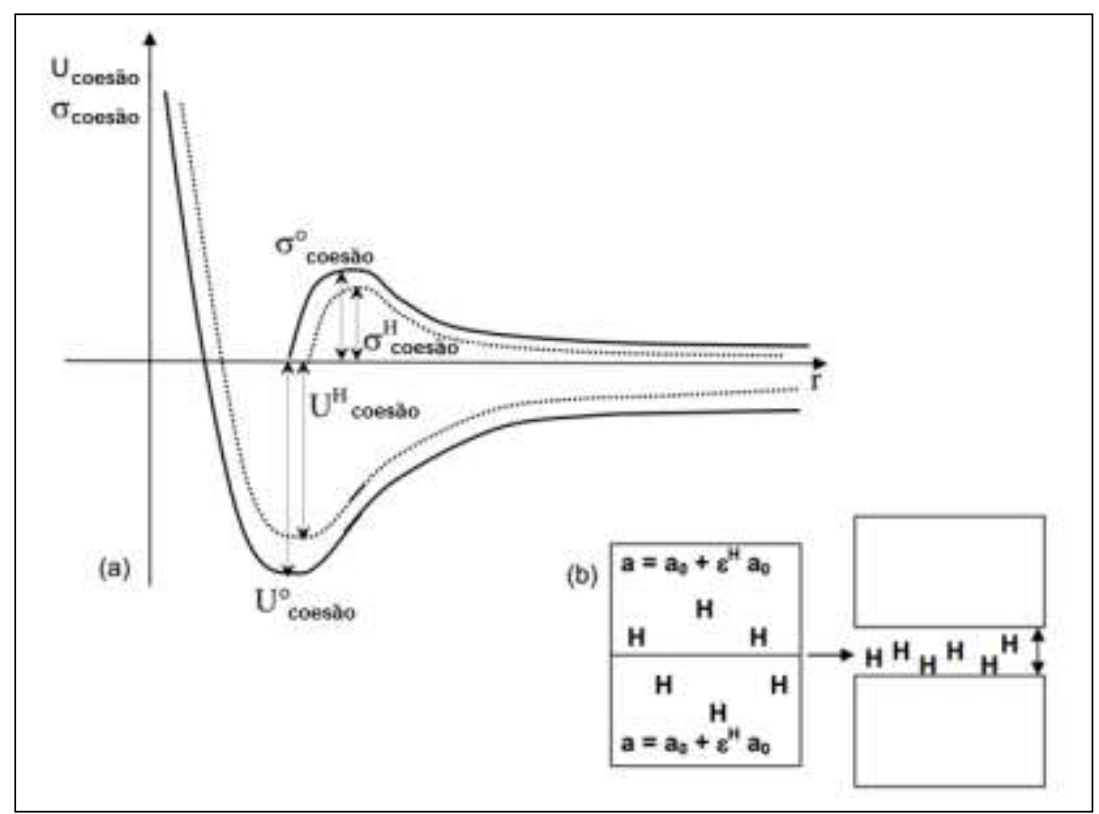

Figura 57 - (a) Redução da energia de coesão entre átomos devido ao hidrogênio $\left(\mathrm{U}^{\mathrm{o}}>\mathrm{U}^{\mathrm{H}}\right)$. (b) Maior distância interatômica com o hidrogênio após deformação da estrutura cristalina (Oriani (1960) apud Stroe, 2006).

Segundo Pressouyre (1980), o mecanismos de aprisionamento é uma forma potente para segregação de hidrogênio. McMahon (2001) avançou os estudos e concluiu que as impurezas atômicas segregadas em contornos de grão também reduziram a resistência de coesão dos metais, contribuindo para o efeito de fragilização do hidrogênio. Em se tratando de componentes trincados, o dano provocado pelo hidrogênio ocorre, como esperado, na ponta da trinca (zona de processamento da fratura), quando as tensões trativas de abertura da ponta da trinca excedem a máxima resistência de coesão já reduzida pela ação do hidrogênio (Oriani (1972) apud Barnoush, 2011).

Um consenso está sendo estabelecido em relação ao mecanismo HEDE. Este vem sendo encontrado nas falhas associadas ao trincamento interno assistido pelo hidrogênio ( IHAC - Internal Hydrogen Assisted Cracking) e ao trincamento assistido pelo hidrogênio contido no ambiente (HEAC - Hidrogen Environment Assisted Cracking) em ligas de alta resistência não formadoras de hidretos por várias razões (Oriani (1990) apud Barnoush, 2011). Entre elas se pode citar:

- grandes concentrações de hidrogênio se acumulam na zona de processamento de fratura devido a altas tensões na ponta da trinca somado ao efeito de aprisionamento do hidrogênio ao longo do caminho até a ponta da trinca (Oriani (1987) apud Barnoush, 2011). 
- experimentos mostram que o aumento da concentração de hidrogênio atua diretamente no raio de arredondamento da ponta da trinca. Estudos realizados com monocristais de $\mathrm{Fe}-3 \% \mathrm{Si}$ mostram que a ponta da trinca tem maior deslocamento de seus flancos, Figura 58, quando tensionadas em ambiente livre de hidrogênio (Vehoff e Rothe, 1983).

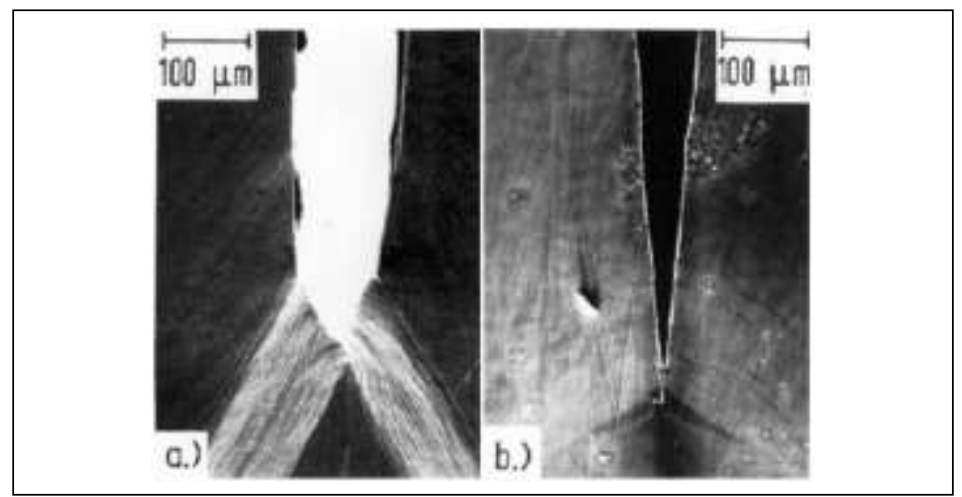

Figura 58 - Maior abertura da ponta da trinca em monocristais de Fe-3\%Si na ausência de hidrogênio (a) e com hidrogênio (b) (Vehoff e Rothe, 1983).

\subsubsection{Plasticidade Localizada Reforçada pelo Hidrogênio (HELP)}

O mecanismo da plasticidade localizada lida com as interações entre o hidrogênio e as discordâncias. Foi primeiramente estabelecido por Beachem (1972). Este sugeriu que o hidrogênio estimula a movimentação suficiente das discordâncias para favorecer a propagação subcrítica de uma trinca com características frágeis em uma escala microscópica (Barnoush, 2011). Segundo Birnbaum e Sofronis (1994) e Ferreira, Robertson e Birnbaum (1998), o modelo HELP propõe que uma solução sólida com hidrogênio impede uma maior interação entre as discordâncias e obstáculos elásticos (átomos de impurezas, contorno de grão, entre outros), facilitando o movimento das discordâncias em níveis mais baixos de tensão. Além do mais, estudos tem verificado que o mecanismo HELP, em alguns casos, resulta em um amaciamento nos materiais que favorece a falha plástica, indo ao contrário da idéia usual de fragilização. Tal efeito contraditório foi explicado por Murakami et al. (2013) que relatou a coexistência de fixação e reforço da mobilidade das discordâncias devido a interação com o hidrogênio. A ocorrência de amaciamento ou endurecimento no material vai estar condicionada a predominâncias de um dos fatores acima. 
Segundo Ferreira, Robertson e Birnbaum (1998) e Murakami, Kanekasi e Mine (2010) a redução da interação entre discordâncias e outros centros elásticos, como átomos de impurezas, pode ser atribuído ao efeito de blindagem provocado pelo hidrogênio, conhecido na literatura por "hydrogen shielding”. Este efeito faz com que os átomos de hidrogênio criem uma atmosfera ao redor das discordâncias, reduzindo assim a tensão microscópica requerida para o movimento das discordâncias.

Evidências experimentais in situ, feitas com auxílio da microscopia eletrônica de transmissão (MET), suportam a idéia que o hidrogênio reforça a mobilidade das discordâncias. Uma consequência direta do efeito shielding causado pelo hidrogênio sobre o comportamento das discordâncias é a redução na distância de separação entre as discordâncias no empilhamento.

Diversos materiais com estrutura cristalina CCC, CFC e hexagonal vem sendo submetidos a análise com MET, onde corpos de prova são tensionados para que se formem empilhamento de discordâncias durante a exposição ao hidrogênio no interior de uma célula ambiental. Observações diretas em resolução suficiente permite verificar a ação do hidrogênio sobre a mobilidade das discordâncias (Robertson, Lillig e Ferreira, 2009).

A etapa seguinte consiste em colocar o corpo de prova deformado em uma célula ambiental, onde é possível manter uma atmosfera gasosa pressurizada de hidrogênio ao redor do corpo de prova para observação direta, em resolução suficiente, da ação do hidrogênio sobre a mobilidade das discordâncias (Robertson, Lillig e Ferreira, 2009).

Em todos os materiais estudados, foi observado que a introdução do hidrogênio ao metal na célula ambiental, aumentou a velocidade das discordâncias móveis e que esta depende diretamente da pressão, ou seja, se a pressão aumenta, a velocidade da discordância também aumenta. Também é possível verificar que quando o hidrogênio é retirado da célula a velocidade da discordância reduz a zero e uma posterior restauração da atmosfera hidrogenada ao redor do corpo de prova é capaz de aumentar novamente a velocidade das discordâncias. A Figura 59 mostra o empilhamento de discordâncias contra um contorno de grão, obtido com observação experimental de amostras de aço inoxidável AISI 310S, ilustra o exposto acima. 

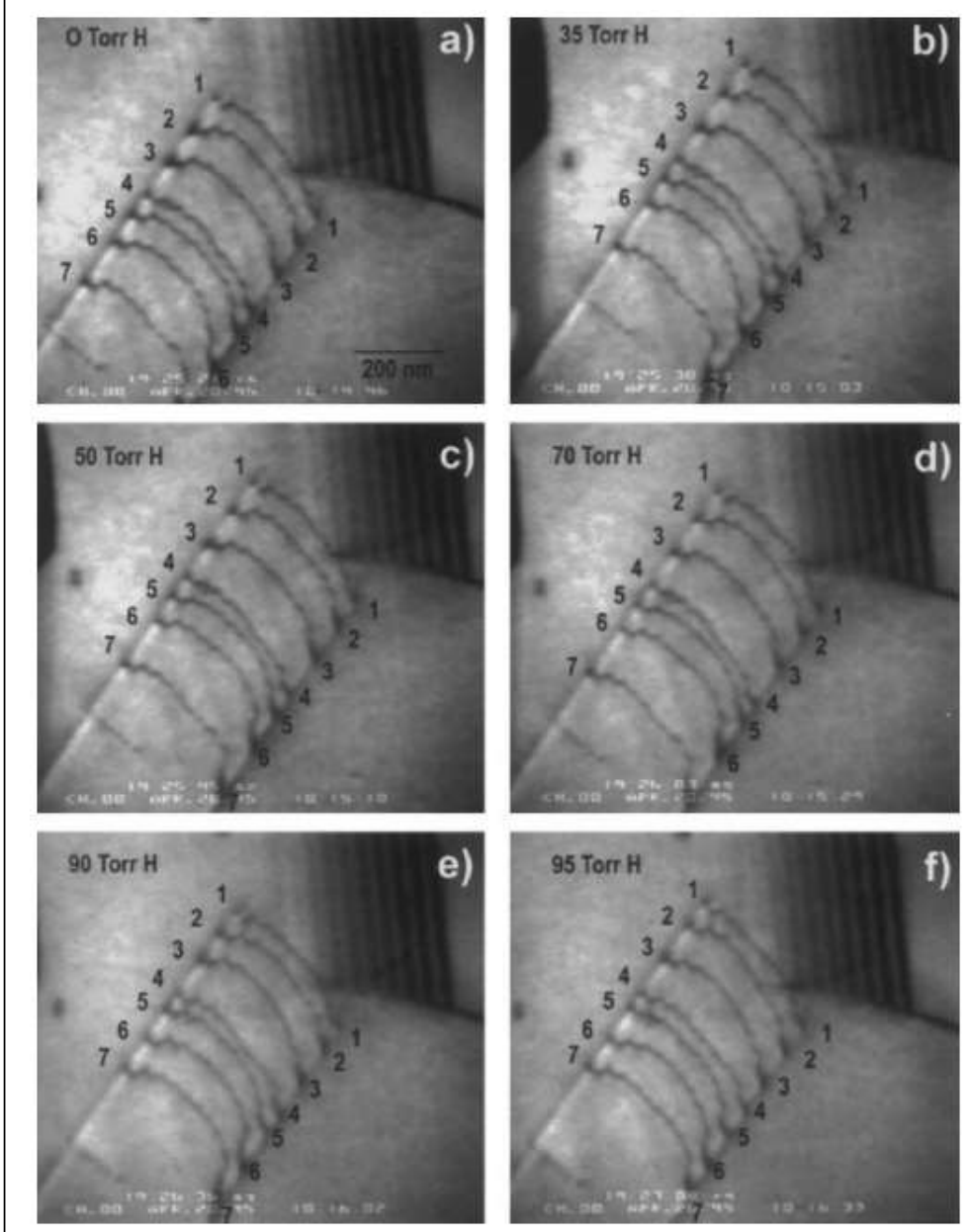

Figura 59 - Visualização do movimento das discordâncias com o aumento da pressão de hidrogênio por MET (Ferreira, Robertson e Birnbaum, 1998).

A imagem (a) mostra as discordâncias em equilíbrio no corpo de prova deformado em vácuo, ou seja, sem hidrogênio. Sob a condição de carregamento constante, o hidrogênio foi introduzido gradativamente na célula (imagens (b) a (f) a pressão que variou de 35 Torr a 95 Torr (4,7 kPa a 12,7 kPa). As imagens (b) a (f) mostram o maior movimento das discordâncias em direção a barreira contorno de grão. Esta consequência pode ser melhor visualizada através da imagem composta ilustrada na Figura 60, onde as discordâncias na condição não hidrogenadas são sobrepostas às discordâncias na condição de maior pressão de hidrogênio. A análise da imagem mostra claramente que a distância entre discordâncias foi reduzida com a introdução do hidrogênio na célula de teste. 


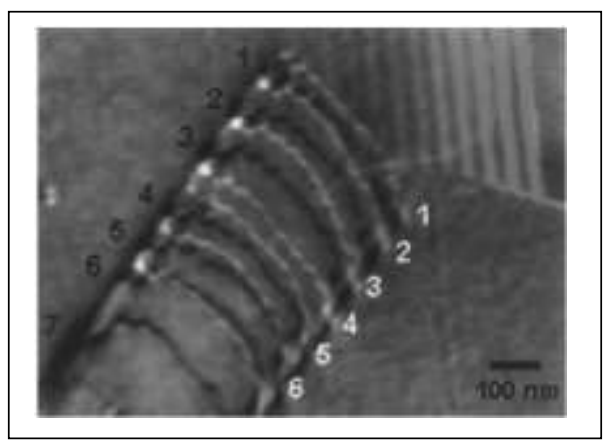

Figura 60 - Sobreposição de discordâncias nas condições com hidrogênio (brancas) e sem hidrogênio (pretas) (Ferreira, Robertson e Birnbaum, 1998).

Segundo Gavriljuk, Shivanyuk e Shanina (2005), a redução na distância de separação entre as discordâncias no empilhamento está relacionada a existência de uma maior densidade de elétrons livres ao redor das discordâncias, que reduz o módulo de cisalhamento do material, e consequentemente a tensão de cisalhamento crítica necessária para o movimento das discordâncias.

Ainda em relação à interação de hidrogênio e discordâncias, existe um consenso geral que a fragilização provocada pelo hidrogênio que resulta na degradação das propriedades mecânicas dos materiais metálicos deve ser relacionada ao movimento de tais defeitos lineares. Porém este consenso é conflitante, já que há relatos que a interação hidrogênio - discordâncias é responsável pela ocorrência do amaciamento (softening) microscópico devido à redução na interação energética entre as discordâncias (Chateau, Delafosse e Magnin, 2002).

Matsui, Kimura e Moriya (1979) verificaram inicialmente que o hidrogenio possui um efeito de fixação sobre as discordâncias, conhecido como pinning effect. $\mathrm{O}$ aprisionamento do hidrogênio no núcleo das discordâncias aumenta a tensão crítica de cisalhamento para o deslizamento e aumenta a resistência dos materiais. Quanto maior a concentração de hidrogênio, mais forte é o efeito de fixação das discordâncias. A Figura 61 explica o efeito de fixação do hidrogênio.

Murakami, Kanezaki e Mine (2010) relatam que a liberação das discordâncias ocorre quando a tensão de cisalhamento aplicada ao material é maior que a tensão de cisalhamento crítica necessária ao movimento das discordâncias, neste momento já reduzida devido a ação do hidrogênio. 


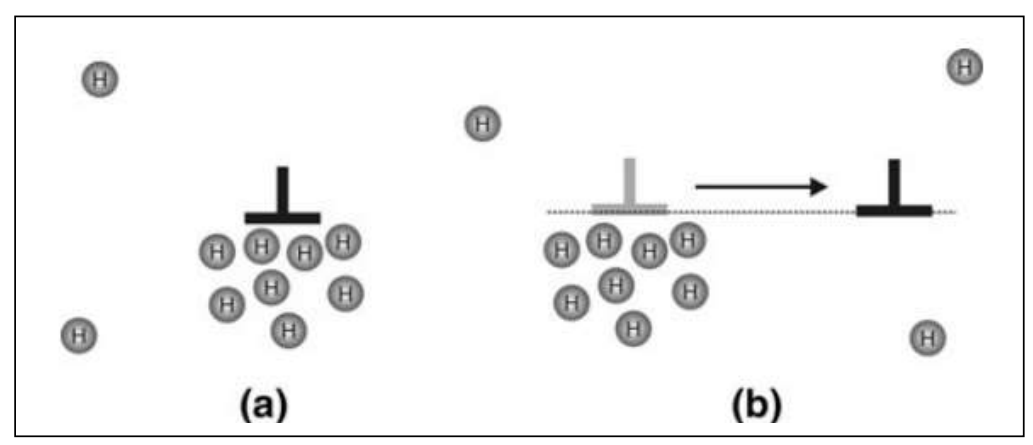

Figura 61 - Efeito de fixação (pinning effect) provocado pela atmosfera de hidrogênio ao redor das discordâncias (a) e liberação das discordâncias. deixando átomos de hidrogênio (Murakami, Kanezaki e Mine, 2010).

Estudos anteriores não tem sido capazes de explicar totalmente os efeitos do hidrogênio sobre a fragilização, devido aos mesmos terem como base apenas ensaios de tração. Por esta razão, Murakami, Kanezaki e Mine (2010) realizou estudos baseados em ensaios de fadiga com aços inoxidáveis (304 e 316L) e aços a base Cr-Mo.

O hidrogênio influência no tamanho da sua zona plástica ao redor da ponta da trinca de fadiga e esta é menor que a zona plástica à frente da ponta da trinca na ausência do hidrogênio.

Em seus estudos, Murakami (2010) observou um número significativo de bandas de deslizamento nos grãos ao redor da trinca de fadiga nas amostras ensaiadas sem hidrogênio. Em compensação, nas amostras ensaiadas na condição hidrogenada, bandas de deslizamento foram observadas apenas nas vizinhanças da trinca de fadiga, indicando que o hidrogênio aumentou a resistência do material ao deslizamento das discordâncias nos grãos mais afastados da ponta da trinca. A Figura 62 mostra as bandas de deslizamento observadas nos grãos mais próximos e mais afastados da trinca de fadiga. 


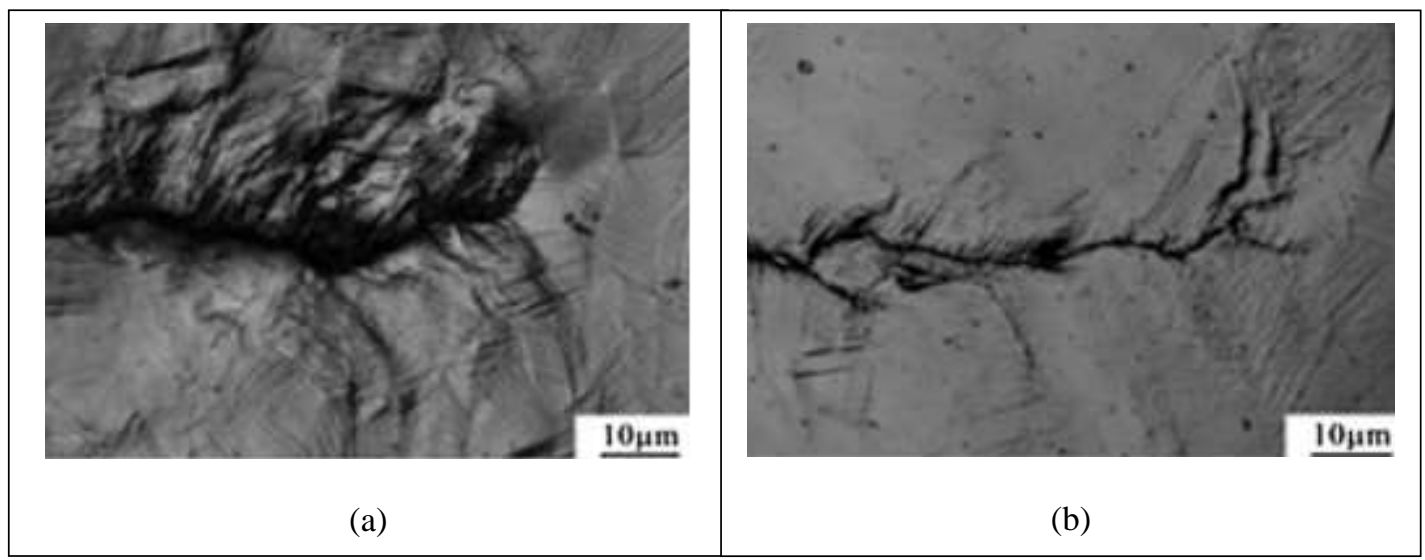

Figura 62 - Observação macroscópica em aço inoxidável 304. (a) Bandas de deslizamento ao redor da trinca de fadiga na condição não hidrogenada. (b) Bandas de deslizamento apenas nas proximidades da trinca de fadiga na presença do hidrogênio (Murakami, Kanezaki e Mine, 2010).

Nos grãos mais afastados da trinca de fadiga, situados a uma distância de 0,2 $\mathrm{mm}$ da ponta da trinca, não foram evidenciados um número considerável de bandas de deslizamento, tanto na condição hidrogenada quanto na condição não hidrogenada (Figura 63).

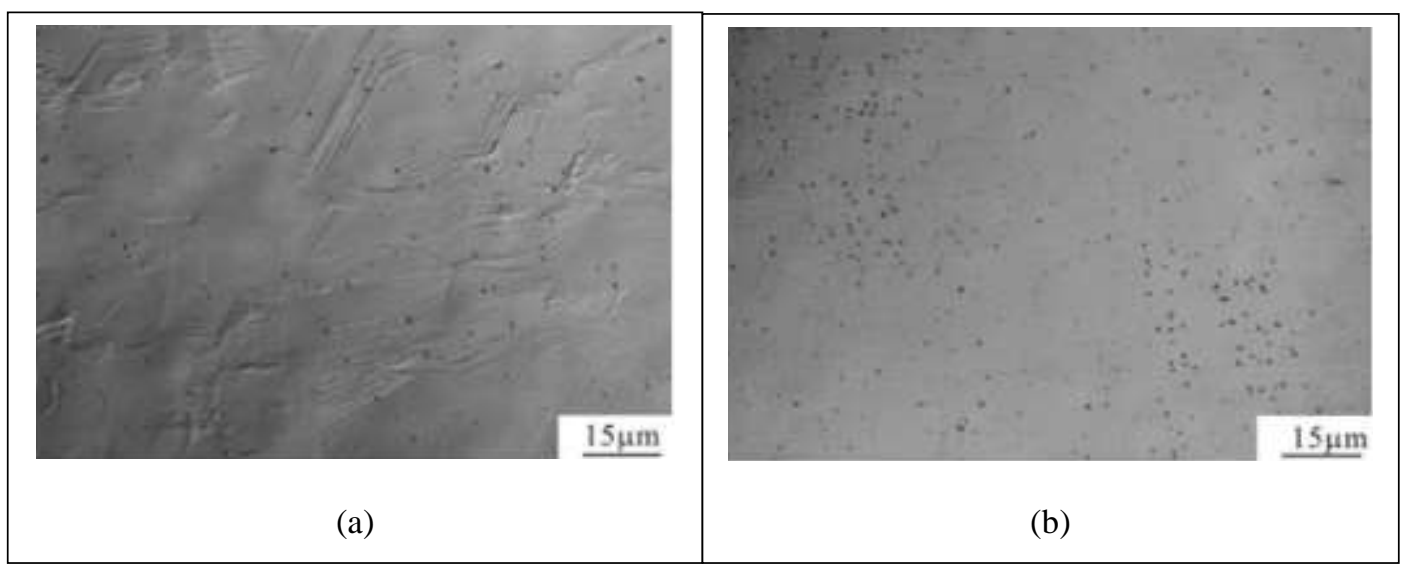

Figura 63 - Baixa quantidade de banda de deslizamento em grãos mais afastados da trinca de fadiga em amostras de aço inoxidável 304 na condição não hidrogenada (a) e com hidrogênio (b) (Murakami, Kanezaki e Mine, 2010).

Em função do comportamento das bandas de deslizamento nos corpos de prova de aço inoxidável 304 se verifica a coexistência dos efeitos de amaciamento vs endurecimento nos grãos do material. O hidrogênio aprisionado no núcleo das discordâncias aumenta a tensão de cisalhamento crítica necessária ao seu movimento. Esta condição causa a fixação das discordâncias (pinning effect) e é visualizado nos grãos mais afastados da ponta da trinca com menos bandas de deslizamento (endurecimento). Porém, com a maior de densidade de elétrons 
livres ao redor das discordâncias, provenientes do hidrogênio, há uma redução na tensão de cisalhamento crítica necessária ao movimento das discordâncias. Como os grãos mais próximos da ponta da trinca são submetidos a uma intensificação de tensões superiores a tensão de cisalhamento crítica é possível o desprendimento das discordâncias e o aumento de sua mobilidade (deformação plástica). Nestes grãos é verificado o amaciamento (Murakami, 2010), indicando a existência do mecanismo de plasticidade localizada. A coexistência do amaciamento e endurecimento é ilustrado na Figura 64.

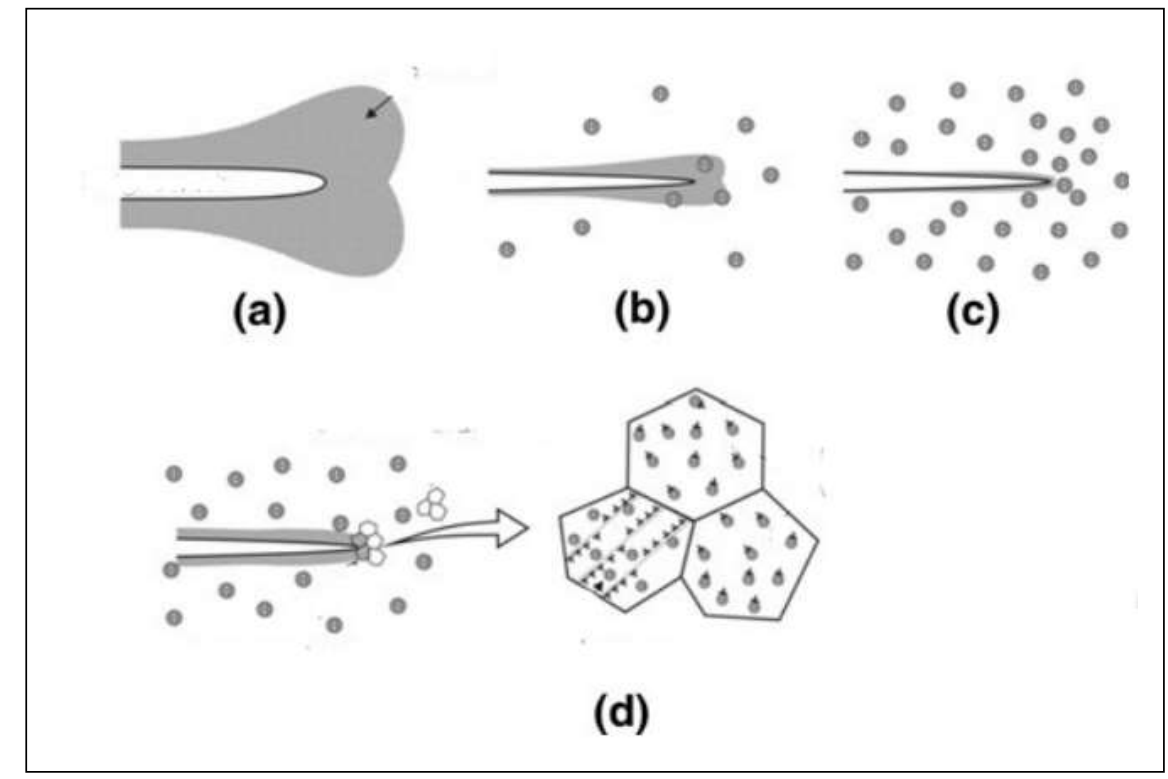

Figura 64 - Amaciamento e endurecimento em grãos hidrogenados de aço. (a), (b) e (c): concentração de hidrogênio na ponta da trinca de fadiga. (d): grãos amaciados, próximos a ponta da trinca de fadiga e grãos endurecidos, afastados da ponta da trinca (Murakami, 2010).

\subsubsection{Fragilização Induzida pela Formação de Hidretos (HIE)}

Alguns sistemas metálicos tem mostrado susceptibilidade a fragilização pelo hidrogênio devido a formação de hidretos. Segundo Eliezer, Tal-Gutelmacher e Boellinghaus (2005), os hidretos metálicos são compostos formados pela combinação direta de uma liga ou metal, pertencentes aos grupos IVB e VB da tabela periódica (Ti, Zr, Nb, V, Ta, Rf, e ligas), com o hidrogênio conforme a Equação (66), (Castro, 2003):

$$
M+\frac{x}{2} H_{2} \rightarrow M H_{x}
$$


A formação de hidretos está relacionada a solubilidade do hidrogênio no metal em questão. Louthan Jr. (2008) reporta que a solubilidade em peso dos metais formadores de hidretos é pequena. Titânio dissolve $0,2 \%$ de hidrogênio quando exposto a pressão de 1 atm a $300{ }^{\circ} \mathrm{C}$, ligas de zircônio dissolve 0,07\% quando exposto a pressão de 1 atm a $550{ }^{\circ} \mathrm{C}$. Quando a concentração de hidrogênio no material excede o limite de solubilidade, há a precipitação dos hidretos metálicos.

Os hidretos metálicos são compostos frágeis, de baixa densidade cuja presença deteriora a ductilidade da liga. Adicionalmente tensões aplicadas e/ou residuais podem interagir com as tensões associadas a expansão volumétrica causada pela precipitação do hidreto e afetam a orientação e distribuição dos hidretos.

A degradação favorecida pelos hidretos podem se manifestar de várias formas. Hidretos pequenos podem agir como sítios iniciadores de microcavidades favorecendo o processo de coalescencia das mesmas e reduzindo a ductilidade da liga em condições de carregamentos trativos.

Um hidreto pode ser um facilitador para a nucleação de uma trinca pelo mecanismo de crescimento cooperativo de hidretos. Observações realizadas em microscopia eletrônica de transmissão em ligas de titânio mostram que um hidreto não cresce por si só. Por um processo autocatalítico, este é auxiliado pelo crescimento de hidretos menores que juntos formam o hidreto maior (Teter, Robertson e Birnbaum, 2001).

A precipitação de um hidreto estável na microestrutura de um material resulta em um campo de tensões e a fratura deste hidreto por clivagem produz uma trinca na matriz do material. A intensificação de tensão na ponta da trinca induz uma deformação plástica e dependendo da quantidade, orientação e distribuição dos hidretos se pode ter uma redução na ductilidade da liga (Louthan Jr., 2008).

Em situações onde o componente hidrogenado é colocado em operação, as tensões aplicadas e/ou residuais junto com gradientes térmicos associados às condições de operação podem causar uma redistribuição do hidrogênio que vai se acumular nas regiões da ponta da trinca e gerar um hidreto. Como o hidreto é um 
composto frágil, este vai fraturar, causando um alívio de tensões. Com o alívio da tensão no hidreto, a tensão agora vai se intensificar na ponta da nova trinca e o hidrogênio vai se difundir para as novas regiões submetidas a tensão.

A sequência acúmulo do hidrogênio-precipitação de hidretos e fratura vai se repetir até a trinca alcançar seu tamanho crítico e levar o componente a fratura.

\subsection{Influência dos parâmetros metalúrgicos na fratura assistida pelo hidrogênio}

Sabe-se que a microestrutura de uma liga metálica é dependente dos elementos de liga presentes na composição química, assim como seus teores em peso e da variáveis do tratamento térmico ao qual o material foi submetido (temperatura de aquecimento, tempo de encharcamento e taxa de resfriamento até a temperatura ambiente). As diversas opções de tratamentos térmicos associados a diversas combinações de ciclos térmicos e taxas de resfriamento possibilita a obtenção de diversas microestruturas e consequentemente uma variedade de propriedades mecânicas para um mesma liga metálica.

Em relação à susceptibilidade à fragilização pelo hidrogênio, é de conhecimento que a influência do hidrogênio sobre as propriedades mecânicas e de comportamento à fratura é controlada por sua difusão na rede cristalina e por sua interação com os sítios aprisionadores existentes na microestrutura (Huang et al., 2010). De uma forma geral, estudos anteriores relatam que a fragilização por hidrogênio aumenta sua intensidade com o aumento da resistência mecânica do material. Este fato foi verificado para materiais com limite de resistência mecânica superiores a $1000 \mathrm{MPa}$. Porém para limites de resistência mecânica entre 400 e $1000 \mathrm{MPa}$ não foi verificado a fragilização por hidrogênio. Sendo assim, conclui-se que o motivo para tal fato está associado a microestrutura com melhor resistência à ação do hidrogênio.

A variedade de alterações microestruturais em aços de baixa liga é significativa e dependendo do tratamento térmico realizado e da composição da liga metálica, é possível obter praticamente todas as microestruturas, ou seja, ferrita, perlita, ferrita/perlita, bainita, ferrita/bainita e martensita (Michnler e 
Naumann, 2010; Park et al., 2008). Além do mais a presença de elementos microligantes tais como manganês $(\mathrm{Mn})$, enxofre $(\mathrm{S})$, níquel (Ni), titânio (Ti), nióbio $(\mathrm{Nb})$, vanádio $(\mathrm{V})$, entre outros contribui para a formação de inclusões não metálicas e precipitados que aumentam a interação do hidrogênio com a microestrutura.

As características físicas dos constituintes de uma microestrutura (formato das fases, inclusões, entre outros), assim como o nível de segregação de impurezas que contribui para a formação de bandeamento microestrutural tendem a influenciar a susceptibilidade à ação prejudicial do hidrogênio.

Apesar dos avanços nos processos de fabricação do aço, é difícil garantir uma microestrutura livre de inclusões não metálicas. É conhecido que a quantidade, o tamanho e o formato das inclusões interfere de maneira significativa no processo de trincamento dos aços, assim como em sua resistência à fragilização pelo $\mathrm{H}$, pois as inclusões são sítios aprisionadores de hidrogênio, que ao se acumularem faz com que as inclusões se tornem sítios preferenciais para a nucleação de trincas (Asahi, 1989).

Em relação a indústria de exploração e produção de petróleo e gás, uma inclusão familiar é o sulfeto de manganês $(\mathrm{MnS})$ devido a altos teores de $\mathrm{H}_{2} \mathrm{~S}$ existentes nas jazidas exploradas. Tal inclusão pode ser encontrada na forma esférica ou na forma alongada. A forma esférica do $\mathrm{MnS}$ é atribuído ao efeito da adição de cálcio $(\mathrm{Ca})$, responsável pelo processo de globulização, evitando a sua forma original, ou seja, alongada e aprimorando a resistência a fragilização por $\mathrm{H}$ (Hallen; González; Hernández; Hernández-Lago, 2013).

A fragilização dos aços está associado a diversos motivos. Entre estes pode-se citar a existência de inclusões e precipitados na microestrutura. Desta forma, é importante conhecer a composição química do aço, uma vez que os elementos presentes determina as características microestruturais do aço. A seguir será abordado a influência dos principais elementos de liga presentes nos aços API.

Carbono (C)

Oferece a melhor custo/benefício para aumento da resistência à tração dos aços. Em relação a outros mecanismos de endurecimento é o menos vantajoso devido às 
reduções indesejadas de ductilidade e tenacidade. No que se refere a soldabilidade, o carbono deve ser mantido nos menores teores possíveis para manutenção de um baixo carbono equivalente e redução da ocorrência de trinca a frio na zona termicamente afetada (ZTA) da junta soldada e soldabilidade devido ao aumento do carbono equivalente. Em se tratando do comportamento mecânico em baixas temperaturas, aços com baixos teores de carbono tem maiores tenacidade e ductilidade em condições de temperatura próxima da transição dúctil-frágil (Hulka, 2001)

Sabe-se que os aços de alta resistência e baixa liga (ARBL) são susceptíveis a falhas em ambientes ricos em $\mathrm{H}_{2} \mathrm{~S}$, devido a dissociação do hidrogênio para a forma atômica.

\section{$\underline{\text { Manganês (Mn) }}$}

O manganês é um dos elementos mais utilizados para aumento de dureza através do mecanismo por solução sólida nos aços ARBL para dutos. Teores reduzidos de manganês, aproximadamente $0,3 \%$, são desejáveis para se evitar segregações centrais e inclusões alongadas de MnS (Williams, 2007). Recentemente tem-se aumentado o teor de manganês em consequência da redução do teor de carbono, já que maiores relações $\mathrm{Mn} / \mathrm{C}$ promove aumento da tenacidade considerando um mesmo limite de resistência mecânica (Williams, 2007).

\section{$\underline{\text { Silício }(\mathrm{Si})}$}

Elemento com a função de desoxidar o aço, favorecendo de maneira significativa o limite de escoamento e a resistência à corrosão sob tensão, fazendo com que inclusões alongadas se tornem globulares.

\section{Enxofre (S)}

O enxofre é uma impureza altamente prejudicial as propriedades dos aços. Por esta razão seus teores são rigorosamente controlado na composição química 
do aços, não ultrapassando valores de $0,05 \%$. De uma forma geral, o enxofre presente no aço é oriunda do processo de fabricação e sua quantidade normalmente encontrada na sua composição química varia entre $0,005 \%$ e $0,010 \%$.

No caso de situações onde o aço está exposto a fontes de hidrogênio, o enxofre se combina ao hidrogênio, formando o sulfeto de hidrogênio $\left(\mathrm{H}_{2} \mathrm{~S}\right)$ que é altamente fragilizante (Santos, 2011). Por esta razão, é necessário o controle do teor de enxofre para níveis bem baixos, menores que 0,002\%, para se evitar a formação de inclusões alongadas de sulfeto de manganês (MnS), que são locais preferenciais para iniciação de trincas (Domizzi; Anteri; Overejo-Garcia, 2001).

\section{Fósforo}

A presença de fósforo $(\mathrm{P})$ aumenta o limite de resistência à tração, favorece a resistência à corrosão e a dureza do material, prejudicando, contudo a ductibilidade e a soldabilidade. A formação de fases duras é promovida pela segregação e o conteúdo de fósforo tem influencia sobre o grau de segregação em aços produzidos por lingotamento contínuo. Por isso o conteúdo de fósforo deve ser controlado para os mínimos valores possíveis (inferiores a 0,015\%), e desta forma melhorar a resistência a fragilização pelo hidrogênio.

\section{$\underline{\text { Níquel }}$}

Elemento atuante para estabilização da fase austenita após a têmpera. Em condições favoráveis de endurecibilidade do aço, a austenita durante o revenimento se transformará em martensita. Durante o revenimento é esperado a decomposição da austenita retida, porém a formação de regiões de elevada dureza (fase martensítica) diminui a resistência ao trincamento por sulfeto induzido por tensão. Sendo assim limita-se os valores de níquel (Ni) a teores inferiores a $1 \%$ para aços de baixa liga em razão da relação entre o limite de escoamento e a tensão limite $\sigma_{\text {th }}$ (Masakatsu; Asahi; Marshall, 1994). 


\section{Bandeamento}

O bandeamento da microestrutura é evidenciado quando se observa bandas alternadas compostas de microestruturas diferentes paralelas à direção de laminação. Este fenômeno é especialmente observado em aços de baixo carbono. A Figura 65 mostra uma microestrutura bandeada composta por ferrita e perlita.

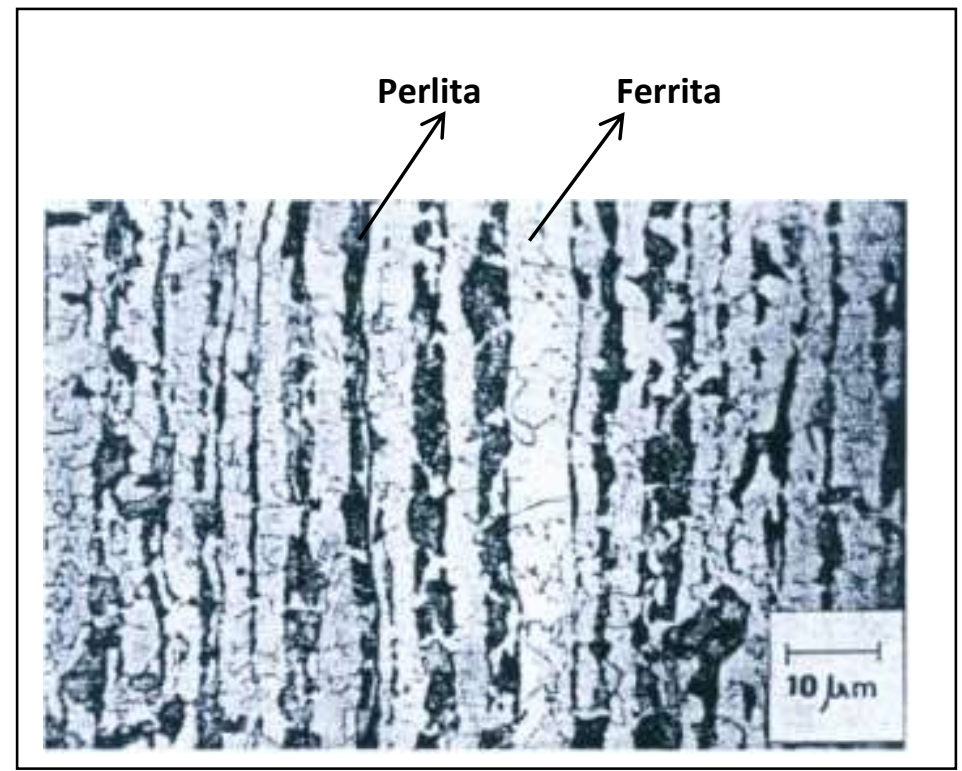

Figura 65 - Microestrutura bandeada de ferrita e perlita em aço carbono - manganês (SarKir Bor, 1991).

Durante a solidificação do material, alguns elementos de liga segregam-se no avanço da frente de solidificação devido a sua menor solubilidade na fase sólida. Como exemplo de elementos encontrados em regiões de segregação se pode citar o enxofre $(\mathrm{S})$, fósforo $(\mathrm{P})$, silício $(\mathrm{Si})$, manganês $(\mathrm{Mn})$, níquel $(\mathrm{Ni})$, entre outros. As bandas são formadas durante a solidificação do lingotamento original devido a segregação de um ou mais elementos de liga $(\mathrm{Cr}, \mathrm{Si}, \mathrm{Mn})$, que surge pela diferença significativa de temperatura entre a fase líquida e sólida.

O controle da composição química dos aços tem como objetivo proporcionar maior homogeneidade microestrutural e melhorar as propriedades mecânicas da liga metálica. Como exemplo de microestrutura bandeada se pode citar a ferrita-perlita em aços de baixo e médio carbono forjados e laminados a quente (Geels, 2007; Offerman, et al., 2002). 
A influência microestrutural na susceptibilidade dos aço à fragilização pelo hidrogênio tem sido exaustivamente pesquisado.

Park et al. (2008) e Beidokhti, Dolati e Koukabi (2009) em estudos realizados com aços API X65 e X70 respectivamente, e submetidos a ensaios de permeação de hidrogênio e comprovaram que a ferrita acicular é uma microestrutura desejada para aços de alta resistência destinados a fabricação de dutos, devido a sua elevada resistência ao trincamento sob tensão por sulfeto e ao trincamento induzido pelo hidrogênio. Dados experimentais confirmaram que a ferrita-bainita é mais vulnerável a ação do hidrogênio do que a ferrita acicular, pois as trincas encontradas nesta microestrutura possuem maior área, ou seja, foram criadas um maior número de novas superfícies durante o trincamento, contribuindo para redução da resistência ao trincamento assistido pelo hidrogênio (HIC). O aumento da área da trinca em microestruturas ferríticos-bainíticas está associado a sua maior dureza que favorece a propagação da trinca. Desta forma, a redução do trincamento assistido pelo hidrogênio pode ser obtido por uma transformação microestrutural controlada da austenita para ferrita-ferrita acicular em vez de ferrita-bainita.

Arafin e Szpunar (2011) estudaram o efeito da microestrutura bainitica nos aços para dutos. Aços API X80 e API X100 de microestruturas ferrítico-bainítica e bainítica, respectivamente, foram submetidos a ensaios de tração a baixa taxa de deformação em atmosfera composta por solução hidrogenada com potenciais catódicos. Fractografias mostraram que a microestrutura bainítica (API X100) apresentou maior susceptibilidade ao HIC do que a ferrítico-bainítica (API X80), apesar da quantidade de hidrogênio difusível no X80 ser maior do que no X100.

A maior susceptibilidade do aço API X100 está associada a característica da microestrutura junto com a eficiência de aprisionamento de átomos de hidrogênio. A microestrutura predominantemente bainítica com contornos na forma de ripas que agem como sítios aprisionadores de hidrogênio.

O acúmulo de hidrogênio ao longo dos contornos induziram a separação das ripas de bainita e consequentemente a iniciação de trincas nestes locais quando a concentração de hidrogênio alcança um valor crítico dependente do nível de potencial catódico, tempo de exposição, dimensões do contorno em ripas e capacidade de aprisionamento. 
A boa resistência da microestrutura composta em sua grande parte por ferrita acicular também foi constatado por Ramírez et al (2008). Corpos de prova em aço C-Mn submetido a ensaios de tração a baixa taxa de deformação em atmosfera hidrogenada apresentou maior redução de área transversal, o que fez concluir que esta microestrutura possui maior resistência ao trincamento sob tensão por sulfeto, quando comparado com outra microestrutura testada (martensítica), devido a menor captação de hidrogênio pelos sítios aprisionadores existentes.

Em se tratando de microestruturas martensíticas, estas são significativamente encontradas nos aços designados para construção de linhas dutoviárias, na condição revenida. A susceptibilidade de aços martensíticos ao trincamento em ambientes compostos por atmosfera hidrogenada é função da temperatura de revenimento.

De uma forma geral a susceptibilidade a ação degradante do hidrogênio diminui com o aumento da temperatura de revenimento (Coleman; Liu, 2007). Microestruturas martensíticas oriundas de aços adicionados com Vanádio (V) são mais propícios aos efeitos do hidrogênio quando são revenidos em temperaturas mais baixas. Ensaios de tração realizados por Asahi, Hirakami e Yamasaki (2003) em corpos de provas entalhados, previamente carregados com hidrogênio e revenidos em temperaturas diferentes, mostraram que a concentração crítica de hidrogênio, ou seja o máximo de hidrogênio antes da falha do aço revenido em $325{ }^{\circ} \mathrm{C}$ foi menor do que para o aço revenido em $625{ }^{\circ} \mathrm{C}$. O revenimento em temperaturas mais altas nos aços com adição de Vanádio (V) permite a precipitação de carbonetos de Vanádio, que age como sítio aprisionador de hidrogênio e contribui para redução do fluxo de hidrogênio difusível na rede.

Carneiro, Ratnapuli e Lins (2003), apesar de não estudar o efeito da temperatura de revenimento sobre a susceptibilidade ao trincamento induzido pelo hidrogenio, comprovou que a microestrutura martensítica revenida possui maior resistência quando comparados a microestruturas ferrítico perlíticas.

Um aspecto interessante sobre a influência microestrutural foi verificado por Michler e Naumann (2010). Aços comerciais de diversas composições químicas submetidos a diferentes tratamentos térmicos foram tracionados em atmosfera hidrogenada pressurizada a $10 \mathrm{MPa}$ e em atmosfera de laboratório (ar livre). Todos os aços testados apresentaram uma significativa redução de área, exceto o 
aço submetido a endurecimento por precipitação. As curvas tensão vs deformação dos dois testes (ar e atmosfera hidrogenada) da Figura 66 elucidam o exposto acima.

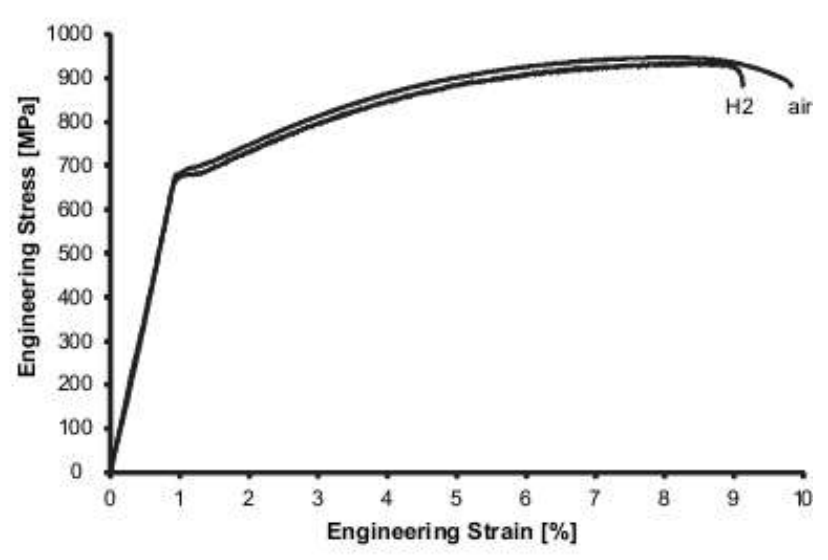

Figura 66 - Curvas tensão vs deformação para material ensaiado ao ar e em atmosfera hidrogenada (Micheler e Naumann, 2010).

A ausência de redução mensurável de área da seção transversal está relacionada com a presença de finos precipitados homogeneamente distribuídos na microestrutura ferrítico-perlítica. Como a ação do hidrogênio sobre as propriedades mecânicas dos aços é controlada por sua difusão na rede cristalina e interação com os sítios aprisionadores da rede, os precipitados na microestrutura possivelmente estão agindo como sítios aprisionadores irreversíveis do hidrogênio. A alta energia de ligação com o forte aprisionamento hidrogênio preso devido à alta energia de ligação do precipitado, a fluxo de hidrogênio difusível é reduzido, diminuindo a fragilização.

\subsection{Efeito do Hidrogênio nas Propriedades Mecânicas dos Aços}

A influência do hidrogênio sobre o comportamento mecânico dos materiais metálicos, principalmente os aços, tem sido extensivamente investigadas ao longo dos anos por diversos pesquisadores (Tiwari et al., 2000; Hardie, Charles e Lopez, 2006; Wang, Akiyama e Tsuzaki, 2007; Dong et al, 2009; Hardianfard, 2009; Mansour, Alfantazi e El-boujdaini, 2009; Moro et al.,2010). No que se 
refere ao efeito fragilizante produzido pelo hidrogênio, a redução de ductilidade e da tensão de fratura do material são bem conhecidos.

\subsubsection{Influência sobre as propriedades trativas}

Devido a maior viabilidade técnica, a maioria dos estudos relatados na literatura sobre a degradação das propriedades mecânicas causado pelo hidrogênio é oriunda de ensaios de tração uniaxial. Isto acaba gerando resultados um pouco controversos quando se estuda a ação do hidrogênio por outras técnicas experimentais, tais como ensaios de fadiga e ensaios de tenacidade à fratura. Sendo assim, é apresentado a seguir alguns resultados obtidos pelas técnicas experimentais citadas.

Os efeitos do hidrogênio sobre as propriedades mecânicas do material podem ser avaliados com corpos de prova liso ou entalhados, usinado ou polido. Tiwari et al. (2000) demonstrou a partir de corpos de prova entalhados e polidos confeccionados em aços de baixo carbono e aços maraging, $0,12 \% \mathrm{C}$ e $0,005 \% \mathrm{C}$, respectivamente, a influência do hidrogênio sobre as propriedades mecânicas trativas dos materiais mencionados.

A exposição dos aços a atmosfera de hidrogênio foi feita através de um carregamento eletrolítico, por 13, 22 e 44 h onde uma extremidade do corpo de prova atua como catodo e uma célula de platina é o anodo da célula eletrolítica. Para a carga de hidrogênio foi utilizada uma solução de $1 \%$ de $\mathrm{NaOH}$ com $1 \mathrm{~g} / \mathrm{l}$ de trióxido arsênico $\left(\mathrm{As}_{2} \mathrm{O}_{3}\right)$. Após a carga de hidrogênio, o corpo de prova é submetido a uma carga constante por um período de $24 \mathrm{~h}$, para posterior ensaio de tração em baixa taxa de deformação $\left(10^{-5} \mathrm{~s}^{-1}\right)$.

Pelas curvas tensão $v s$ deformação para material com e sem hidrogênio é claro que a influência do hidrogênio sobre o comportamento mecânico dos aços. A Figura 67 ilustra as curvas tensão $v s$ deformação do aço carbono e do aço maraging com e sem hidrogênio, onde é possivel verificar que longos tempos de exposição ao hidrogênio ( $44 \mathrm{~h}$ ) causaram redução na ductilidade, melhora na resistência mecânica, aumento do módulo de elasticidade. 


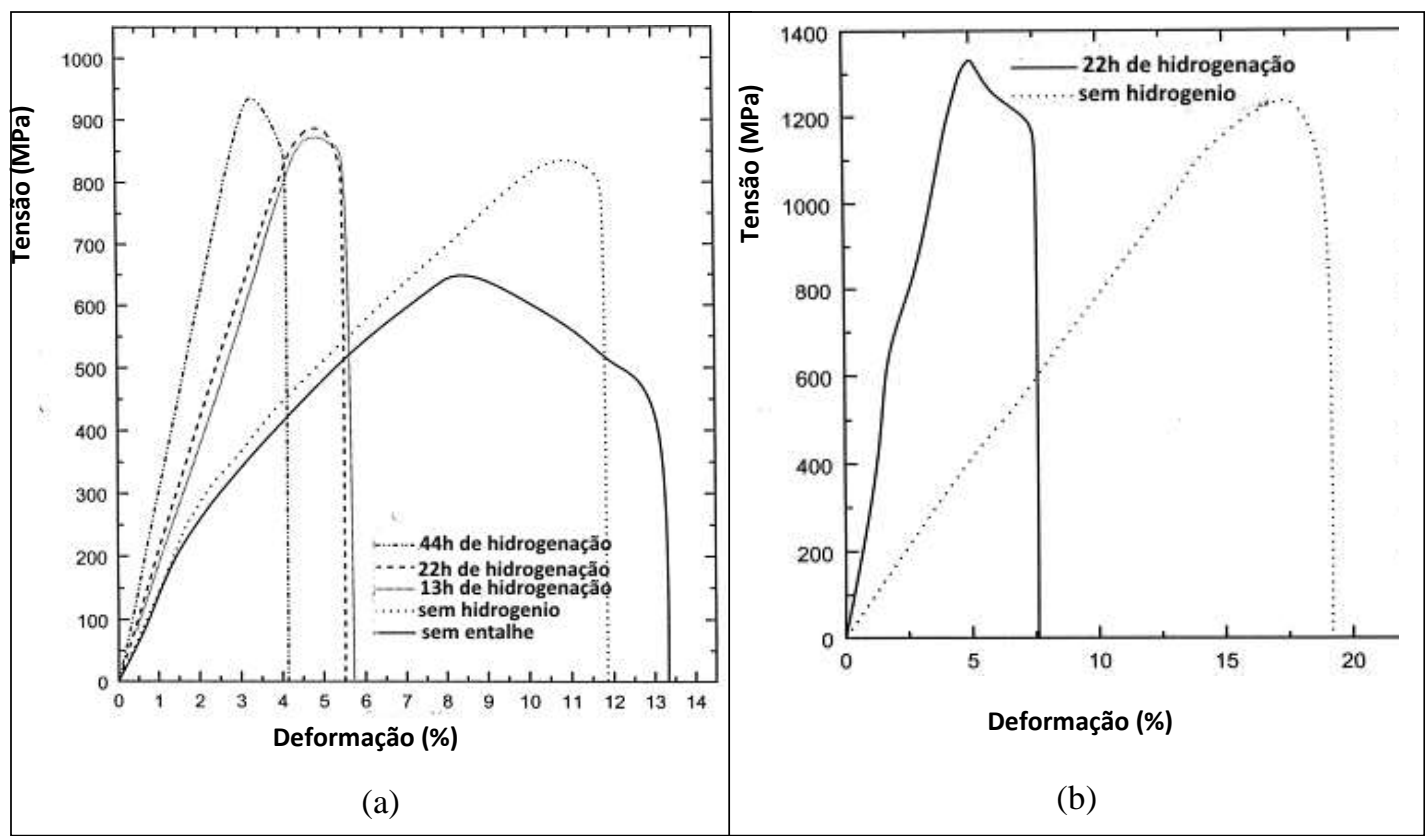

Figura 67 - (a) Curvas tensão vs deformação de aço de baixo carbono (a) e de aço maraging (b) com e sem hidrogênio (Tiwari, et al., 2000).

A partir dos resultados dos aços de baixo carbono se confirma que a presença do entalhe (estado triaxial de tensões) associado a longos tempos de carga intensificam o efeito do hidrogênio. A Tabela 4 mostra os resultados.

Tabela 4 - Variação das propriedades mecânicas do aço carbono na presença de concentrador de tensões e hidrogênio (Tiwari et al., 2000).

\begin{tabular}{|l|c|c|c|}
\hline \multicolumn{1}{|c|}{ Corpo de Prova } & $\begin{array}{c}\text { Módulo de } \\
\text { Elasticidade } \\
(\mathrm{GPa})\end{array}$ & $\begin{array}{c}\text { Limite de } \\
\text { Resistência } \\
\text { Mecânica (MPa) }\end{array}$ & $\begin{array}{c}\text { Alongamento } \\
\text { total (\%) }\end{array}$ \\
\hline $\begin{array}{l}\text { Sem entalhe e não } \\
\text { hidrogenado }\end{array}$ & 11 & 652 & 13,3 \\
\hline $\begin{array}{l}\text { Entalhado e não } \\
\text { hidrogenado e }\end{array}$ & 11,5 & 845 & 11,2 \\
\hline $\begin{array}{l}\text { Entalhado e } \\
\text { hidrogenado por 13 h }\end{array}$ & 20,6 & 935 & 4,1 \\
\hline $\begin{array}{l}\text { Entalhado } \\
\text { hidrogenado por 44 h }\end{array}$ & 11,5 & 880 & \\
\hline
\end{tabular}

A redução da ductilidade verificada nos corpos de prova hidrogenados faz com que ocorra uma transição no modo de fratura dos aços. A fratura é tipicamente dúctil para corpos de prova sem entalhe e não hidrogenados, porém a 
presença do entalhe junto com maiores tempos de carga de hidrogênio resulta no aparecimento de nítidas áreas de clivagem, indicativas do efeito fragilizante do hidrogênio nest condição de ensaio (Tiwari et al., 2000).

Os aços utilizados para construção de tubos utilizados na montagem de linhas de dutos (aços API) também tem sido investigados quanto à ação degradante do hidrogênio sobre suas propriedades mecânicas e aos fatores de influência. Hardie, Charles e Lopez (2006), Dong et al. (2009), Wang (2009), Moro et al. (2010) e Chatzidouros et al. (2011).

Hardie, Charles e Lopez (2006) fez um estudo comparativo entre aços API de grau X60, X80 e X100 sob o ponto de vista da susceptibilidade a fragilização pelo hidrogênio, com o objetivo de avaliar se aços de alta resistência tem maior tendência de sofrerem fragilização pelo hidrogênio. $O$ processo de carregamento de hidrogênio foi baseado nos princípios do sistema de prevenção a corrosão conhecido como proteção catódica e foi realizado a $40{ }^{\circ} \mathrm{C}$ para simular as condições de operação de downstream do gás até as estações de compressão.

Os ensaios de tração realizados nos corpos de prova retirados dos dutos e hidrogenados com densidades de correntes variáveis até $0,7 \mathrm{~mA} \mathrm{~cm}{ }^{-2}$ comprovaram uma significativa perda de ductilidade atribuída a absorção de hidrogênio pela estrutura cristalina. Esta perda de ductilidade foi mais evidenciada com maiores densidades de corrente.

Análises metalográficas também confirmaram o dano provocado pelo hidrogênio. Foram observadas nos corpos de prova hidrogenados, após a falha, microtrincas não verificadas nos corpos de prova não expostos ao hidrogênio.

Hardie e colaboradores também verificaram que as consequências adversas somente são evidenciadas enquanto o hidrogênio se difunde pela estrutura cristalina do aço. Isto foi comprovado com um teste em um corpo de prova deixado ao ar livre durante uma semana após a hidrogenação. Tal corpo de prova não apresentou o mesmo nível de redução na ductilidade que os outros testados imediatamente após a carga de hidrogênio. Não houve redução da ductilidade devido ao hidrogênio ter se difundido para fora da rede cristalina do aço.

A Tabela 5 mostra os resultados médios que demonstram a variação das propriedades mecânicas dos aços API avaliados. 
Tabela 5 - Variação das propriedades mecânicas de aços para dutos hidrogenados por carregamento catódico. Notas: (1) DC = Densidade de Corrente, (2) LE = Limite de Escoamento, (3) Resistência à Tração, (4) t = tempo até a falha, (5) $\mathrm{A}=$ Alongamento e (6) = Redução de Área. Compilado de Hardie, Charles e Lopez, 2006.

\begin{tabular}{|c|c|c|c|c|c|c|}
\hline $\begin{array}{c}\text { Aço } \\
\text { API }\end{array}$ & $\begin{array}{c}\mathrm{DC}^{(1)} \\
\left(\mathrm{mA} \mathrm{mm}^{-2}\right)\end{array}$ & $\begin{array}{c}\mathrm{LE}^{(2)} \\
(\mathrm{MPa})\end{array}$ & $\begin{array}{c}\mathrm{RT}^{(3)} \\
(\mathrm{MPa})\end{array}$ & $\begin{array}{c}\mathrm{t}^{(4)} \\
(\mathrm{h})\end{array}$ & $\begin{array}{c}\mathrm{A}^{(5)} \\
(\%)\end{array}$ & $\begin{array}{c}\mathrm{RA}^{(6)} \\
(\%)\end{array}$ \\
\hline $\mathrm{X} 60$ & 0 & 527 & 560 & 2,27 & 20 & 78 \\
\hline $\mathrm{X} 60$ & 0,4 & 497 & 557 & 1,4 & 10 & 27 \\
\hline$* * *$ & $* * *$ & $* * *$ & $* * *$ & $* * *$ & $* * *$ & $* * *$ \\
\hline $\mathrm{X} 80$ & 0 & 614 & 650 & 2,31 & 19 & 78 \\
\hline $\mathrm{X} 80$ & 0,4 & 612 & 635 & 1,05 & 5 & 22 \\
\hline$* * *$ & $* * *$ & $* * *$ & $* * *$ & $* * *$ & $* * *$ & $* * *$ \\
\hline $\mathrm{X} 100$ & 0 & 833 & 858 & 2,05 & 17 & 76 \\
\hline $\mathrm{X} 100$ & 0,3 & 824 & 834 & 1,27 & 7 & 38 \\
\hline
\end{tabular}

Investigações posteriores confirmaram que aços de alta resistência tem maior susceptibilidade aos danos provocados pelo hidrogênio. Wang (2009), Moro et al. (2010), Dong et al. (2009) relataram o estudo desenvolvido com aços API X70, X80 e X100 respectivamente. Wang (2009) analisou a influência do modo como foi feita o processo de hidrogenação dos corpos de prova. Este processo foi feito de duas maneiras diferentes: por carga estática e por carga dinâmica.

A carga de hidrogênio estática é feita através da imersão do corpo de prova em uma solução antes de ensaiá-lo enquanto que a carga dinâmica é feita simultaneamente com o ensaio de tração a baixas taxas de deformação. Foi deduzida uma relação entre a concentração de hidrogênio e a densidade de corrente através da Equação (67):

$$
C_{H}=0,022+0,20 \sqrt{i}
$$

na qual,

$\mathrm{C}_{\mathrm{H}}=$ concentração de hidrogênio

$\mathrm{i}=$ densidade de corrente

A resistência à fratura varia com o aumento da densidade de corrente da carga estática. A Figura 68 mostra que houve uma leve redução no valor da 
resistência à fratura $\left(\mathrm{K}_{\mathrm{IQ}}\right)$ a partir de uma densidade de corrente igual a $25 \mathrm{~mA} / \mathrm{cm}^{2}$. Esta densidade de corrente, denominada de densidade de corrente crítica, leva a uma concentração de hidrogênio crítica de 1 ppm necessária a fragilização por hidrogênio.

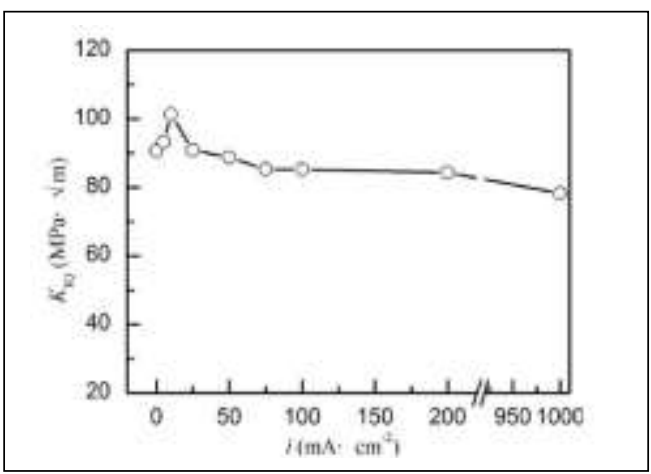

Figura 68 - Variação da resistência à fratura a partir da densidade de corrente crítica de $25 \mathrm{~mA} / \mathrm{cm}^{2}$ em carregamento estático (Wang, 2009).

Entretanto para a condição de carga dinâmica de hidrogênio notou-se uma redução mais acentuada da resistência à fratura com o aumento da densidade de corrente, conforme ilustra a Figura 69.

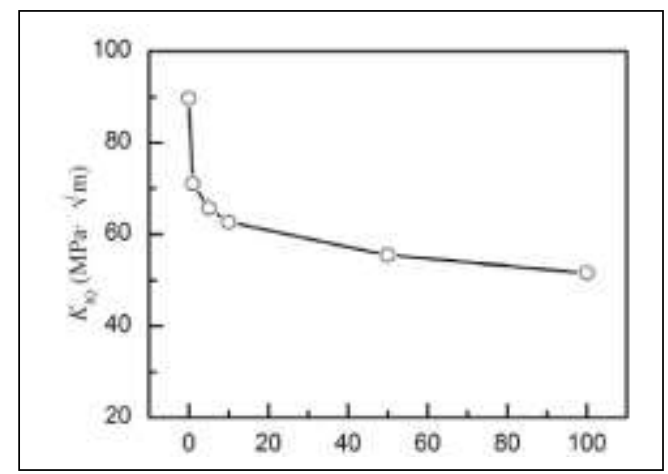

Figura 69 - Variação da resistência à fratura para condição de carregamento dinâmico(Wang, 2009).

$\mathrm{Na}$ condição de carregamento dinâmico de hidrogênio a concentração necessária a fragilização é bem menor que na condição estática e corresponde a 0,02 ppm. Pela Equação (67) a densidade de corrente crítica é $1 \times 10^{-3} \mathrm{~mA} / \mathrm{cm}^{2}$.

O baixo valor de concentração crítica de hidrogênio foi atribuído a forma como a carga de hidrogênio foi realizada, ou seja, de forma dinâmica e em baixas taxas de deformação o que favorece a difusão do hidrogênio para o interior do aço. 
Wang, Akiyama e Tsuzaki (2007) avaliaram a presença de entalhes concentradores de tensão associado a concentração de hidrogênio em aço AISI 4135 na condição temperado e revenido. Corpos de prova cilíndricos entalhados foram hidrogenados por carregamento eletroquímico em solução aquosa em densidades de correntes entre 0,3 e $30 \mathrm{~mA} / \mathrm{m}^{2}$ durante o tempo máximo de $72 \mathrm{~h}$ e posteriormente tracionados a uma velocidade de $0,005 \mathrm{~mm} / \mathrm{min}$, o que corresponde a uma taxa de deformação de $8,3 \times 10^{-7} \mathrm{~s}^{-1}$ baixa para favorecer a difusão do hidrogênio para as proximidades da raiz do entalhe. Como esperado, o resultado do estudo mostrou que o comportamento mecânico dos aços entalhados mediante a presença do hidrogênio é inferior quando comparado com o obtido a partir de corpos de prova lisos. Corpos de prova lisos tem suas propriedades mecânicas reduzidas com o aumento da concentração do hidrogênio, enquanto que os entalhados são dependentes do concentrador de tensões $\left(K_{t}\right)$ e associado a concentração do hidrogênio. A Figura 70 ilustra as curvas de tração para os corpos de prova liso e entalhados.

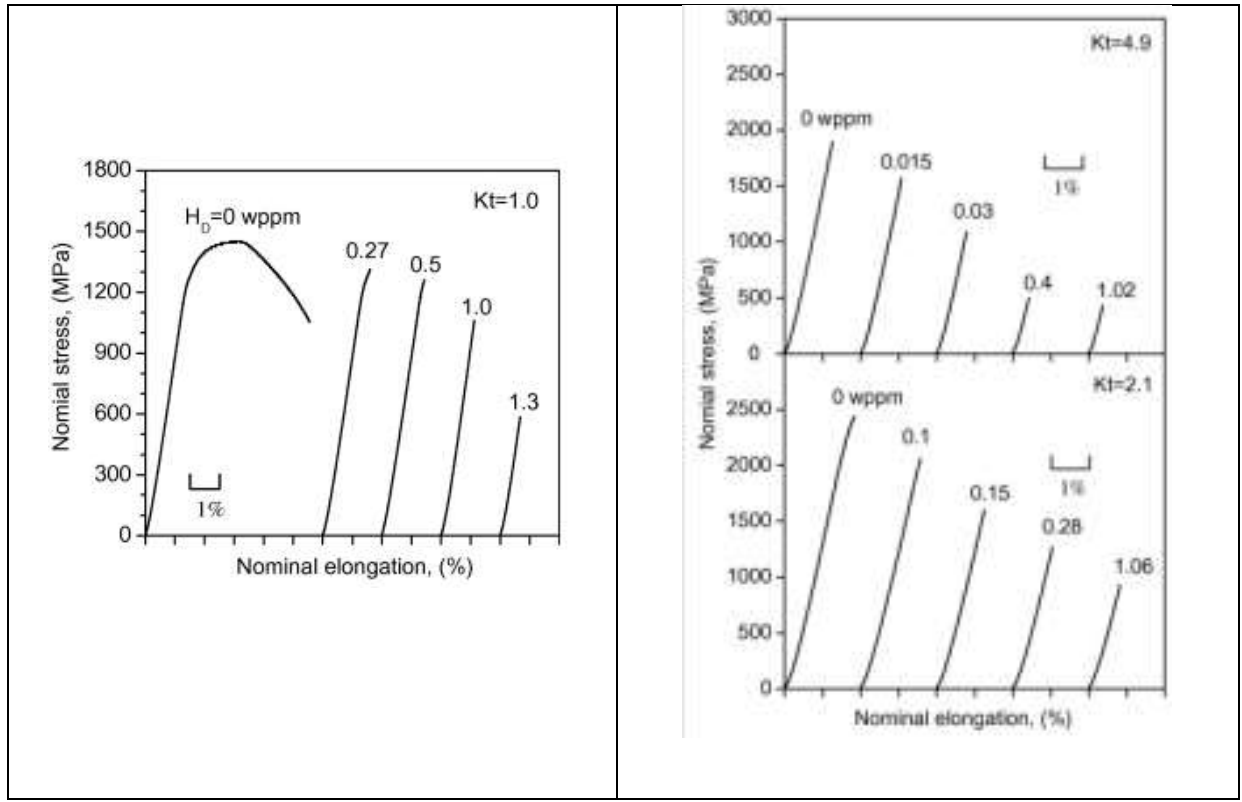

(a) (b)

Figura 70 - Influência da concentração de hidrogênio associado ao concentrador de tensão no comportamento trativo de corpos de prova. (a) Liso (b) Entalhado com diferentes concentradores de tensão. Adaptado de (Wang, Akiyama e Tsuzaki, 2007).

Análises fractográficas comprovaram as variações no comportamento mecânico do aço em questão. Wang e colaboradores observaram o micromecanismo da fratura na região de iniciação e propagação da trinca (região 
central do corpo de prova). Na região central do corpo de prova não hidrogenado houve predominância do micromecanismo de nucleação, crescimento e coalescimento de cavidades. Já nas região periférica (lábios de cisalhamento), se observa a presença de dimples mais finos, indicando uma menor deformação plástica devido a maior triaxialidade de tensões na região.

Ao contrário, os corpos de prova lisos hidrogenados, apresentaram na região central a predominância da micromecanismo de fratura por clivagem com a fratura do tipo intergranular, e lábios de cisalhamento de menor largura devido ao o aumento da quantidade de hidrogênio difusível. Todos estes indicativos confirmam a ação degradante do hidrogênio sobre o aço AISI 4135 temperado e revenido. A Figura 71 ilustra o exposto acima.

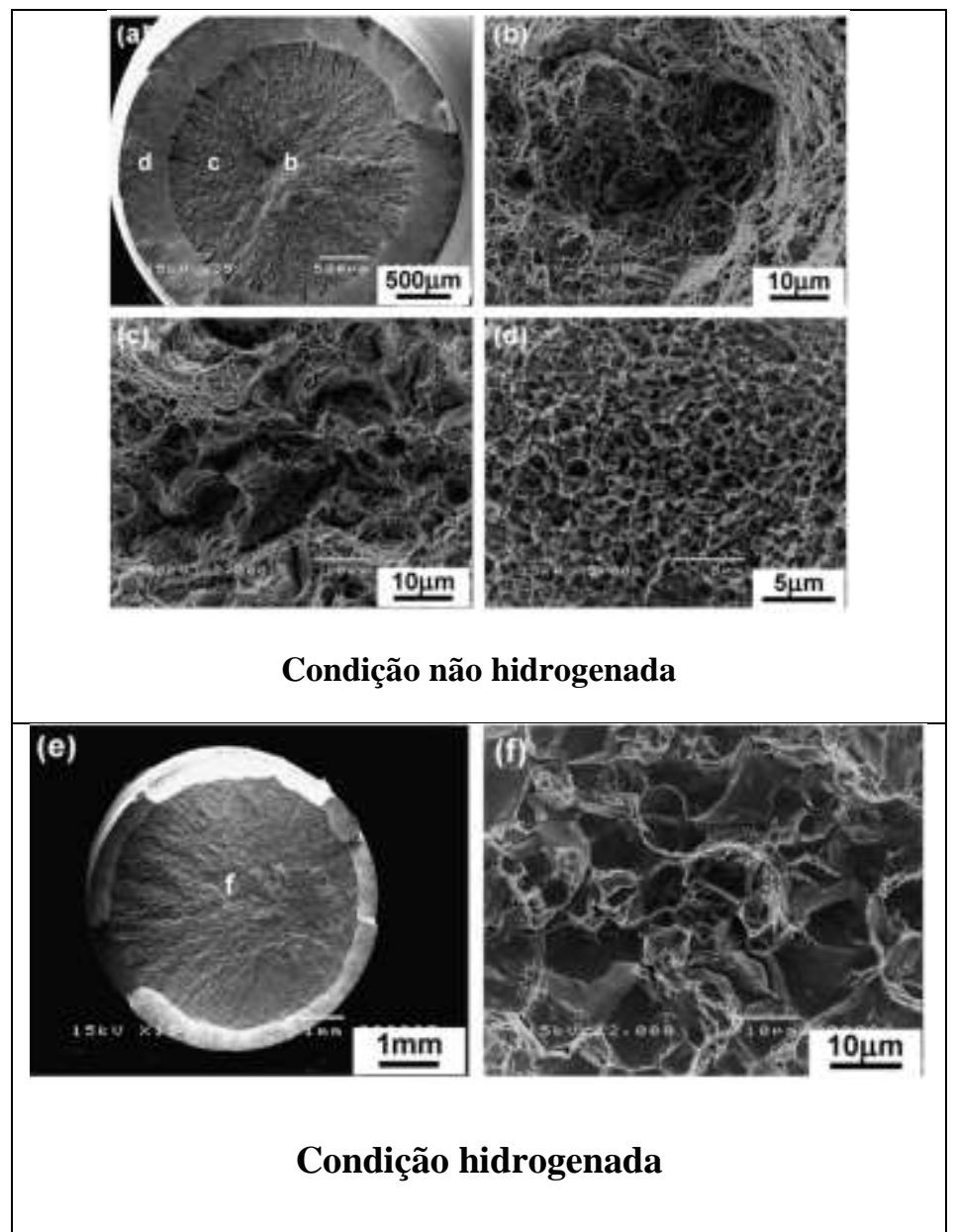

Figura 71 - (a) Seção transversal de corpo de prova não hidrogenado tracionado. (b) Micromecanismo de dimples na região central $\underline{\mathbf{b}}$. (c) e (d). Dimples reduzidos nos lábios de cisalhamento. (e) Seção transversal de corpo de prova tracionado após hidrogenação. (f) Micromecanismo de clivagem na região central $\underline{\mathbf{f}}$ ( Wang, Akiyama e Tsuzaki, 2007). 
A concentração de hidrogênio na estrutura cristalina também é dependente do tempo de exposição do material com a fonte de hidrogênio. A partir deste consenso, Dong et al. (2009), submeteu corpos de prova de tração de aço API X100 a carregamento eletroquímico com duração variada (1, 5 e 8 h) em uma solução composta de ácido sulfúrico $\left(\mathrm{H}_{2} \mathrm{SO}_{4}\right)$ e trióxido de arsênio $\left(\mathrm{As}_{2} \mathrm{O}_{3}\right)$ com uso de correntes de $20 \mathrm{~mA} / \mathrm{cm}^{2}$ e constatou o consenso que o aumento do tempo de carga de hidrogênio influencia no comportamento macroscópico trativo do material (Figura 72).

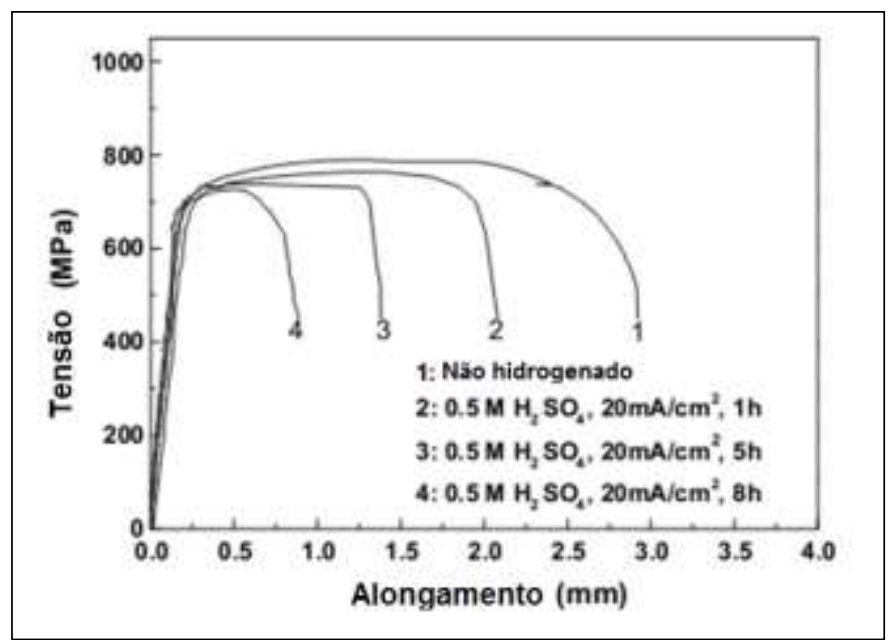

Figura 72 - Curvas tensão vs deformação de um aço X100 submetido a vários tempos de hidrogenação (Dong et al., 2009).

A susceptibilidade de aços de alta resistência e baixa liga foi estudada em reaão a susceptibilidade ao trincamento por sulfeto induzido por tensão (SSC Sulfide Stress Cracking) quando exposto a ambientes ácidos com concentrações de sulfeto de hidrogênio $\left(\mathrm{H}_{2} \mathrm{~S}\right)$, normalmente encontrados nas operações da indústria de óleo e gás.

Mansour, Alfantazi e El-boujdaini (2009) provocaram a entrada do hidrogênio no interior da estrutura cristalina do aço API X100 com a imersão do corpo de prova e uma solução aquosa de cloreto de sódio e ácido acético supersaturada com sulfeto de hidrogênio gasoso $\left(\mathrm{H}_{2} \mathrm{~S}\right)$ associado a aplicação de carga compreendida entre 30 e $80 \%$ da tensão limite de escoamento do material. A susceptibilidade ao trincamento foi determinada com base no tempo até a falha para duração máxima do ensaio de 720 h.

Mansour e assistentes verificou que tal aço possui uma alta susceptibilidade ao trincamento por sulfeto induzido por tensão devido aos baixos tempos de falhas 
ocorridos no ensaio e a existência de microtrincas na superfície observadas na análise metalográfica da amostra retirada do corpo de prova ensaiado. Esta alta susceptibilidade foi atribuída aos valores elevados de dureza e resistência mecânica, além da microestrutura propensa a fragilização.

Não apenas o hidrogênio proveniente de reações entre susbstâncias em solução aquosa é prejudicial ao comportamento mecânico dos aços. A exposição de tais materiais ao hidrogênio gasoso também tem o mesmo poder deletério.

Moro et al. (2009) avaliou a presença do gás hidrogênio em um vaso de pressão durante o ensaio de tração, a temperatura ambiente, em corpos de prova aço API grau X80 com microestrutura ferrítico-perlítica. Ensaios em atmosfera composta por nitrogênio foram realizados assim como mudança da atmosfera, de hidrogênio para nitrogênio ou vice-versa durante o andamento do ensaio, foram utilizados para validação do estudo.

Por comparação de resultados obtidos nos ensaios foi percebida uma nítida redução da ductilidade nos corpos de prova ensaiados em atmosfera hidrogenada. Este fato não foi constatado nos ensaios realizado nas mesmas condições de operação (pressão, velocidade do ensaio) em atmosfera nitrogenada. Para confirmar o efeito do hidrogênio mencionado acima se tem o comportamento mecânico do corpo de prova submetido a mudança da atmosfera gasosa de nitrogenada para hidrogenada, durante o ensaio de tração.

A redução de ductilidade percebida na mudança de gás (nitrogênio para hidrogênio) não foi constatada quando se modificou a atmosfera de hidrogenada para nitrogenada. A Figura 73(a) e 73(b) ilustra o comentário exposto acima.

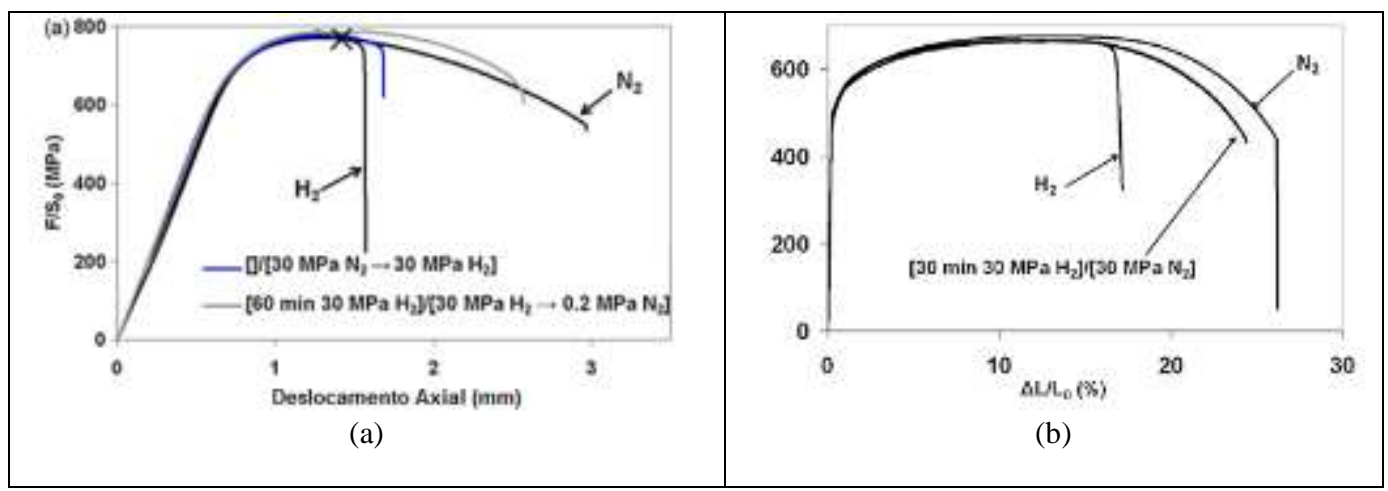

Figura 73 - Curvas do ensaio de tração obtidas em atmosfera hidrogenada, nitrogenada e em atmosfera submetida a mudança de gás $\left(\mathrm{N}_{2} \rightarrow \mathrm{H}_{2}\right)$ (a) e mudança de gás $\left(\mathrm{H}_{2} \rightarrow \mathrm{N}_{2}\right)$ (b). Adaptado de Moro et al., 2010. 
Conforme foi verificado que o tempo destinado ao carregamento de hidrogênio no material influencia diretamente em seu comportamento macroscópico em tração, Moro et al.(2010) estudou o efeito da pressão de gás no interior do vaso de pressão durante o ensaio de tração. Com o aumento da pressão, não se observou redução do limite de resistência mecânica, porém se teve maior redução de ductilidade, principalmente na faixa entre 5 e $30 \mathrm{MPa}$ quando comparado a pressão de $0,1 \mathrm{MPa}$ de $\mathrm{H}_{2}$. A redução de ductilidade não foi observada com a pressão de $30 \mathrm{MPa}$ de gás nitrogênio, confirmando mais uma vez a ação degradante do hidrogênio no que se refere a perda de ductilidade analisada por ensaios de tração (Figura 74).

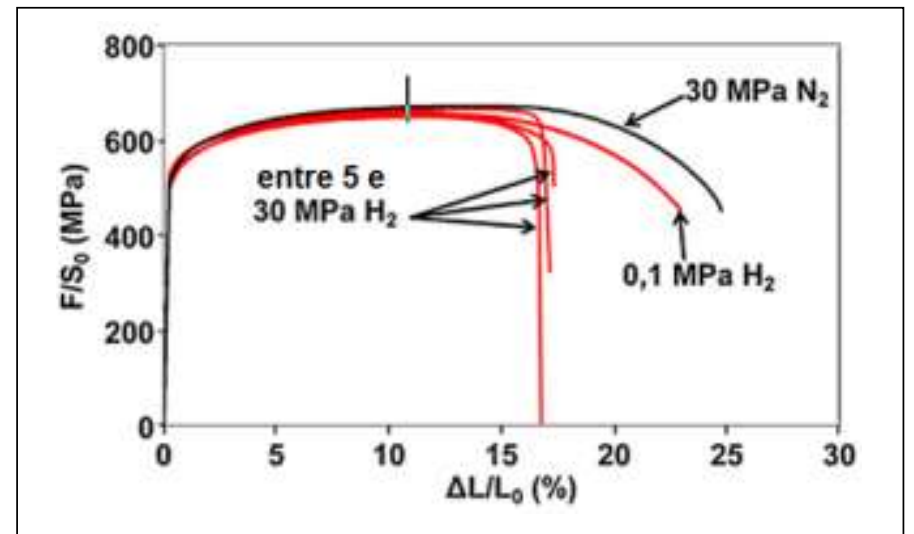

Figura 74 - Influência da pressão do hidrogênio no comportamento mecânico em tração do aço API X80 (Moro et al., 2010).

Os efeitos do hidrogênio nas propriedades mecânicas dos aços são favorecidos pela variável tempo, já tais efeitos são dependentes da difusão do hidrogênio na forma atômica na estrutura cristalina após adsorção do mesmo na superfície do metal. Sendo assim, o tempo decorrido entre o início e fim dos ensaios utilizados para avaliação do comportamento mecânico do material tem papel fundamental em se tratando da interação do hidrogênio com defeitos presentes no material.

A influência do tempo foi investigada por Moro et al. (2010) em função da taxa de deformação, onde se concluiu que quanto maior a taxa de deformação aplicada no ensaio de tração, menor a redução da ductilidade macroscópica no material.

Como os ensaios a altas taxas de deformação tem menor duração, o tempo para difusão do hidrogênio para regiões de maiores níveis de tensão é reduzido e 
consequentemente interação do hidrogenio com defeitos da estrutura cristalina é menor. Por esta razão a fratura dos corpos de prova foi predominantemente dúctil. Este fato é evidenciado na Figura 10. Comparando as curvas obtidas no ensaio com hidrogênio e hidrogênio a $0,55 \mathrm{~s}^{-1}$ (Figura 75) se percebeu que ambos apresentaram o mesmo nível de ductilidade. Este nível de ductilidade não foi percebido com ensaio feitos a menores taxas de deformação, da ordem de, $10^{-7} \mathrm{~s}^{-1}$.

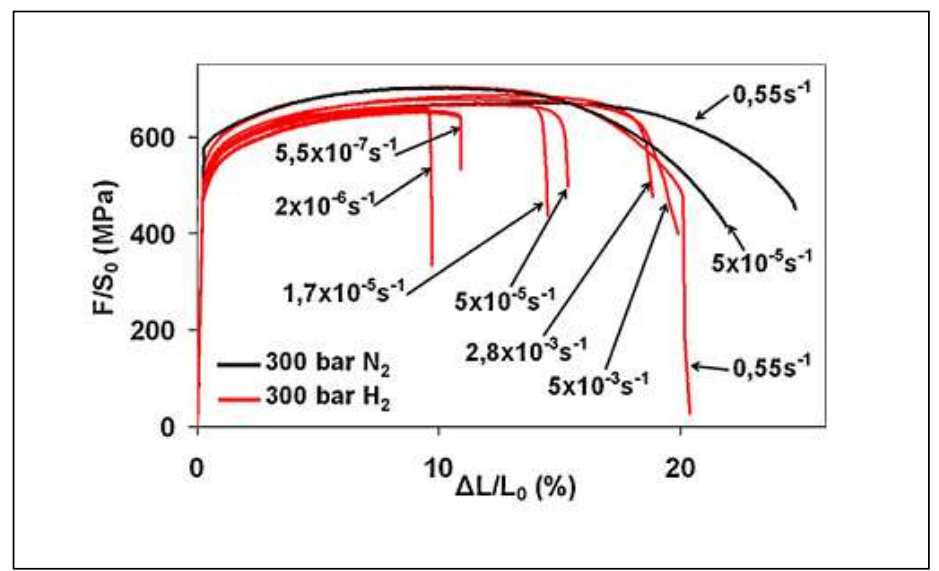

Figura 75 - Influência da taxa de deformação no ensaio de tração na fragilização do X80 (Moro et al., 2010).

Investigações mais profundas realizadas alguns $\mu \mathrm{m}$ abaixo da superficie de fratura feitas por Srinivasan e Neeraj, 2014 confirmaram que a deformação macroscópica imposta aos corpos de prova pelo ensaio de tração podem ser visualizadas no tamanho do subgrão (Srinivasan e Neeraj, 2014) . A deformação subestrutural verificada em amostras extraídas da região dúctil do corpo de prova de aço API 5L X65, ferrítico-perlítico, hidrogenado é um indicativo da plasticidade existente.

Comparando a condição da subsuperfície sem hidrogênio com a hidrogenada, se nota o refino significativo e um aumento gradual do subgrão a medida que se afasta da superfície de fratura. A Figura 76 ilustra o refino do subgrão observado na subsuperfície do aço API 5L X65 hidrogenado. 


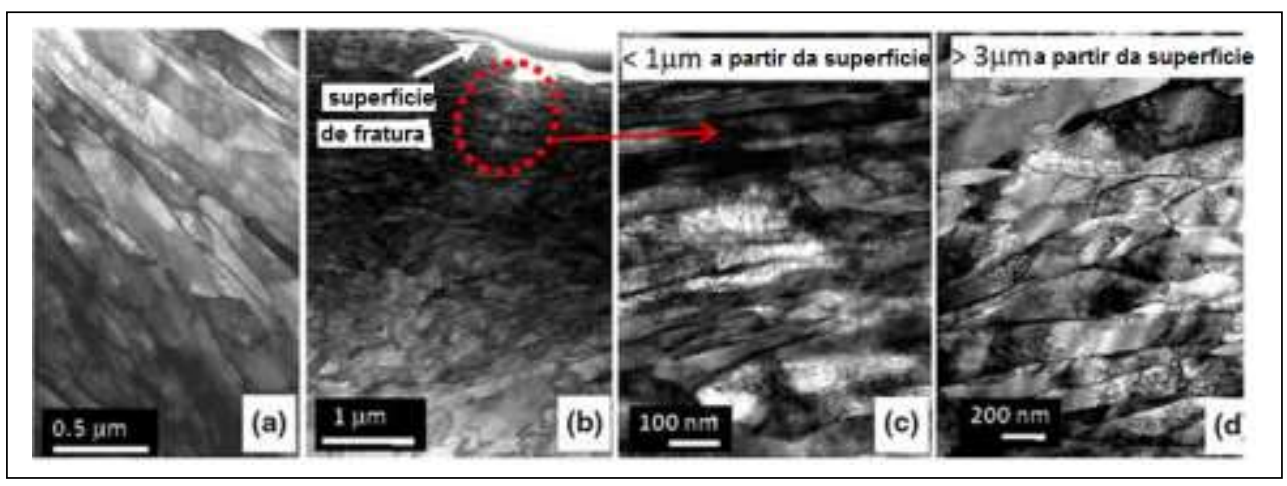

Figura 76 - Deformação subsuperficial de amostra não hidrogenada (a). Refino do subgrão a $1 \mu \mathrm{m}$ da superfície (b). Maior tamanho do subgrão em maiores profundidades da superfície da fratura (c) e (d) (Srinivasan e Neeraj, 2014).

\subsubsection{Influência na resistência à fratura}

Os efeitos do hidrogênio sobre a tenacidade à fratura de aços estruturais são pouco divulgados já que a maioria dos estudos relatados são baseados nos ensaios de tração. A tenacidade à fratura de um material de boa ductilidade na presença do hidrogênio tem se mostrado controverso. Em alguns aços estruturais para fins de transporte de óleo e gás não se verifica reduções significativas nos parâmetros de tenacidade à fratura (CTOD e/ou Integral J), o que mostra que a tenacidade à fratura com a influência do hidrogênio é função de diversos fatores tais como, taxa de deformação, processo de hidrogenação, microestrutura, existência de sistemas de prevenção à corrosão (proteção catódica), entre outros.

Strohaecker (1989) caracterizou o comportamento à fratura dos aços de alta resistênca $\mathrm{C}(0,16 \%)$ - Mn $(\sim 0,6-1,2)$, especificado por $\operatorname{SAR} 80$, de $\sigma_{\mathrm{ys}}$ e $\sigma_{\text {us }}$ igual a $805 \mathrm{MPa}$ e $840 \mathrm{MPa}$, respectivamente frente a uma solução aquosa de $\mathrm{NaCl}$ com e sem aplicação de proteção catódica utilizando corpos de prova tipo alternativos de acordo com norma BS 5762 (1979). Ensaios realizados com solução sem proteção catódica para cálculo do CTOD de carga máxima foram comparados com os realizados em atmosfera hidrogenada com niveis diferentes de proteção catódica.

Após exposição de 100 h a solução aquosa com proteção catódica seguido de ensaio imediato foi encontrado um valor de CTOD de carga máxima de 0,05 mm, enquanto que o valor obtido para condição de ensaio em solução não 
protegida catodicamente (sem hidrogênio) foi de $0,1 \mathrm{~mm}$, similar ao obtido quando se ensaia em atmosfera de laboratório, ou seja, ao ar.

A alta susceptibilidade do aço estudado (SAR-80) também foi verificado através do nivel do potencial de proteção catódica da solução aquosa. $\mathrm{O}$ aumento do potencial de proteção catódica de $-820 \mathrm{mV}$ para $-1100 \mathrm{mV}$ alterou o micromecanismo de propagação da trinca. Devido a maior quantidade de hidrogênio na condição de superproteção catódica $(-1100 \mathrm{mV})$, este passou de coalescimento de microcavidades para micromecanismo de quase-clivagem.

Hagiwara e Oguchi (1999) avaliaram a susceptibilidade a corrosão sob tensão na presença do hidrogênio (HSC - Hydrogen Stress Cracking) do aço API 5L X65 baseados em ensaios de mecânica da fratura (CTOD) considerando a existência de proteção catódica. Também foi avaliado a influência da densidade de corrente utilizada durante o processo de hidrogenação e a velocidade do ensaio (taxa de deformação).

Os ensaios de CTOD em corpos de prova flexão por três apoios foram conduzidos em célula com solução para carregamento catódico de hidrogênio e também ao ar. O tempo destinado a hidrogenação foi de $12 \mathrm{~h}$ e os ensaios foram realizados em velocidades entre 0,25 e $0,001 \mathrm{~mm} / \mathrm{min}$.

Foram verificados valores iguais de CTOD crítico para as duas condições de teste (ar e soluçao hidrogenada) para velocidade de ensaio igual a $0,25 \mathrm{~mm} / \mathrm{min}$, o que corresponde a uma taxa de deformação de $4,2 \times 10^{-3} \mathrm{~s}^{-1}$. A redução significativa do valor do CTOD somente foi observado para hidrogenação a 100 $\mathrm{mA} / \mathrm{cm}^{2}$ com velocidades de ensaio entre 0,1 e $0,001 \mathrm{~mm} / \mathrm{min}$, o corresponde a a uma taxa de deformação de $1,7 \times 10^{-3} \mathrm{~s}^{-1}$ e $1,7 \times 10^{-5} \mathrm{~s}^{-1}$, respectivamente, conforme Figura 77. Não foi observada a mesma dependência da taxa de deformação nos ensaios conduzidos ao ar.

Segundo Hagiwara e Oguchi (1999), ss valores encontrados por CTOD na condição hidrogenada reduzem o tamanho máximo de defeito suportado pelos aços utilizados na fabricação de tubos para linha de dutos. 


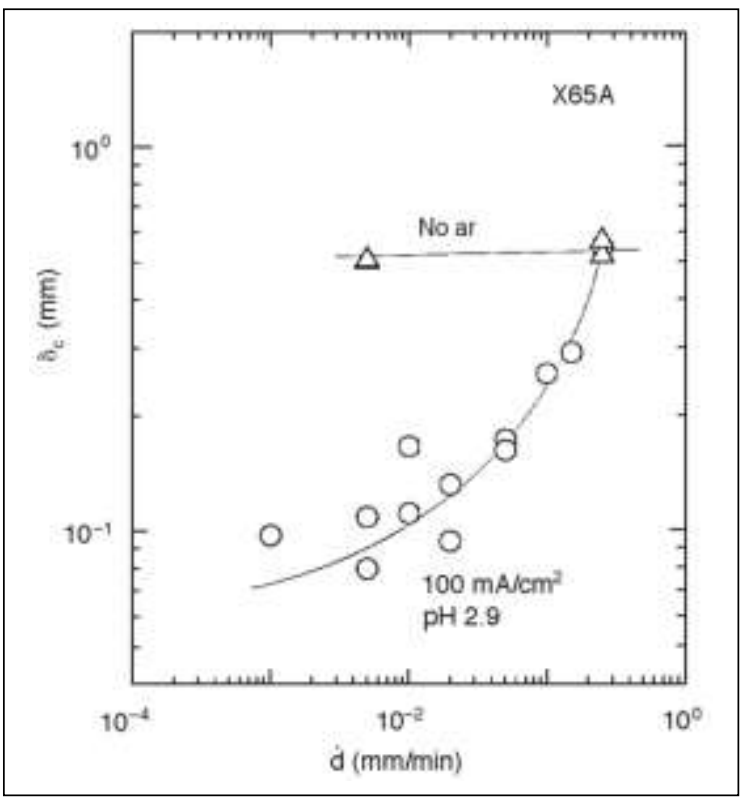

Figura 77 - Influência da velocidade do ensaio sobre valor do CTOD crítico (Hagiwara e Oguchi, 1999).

Estudos continuaram sendo realizados quanto a influência da taxa de deformação. Andrews, McQuen e Millwood (2001) realizaram uma bateria de ensaios de CTOD com corpos de prova de API 5L X80, do tipo flexão por três apoios, hidrogenados a partir do princípio da proteção catódica, com tempos entre 4 e 336 h. Os ensaios foram realizados no interior da célula de hidrogenação (in situ), com velocidades de ensaio entre 0,05 e $0,002 \mathrm{~mm} / \mathrm{min}$, o que equivale a taxas de deformação entre $8,5 \times 10^{-4} \mathrm{~s}^{-1}$ e $3,4 \times 10^{5} \mathrm{~s}^{-1}$ e o CTOD obtido foi o de carga máxima.

A partir da análise dos resultados obtidos, Andrews e assistentes não encontraram uma unanimidade quanto a predominância da taxa de deformação, tempo de hidrogenação ou valor do pH da solução na variação do parâmetro CTOD.

Para uma solução de $\mathrm{pH}=7,0$ e uma velocidade de $0,01 \mathrm{~mm} / \mathrm{min}$, o aumento do tempo de hidrogenação causou uma redução significativa nos valores do CTOD, quando comparado com os valores obtidos ao ar. A partir dos maiores tempos de hidrogenação (168 h) não foi verificado reduções significativas o que indica que se alcancou a concentração de supersaturação estacionária no corpo de prova.

A influência da velocidade do ensaio foi verificada nos ensaios após $24 \mathrm{~h}$ de hidrogenação em solução de $\mathrm{pH}=7,0$. A redução da velocidade de ensaio, 
consequentemente da taxa de deformação provocou reduções consideráveis no valor do CTOD resultados obtidos.

No que se refere ao influência do valor do $\mathrm{pH}$, Andrews, McQueen e Millwood (2001) evidenciaram baixos valores de CTOD em relação aos obtidos nos ensaios ao ar. Porém a redução no valor do $\mathrm{pH}(7,0,4,0$ e 2,5), imposta nos ensaios, não reduziu significativamente o CTOD de carga máxima, o que indica que para o nível de $\mathrm{pH}$ testado não se verifica aumento do efeito do hidrogênio no parametro de tenacidade à fratura.

O efeito da redução da velocidade de ensaio sobre a tenacidade à fratura de um metal solda em ambiente ácido com $\mathrm{H}_{2} \mathrm{~S}$ também foi avaliada. Guo et al. (2010) submeteu corpos de prova SENT (Single edge notched tension) extraídos transversalmente de cordão de solda existente em um duto exposto a hidrogenação por $240 \mathrm{~h}$, conforme norma NACE TM0177. A hidrogenação ocorreu após aplicação de uma pré-carga ao corpo de prova suficiente para alcançar a tensão longtudinal oriunda da máxima pressão de operação do duto.

O experimento consistiu em ensaiar os corpos de prova nas velocidades de $0,033 \mathrm{~mm} / \mathrm{min}, 0,02 \mathrm{~mm} / \mathrm{min}, 0,004 \mathrm{~mm} / \mathrm{min}$ e $0,002 \mathrm{~mm} / \mathrm{min}$, que reflete as respectivas taxas de deformação $1,9 \times 10^{-6} \mathrm{~s}^{-1}, 1,15 \times 10^{-6} \mathrm{~s}-1,0,23 \times 10^{-6} \mathrm{~s}^{-1} \mathrm{e}$ $0,115 \times 10^{-6} \mathrm{~s}^{-1}$ e os parâmetros obtidos foram os de carga máxima. A Figura 78 abaixo mostra os resultados encontrados por Guo et al. (2010).

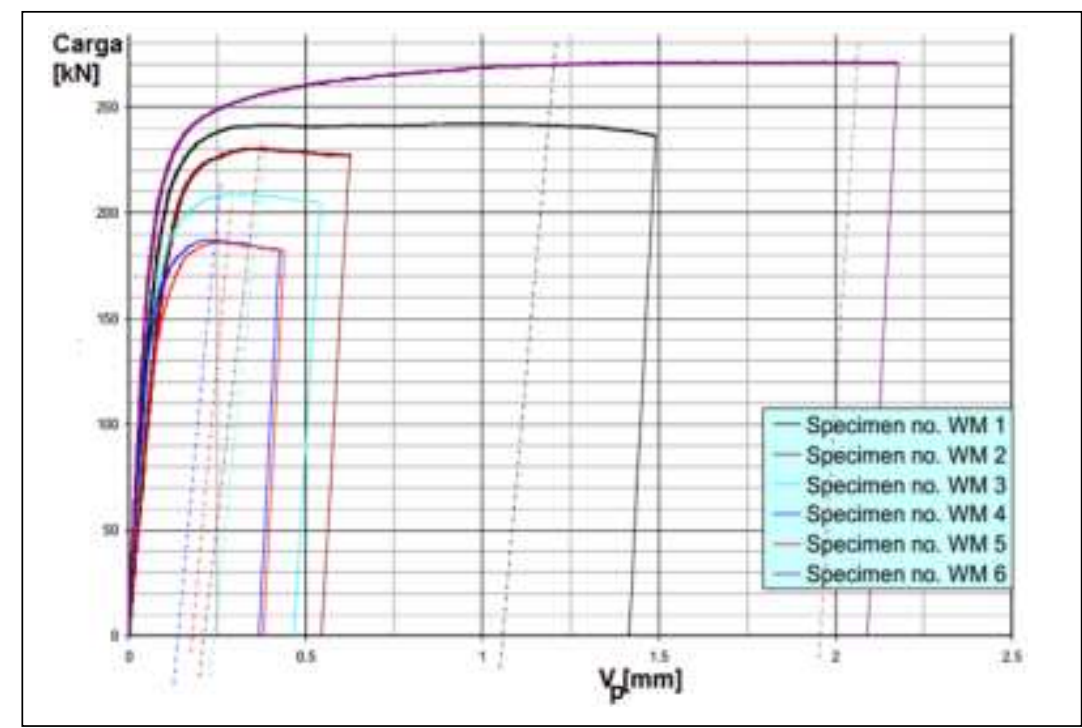

Figura 78 - Curva Carga $\mathrm{x}\left(\mathrm{V}_{\mathrm{p}}\right)$ de corpos de prova hidrogenados (Guo et al., 2010). 
Em comparação com os ensaios feitos no ar (WM 6), os ensaios realizados em amabientes ácidos obtiveram menor redução do CTOD. Quanto menor a taxa de redução, menor o valor do CTOD. Porém a redução significativa ocorreu na faixa entre $1,0 \times 10^{-6} \mathrm{~s}^{-1}$ e $2,0 \times 10^{-6} \mathrm{~s}^{-1}$, onde a redução chegou na ordem de $77 \%$. A Tabela 6 resume os valores de CTOD encontrados no estudo.

Tabela 6 - Influência da taxa de deformação no efeito do hidrogênio sobre os valores do CTOD. ( Guo et al.,2010).

\begin{tabular}{|c|c|c|c|}
\hline $\begin{array}{c}\text { Identificação } \\
\text { Corpo de Prova }\end{array}$ & $\begin{array}{c}\text { Tempo de } \\
\text { Hidrogenação (h) }\end{array}$ & $\begin{array}{c}\text { Taxa de } \\
\text { Deformação } \\
\left(10^{-6} \mathrm{~s}^{-1}\right)\end{array}$ & $\begin{array}{c}\text { CTOD } \\
(\mathrm{mm})\end{array}$ \\
\hline WM6 & - & 1,90 & 0,81 \\
\hline WM1 & 240 & 1,90 & 0,52 \\
\hline WM2 & 240 & 1,15 & 0,19 \\
\hline WM3 & 240 & 0,23 & 0,15 \\
\hline WM4 & 240 & 0,115 & 0,12 \\
\hline
\end{tabular}

Fassina et al. (2012) também avaliou a tenacidade à fratura frente a susceptibilidade ao trincamento induzido por tensão na presença de $\mathrm{H}_{2} \mathrm{~S}$. Os materiais investigados foram aços de baixa liga Cr-Mo (F22) e C-Mn (API 5L X65) com microestrutura temperada e revenida.

Corpos de prova compactos por tração com espessura de $20 \mathrm{~mm}$ entalhados lateralmente hidrogenados eletroquimicamente por $20 \mathrm{~h}$ a temperatura ambiente. Posteriormente, os mesmos foram imersos em nitrogênio líquido para evitar o escape do hidrogênio para a atmosfera antes dos ensaios de tenacidade à fratura foram realizados entre $23{ }^{\circ} \mathrm{C}$ e $-120{ }^{\circ} \mathrm{C}$ para determinação da Integral J e CTOD.

Fassina et al. (2012) verificou que ambos os materiais possuem a tenacidade à fratura comprometida quando comparado com o ar. A Tabela 7 resume os valores de CTOD $(\delta)$ encontrados para temperatura de teste igual a $-70{ }^{\circ} \mathrm{C}$ para o aço API 5L X65. 
Tabela 7 - Resultados eperimentais para condição hidrogenada e não hidrogenada a $-70{ }^{\circ} \mathrm{C}$ para aço API 5L X65. Adaptada de Fassina et al.,2012.

\begin{tabular}{|l|c|c|c|c|}
\hline & $\begin{array}{c}\text { Corpo de } \\
\text { Prova }\end{array}$ & $\delta_{\mathrm{el}}(\mathrm{mm})$ & $\delta_{\mathrm{pl}}(\mathrm{mm})$ & $\delta(\mathrm{mm})$ \\
\hline \multirow{2}{*}{ S/ Hidrogênio } & $\mathrm{X} 1$ & 0,090 & 0,753 & 0,843 \\
\cline { 2 - 5 } & $\mathrm{X} 2$ & 0,081 & 0,689 & 0,770 \\
\hline \multirow{2}{*}{ C/ Hidrogênio } & $\mathrm{X} 1$ & 0,063 & 0,036 & 0,099 \\
\cline { 2 - 5 } & $\mathrm{X} 2$ & 0,049 & 0,014 & 0,063 \\
\hline
\end{tabular}

A presença do hidrogênio na microestrutura dos aços muda o micromecanismo de fratura reduzindo o tamanho da zona plástica e aumentado a propagação da trinca. A Figura 79 mostra a diferença na curva carga (P) vs deslocamento da linha de carga (LLD).

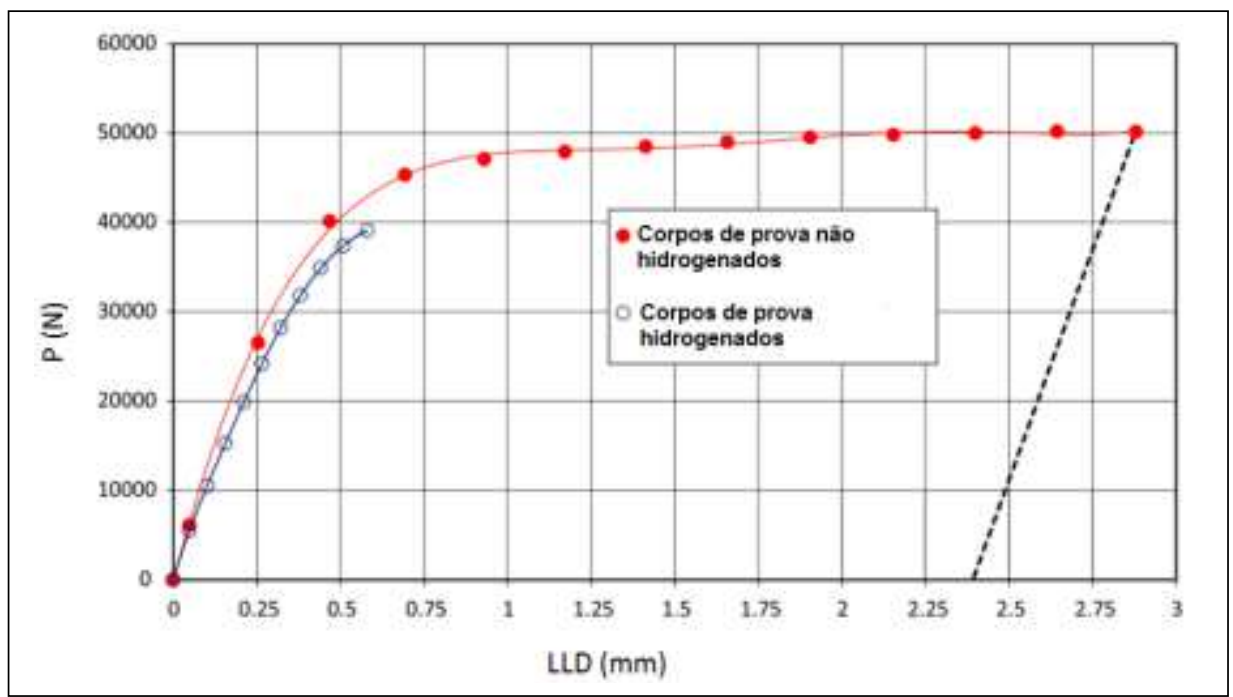

Figura 79 - Curva P vs LLD de aço hidrogenado e não hidrogenado a $-70{ }^{\circ} \mathrm{C}$ (Fassina et al., 2012).

Chatzidouros et al. (2011) estudaram o efeito do carregamento de hidrogênio "in loco" na resistência à fratura de tubo com costura construído em aço API 5L X70. Foram realizados ensaios de fratura por flexão em três apoios simultâneos a hidrogenação, para determinação da Integral J, com o objetivo de reduzir a probabilidade do hidrogênio se difundir para a atmosfera, e proporcionar uma condição mais próxima da realidade pra o materila quando este estiver em serviço. Os corpos de prova extraídos de um tubo enterrado incluiram a região do cordão de solda para análise tanto do metal de base quanto da zona termicamente 
afetada. A hidrogenação foi feita por método eletrolítico com densidades de corrente usadas foram 1,5 e $10 \mathrm{~mA} \mathrm{~cm}^{-2}$.

Com os resultados obtidos foi constatado uma redução no valor da Integral J para o metal de base e para o metal de solda com o aumento da densidade de corrente da hidrogenação, e consequentemente maior concentração de hidrogênio, conforme pode ser visualizado na Figura 80 e 81 respectivamente.

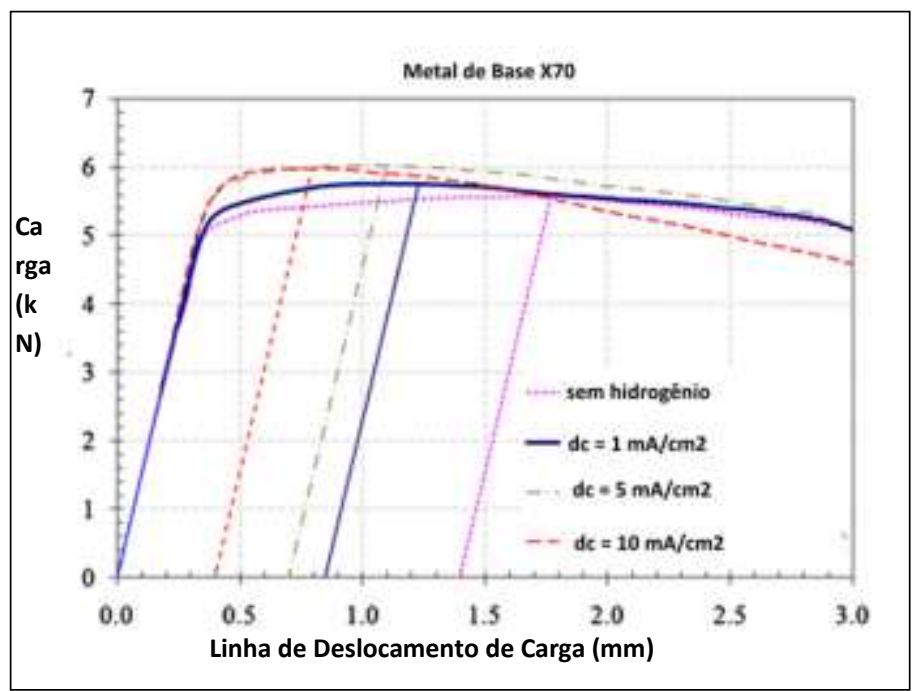

Figura 80 - Redução de ductilidade do metal base com o aumento da densidade de corrente (Chatzidouros et al., 2011).

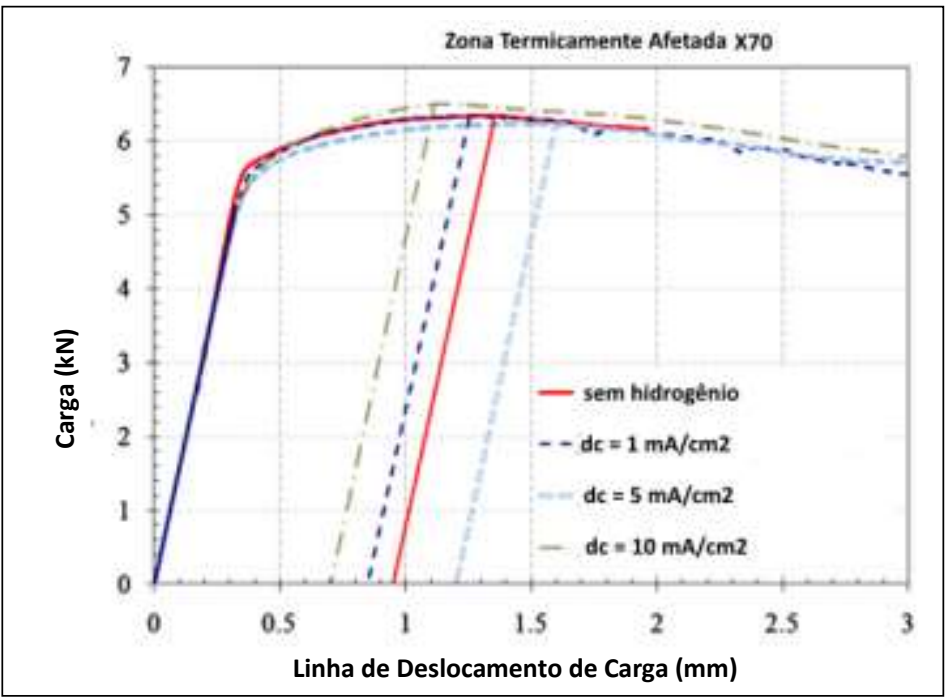

Figura 81 - Redução de ductilidade da ZTA do X70 com o aumento da densidade de corrente (Chatzidouros et al., 2011).

O menor valor de Integral $\mathbf{J}$ foi observado para uma densidade de corrente igual a $10 \mathrm{~mA} / \mathrm{cm}^{2}$. Na densidade de corrente citada verificou uma redução da 
ordem de $63 \%$ e $34 \%$ para o metal de base e de solda, respectivamente, quando comparado com o valor obtido no teste ao ar. A Tabela 8 apresenta os resultados do comentário acima.

Tabela 8 - Redução dos valores da Integral $\mathbf{J}$ do metal de base e da ZTA com aumento da densidade de corrente. Compilado de Chatzidouros et al., 2011.

\begin{tabular}{|c|c|c|c|c|}
\hline \multirow{2}{*}{} & \multicolumn{4}{|c|}{ Integral J (N/mm) } \\
\cline { 2 - 5 } & $\mathrm{X} 70(\mathrm{MB})$ & $\%$ & $\mathrm{X} 70$ (ZTA) & $\%$ \\
\hline $\mathrm{Ar}$ & 285,3 & - & 266,1 & - \\
\hline $1 \mathrm{~mA} \mathrm{~cm}^{-2}$ & 195,2 & $-31,57$ & 238,9 & $-10,23$ \\
\hline $5 \mathrm{~mA} \mathrm{~cm}^{-2}$ & 168 & $-41,11$ & 253,1 & $-4,89$ \\
\hline $10 \mathrm{~mA} \mathrm{~cm}^{-2}$ & 104,3 & $-63,44$ & 174,9 & $-34,27$ \\
\hline
\end{tabular}

A análise dos valores de Integral $\mathbf{J}$ mostraram que o metal de base obteve maior redução de ductilidade comparado com ao metal de solda na presença do hidrogênio. Este fato foi associado a microestrutura do aço em questão. Os grãos alongados na direção da laminação, o gradiente de deformação entre a ferrita / banda mista de bainita e perlita e principalmente às inclusões de sulfeto de manganês $(\mathrm{MnS})$ e alumina $\left(\mathrm{Al}_{2} \mathrm{O}_{3}\right)$ paralelas as bandas possivelmente favoreceram a ação do hidrogênio frente a tenacidade à fratura do metal de base, contribuindo para a redução da Integral J.

Grande parte dos estudos voltados para maior sobre a influência do hidrogênio nas propriedades mecânicas dos materiais metálicos são feitos a partir de corpos de prova extraídos de material na condição de como recebido, para depois serem submetidos a hidrogenação.

Hardianfard (2010) extraiu corpos de prova de um flange de aço C-Mn com 0,35\%C, ASTM A105M, existente em duto de alimentação de uma refinaria. Foi analisada a falha provocada no componente mencionado devido a existência de pequena quantidade de sulfeto de hidrogênio $\left(\mathrm{H}_{2} \mathrm{~S}\right)$ no fluido transportado.

Com o intuito de comprovar o efeito do hidrogênio sobre o aço em questão foram preparados três grupos de corpos de prova. O primeiro grupo consistiu de corpos de prova retirados do próprio flange após a falha sem nenhum tipo de tratamento. Os corpos de prova do segundo grupo foram submetidos a tratamento térmico para remoção do hidrogênio residual do interior da estrutura cristalina e 
os corpos de prova do terceiro grupo foram banhados em uma solução de ácido sulfúrico $\left(\mathrm{H}_{2} \mathrm{SO}_{4}\right)$ com óxido de arsênio para hidrogenação por intervalo de tempo que variou de 0 a 6 h. A Tabela 9 resume a distribuição dos corpos de prova utilizados por Hardianfard (2010).

Tabela 9 - Distribuição de corpos de prova extraídos de flange.

\begin{tabular}{|c|c|c|c|}
\hline & $1 .^{\circ}$ grupo & $2 .^{\circ}$ grupo & $3 .^{\circ}$ grupo \\
\hline Corpo de Prova & $\begin{array}{l}\text { Extraído do } \\
\text { flange após a } \\
\text { falha }\end{array}$ & $\begin{array}{c}\text { Extraído do flange } \\
\text { após a falha }\end{array}$ & $\begin{array}{l}\text { Extraído do } \\
\text { flange após a } \\
\text { falha }\end{array}$ \\
\hline Tratamento Térmico & Não realizado & $\begin{array}{l}\text { Realizado para } \\
\text { remoção de } \\
\text { hidrogênio }\end{array}$ & Não realizado \\
\hline $\begin{array}{l}\text { Processo de } \\
\text { Hidrogenação }\end{array}$ & $\begin{array}{c}\text { Oriundo do } \\
\mathrm{H}_{2} \mathrm{~S} \text { presente } \\
\text { no fluido }\end{array}$ & Não realizado & $\begin{array}{c}\text { Banho em } \\
\text { solução de ácido } \\
\text { sulfúrico }\end{array}$ \\
\hline
\end{tabular}

Os efeitos do hidrogênio sobre o material foram avaliados por ensaios de tenacidade à fratura, realizado na velocidade de $1,0 \mathrm{~mm} / \mathrm{min}$, através do valor de tenacidade à fratura sob o estado plano de tensão $\left(\mathrm{K}_{\mathrm{Q}}\right)$, dependente da espessura do corpo de prova.

No ensaio de tenacidade à fratura foi encontrado um valor de 47 $\mathrm{MPa}(\mathrm{m})^{1 / 2}$ e $63 \mathrm{MPa}(\mathrm{m})^{1 / 2}$ para o primeiro e segundo grupo de corpos de prova, respectivamente. Os valores evidenciam o efeito do hidrogênio, pois o menor valor de tenacidade à fratura foi obtido para corpos de prova retirados do próprio flange sem nenhum tratamento extra, ou seja, com hidrogênio residual oriundo do fluido transportado.

A ação do hidrogênio também pode ser constatada com os corpos de prova submetidos a hidrogenação por solução ácida (terceiro grupo). Como não se obteve a tenacidade à fratura, independente da espessura $\left(\mathrm{K}_{\mathrm{Ic}}\right)$, análise foi efetuada através de $\mathrm{K}_{\mathrm{Q}}$.

O aumento do tempo de exposição a solução ácida, diminuiu a tenacidade à fratura $\left(\mathrm{K}_{\mathrm{Q}}\right)$. Para otempo máximo de hidrogenação $(6 \mathrm{~h})$ se alcançou $25 \mathrm{MPa}(\mathrm{m})^{1 / 2}$, o que corresponde a uma redução da ordem de $60 \%$ em relação ao 
valor do segundo grupo submetido a remoção de hidrogênio residual. A Figura 82 mostra a tenacidade à fratura $\left(\mathrm{K}_{\mathrm{Q}}\right)$ em função do tempo de hidrogenação.

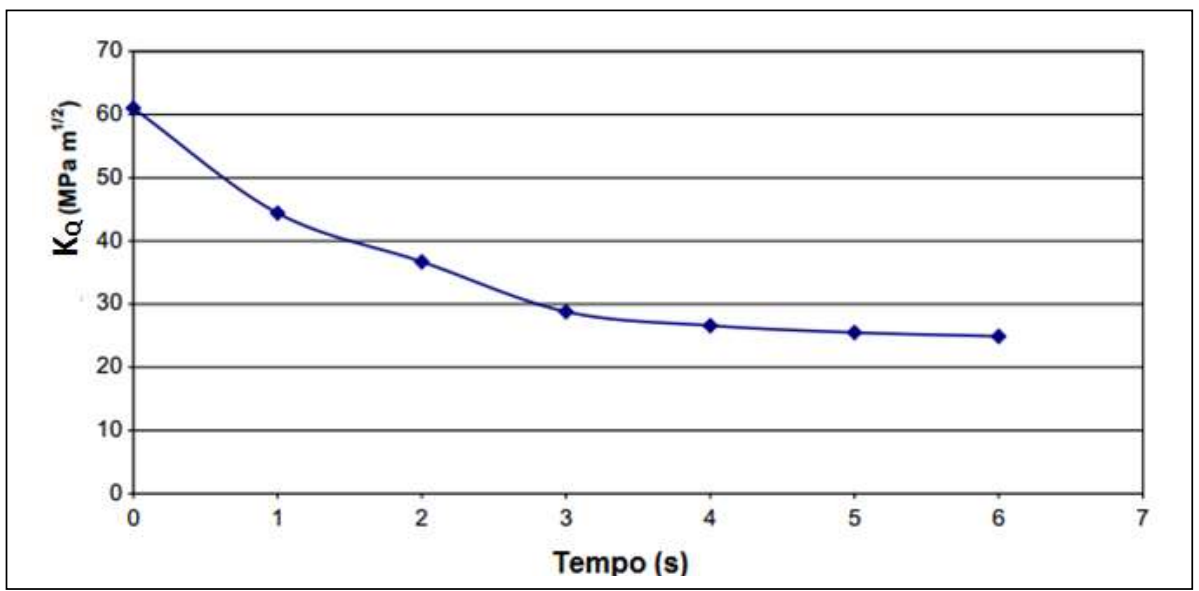

Figura 82 - Redução da tenacidade à fratura aparente $\left(\mathrm{K}_{\mathrm{Q}}\right)$ em função do tempo de hidrogenação (Hardianfard, 2010).

Pela curva também pode se verificar que a partir de $4 \mathrm{~h}$ de hidrogenação não se observa mais a redução da tenacidade à fratura em tensão plana $\left(K_{Q}\right)$, o que indica o alcance da concentração de saturaçã de hidrogênio no material.

O forte efeito do hidrogênio comprovado pela alteração do comportamento à fratura do aço em questão pode ser visualizado pela mudança da morfologia da fratura analisada na fractografia. A superfície de Fratura verificada nos corpos de prova do segundo grupo foi controlada pelo micromecanismo de dimples enquanto que a do terceiro grupo foi frágil controlada pelo micromecanismo de clivagem (Figura 83).

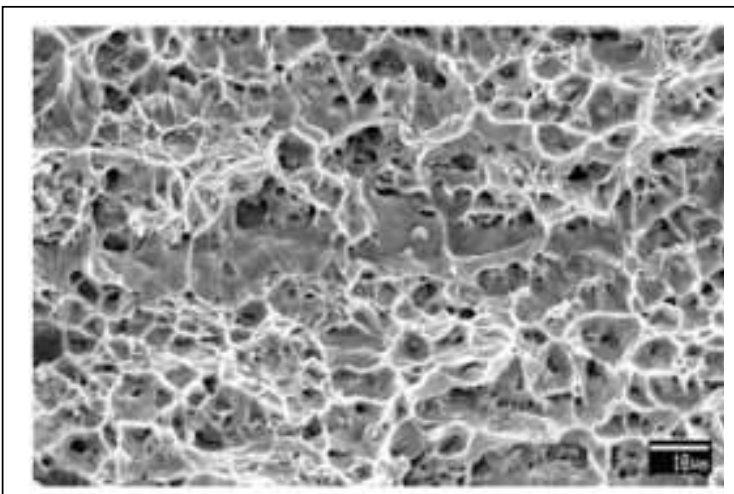

(a)

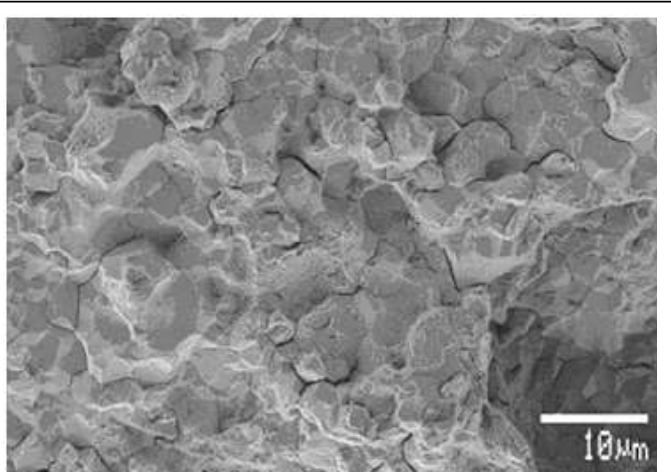

(b)

Figura 83 - a) Superfície de fratura com micromecanismo de dimples. (b) Superfície de fratura com micromecanismo de clivagem (Hardianfard, 2010). 


\subsubsection{Influência a resistência à fadiga}

O comportamento dos materiais na presença de hidrogênio frente a carregamentos cíclicos (fadiga) foi analisado em estudos realizados por pesquisadores a citar Fassina et al. (2012), Murakami (2012) e Vergani et al.(2014)

Fassina et al (2012) avaliou o comportamento de uma trinca de fadiga em aço API 5L X65 na presença de hidrogênio em carregamentos cíclicos com variação de frequência e temperatura. As frequências de carga foram 1 e $10 \mathrm{H}_{\mathrm{z}} \mathrm{e}$ as temperaturas de teste foram $-30{ }^{\circ} \mathrm{C}$ e $23{ }^{\circ} \mathrm{C}$.

Os corpos de prova, do tipo compacto por tensão (CT), foram hidrogenados por método eletroquímico com solução ácido em temperatura ambiente, densidade de corrente de $0,5 \mathrm{~mA} / \mathrm{cm}^{2}$ por $20 \mathrm{~h}$. A técnica de imersão em nitrogênio líquido a - $196{ }^{\circ} \mathrm{C}$ foi utilizada para evitar a saída do hidrogênio após hidrogenação. Foram ensaiados dois corpos de prova para cada combinação de frequência e temperatura.

Fassina et al. (2012), verificou que a presença de hidrogênio na ponta da trinca de fadiga influencia de maneira significativa sua taxa de crescimento.

Comparando os resultados da condição não hidrogenada, foi constatado que o aumento da taxa de crescimento da trinca de fadiga foi de até duas ordens de grandeza. De uma maneira geral, para um mesmo valor de variação do fator intensificador de tensões $(\Delta \mathrm{K})$, a taxa de crescimento da trinca $(\mathrm{da} / \mathrm{dN})$ aumenta quando a temperatura aumenta ou a frequência de carga diminui. A Figura 84 mostra a curva do comprimento da trinca de fadiga em função do número de ciclos obtidos no ensaio. 


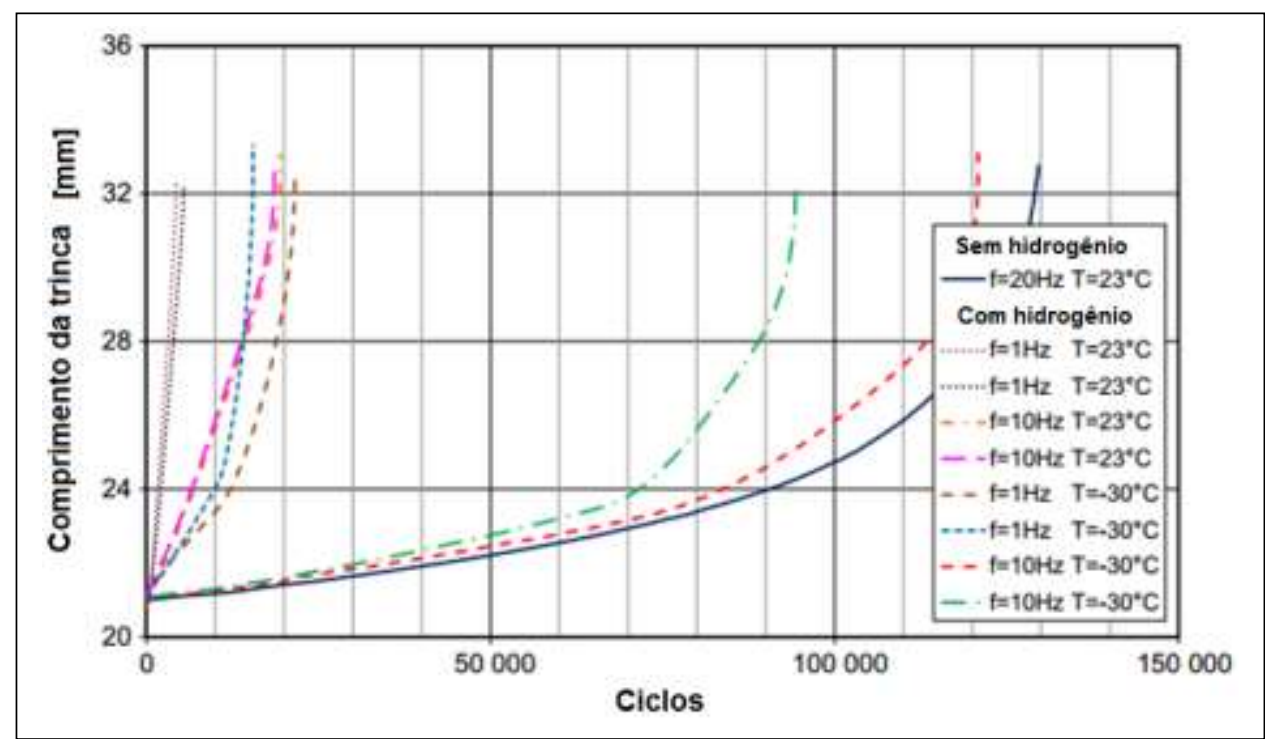

Figura 84 - Influência da temperatura e da frequencia de carga na taxa de crescimento da trinca de fadiga com hidrogênio (Fassina et al., 2012).

Com a investigação do comprimento da trinca em função do número de ciclos, observou-se que a maior taxa de crescimento da trinca de fadiga ocorreu para a combinação da menor frequência de carga com a maior temperatura, ou seja, $1 \mathrm{~Hz}$ e $23{ }^{\circ} \mathrm{C}$. Isto foi atribuído ao efeito causado pelo hidrogênio ser controlado por difusão que é um fenômeno termicamente ativado. A difusão dos átomos de hidrogênio em direção a ponta da trinca que se propaga, e posterior acúmulo, é facilitado com a redução da frequência de carregamento, pois menores frequência de carga proporcionam ciclos com maior período (tempo).

Murakami (2012) analisou os efeitos do hidrogênio associados a frequência de teste no crescimento de uma trinca de fadiga em aços inoxidáveis austeníticos tipo 304, 316 e 316L. Os ensaios de fadiga foram do tipo tração e compressão conduzidos com frequências de carga entre $0,0015 \mathrm{~Hz}$ e $20 \mathrm{~Hz}$ a temperatura ambiente. $\mathrm{O}$ crescimento da trinca de fadiga ocorreu a partir de um furo usinado no corpo de prova.

Murakami (2012) confirmou a redução da área de deformação plástica ao redor da ponta da trinca na presença do hidrogênio. Com o carregamento cíclico, menores capacidade de deformação plástica favorece a propagação, aumentando assim a taxa de crescimento da trinca de fadiga, para ambos os aços estudados.

O aumento do crescimento da trinca é reforçado com a redução da frequência de carga, até mesmo para ensaios feitos com corpos de prova não 
hidrogenados. A Figura 85 mostra o aumento da trinca de fadiga em função do número de ciclos para o aço inoxidável 304.

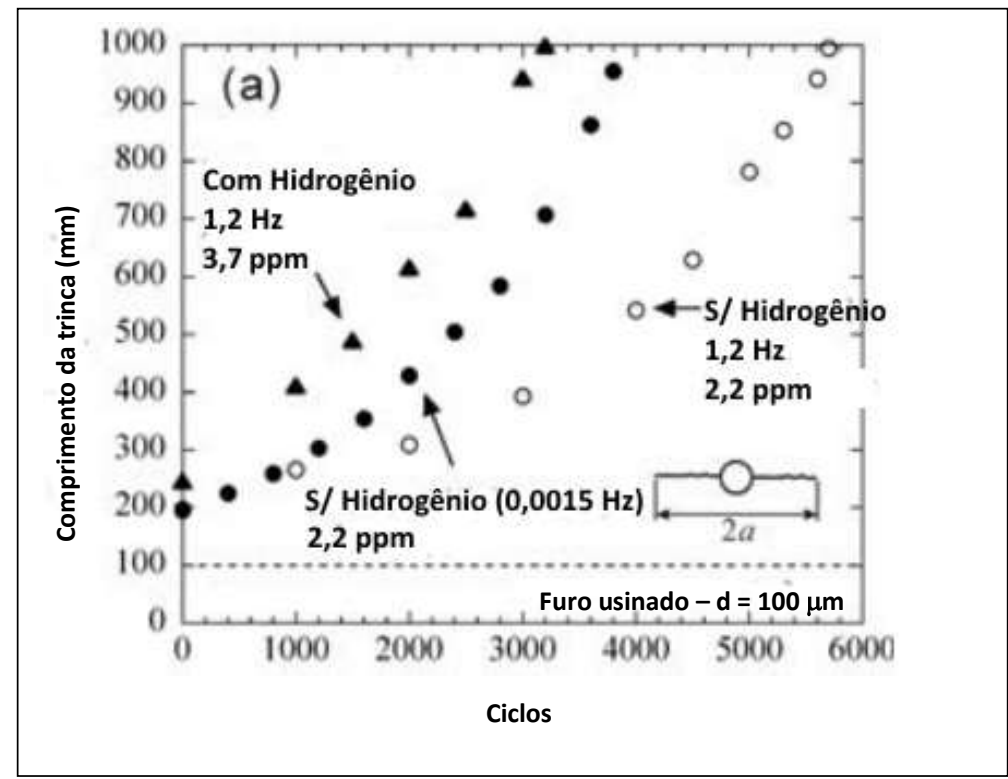

Figura 85 - Influência do hidrogênio e frequência de teste no crescimento da trinca de fadiga do aço inoxidável tipo 304 (Murakami, 2012).

Os efeitos provocados pelo hidrogênio nas propriedades mecânicas de um material são controlados pela difusão. Aços inoxidáveis austeníticos possuem estrutura cristalina cúbica de face centrada (CFC), e o crescimento acelerado da trinca é dependente da frequência de carga porque o hidrogênio tem baixa taxa de difusão em estruturas cristalinas CFC.

Pesquisas realizadas por Vergani et al. (2014) também constataram como a redução da frequência de carregamento de fadiga interfere negativamente no crescimento da trinca de fadiga. Corpos de prova compactos de tração de aço AISI 4130, na condição temperada e revenida hidrogenados, foram testados na frequência de 0,1, 1,0 e $10 \mathrm{~Hz}$ em temperatura ambiente.

Considerando uma mesma variação de fator intensificador de tensões, a maior taxa de crescimento da trinca ocorreu para menor frequência de carga $(0,1$ $\mathrm{Hz}$ ). O aumento da frequência de carga resulta em taxas de crescimento cada vez mais próximas da obtida para o material não hidrogenado. Tal fato pode ser observado na Figura 86. 


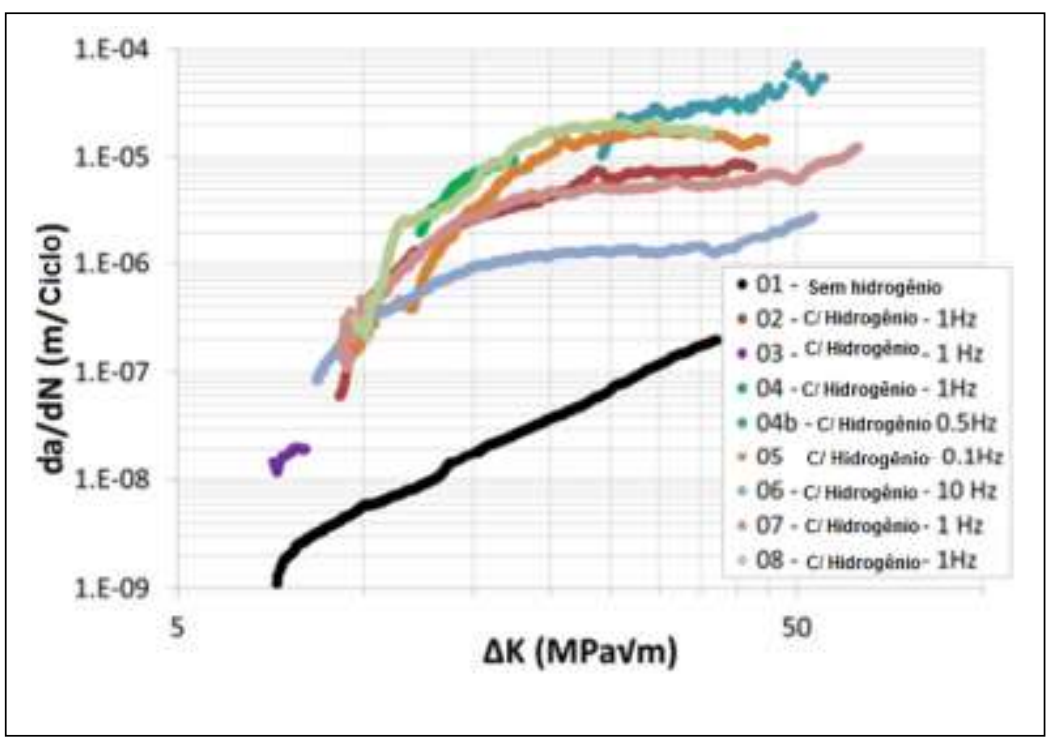

Figura 86 - Taxa de crescimento da trinca em função da frequência de carregamento de fadiga (Vergani et al., 2014). 


\section{Metodologia Experimental}

\subsection{Especificação do Material}

Para o estudo foi escolhido um aço estrutural de baixo carbono e baixa liga, API 5L grau X65 utilizado na fabricação de tubos sem costura, para montagem de linhas de dutos que fazem a condução do petróleo e derivados.

Os tubos com 323,9 mm de diâmetro externo e espessura de parede de 27 mm são produzidos por laminação a quente, conforme norma API 5L (2007) e DNV OS F101 (2007), específica para dutos submarinos. A Tabela 10 apresenta a composição química máxima especificada pelas normas citadas.

Tabela 10 - Composição química do aço estrutural escolhido para este estudo.

\begin{tabular}{|c|c|c|}
\hline & \multicolumn{2}{|c|}{ (\% em peso) } \\
\hline Elemento & DNV OS F101 & API 5L \\
\hline $\mathrm{C}$ & 0,160 & 0,180 \\
\hline $\mathrm{Mn}$ & 1,650 & 1,700 \\
\hline$P$ & 0,020 & 0,025 \\
\hline $\mathrm{S}$ & 0,010 & 0,015 \\
\hline $\mathrm{Si}$ & 0,450 & 0,450 \\
\hline $\mathrm{Al}$ & & 0,500 \\
\hline $\mathrm{Nb}$ & 0,050 & \\
\hline V & 0,090 & $\operatorname{Nota}^{(2)}$ \\
\hline $\mathrm{Ti}$ & 0,060 & \\
\hline Outros & $\operatorname{Nota}^{(1)}$ & $\operatorname{Nota}^{(3)}$ \\
\hline $\mathrm{CE}$ & 0,420 & 0,430 \\
\hline
\end{tabular}

(1) $\mathrm{Cu} \leq 0,50 ; \mathrm{Ni} \leq 0,50 ; \mathrm{Cr} \leq 0,50 ; \mathrm{Mo} \leq 0,50$ e $\mathrm{B} \leq 0,50$.

(2) A não ser que combinado diferente, a soma da concentração de $\mathrm{Nb}$, $\mathrm{V}$ e Ti deve ser $\leq 0,15 \%$.

(3) A não ser que combinado diferente, $\mathrm{Cu} \leq 0,50 ; \mathrm{Ni} \leq 0,50 ; \mathrm{Cr} \leq 0,50$ e $\mathrm{Mo} \leq 0,50$. 
A especificação do aço proposto segundo a norma DNV OS F101 é Grau DNV SMLS 450 SFDP e possui as seguintes especificações:

- SMLS significa sem costura;

- 450 é o limite de escoamento mínimo que corresponde a $450 \mathrm{MPa}$;

- SFDP são requisitos suplementares aplicáveis ao aço exigidos pela norma que possuem os seguintes significados:

- S = aplicação em ambiente com agressividade corrosiva;

- F = aplicação em locais que exigem boa tenacidade;

- P = aplicação em situações de necessidade de deformação plástica, como por exemplo, no lançamento do duto através de navio com carretel;

- D = aplicação para situações de rígido controle dimensional.

As propriedades mecânicas mínimas exigidas pela norma DNV OS F101 (2007) e API 5L (2007) são apresentadas na Tabela 11:

Tabela 11 - Propriedades mecânicas especificadas para o aço estrutural proposto.

\begin{tabular}{|c|c|c|}
\hline $\begin{array}{c}\text { Propriedades Mecânicas } \\
\text { Mínimas }\end{array}$ & DNV OS F101 & API 5L \\
\hline $\begin{array}{c}\text { Limite de Escoamento } \\
\left(\sigma_{\mathrm{ys} 0,5}\right)\end{array}$ & $450 \mathrm{MPa}$ & $450 \mathrm{MPa}$ \\
\hline $\begin{array}{c}\text { Limite de Resistência } \\
\text { Mecânica }\left(\sigma_{\mathrm{us} 0,5)}\right.\end{array}$ & $535 \mathrm{MPa}$ & $535 \mathrm{MPa}$ \\
\hline $\begin{array}{c}\text { Alongamento } \\
\text { Dureza }\end{array}$ & $18 \%$ & $18 \%$ \\
\hline $\begin{array}{c}\text { Energia Absorvida }- \\
\text { técnica Charpy }\end{array}$ & $270 \mathrm{HV} 10$ & $250 \mathrm{HV} 10$ \\
\hline
\end{tabular}

Para confecção de amostras e corpos de prova para as análises mencionadas acima contou-se com matéria prima fabricada em um conversor a oxigênio LD, com capacidade de $80.000 \mathrm{~kg}$. Após a fabricação do ferro gusa fundido, foi feito 
o seu vazamento para o forno panela (metalurgia secundária) para adição de elementos de liga que proporcionarão as propriedades mecânicas desejadas, com temperatura controlada, e tratamento de inclusões feito com cálcio e silício $(\mathrm{CaSi})$.

O estágio seguinte consiste na desgaseificação à vácuo realizada a baixas pressões para remoção de gases, tais como, oxigênio, nitrogênio e hidrogênio. Após a desgaseificação, a aço líquido é submetido a rinsagem através de um borbulhamento de argônio para flotação das inclusões e posterior incorporação á escória.

Após processo metalúrgico para obtenção das propriedades mecânicas foi feito o lingotamento contínuo de tarugos de seção circular de diâmetro igual a $230 \mathrm{~mm}$ e comprimento igual a $6000 \mathrm{~mm}$, em moldes de cobre refrigerados à agua.

O tubo sem costura em sua forma final para extração das amostras e corpos de prova foi obtido por processo de laminação automática, onde um mandril rotativo perfura os tarugos e por deformação plástica a quente o tubo tem seu diâmetro e comprimento aumentados. Após laminação automática, o tubo foi submetido a têmpera com resfriamento em tanque com água seguido de revenimento para obtenção das propriedades mecânicas desejadas para o aço API $5 \mathrm{~L}$ X65.

\subsection{Caracterização microestrutural do material}

\subsubsection{Análise metalográfica}

A caracterização microestrutural foi realizada pela técnica convencional de metalografia. Para tal finalidade foram retiradas amostras no sentido longitudinal (direção de laminação) do tubo para preparação da superfície com lixas de granulometria n. ${ }^{\circ} 220,400,600,800$ e 1200 . O procedimento foi conduzido segundo norma ASTM E407-07e1 (2007).

Após o lixamento foi realizado polimento de acabamento com feltro umidecido com pasta de diamante, em uma politriz manual. Utilizou-se pasta de diamante de $1 \mu \mathrm{m}$ e em seguida a de $0,5 \mu \mathrm{m}$ e o tempo destinado ao polimento foi de 8 minutos. 
$\mathrm{O}$ ataque químico da superfície da amostra foi feito através de imersão em Nital 5\% (solução de ácido nítrico $\left(\mathrm{HNO}_{3}\right)$ e álcool etílico) durante $8 \mathrm{~s}$ para posterior observação em microscópio ótico Zeiss, modelo Imager.M2m.

\subsubsection{Análise de Inclusões}

Este procedimento é estabelecido pela norma ASTM E45-11 (2011) Método D. A análise das inclusões contidas no aço API 5L X65 foi feita em uma superfície polida por observação microscópica de uma área mínima de $190 \mathrm{~mm}^{2}$, obtida pelo acúmulo de campos visualizados em qualquer aumento, desde que com área mínima de $0,5 \mathrm{~mm}^{2}$.

O método D , também conhecido por método de contagem, devido a análise se basear em contagem do número de inclusões nos campos de visualização. Nesta observação microscópica buscou-se através de método comparativo os seguintes itens:

1) Classificar o tipo(s) de inclusão(ões) existentes em um ou mais grupos: sulfetos (grupo A), aluminas (grupo B), silicatos (grupo C) e óxidos (grupo D) baseando-se em um quadro morfológico fornecido pela norma citada e ilustrado na Figura 87.

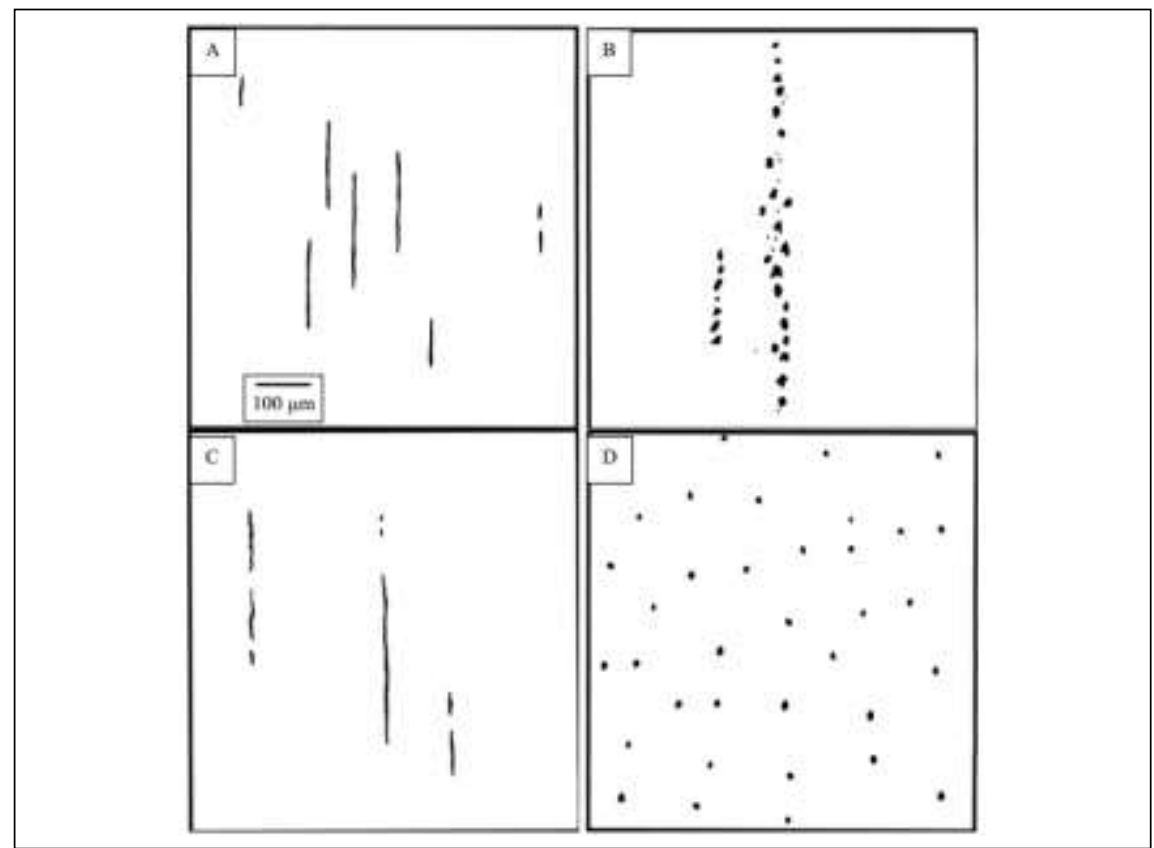

Figura 87 - Morfologia de inclusões em aço. A: tipo sulfeto. B: tipo alumina. C: tipo silicato e D: tipo óxido globular (ASTM E45-11, 2011). 
2) Categorizar as inclusões em séries fina e/ou grossa. Esta classificação é baseada na largura ou diâmetro da inclusão de acordo com a severidade da inclusão $(0,5$ a 3,0).

\subsection{Caracterização de Propriedades Mecânicas}

Para o levantamento das propriedades mecânicas do aço em questão se realizou ensaios mecânicos destrutivos de dureza, tração e impacto. Todos os ensaios mecânicos foram realizados no laboratório de pesquisa e desenvolvimento da Vallourec situado na cidade de Belo Horizonte (MG).

\subsubsection{Ensaio de Dureza}

O ensaio de dureza foi feito pelo método de penetração através da técnica Vickers (HV) segundo a norma ASTM E92 (2008). A carga utilizada foi de 10 kgf.

As medições foram feitas em 12 posições, espaçadas de $120^{\circ}$ ao longo da seção transversal, agrupadas em 3 diferentes posições (A, B e C), conforme Figura 88(a). A escolha da posição para as medições é uma recomendação da norma API 5L (2007), para mostrar a variação da dureza em material submetida a tratamento térmico.

Em cada posição foram feitas 4 medições a 1,5 mm da superfície externa, 4 medições no meio da espessura de parede e 4 medições a 1,5 $\mathrm{mm}$ da superfície interna.. A Figura 88(b) apresenta o posicionamento esquemático dos pontos de medição para o ensaio de dureza. 


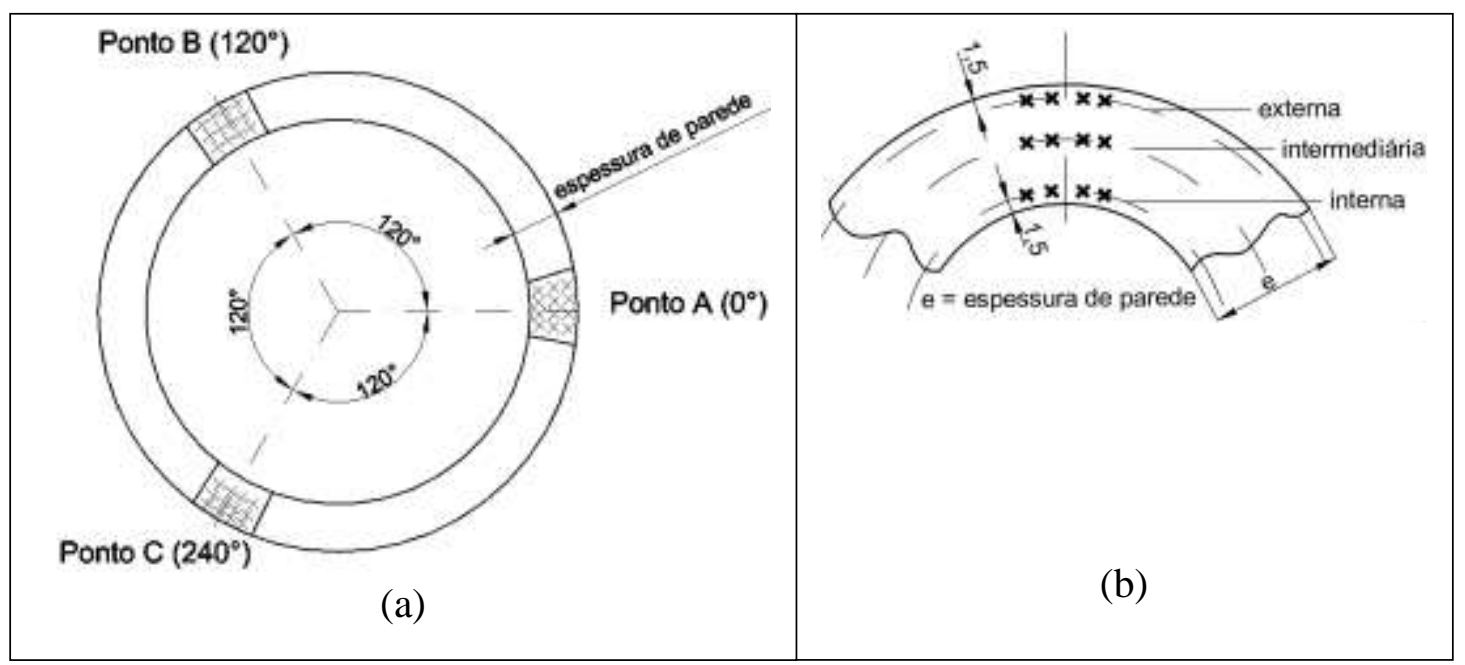

Figura 88- (a) Pontos de medição para o ensaio de dureza Vickers. (b) Medições na espessura de parede Norma API 5L, 2007).

\subsubsection{Ensaio de Tração}

Os corpos de prova para o ensaio de tração, extraídos do tubo sem costura no sentido longitudinal nas posições pé e ponta, do tubo, foram do tipo cilíndrico conforme norma ASTM A-370 (2012).

O posicionamento adotado é devido a ordem de entrada do tubo no forno para tratamento térmico. A ponta é a primeira parte a entrar no forno enquanto que a outra extremidade, denominada pé, entra por último. Sendo assim decidiu-se retirar 2 corpos de prova para verificar a uniformidade das propriedades mecânicas. A Figura 89 mostra a posição de onde foi extraído o corpo de prova.

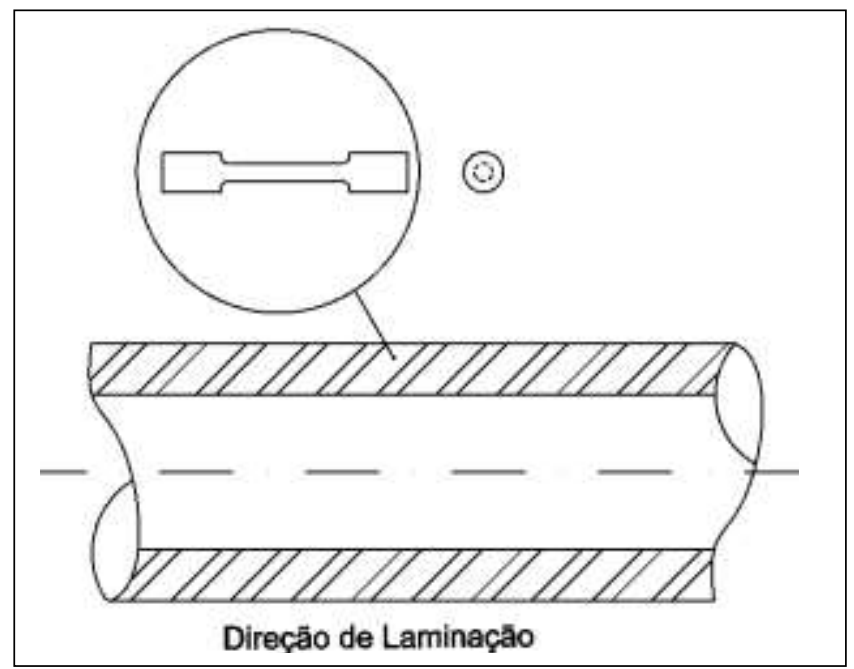

Figura 89 - Esquema da usinagem do corpo de prova para ensaio de tração a partir do tubo sem costura. 
Para o ensaio de tração, realizado a temperatura ambiente $\left(25^{\circ} \mathrm{C}\right)$, utilizouse uma máquina universal, Instron, modelo 1125, de acionamento servohidráulico e célula de carga de 700 kN.

Para a instrumentação dos corpos de prova para monitoramento das deformações adotou-se um medidor de deformação, do tipo extensômetro, posicionado em superfície limpa do comprimento útil do corpo de prova.

Os valores do limite de escoamento e do limite de resistência mecânica foram obtidos a partir da curva tensão $v s$ deformação, onde para o linite de escoamento foi considerado um valor de referência para deformação de $0,5 \%$.

\subsubsection{Ensaio de Impacto}

Os corpos de prova para o ensaio de impacto tipo Charpy foram obtidos a partir da usinagem na direção transversal a de laminação do tubo conforme Figura 90.

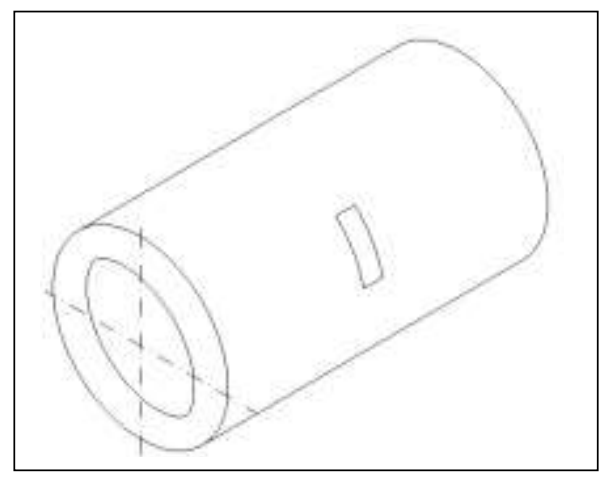

Figura 90 - Orientação para extração do corpo de prova tipo Charpy. Adaptado da norma API 5L, 2007.

As dimensões finais do corpo de prova $55 \times 10 \times 7,5 \mathrm{~mm}$, indicadas na Figura 91, foram alcançadas com a utilização de uma retífica plana e o entalhe central foi realizado com uma fresa na direção de laminação do tubo.

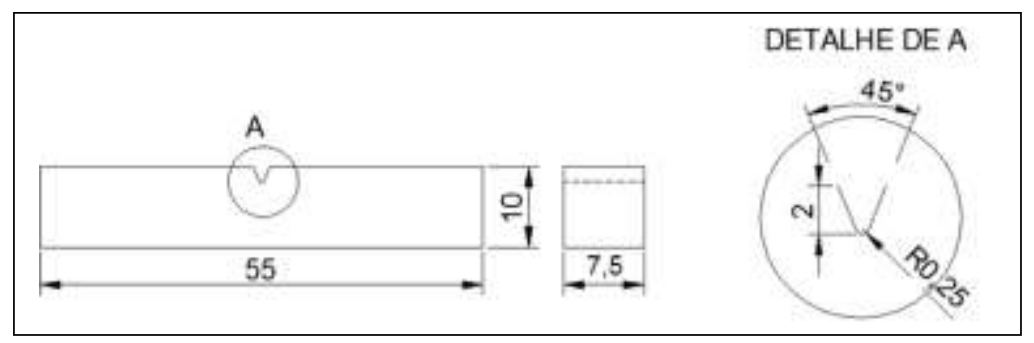

Figura 91 - Dimensões finais do corpo de prova para ensaio Charpy (ASTM E23-12c, 2012). 
A Figura 92 seguinte mostra a configuração final do corpo de prova e o mesmo após término da usinagem.

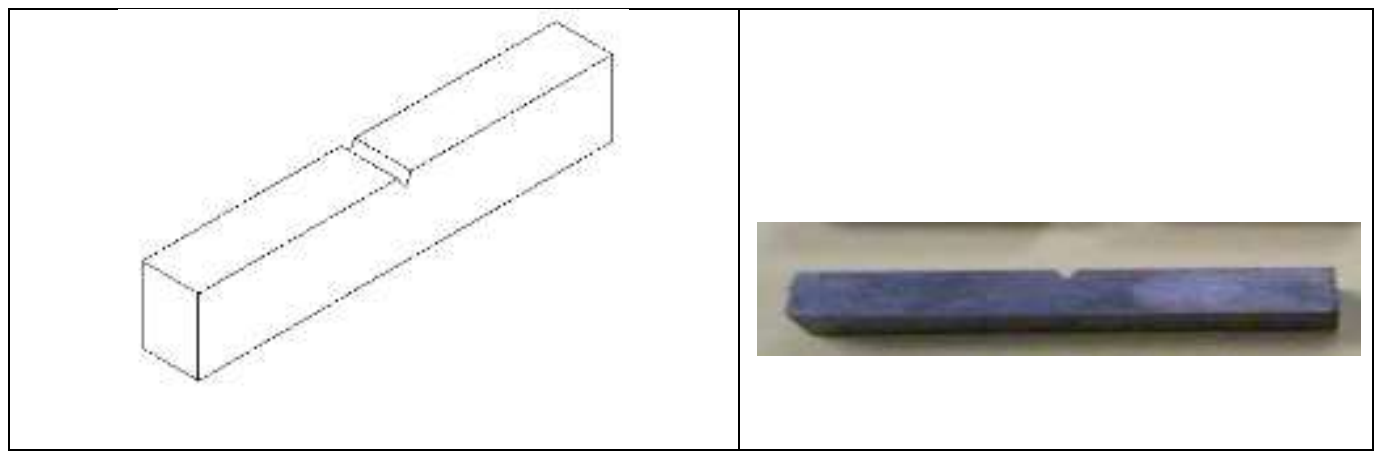

Figura 92- Corpo de prova Charpy segundo norma API 5L(2007) e ASTM E23-12c (2012).

Foram utilizados 15 corpos de prova ensaiados nas seguintes temperaturas: $0{ }^{\circ} \mathrm{C},-10{ }^{\circ} \mathrm{C},-30{ }^{\circ} \mathrm{C},-50{ }^{\circ} \mathrm{C}$ e $-70{ }^{\circ} \mathrm{C}$, divididos em grupos de 3 para cada temperatura de teste.

O ensaio de impacto foi realizado em uma máquina Instron-Wolpert PW30, modelo SI-1D3, controlada por software Impact Testing Instron, com capacidade máxima de $406 \mathrm{~J}$ e constituída de martelo pendular, dial de leitura, suporte para posicionamento do corpo de prova e cutelo. Figura 93 ilustra a máquina utilizada.

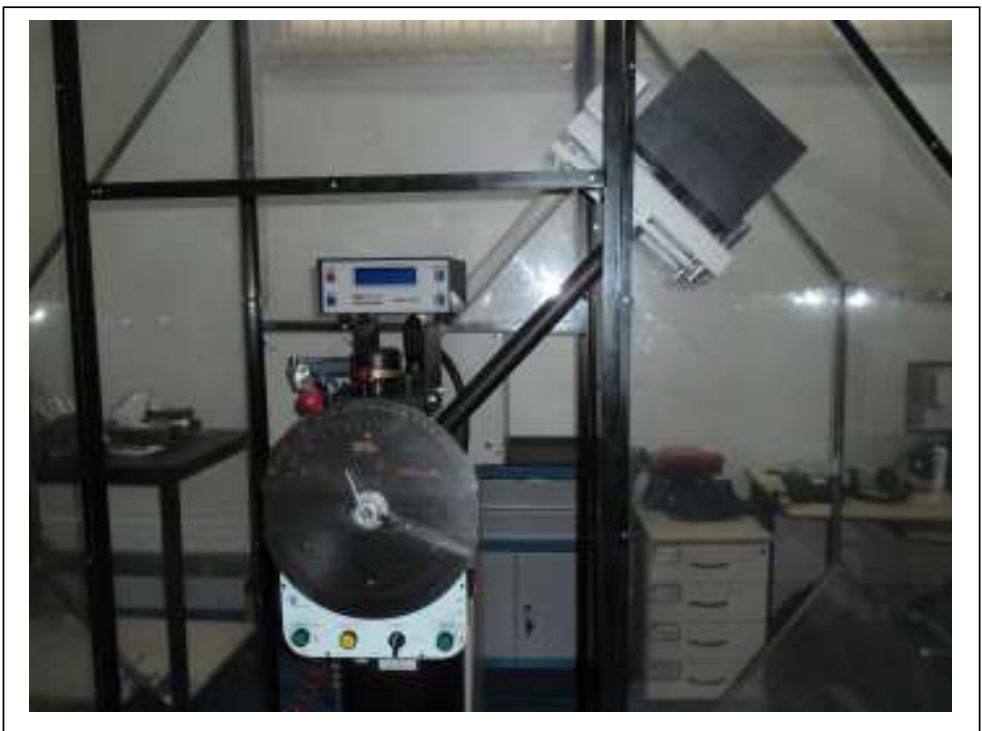

Figura 93 - Máquina de ensaio Charpy para ensaio de impacto (Laboratório de Pesquisa e Desenvolvimento Vallourec, 2013).

Para resfriamento dos corpos de prova foi utilizado a técnica de imersão em uma mistura de água, nitrogênio líquido e gelo para se atingir as temperaturas de ensaio desejadas. A verificação da temperatura do conjunto corpo de prova - meio 
de resfriamento foi realizada com um termômetro de mercúrio para todas as temperaturas de teste.

O ensaio foi realizado imediatamente após resfriamento do corpo de prova e posicionamento do mesmo no suporte da máquina. O impacto do martelo deve ser dado na superfície oposta a superfície do entalhe. Para garantir o correto posicionamento do corpo de prova, é utilizada um pinça gabarito.

\subsection{Avaliação de Tenacidade à Fratura}

Para a avaliação da tenacidade à fratura de aço estrutural escolhido, API 5L $\mathrm{X} 65$, foi adotado uma metodologia experimental dividida em duas fases com as seguintes etapas em comum:

- Retirada dos corpos de prova;

- Usinagem de entalhe central no corpo de prova;

- Pré-trincamento por fadiga;

- Hidrogenação;

- Ensaio de tenacidade à fratura (CTOD e Integral J).

Após ensaio do primeiro lote de corpos de prova, e em função dos resultados obtidos (vide Capítulo 4, item 4.3.4) decidiu-se realizar novos ensaios com corpos de prova entalhados lateralmente para avaliar a influência do side groove na tenacidade à fratura do material.

O fluxograma na Figura 94 ilustra a rotina experimental que foi dividida em duas partes. Tais etapas serão descritas a seguir. 
1.a PARTE

Extração d

corpos de prova
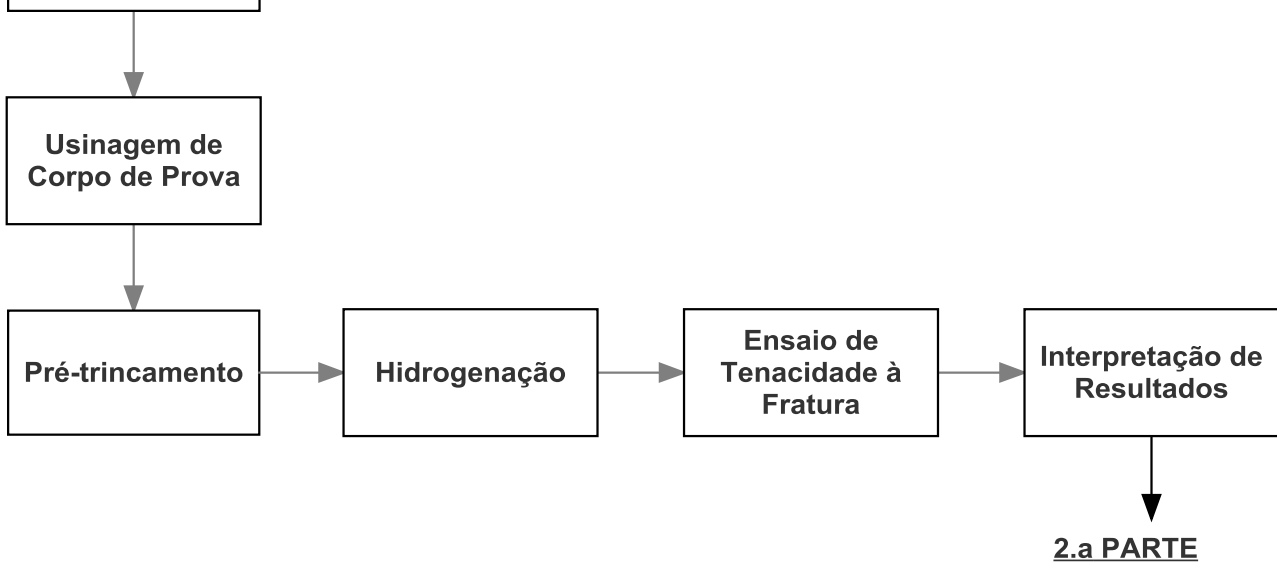

2.a PARTE

Usinagem de

Novos Corpos de Prova

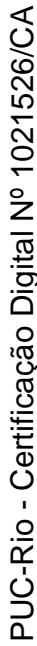

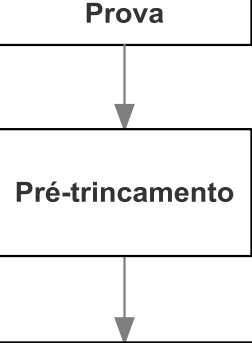

Usinagem de Side

Groove em

Corpos de Prova

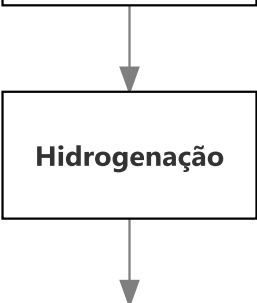

Ensaio de

Tenacidade à

Fratura

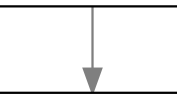

Interpretação de

Resultados

Figura 94 - Fluxograma de avaliação de tenacidade à fratura. 


\subsubsection{Retirada dos Corpos de Prova}

Os corpos de prova de flexão por três apoios extraído no sentido longitudinal do tubo foram submetidos a operação de retífica plana com a finalidade de deixa-los nas dimensões finais e com estado de superfície e tolerância dimensionais e geométricas estabelecidos pela norma BS 7448:1 (1991).

Os corpos de provas nas dimensões finais foram submetidos a operação de fresamento para confecção de entalhe central conforme Figura 95, de modo a ter um corpo de prova com orientação X-Y.

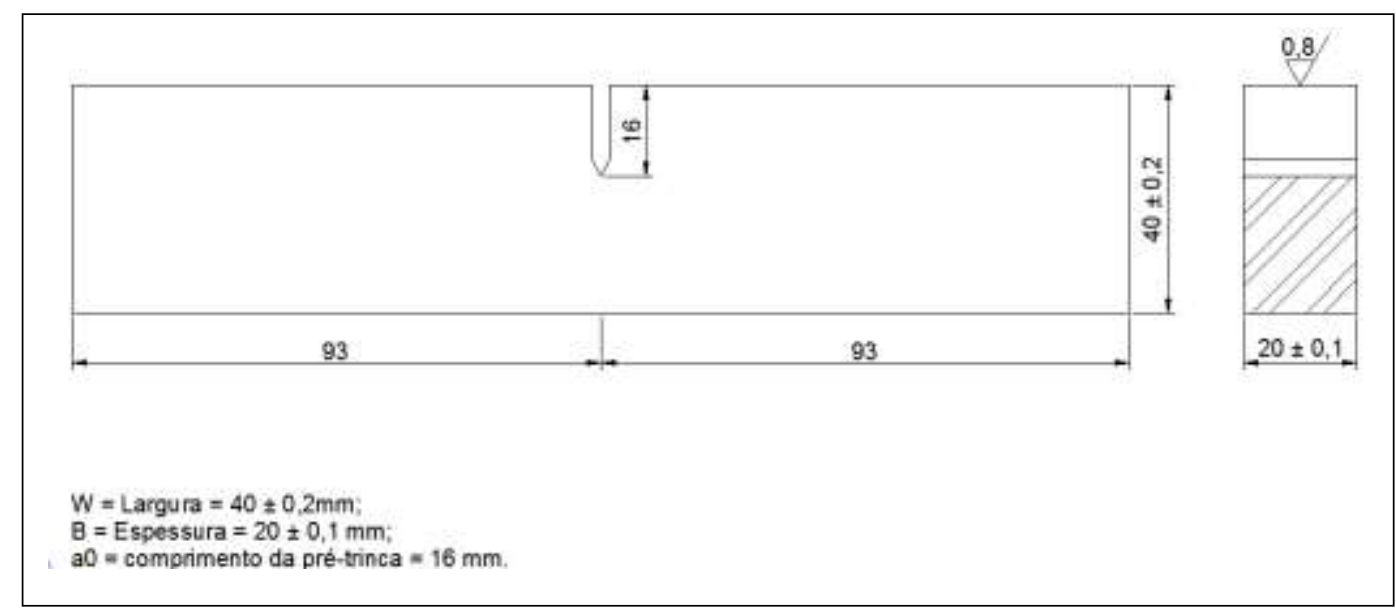

Figura 95 - Dimensões finais do corpo de prova.

O equipamento utilizado foi uma fresadora Romi, modelo D600 de disco com ferramenta de ponta de corte com ângulo em V. A Figura 96 exemplifica a operação de confecção do entalhe central em corpos de prova similares ao utilizado neste trabalho. 


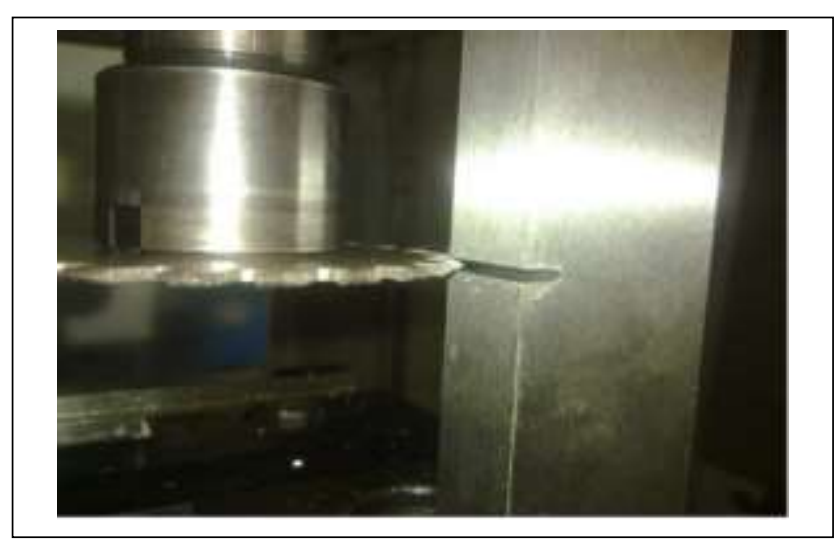

Figura 96 - Fresamento do entalhe do corpo de prova (Souza, 2011).

\subsubsection{Pré-trincamento}

O pré-trincamento do corpo de prova tem o objetivo de introduzir uma descontinuidade mais severa, já que não é possível ter uma ponta aguda $(\rho \rightarrow 0)$, a partir de um entalhe usinado. Para tanto, é necessário a aplicação de carregamentos cíclicos de fadiga ao corpo de prova para iniciar a pré trinca na raiz do entalhe.

Segundo a norma BS 7448-1 (1991), a pré trinca de fadiga deve possuir comprimento mínimo de $1,3 \mathrm{~mm}$ ou $2,5 \% \mathrm{~W}$, e ainda deve estar compreendido entre 0,45 e 0,55W, onde W é a largura do corpo de prova, conforme Figura 95.

Sendo assim, para corpos de prova de $186 \mathrm{~mm}$ x $40 \mathrm{~mm}$ x $20 \mathrm{~mm}$, o comprimento da pré trinca mais entalhe deveria estar entre 18 e $22 \mathrm{~mm}$.

A razão entre o comprimento final da pré-trinca (a) e a largura do corpo de prova $(\mathrm{W})$, a/W, escolhida neste trabalho foi 0,5 . Desta forma o comprimento da pré-trinca a ser alcançado é $4 \mathrm{~mm}$, já que o entalhe possui comprimento igual a $0,4 \mathrm{~W}$, ou seja, $16 \mathrm{~mm}$.

O cálculo da carga máxima de fadiga $\left(\mathrm{F}_{\mathrm{f}}\right)$ a ser aplicada no corpo de prova é obtida a partir da seguinte Equação (68)

$$
F_{f}=\left[\frac{B \times b_{0}{ }^{2} \times\left(\sigma_{y s}+\sigma_{r}\right)}{4 S}\right]=12720 \mathrm{~N}
$$

na qual, 
$\mathrm{B}=$ espessura do corpo de prova $=20 \mathrm{~mm}$;

$\mathrm{b}_{0}=$ ligamento do corpo de prova $=20 \mathrm{~mm} ;$

$\sigma_{\mathrm{ys}}=$ limite de escoamento $=462 \mathrm{MPa}$ (vide item 4.3.2 no capítulo 4);

$\sigma_{\mathrm{us}}=$ limite de resistência mecânica $=555 \mathrm{MPa}$ (vide item 4.3.2 no capitulo 4);

$\mathrm{S}=$ distância entre apoios no corpo de prova $=160 \mathrm{~mm}$;

A razão de carga utilizada nos ensaios foi de $R=0,1$. Desta forma o valor mínimo do carregamento é obtido pela Equação (69).

$$
F_{\min }=0,1 \times F_{f}=1272 N
$$

Os valores da carga média $\mathrm{S}_{\mathrm{p}}$ e amplitude do carregamento $\Delta \mathrm{F}$, foram calculados a partir das Equações (70) e (71), respectivamente.

$$
\begin{aligned}
& S_{P}=\left[\frac{F_{f}+F_{\min }}{2}\right]=6995 N \\
& \Delta F=\left[\frac{F_{f}-F_{\min }}{2}\right]=5760 N \text { na qual, }
\end{aligned}
$$

$\mathrm{F}_{\mathrm{f}}=$ carga de fadiga $[\mathrm{N}]$

$\mathrm{F}_{\min }=$ carga mínima de fadiga $[\mathrm{N}]$;

Em seguida calcula-se o valor máximo do fator intensificador de tensões K(a) pela Equação (72) a seguir:

$$
K(a)=\left[\frac{F_{f} \times f(a / W)}{B \times \sqrt{W}}\right]
$$

na qual,

$\mathrm{F}_{\mathrm{f}}=$ carga de fadiga $[\mathrm{N}]$;

$\mathrm{f}(\mathrm{a} / \mathrm{W})=$ fator geométrico;

$\mathrm{W}=$ largura do corpo de prova $[\mathrm{m}]$;

$\mathrm{B}=$ espessura do corpo de prova $[\mathrm{m}]$; 
A partir do fator intensificador de tensões máximo $K(a)$ se obtém o fator intensificador de tensões mínimo $K_{\text {mín }}(a)$ e amplitude do fator intensificador de tensões $\Delta \mathrm{K}(\mathrm{a})$ pela Equação (73) e (74):

$$
\begin{gathered}
K_{\text {min }}(a)=K(a) \times 0,1 \\
\Delta K(a)=K(a)-K_{\text {min }}(a)
\end{gathered}
$$

Após cálculo dos parâmetros para carregamento de fadiga, o corpo de prova é posicionado na máquina Instron de capacidade $10 \mathrm{kN}$ e fixado com uma précarga de $0,4 \mathrm{kN}$. Foi adotada uma taxa de crescimento da trinca por ciclo (da/dN) menor que $10^{-4} \mathrm{~mm} /$ ciclo para que o crescimento da pré-trinca, a partir da raiz do entalhe ocorra sem deformação plástica em sua ponta durante o carregamento cíclico de fadiga.

O carregamento de fadiga para abertura da pré trinca iniciou-se após inserção no software $\mathrm{Da} / \mathrm{DN}$ das informações relacionadas a geometria do corpo de prova, propriedades mecânicas do material e ao carregamento.

Durante o carregamento de fadiga realizou-se inspeções visuais no corpo de prova com auxílio de lupa e luz branca para um eficiente acompanhamento do crescimento da pré-trinca até o comprimento estabelecido de $4 \mathrm{~mm}$.

\subsubsection{Hidrogenação}

O processo de hidrogenação dos corpos de provas foi realizado após prétrincamento no laboratório de corrosão da Vallourec segundo norma NACE TM 0284-2003 (2003) (Evaluation of Pipeline and Pressure Vessel Steels for Resistance to Hydrogen-Induced Cracking). Esta estabelece procedimento para avaliação da resistência de aços aplicados como "pipeline" (tubos) e vasos de pressão ao trincamento (nucleação e propagação) induzido pelo hidrogênio. Associada a norma NACE TM 0284-2003 (2003), também foi utilizado a norma NACE 0177-2005 (2005) que estabelece métodos para avaliar a resistência causada pela absorção de hidrogênio e corrosão anódica em uma amostra 
submetida a tensões. Porém, neste trabalho a norma NACE 0177-2005 foi utilizada para especificar a solução de hidrogenação, pois o processo de hidrogenação ocorreu sem aplicação de carregamento mecânico ao corpo de prova.

A hidrogenação consistiu em submergir os corpos de prova com suas superfícies livres de óxidos e/ou impurezas em uma cuba com uma solução ácida especificada pela norma NACE TM 0177-2005 por um tempo mínimo de 96 h, para uma espessura de corpo de prova igual a $20 \mathrm{~mm}$, a temperatura ambiente.

O volume mínimo de solução de hidrogenação indicada pela norma NACE TM 0284-2003 (2003), para uma imersão eficiente, é de $3 \mathrm{ml}$ para cada $\mathrm{cm}^{2}$ de área e os corpos de prova devem ser colocados na cuba com suas maiores superfícies na posição vertical e separados das paredes da cuba e dos outros corpos de prova por haste de material inerte (vidro ou material não metálico), com diâmetro mínimo de 6 mm, conforme mostrado na Figura 97(a).A Figura 97(b) ilustra os corpos de prova imersos na solução de hidrogenação no laboratório de corrosão da Vallourec.

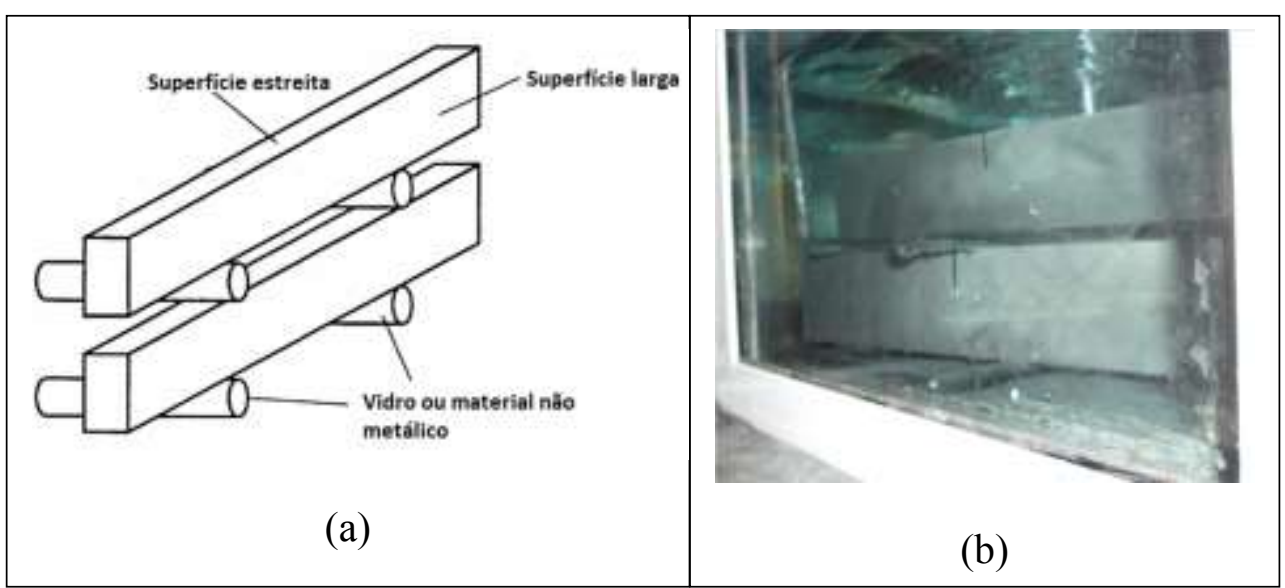

Figura 97 - (a) Disposição dos corpos de prova na cuba segundo NACE TM0284-2003 (2003). (b) Corpos de prova posicionados para hidrogenação no laboratório de corrosão. Adaptada pela autora, 2014.

A solução ácida (solução A) é composta pelos seguintes elementos (percentuais em peso): $5 \%$ de cloreto de sódio e 0,5\% de ácido acético glacial dissolvidos em água deionizada. O meio corrosivo foi atingindo pelo borbulhamento de sulfeto de hidrogênio $\left(\mathrm{H}_{2} \mathrm{~S}\right)$ gasoso a pressão e temperatura ambiente associado ao controle do potencial hidrogênio da solução $(\mathrm{pH})$ que deve 
ser mantido entre 2,6 e 2,8. Vale ressaltar que durante o tempo de hidrogenação o pH da solução não deve ser maior que 4,0.

A Figura 98, a seguir, mostra um esquema da instalação utilizada para o processo de hidrogenação.

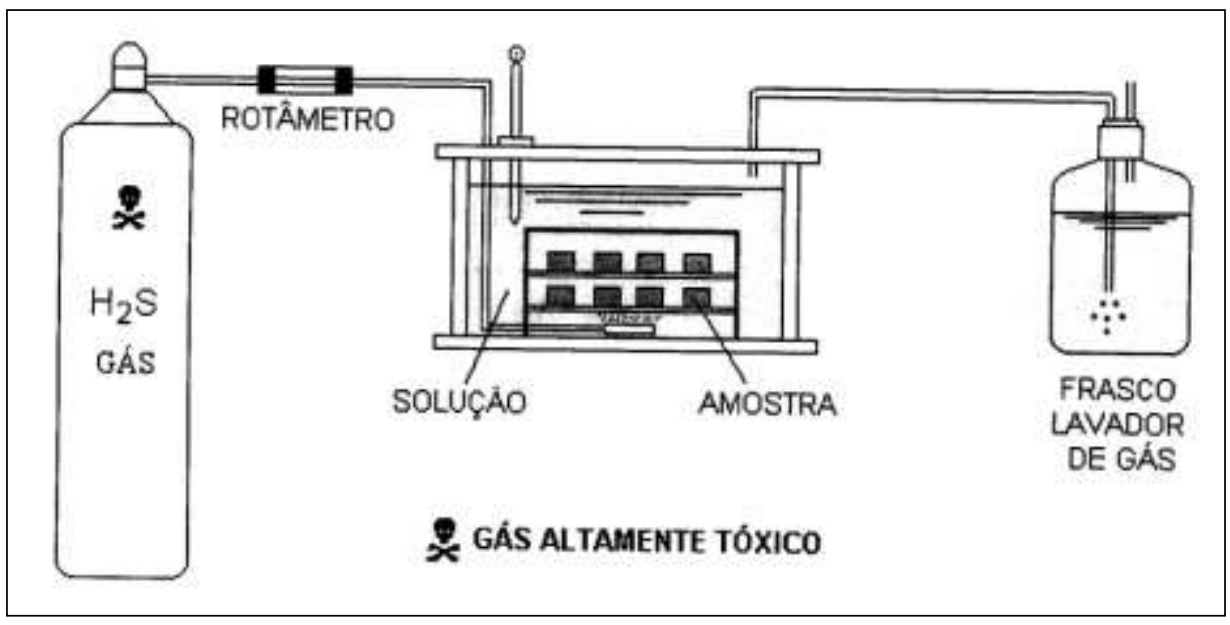

Figura 98 - Instalação para hidrogenação dos corpos de prova de acordo com NACE TM 02842003(Menezes, 2006).

De um total de 30 corpos de prova do tipo flexão por três apoios disponibilizados para o estudo, 24 foram organizados em 4 grupos compostos por 6 unidades para a hidrogenação. Os tempos de hidrogenação adotados neste trabalho foram 168, 96 e $48 \mathrm{~h}$. Deve-se dar ênfase que o restante dos corpos de prova (6 unidades - grupo A) não foram submetidos a hidrogenação, com o intuito de comparar os resultados obtidos com os do ensaio realizado com corpos de prova na condição hidrogenada. A Figura 99 ilustra a organização dos corpos de prova para a hidrogenação.

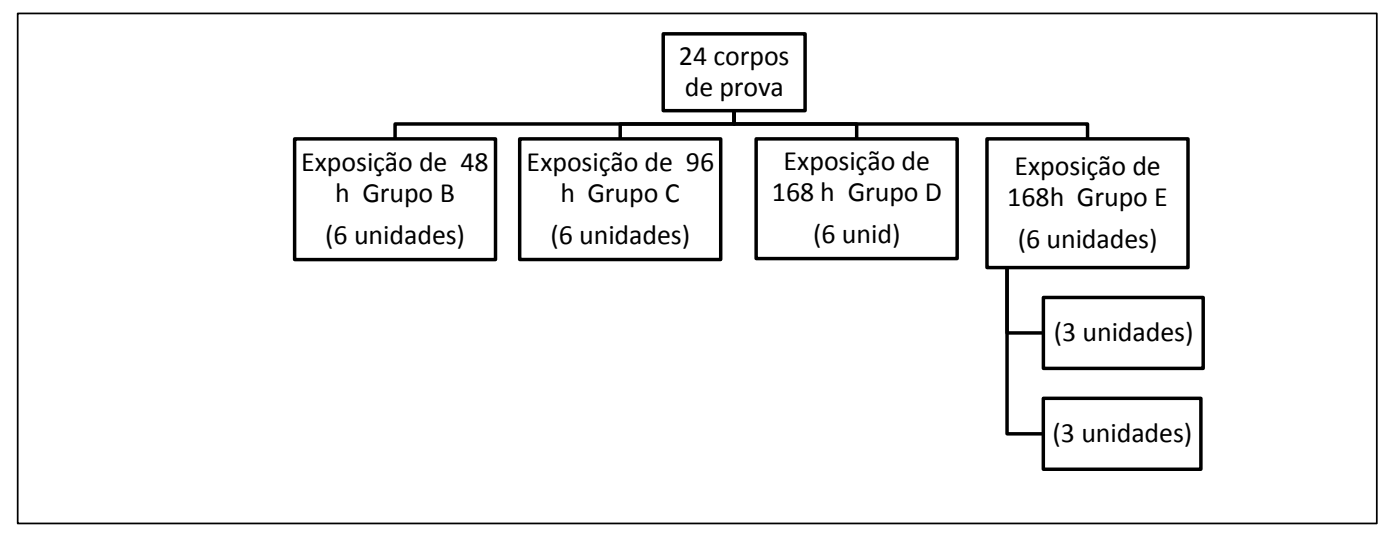

Figura 99 - Divisão dos corpos de prova para hidrogenação. 
Apesar do grupo D e E terem a mesma quantidade de corpos de prova hidrogenados, a subdivisão do grupo $\mathrm{E}$ foi necessária devido a realização de ensaios de tenacidade à fratura em velocidades diferente do realizado no grupo D.

\subsection{Ensaio de Tenacidade à Fratura}

Após decorrido o tempo estipulado para a hidrogenação, cada corpo de prova foi retirado da solução para imediata realização do ensaio de tenacidade à fratura. A montagem do corpo de prova se deu com o posicionamento do mesmo no dispositivo de aplicação de carga, de modo a se obter flexão com modo I de carregamento na ponta da trinca. A Figura 100 ilustra esquema da montagem do corpo de prova na máquina de ensaio.

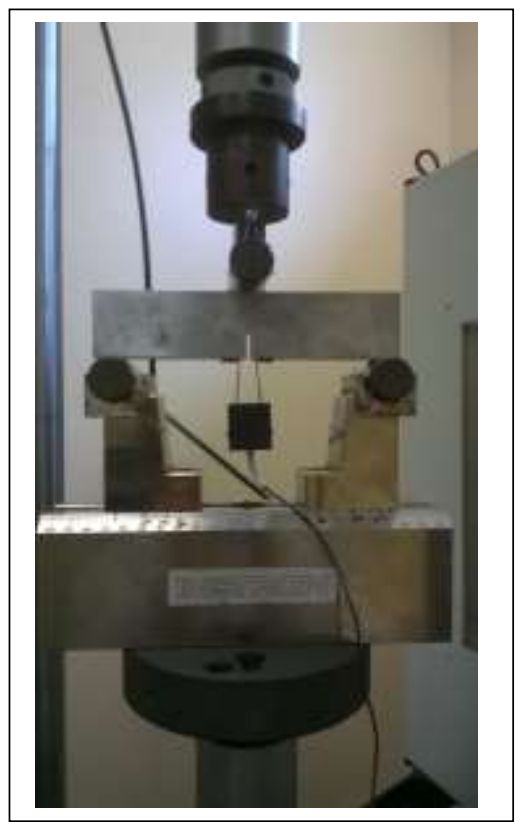

Figura 100 - Corpo de prova na máquina para ensaio de CTOD.

Para atingir a temperatura do ensaio, estabelecida em $-30^{\circ} \mathrm{C}$, utilizou-se uma câmara de resfriamento alimentada com gás dióxido de carbono $\left(\mathrm{CO}_{2}\right)$. Após posicionamento do corpo de prova na máquina de ensaio, a câmara é colocada ao redor do corpo de prova, de modo que o mesmo fique fechado em seu interior para ser resfriado pelo $\mathrm{CO}_{2}$. 
A Figura 101 mostra a câmara mencionada acima, assim como a máquina de ensaio e seu mecanismo de fixação do corpo de prova.

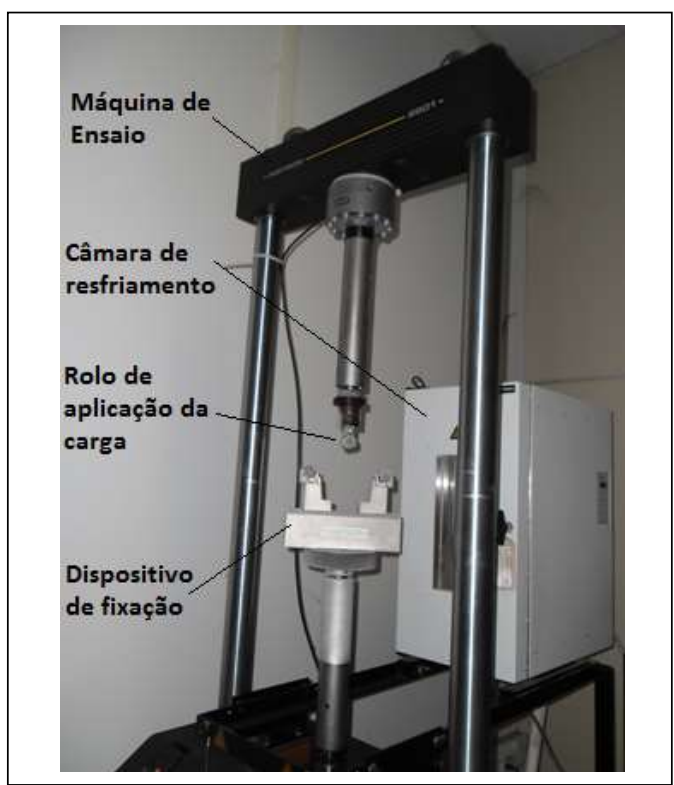

Figura 101 - Máquina de ensaio de CTOD do laboratório de pesquisa e desenvolvimento da Vallourec.

Depois de alcançada a temperatura de $-30{ }^{\circ} \mathrm{C}$ na superfície do corpo de prova, o mesmo foi mantido nesta temperatura por tempo suficiente para se garantir a uniformidade da temperatura em toda sua espessura. De acordo com a norma BS 7448:1 (1991), o tempo para uniformização (encharcamento) da temperatura do corpo de prova é de $1 \mathrm{~min} / \mathrm{mm}$, resultando assim em um tempo total de 20 minutos para toda sua espessura. Também é estabelecido por norma que a faixa de temperatura do ensaio deve estar compreendida em $\pm 2{ }^{\circ} \mathrm{C}$.

O início do ensaio ocorreu após inserção do tipo de corpo de prova e seus parâmetros geométricos, temperatura de teste, umidade relativa do ambiente propriedades mecânicas do material, dados do pré-trincamento, amplitude do fator intensificador de tensões $\left(\Delta \mathrm{K}_{\mathrm{a}}\right)$, velocidade de teste, entre outros no software $\mathrm{K}_{\mathrm{Ic}^{-}}$ CTOD. As velocidades de teste adotadas para o trabalho foram $0,25 \mathrm{~mm} / \mathrm{min}$ (grupo E), 0,5 mm/minuto (grupo A e D) e 1,0 mm/minuto (grupo B, C e E) e 1,5 $\mathrm{mm} / \mathrm{min}$ (grupo B).

Durante o decorrer do ensaio, os valores de carga e deslocamento da abertura da boca da trinca foram continuamente monitorados e um gráfico carga 
vs deslocamento de abertura da boca da trinca (CMOD) foi gerado simultaneamente a realização do ensaio. Para cálculo do CTOD, a carga e o deslocamento de abertura da boca da trinca foram obtidos diretamente da análise do gráfico.

Nesta etapa do trabalho, deve ser comentado que existiu uma limitação física do ensaio de CTOD, em função da capacidade de abertura nominal máxima do clip gage, que foi de $5 \mathrm{~mm}$. Nesta abertura do medidor, os ensaios foram interrompidos automaticamente pelo software controlador da máquina, $K_{I c_{-}} C T O D$ Fracture Testing que coincidiu com um carregamento do corpo de prova ainda crescente, caracterizando naquele instante do ensaio a ausência de um evento físico relevante do material que impossibilitou a obtenção dos valores de CTOD referentes à condição crítica $\left(\delta_{\mathrm{c}}\right)$, última $\left(\delta_{\mathrm{u}}\right)$ ou de carga máxima $\left(\delta_{\mathrm{m}}\right)$.

Em função dos resultados obtidos nos ensaios descritos anteriormente se optou por aumentar a severidade do ensaio utilizando entalhes laterais para obter um parâmetro de tenacidade do material associado a um evento físico relevante, ou seja, $\delta_{\mathrm{c}}, \delta_{\mathrm{u}}$ ou $\delta_{\mathrm{m}}$. Foi seguido orientações estabelecidas pela norma ASTM 1820-11 (2011), já que a norma BS 7448:1 (1991) não comtempla o uso de entalhes laterais. A Figura 102 apresenta esquema de um corpo de prova entalhado lateralmente.

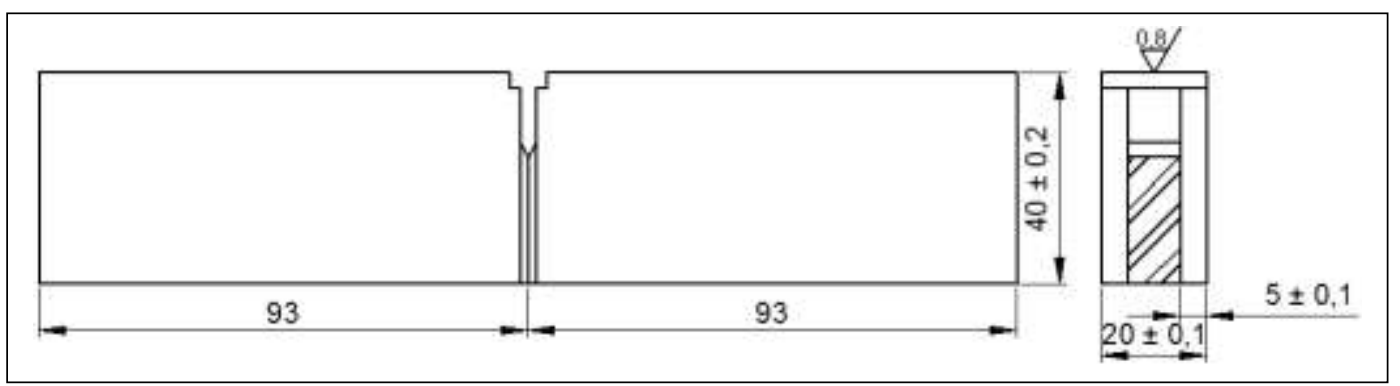

Figura 102 - Corpo de prova SENB com entalhe lateral.

A usinagem do entalhe lateral foi feito em fresadora com uma fresa de aço rápido, também utilizada para confecção de entalhe charpy, no Instituto Tecnológico da PUC-Rio (ITUC). O entalhe possui ângulo de $22,5^{\circ}$ e sua extremidade possui raio de curvatura igual a $0,25 \mathrm{~mm}$. A Figura 103 ilustra uma das etapas de confecção do entalhe lateral. 


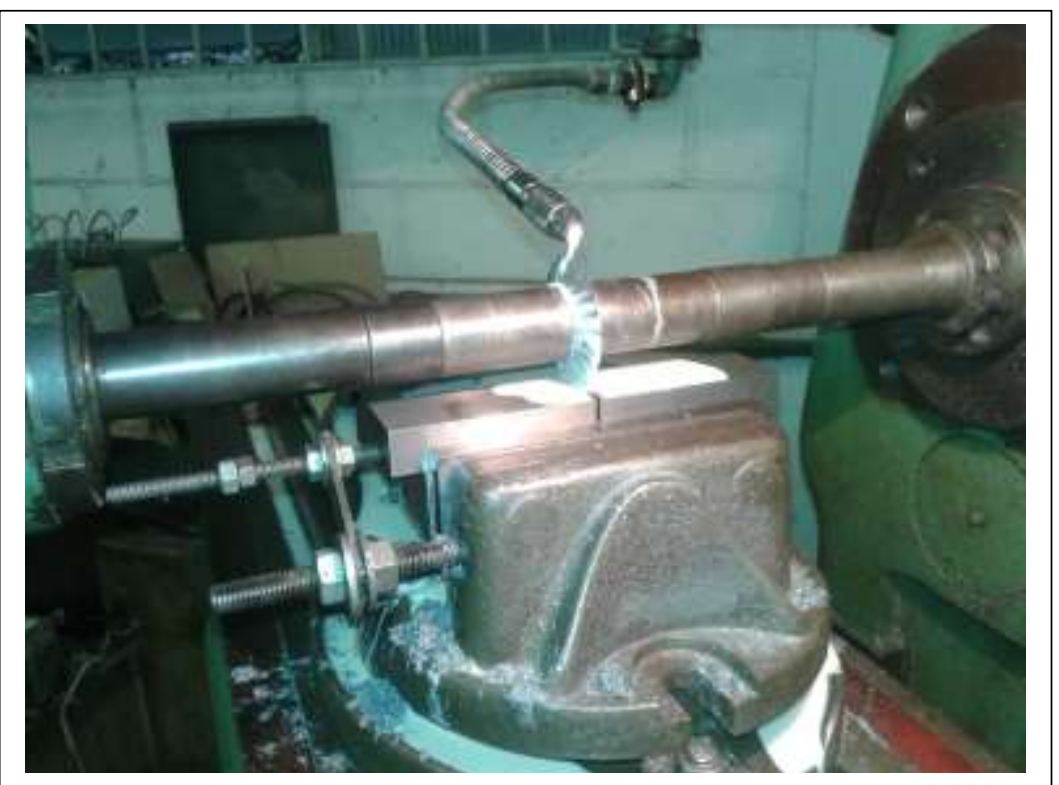

Figura 103 - Usinagem de entalhe lateral nos corpos de prova no laboratório do ITUC-RJ..

\subsubsection{Validade do Entalhe Lateral}

Inicialmente se optou por uma redução de $25 \%$ da espessura de um único corpo de prova, o que correspondeu a dois entalhes laterais com profundidade equivalente a 2,5 $\mathrm{mm}$ cada um. Este corpo de prova foi testado a $-30{ }^{\circ} \mathrm{C}$ sem carga de hidrogênio para verificação da funcionalidade dos entalhes laterais.

Em função dos resultados obtidos, vide item 4.3.4, se decidiu por uma redução de $50 \%$ da espessura de um segundo corpo de prova, correspondendo a dois entalhes laterais com profundidade equivalente a $5 \mathrm{~mm}$ cada um. De maneira idêntica, o segundo corpo de prova foi testado como o primeiro corpo de prova, ou seja, $\mathrm{a}-30{ }^{\circ} \mathrm{C}$ e sem carga de hidrogênio.

\subsubsection{Preparação dos Corpos de Prova}

Embora os ensaios dos corpos de prova com 50\% de redução de espessura tenham atendido as expectativas de obtenção do $\delta_{\mathrm{m}}$, vide item 4.3 .4 decidiu-se usinar entalhes mais severos em outra bateria de corpos de prova, com profundidade de $7 \mathrm{~mm}$, o que correspondeu a uma redução de espessura de $70 \%$ objetivando a determinação do $\delta_{c}$. 


\subsubsection{Ensaios}

Os ensaios com os corpos de prova entalhados lateralmente e com carga de hidrogênio seguiram a metodologia descrita no item 3.5.

\subsubsection{Medição do Comprimento Real da Pré-Trinca}

Para a avaliação da tenacidade à fratura é necessário conhecimento do comprimento real da pré-trinca de fadiga. Para esta finalidade, o corpo de prova após o ensaio de CTOD foi imerso em nitrogênio líquido, a temperatura de $196^{\circ} \mathrm{C}$, por 15 minutos e posteriormente rompido com auxílio de um martelo. A imersão em nitrogênio líquido tem o objetivo de fazer que as características de fratura no ligamento do corpo de prova sejam diferentes das características da propagação da trinca durante o ensaio de CTOD.

Para medição do comprimento real da pré-trinca de fadiga (entalhe mais pré-trinca) deve-se seguir procedimento estabelecido pela norma BS 7448:1 (1991) onde se deve medir o comprimento da pré-trinca em nove pontos posicionados ao longo da espessura do corpo de prova conforme esquema da Figura 104. A medição foi realizada em um analisador de imagens.

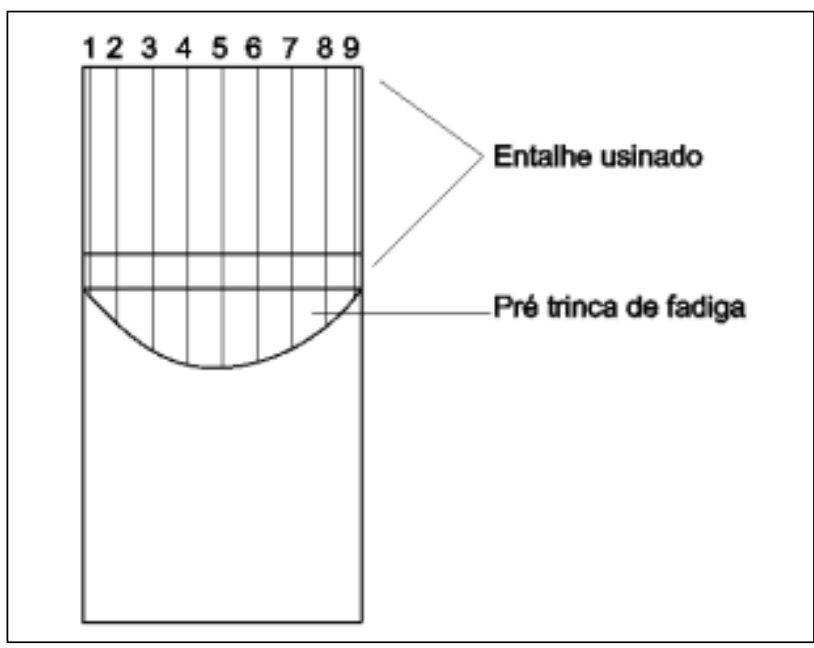

Figura 104 - Esquema para medição do comprimento real da pré-trinca de fadiga. Adaptado da norma BS 7448:1 (1991).

Vale ressaltar que as medições das posições 1 e 9 são feitas a $1 \%$ da espessura do corpo de prova. 
O comprimento real da pré-trinca foi calculado a partir de uma média da propagação estável da pré-trinca nas laterais do corpo de prova com a propagação verificada na parte central do corpo de prova. A Equação (75) abaixo representa o exposto acima:

$$
a_{r}=\frac{\left(a_{1}+a_{9}\right) / 2+\left(a_{2}+a_{3}+a_{4}+a_{5}+a_{6}+a_{7}+a_{8}\right)}{8}
$$

\subsection{Fractografia}

Após a medição do comprimento real da pré-trinca de fadiga $\left(\mathrm{a}_{\mathrm{r}}\right)$, as superfícies de fratura, dos corpos de prova na condição com e sem hidrogênio foram submetidas a fractografia para avaliação da morfologia da propagação da pré-trinca durante o ensaio.

A fractografia foi realizada em microscópico eletrônico de varredura (MEV), fabricante Hitachi, modelo TM 3000 com capacidade de ampliação de até 30.000x e resolução de $30 \mathrm{~nm}$.

Para a análise da superfície de fratura, a amostra foi posicionada na superfície do porta amostra no interior do microscópio eletrônico onde o ajuste da distancia da superfície até o canhão de elétrons se deu por um parafuso ajustador de altura.

Após os ajustes, a amostra é fechada na câmara do microscópio e submetida a vácuo para maximizar a ação do feixe de elétrons emitido pelo canhão de elétrons. O vácuo é necessário para eliminar as possíveis colisões dos elétrons com as moléculas existentes no ar, permitindo assim que os eletróns atinjam a superfície da amostra sem desvios.

Com as análises da superfície de fratura em aumentos significativos, na faixa de 1500 - 2000X, foi possível analisar a superfície de fratura e mostrar o micromecanismo de fratura atuante durante a propagação da trinca com e sem o hidrogênio. 


\section{Resultados e Discussões}

\subsection{Composição Química}

O resultado da análise da composição química retirada da amostra do tubo do aço API 5L X65 está apresentada na Tabela 12, assim como os limites de cada elemento especificados por norma.

Tabela 12 - Composição química do aço API 5L X65.

\begin{tabular}{|c|c|c|c|}
\hline Elemento & \% em peso & $\begin{array}{c}\text { Especificação } \\
\text { DNV }\end{array}$ & $\begin{array}{c}\text { Especificação } \\
\text { API 5L }\end{array}$ \\
\hline $\mathrm{C}$ & 0,09 & 0,16 & 0,18 \\
\hline $\mathrm{Mn}$ & 1,41 & 1,65 & 1,70 \\
\hline $\mathrm{P}$ & 0,01 & 0,02 & 0,025 \\
\hline $\mathrm{S}$ & 0,002 & 0,01 & 0,015 \\
\hline $\mathrm{Si}$ & 0,26 & 0,45 & 0,45 \\
\hline $\mathrm{Cu}$ & 0,01 & 0,50 & 0,50 \\
\hline $\mathrm{Ni}$ & 0,01 & 0,50 & 0,50 \\
\hline $\mathrm{Cr}$ & 0,06 & 0,50 & 0,50 \\
\hline $\mathrm{Mo}$ & 0,06 & 0,50 & 0,50 \\
\hline $\mathrm{Al}$ & 0,032 & - & 0,50 \\
\hline $\mathrm{Nb}$ & 0,028 & 0,05 & 0,15 \\
\hline $\mathrm{V}$ & 0,04 & 0,15 & 0,15 \\
\hline $\mathrm{Ti}$ & 0,002 & 0,15 & 0,15 \\
\hline
\end{tabular}

A partir dos valores encontrados pode-se perceber que a especificação do aço em questão está de acordo com o especificado pelas normas API 5L (2007) e DNV OS F101 (2007). 
Com base na Tabela 13 é possível calcular o carbono equivalente (CE) através da Equação (76):

$$
\% C E=C+\frac{\% M n}{6}+\frac{(\% C r+\% M o+\% V)}{5}+\frac{(\% N i+\% C u)}{15}
$$

Pela Equação (76), o carbono equivalente (CE) do aço API 5L X65 é igual a 0,358, o que também está de acordo com o especificado pelas norma API 5L (2007) e DNV OS F101 (2007).

\subsection{Caracterização Microestrutural}

\subsubsection{Análise Metalográfica}

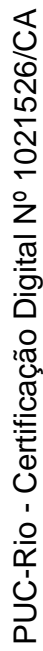

A análise microestrutural de uma amostra do aço API 5L X65, retirada no sentido transversal, do tubo revelou o esperado para um aço submetido a tratamento térmico de têmpera seguido de revenimento. Foi observada uma microestrutura martensítica revenida. A Figura 105 ilustra a microestrutura encontrada

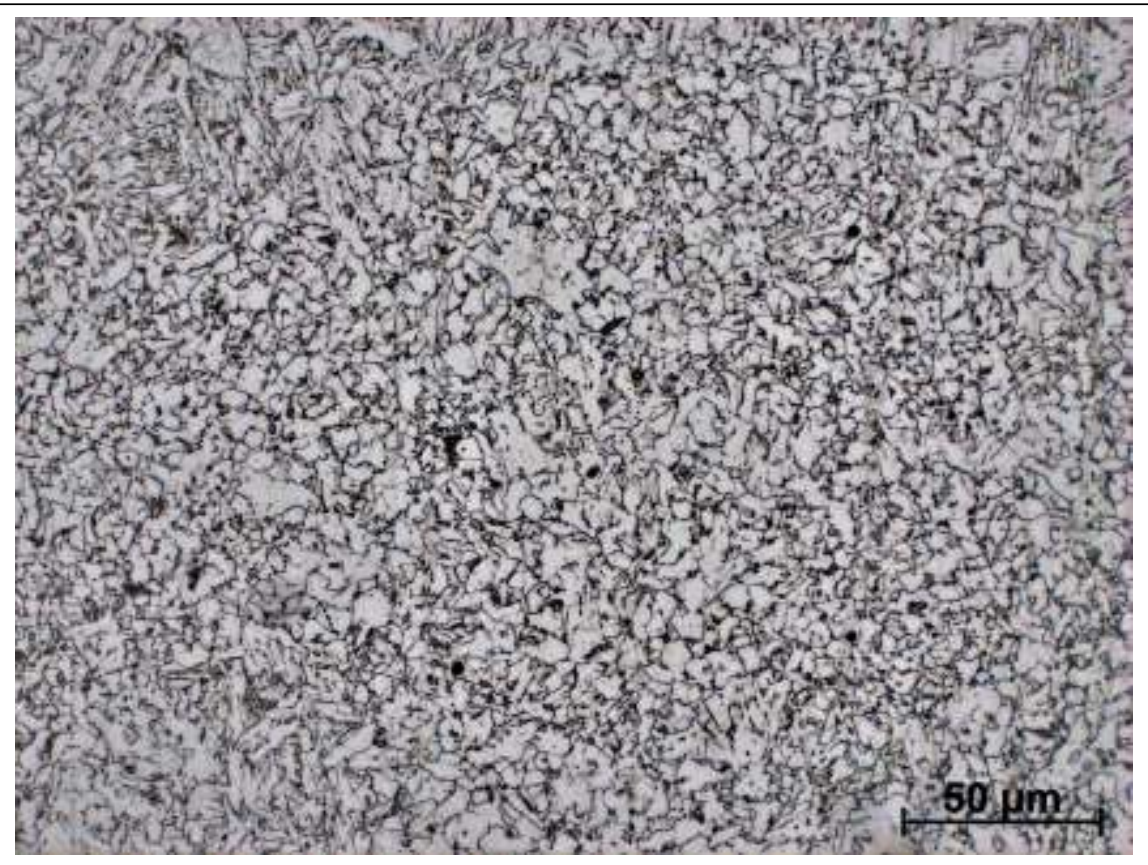

Figura 105 - Microestrutura martensítica revenida do aço API 5L X65. Aumento: 500x. 


\subsubsection{Análise de Inclusões}

As inclusões encontradas na amostra de aço API 5L X65, observada por microscopia ótica são globulares, do tipo D conforme quadro morfológico de inclusões da norma ASTM E45-11 (2011) ilustrado na Figura 87. A Figura 106 mostra a distribuição das inclusões visualizada na superfície polida da amostra observada.

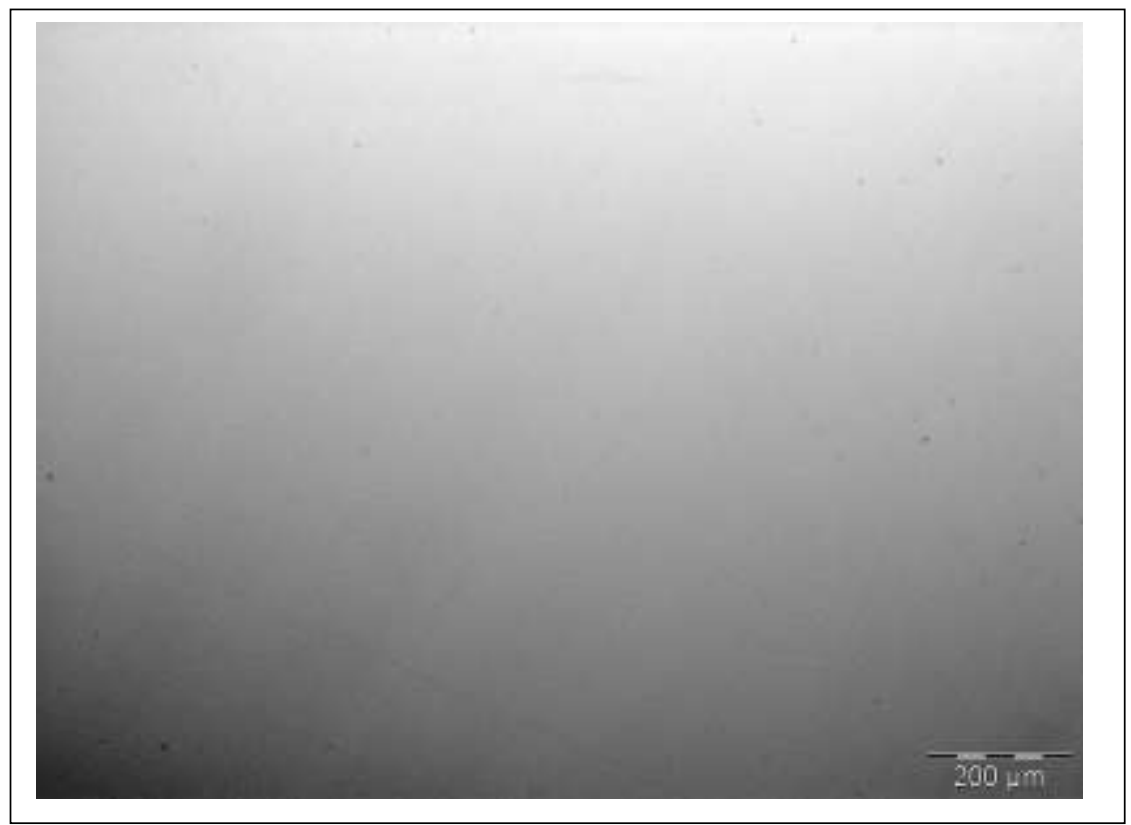

Figura 106 - Perfil de inclusões na amostra de aços API 5L X65.

Segundo o método de contagem (método D), as inclusões existentes são de série fina com severidade de 0,5 e 1,0. A Tabela 13 ilustra o resultado da análise.

Tabela 13 - Análise de inclusões no aço API 5L X65.

\begin{tabular}{|c|c|c|c|c|c|c|c|c|}
\hline & \multicolumn{9}{|c|}{ Inclusões } \\
\hline \multirow{3}{*}{ Severidade } & \multicolumn{2}{|c|}{ Tipo A } & \multicolumn{2}{c|}{ Tipo B } & \multicolumn{2}{c|}{ Tipo C } & \multicolumn{2}{c|}{ Tipo D } \\
\cline { 2 - 9 } & Série & Série & Série & Série & Série & Série & Série & Série \\
& Fina & Grossa & Fina & Grossa & Fina & Grossa & Fina & Grossa \\
\hline 0,5 & - & - & - & - & - & - & 60 & - \\
\hline 1,0 & - & - & - & - & - & - & 8 & - \\
\hline
\end{tabular}


Como a análise de inclusões pelo método $\mathrm{D}$ consiste na varredura da superficie campo a campo com $0,5 \mathrm{~mm} 2$ de área, os resultados na Tabela 13 mostram a existência de 60 campos de severidade 0,5 e 8 campos de severidade 1,0, ambos de série fina. Segundo a norma ASTM E45-11 (2011), campos de severidade 0,5 mostram a existência de 1 inclusão nos limites observados e os de severidade 1,0 mostram que no interior do campo observado foram encontrados de 4 a 8 inclusões. Como as inclusões são de série fina, todas possuem diâmetro de no máximo $0,8 \mathrm{~mm}$.

O resultado encontrado está de acordo com o esperado, já que o aço utilizado no desenvolvimento deste trabalho foi submetido a tratamento de metalurgia secundária associado ao processo de controle de inclusões.

\subsection{Propriedades Mecânicas}

\subsubsection{Ensaio de Dureza}

A Figura 107 exemplifica uma amostra com impressões feitas com o penetrador de diamante (ensaio Vickers) em material similar ao adotado neste estudo.

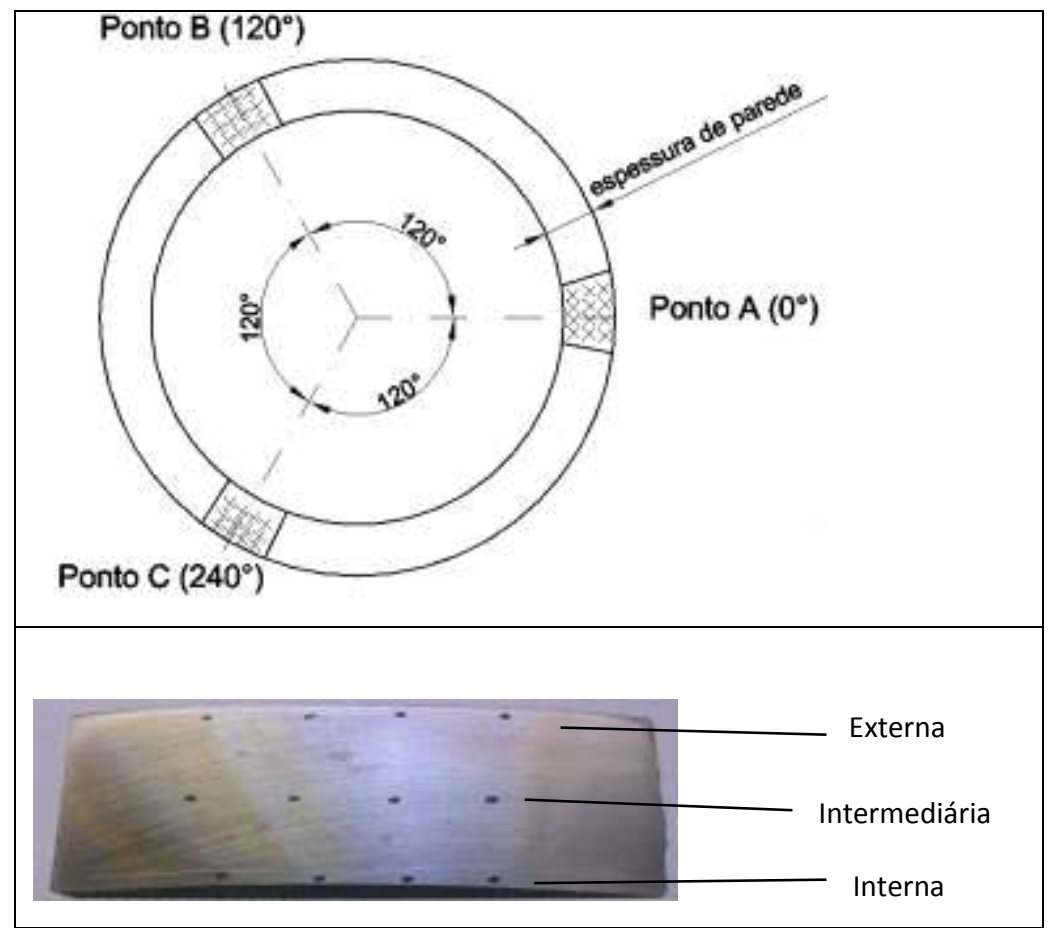

Figura 107 - Amostra utilizada para levantamento de dureza do aço API 5L X65 (Souza, 2011). 
Os valores da dureza obtidos com medições em quatro pontos localizados na porção externa, intermediária e interna da espessura de parede do tubo estão indicados na Tabela 14. Vale ressaltar que a carga utilizada durante o ensaio foi de $10 \mathrm{kgf}$.

Tabela 14 - Valores de dureza Vickers para aço API 5L X65 segundo norma API 5L (2007).

\begin{tabular}{|c|c|c|c|c|c|}
\hline \# & \multicolumn{5}{|c|}{ Porção Externa - Dureza (HV) } \\
\hline Pontos & Medida 1 & Medida 2 & Medida 3 & Medida 4 & Média \pm DP \\
\hline $\mathrm{A}$ & 199 & 187 & 192 & 199 & $194,25 \pm 5,85$ \\
\hline B & 202 & 179 & 186 & 203 & $192,50 \pm 11,90$ \\
\hline $\mathrm{C}$ & 201 & 194 & 190 & 200 & $196,25 \pm 5,19$ \\
\hline \# & \multicolumn{5}{|c|}{ Porção Intermediária - Dureza (HV) } \\
\hline Pontos & Medida 1 & Medida 2 & Medida 3 & Medida 4 & Média $\pm \mathrm{DP}$ \\
\hline A & 170 & 164 & 168 & 162 & $166,00 \pm 3,65$ \\
\hline B & 174 & 167 & 174 & 167 & $170,50 \pm 4,04$ \\
\hline $\mathrm{C}$ & 171 & 163 & 169 & 166 & $167,25 \pm 3,50$ \\
\hline$\#$ & \multicolumn{5}{|c|}{ Porção Interna - Dureza (HV) } \\
\hline Pontos & Medida 1 & Medida 2 & Medida 3 & Medida 4 & Média \pm DP \\
\hline $\mathrm{A}$ & 174 & 174 & 169 & 174 & $172,75 \pm 2,50$ \\
\hline B & 171 & 173 & 171 & 166 & $170,25 \pm 2,99$ \\
\hline $\mathrm{C}$ & 172 & 169 & 171 & 168 & $170,00 \pm 1,83$ \\
\hline
\end{tabular}

Pela análise dos valores da Tabela 14 se pode observar que a dureza na parte externa do tubo é maior que na parte interna. Isto deve-se ao fato de como o tubo é resfriado durante o tratamento térmico.

Após a etapa de austenitização, o tubo é resfriado por imersão em um tanque com água a temperatura ambiente. Como a superfície externa do tubo é o primeiro local a entrar em contato com a água, esta é submetida a uma maior taxa de resfriamento, dando início a transformação martensítica. Já a superfície interna do tubo não é exposta a mesma taxa de resfriamento que a externa, pois a entrada de água no interior do tubo é mais lenta que o contato com a água na superfície externa, resultando em uma taxa de resfriamento menor. 
No meio da espessura de parede do tubo, a última parte do tubo a resfriar, a taxa de resfriamento ainda é menor, já que o gradiente de temperatura oriundo das superfícies externas e internas conduzem o resfriamento resultando em menores valores de dureza. A variação da dureza ao longo da espessura de parede do tubo pode ser visualizada na Figura 108 através de um ajuste de curvas utilizando o método dos mínimos quadrados. A partir do valor de $\mathrm{R}^{2}$ se verifica que a curva descreve adequadamente o fenômeno descrito.

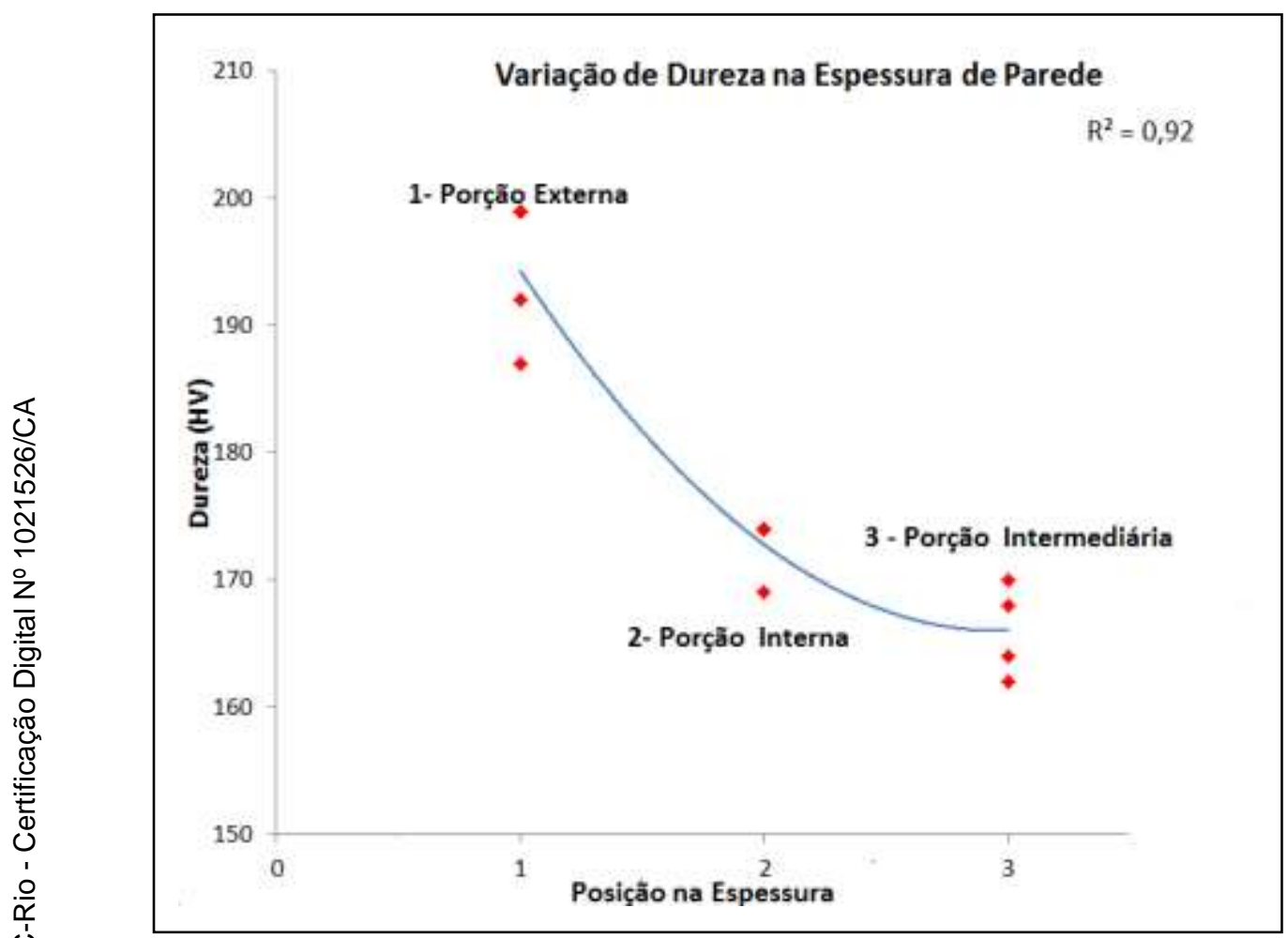

Figura 108 - Variação da dureza ao longo da espessura de parede do tubo.

\subsubsection{Ensaio de Tração}

Os resultados obtidos de um ensaio de tração longitudinal nos corpos de prova da ponta e do pé do tubo, descritos no item 3.3.2, realizados em temperatura ambiente $\left(25^{\circ} \mathrm{C}\right)$ são apresentados na Tabela 15. 
Tabela 15- Propriedades mecânicas obtidas do ensaio de tração a temperatura ambiente $\left(25^{\circ} \mathrm{C}\right)$.

\begin{tabular}{|c|c|c|c|c|}
\hline & Especificação & \multicolumn{2}{|c|}{ Corpo de Prova } & \multirow{2}{*}{ Média \pm DP } \\
\cline { 3 - 4 } & API 5L & (Pé) & (Ponta) & \\
Limite de & & & & \\
Escoamento & $450 \mathrm{MPa}$ & $463,5 \mathrm{MPa}$ & $460,4 \mathrm{MPa}$ & $462 \pm 2,20 \mathrm{MPa}$ \\
$\left(\sigma_{\mathrm{ys} 0,5}\right)$ & & $558 \mathrm{MPa}$ & 552,3 & $555 \pm 4,03 \mathrm{MPa}$ \\
\hline $\begin{array}{c}\text { Limite de } \\
\text { Resistência } \\
\text { Mecânica }\end{array}$ & $535 \mathrm{MPa}$ & 550 & \\
\hline
\end{tabular}

Pela análise dos valores obtidos para corpos de prova extraídos da ponta e do pé do tubo confirma-se que o material em questão atendeu aos requisitos mínimos exigidos pela norma API 5L (2007). A pequena variação nos resultados entre os corpos de prova da ponta e do pé do tubo foram provenientes do resfriamento do tubo durante a têmpera do material.

$\mathrm{O}$ ensaio de tenacidade à fratura requer as propriedades mecânicas de limite de escoamento e de resistência mecânica na temperatura de teste, ou seja, - $30{ }^{\circ} \mathrm{C}$. Sendo assim adotou-se estimar tais propriedades através Equações analíticas (77) e (78), respectivamente, recomendadas pela norma japonesa WES2808 (Tagawa et al., 2010).

$$
\sigma_{y s 0,5}\left(-30^{\circ} C\right)=\sigma_{y s 0,5}\left(T_{a m b}\right) \exp \left\{8,48 \times 10^{-3}\left(\frac{\sigma_{y s 0,5}\left(T_{a m b}\right)}{E}\right)^{-1,5}\left(\frac{1}{T+273}-\frac{1}{293}\right)\right\}
$$

$$
\sigma_{u s}\left(-30^{\circ} C\right)=\sigma_{u s}\left(T_{a m b}\right) \exp \left\{7,83 \times 10^{-3}\left(\frac{\sigma_{u s}\left(T_{a m b}\right)}{E}\right)^{-1,5}\left(\frac{1}{T+273}-\frac{1}{293}\right)\right\}
$$

na qual,

$\sigma_{\text {ys } 0,5}\left(-30^{\circ} \mathrm{C}\right)=$ limite de escoamento $\mathrm{a}-30^{\circ} \mathrm{C}$;

$\sigma_{\mathrm{ys} 0,5}\left(\mathrm{~T}_{\mathrm{amb}}\right)=$ limite de escoamento a temperatura ambiente $\left(25^{\circ} \mathrm{C}\right)$;

$\sigma_{\text {us }}\left(-30^{\circ} \mathrm{C}\right)=$ limite de resistência mecânica a $-30{ }^{\circ} \mathrm{C}$;

$\sigma_{\mathrm{us}}\left(\mathrm{T}_{\mathrm{amb}}\right)=$ limite de resistência mecânica a temperatura ambiente $\left(25^{\circ} \mathrm{C}\right)$; 
A Tabela 16 apresenta o limite de escoamento e o limite de resistência mecânica do aço em questão, calculadas pelas Equações 77 e 78.

Tabela 16 - Propriedades mecânicas analíticas para temperatura de $-30^{\circ} \mathrm{C}$ do aço API 5L X65.

\begin{tabular}{|c|c|c|}
\hline & $\begin{array}{c}\text { Especificação } \\
\text { API 5L }\end{array}$ & API 5L X65 \\
\hline $\begin{array}{c}\text { Limite de Escoamento } \\
\sigma_{\mathrm{ys} 0,5\left(-30^{\circ} \mathrm{C}\right)}\end{array}$ & 450 & 490 \\
\hline Limite de Resistência Mecânica & 535 & 580 \\
\hline
\end{tabular}

Pela análise dos valores das propriedades mecânicas, observa-se que são condizentes a um material de média resistência mecânica, segundo a norma API 5L (2007). Verifica-se também que não há uma variação significativa entre os valores obtidos para temperatura ambiente $\left(25^{\circ} \mathrm{C}\right)$ e para $-30^{\circ} \mathrm{C}$. Sendo assim, o uso dos valores obtidos do ensaio de tração a temperatura ambiente não vai interferir de maneira relevante no andamento da avaliação de tenacidade à fratura do material.

Pelos valores expostos acima, verifica-se que as propriedades mecânicas encontradas de modo analítico e encontram-se na faixa especificada pelas normas API 5L (2007) e DNV OS F101 (2007).

\subsubsection{Ensaio de Impacto}

Os ensaios de impacto Charpy foram realizados em cinco temperaturas diferentes. Para cada temperatura foram ensaiados três corpos de prova, gerando em um total de 15 resultados apresentados na Tabela 17, conforme descrito no item 3.3.3 do Capítulo 3. 
Tabela 17 - Energias absorvidas obtidas por ensaio de impacto tipo Charpy em baixas temperaturas.

\begin{tabular}{|c|c|c|c|}
\hline $\begin{array}{c}\text { Temperatura } \\
\left({ }^{\circ} \mathrm{C}\right)\end{array}$ & $\begin{array}{c}\text { Identificação } \\
\text { Corpo de Prova }\end{array}$ & $\begin{array}{c}\text { Energia } \\
\text { Absorvida }(\mathrm{J})\end{array}$ & Média \pm DP \\
\hline \multirow{3}{*}{0} & 1 & 280 & \multirow{3}{*}{$283,33 \pm 3,06$} \\
\hline & 2 & 284 & \\
\hline & 3 & 286 & \\
\hline \multirow{3}{*}{-10} & 1 & 276 & \multirow{3}{*}{$284,67 \pm 8,08$} \\
\hline & 2 & 292 & \\
\hline & 3 & 286 & \\
\hline \multirow{3}{*}{-30} & 1 & 282 & \multirow{3}{*}{$291,33 \pm 8,33$} \\
\hline & 2 & 294 & \\
\hline & 3 & 298 & \\
\hline \multirow{3}{*}{-50} & 1 & 278 & \multirow{3}{*}{$287,33 \pm 9,02$} \\
\hline & 2 & 288 & \\
\hline & 3 & 296 & \\
\hline \multirow{3}{*}{-70} & 1 & 280 & \multirow{3}{*}{$294 \pm 12,17$} \\
\hline & 2 & 302 & \\
\hline & 3 & 300 & \\
\hline
\end{tabular}

Tendo em vista que a redução de temperatura causa uma diminuição na energia absorvida pelo material durante o ensaio de impacto, a análise dos valores acima mostraram que o aço avaliado obteve uma considerável absorção de energia em baixas temperaturas, confirmando a sua ductilidade e estando de acordo com resultados obtidos por Souza (2011) em ensaio com material similar ao utilizado neste estudo.

Pela análise dos resultados obtidos por Souza (2011), se verifica uma similaridade no comportamento ao impacto de ambos os materiais na faixa de temperatura situada $-70{ }^{\circ} \mathrm{C}$ e $-90{ }^{\circ} \mathrm{C}$. A Tabela 18 mostra os resultados obtidos por Souza (2011). 
Tabela 18 - Energias de absorção por impacto em aço de mesmo grau ao adotado neste estudo. Adaptada de Souza (2011) pela autora.

\begin{tabular}{|c|c|c|}
\hline $\begin{array}{c}\text { Temperatura } \\
\left({ }^{\circ} \mathrm{C}\right)\end{array}$ & Corpo de Prova & $\begin{array}{c}\text { Energia } \\
\text { Absorvida }(\mathrm{J})\end{array}$ \\
\hline \multirow{3}{*}{-50} & 1 & 294 \\
\hline & 2 & 296 \\
\hline & 3 & 296 \\
\hline \multirow{3}{*}{-70} & 1 & 284 \\
\hline & 2 & 294 \\
\hline & 3 & 306 \\
\hline \multirow{3}{*}{-90} & 1 & 302 \\
\hline & 2 & 292 \\
\hline & 3 & 300 \\
\hline \multirow{3}{*}{-100} & 1 & 5 \\
\hline & 2 & 5 \\
\hline & 3 & 5 \\
\hline \multirow{3}{*}{-197} & 1 & 5 \\
\hline & 2 & 5 \\
\hline & 3 & 5 \\
\hline
\end{tabular}

Com a análise dos valores da Tabela 18 , se conclui que a temperatura de transição dúctil-frágil (TTDF) encontra-se na faixa entre a última temperatura do patamar superior $\left(-90{ }^{\circ} \mathrm{C}\right)$ e a primeira temperatura do patamar inferior $(-100$ $\left.{ }^{\circ} \mathrm{C}\right)$.

Tendo em vista que a temperatura de transição dúctil frágil do material é menor que a temperatura de ensaio adotada nos ensaios de tenacidade à fratura, pode-se afirmar que o material avaliado, sob o aspecto de absorção de energia, é adequado para aplicações offshore em temperaturas negativas pois o mesmo apresenta um comportamento dúctil. Sendo assim, o aço avaliado possui um comportamento dúctil a $-30{ }^{\circ} \mathrm{C}$, temperatura de avaliação de tenacidade à fratura, e espera-se que o mesmo no ensaio de tenacidade á fratura exiba um comportamento dúctil com propagação estável de trinca. 


\subsubsection{Ensaios de Tenacidade à Fratura}

Nesta seção apresentam-se os resultados obtidos nos ensaio de tenacidade à fratura para cálculo do parâmetro CTOD. Foram realizados ensaios com corpos de prova na condição de "como recebido" e na condição hidrogenada, com tempos de hidrogenação de 168 h, 96 h e 48 h.

Todos os ensaios foram conduzidos até abertura máxima nominal do clip gage $(5 \mathrm{~mm})$ ou até o corpo de prova apresentar um colapso plástico, ou seja, este perder a capacidade de resistir a carregamentos.

Após ensaio de CTOD, os corpos de prova foram imersos em nitrogênio líquido e rompidos sob carregamento dinâmico com o objetivo de expor a superfície de fratura e permitir a medição do comprimento real da pré-trinca de fadiga e de sua propagação estável durante o ensaio.

De posse dos parâmetros do ensaio e dos dados geométricos do corpo de prova se obteve o valor experimental $\left(\mathrm{CTOD}^{1}\right)$ através do software controlador do ensaio $K_{I C}$ CTOD Fracture Toughness Testing. Simultaneamente, a autora realizou o cálculo do parâmetro CTOD pela norma BS 7448:1 (1991), (CTOD $\left.{ }^{(2)}\right)$, e ASTM 1820-11 (2011), (CTOD $\left.{ }^{(3)}\right)$. Todos os parâmetros estão representados na Tabela 19.

Tabela 19 - Valores de CTOD obtidos a partir de ensaio realizado no laboratório de pesquisa e desenvolvimento da Vallourec.

\begin{tabular}{|c|l|}
\hline $\begin{array}{c}\text { Nomenclatura } \\
\text { CTOD }^{(1)}\end{array}$ & $\begin{array}{l}\text { Obtidos experimentalmente de acordo com a norma } \\
\text { BS 7448:1 (1991). }\end{array}$ \\
\hline CTOD $^{(2)}$ & $\begin{array}{l}\text { Calculados de acordo com a norma BS 7448:1 } \\
(1991) .\end{array}$ \\
\hline CTOD $^{(3)}$ & $\begin{array}{l}\text { Calculados de acordo com a norma ASTM 1820-11 } \\
(2011) .\end{array}$ \\
\hline
\end{tabular}

Além disto, o mesmo software ( $K_{I C} C T O D$ Fracture Toughness Testing) determinou também o valor experimental da Integral $\mathbf{J}\left(\mathbf{J}^{(1)}\right)$, de acordo com os parâmetros de ensaio e os dados geométricos do corpo de prova. De maneira análoga ao procedimento de cálculo utilizado para obtenção dos valores de CTOD 
a autora obteve os valores da Integral J pelas normas BS 7448 (1991) e ASTM 1820-11 (2011) (2011), $\left(\mathbf{J}^{(2)}\right)$ e $\left(\mathbf{J}^{(3)}\right)$, respectivamente. Os valores de Integral J obtidos estão descritos na Tabela 20.

Tabela 20 - Valores de Integral J obtidos a partir de ensaio realizado no laboratório de pesquisa e desenvolvimento da Vallourec.

\begin{tabular}{|c|l|}
\hline Nomenclatura & \multicolumn{1}{c|}{ Origem } \\
\hline $\mathbf{J}^{(1)}$ & $\begin{array}{l}\text { Obtidos experimentalmente acordo com a norma BS } \\
7448: 1(1991) .\end{array}$ \\
\hline $\mathbf{J}^{(2)}$ & $\begin{array}{l}\text { Calculados de acordo com a norma BS 7448:1 } \\
(1991) .\end{array}$ \\
\hline $\mathbf{J}^{(3)}$ & $\begin{array}{l}\text { Calculados de acordo com a norma ASTM 1820-11 } \\
(2011) .\end{array}$ \\
\hline
\end{tabular}

\subsubsection{Corpos de prova na condição não hidrogenada}

A Figura 109 apresenta as curvas carga vs CMOD para os 6 corpos de prova testados na condição não hidrogenada ensaiados a $0,5 \mathrm{~mm} / \mathrm{min}$.

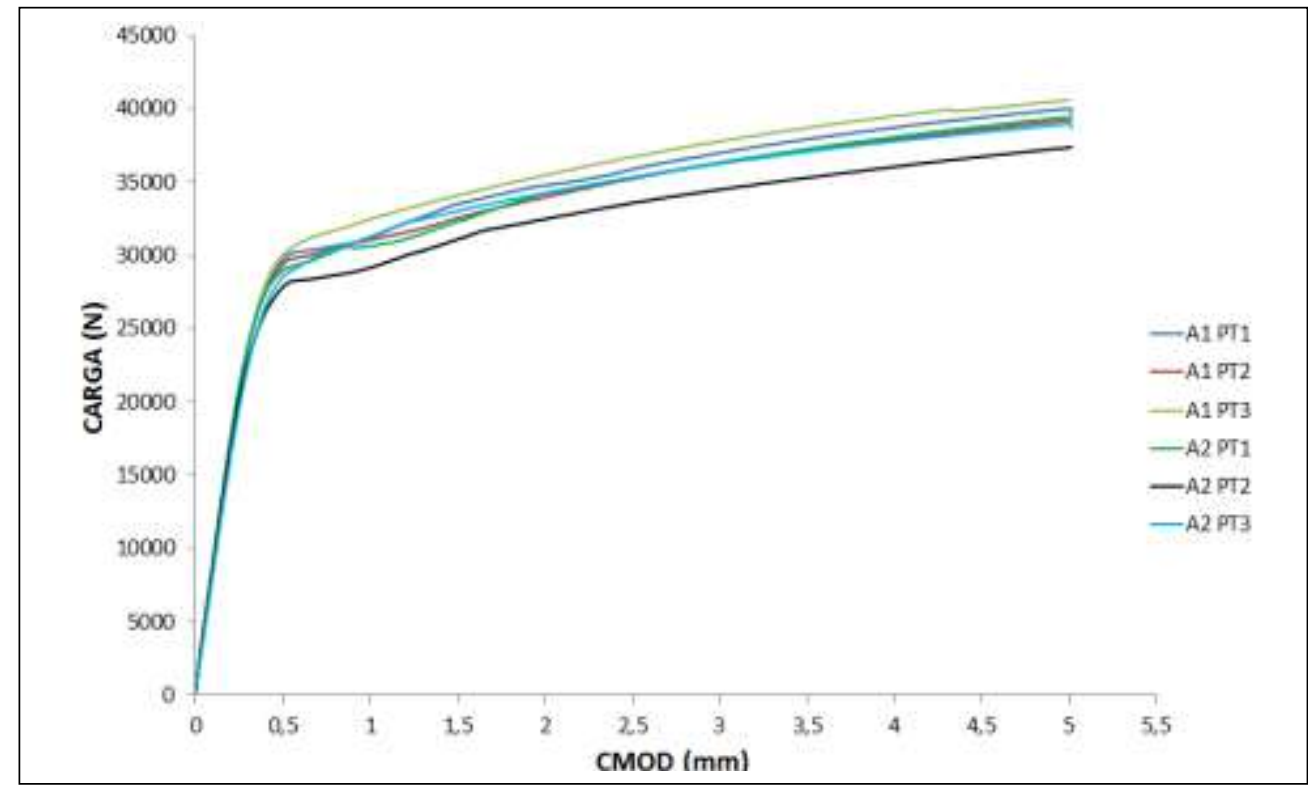

Figura 109 - Curva carga vs CMOD de corpo de prova não hidrogenado. 
Os valores da carga correspondem ao ponto de interrupção do ensaio, vide descrição no item 3.5. Enquanto que as componentes plásticas do deslocamento de abertura da boca da trinca $\left(\mathrm{V}_{\mathrm{p}}\right)$ foram obtidas a partir da reta traçada paralelamente ao trecho linear da curva até a carga , conforme esquema na Figura 110

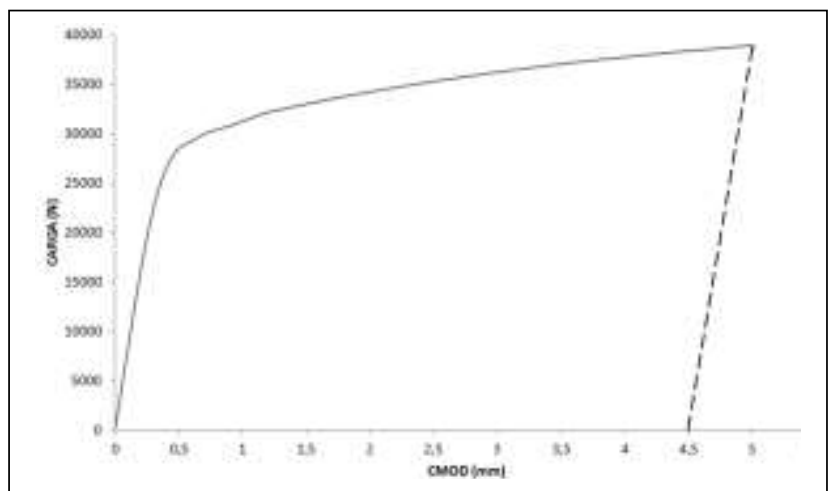

Figura 110 - Componente plástica $\left(\mathrm{V}_{\mathrm{p}}\right)$ do deslocamento de abertura da boca da trinca.

O comprimento real da pré-trinca foi obtido pela medição de pontos na superfície da fratura, conforme norma BS 7448:1 (1991), ilustrado na Figura 111.

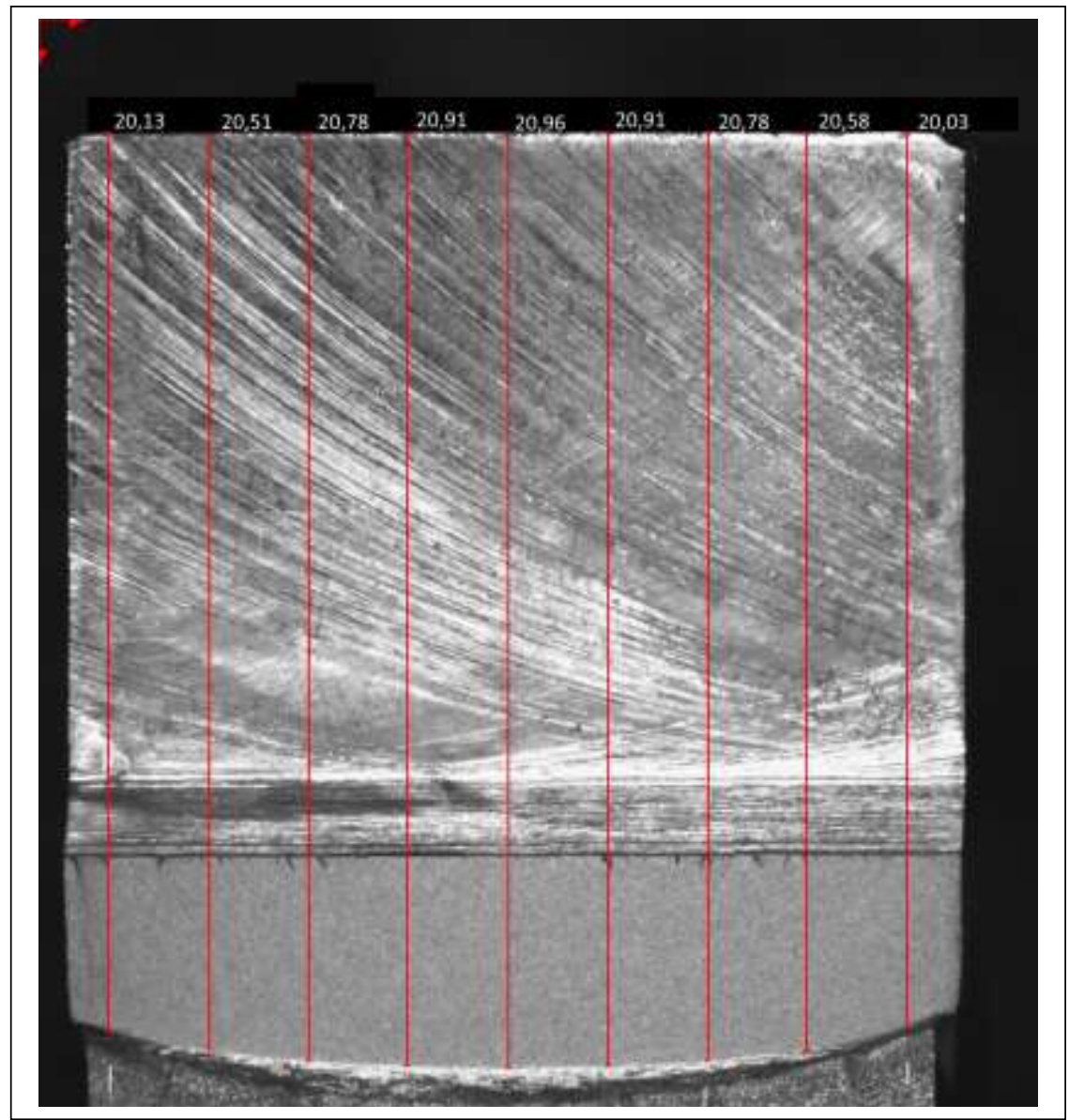

Figura 111 - Comprimento real da pré-trinca de fadiga. 
Os resultados de CTOD e Integral J obtidos para a condição em questão são apresentados nas Tabelas 21 e 22, de acordo com a Tabela 19 e 20. Mas apesar da apresentação dos valores da Integral $\mathrm{J}$, a discussão dos valores obtidos nas diferentes condições de ensaio será feita em função do CTOD, já que ambos os parâmetros se aplicam para materiais de boa ductilidade.

Tabela 21 - Parâmetros do ensaio CTOD dos corpos de prova não hidrogenados.

\begin{tabular}{|c|c|c|c|c|c|c|}
\hline CP & $\begin{array}{c}\mathrm{P} \\
(\mathrm{N})\end{array}$ & $\begin{array}{c}\mathrm{a}_{\mathrm{r}} \\
(\mathrm{mm})\end{array}$ & $\begin{array}{c}\mathrm{V}_{\mathrm{p}} \\
(\mathrm{mm})\end{array}$ & $\begin{array}{c}\mathrm{CTOD}^{(1)} \\
(\mathrm{mm})\end{array}$ & $\begin{array}{c}\text { CTOD }^{(2)} \\
(\mathrm{mm})\end{array}$ & $\begin{array}{c}\text { CTOD }^{(3)} \\
(\mathrm{mm})\end{array}$ \\
\hline A1 PT1 & 40040 & 20,70 & 4,55 & 1,22 & 1,23 & 0,85 \\
\hline A1 PT2 & 39284 & 20,84 & 4,55 & 1,21 & 1,21 & 0,85 \\
\hline A1 PT3 & 40632 & 20,53 & 4,50 & 1,23 & 1,23 & 0,86 \\
\hline A2 PT1 & 39517 & 20,74 & 4,55 & 1,22 & 1,22 & 0,84 \\
\hline A2 PT2 & 37462 & 21,15 & 4,50 & 1,18 & 1,17 & 0,81 \\
\hline A2 PT3 & 38985 & 21,11 & 4,50 & 1,19 & 1,18 & 0,85 \\
\hline $\begin{array}{c}\text { Média } \pm \\
\text { DP }\end{array}$ & $39320 \pm$ & $20,85 \pm$ & $4,53 \pm$ & $1,21 \pm$ & $1,21 \pm$ & $0,84 \pm$ \\
0,24 & 0,03 & 0,02 & 0,03 & 0,02 \\
\hline
\end{tabular}

Tabela 22 - Parâmetros do ensaio CTOD dos corpos de prova não hidrogenados.

\begin{tabular}{|c|c|c|c|}
\hline \multirow{2}{*}{ CP } & \multicolumn{3}{|c|}{ Integral $\mathbf{J}\left(\mathrm{J} / \mathrm{mm}^{2}\right)$} \\
\cline { 2 - 4 } & $\mathbf{J}^{(1)}$ & $\mathbf{J}^{(2)}$ & $\mathbf{J}^{(3)}$ \\
\hline A1 PT1 & 0,90 & 0,89 & 0,85 \\
\hline A1 PT2 & 0,88 & 0,89 & 0,84 \\
\hline A1 PT3 & 0,90 & 0,90 & 0,85 \\
\hline A2 PT1 & 0,88 & 0,88 & 0,84 \\
\hline A2 PT2 & 0,85 & 0,85 & 0,81 \\
\hline A2 PT3 & 0,89 & 0,89 & 0,85 \\
\hline Média + DP & $0,88 \pm 0,02$ & $0,88 \pm 0,02$ & $0,84 \pm 0,02$ \\
\hline
\end{tabular}

Com a análise das curvas carga $v s$ CMOD se evidencia que o material tem uma considerável ductilidade. Foi verificado o aumento da carga após escoamento generalizado do material, associado com a propagação estável do defeito. Como o ensaio não proporcionou o alcance do patamar de carga, não se conseguiu o CTOD de carga máxima ou nenhum outro CTOD relevante a tenacidade do material. Sendo assim o valor do CTOD calculado foi o correspondente a máxima 
abertura do clip gage posicionado no entalhe do corpo de prova, como já esclarecido no item 3.5 .

\subsubsection{Corpos de prova hidrogenados por $168 \mathrm{~h}$ - Grupo B}

A hidrogenação dos corpos de prova foi realizada por imersão em solução A especificada pela norma NACE TM0177-2005 (2005) com as seguintes concentrações de $\mathrm{H}_{2} \mathrm{~S}$ e valores de $\mathrm{pH}$, indicados na Tabela 23.

Tabela 23 - Especificação da solução de hidrogenação para tempo de 168 h.

\begin{tabular}{|c|c|}
\hline \multicolumn{2}{|c|}{ Especificação Solução A } \\
\hline $\mathrm{pH}$ antes da saturação & 2,70 \\
\hline $\mathrm{pH}$ após o ensaio & 3,81 \\
\hline Concentração $\mathrm{H}_{2} \mathrm{~S}$ inicial (antes do teste) & $2584 \mathrm{ppm}$ \\
\hline Concentração $\mathrm{H}_{2} \mathrm{~S}$ final (após do teste) & $2618 \mathrm{ppm}$ \\
\hline
\end{tabular}

Os resultados dos parâmetros de hidrogenação encontrados mostram que a solução utilizada para a hidrogenação do material estava de acordo com o especificado pela norma NACE TM0177-2003 (2003).

A Figura 112 apresenta as curvas carga $v s$ CMOD para os 6 corpos de prova ensaiados com velocidade de $0,5 \mathrm{~mm} / \mathrm{min}$, o que corresponde a um taxa de deformação $8,3 \times 10^{-3} / \mathrm{s}$ na condição de hidrogenação mencionada.

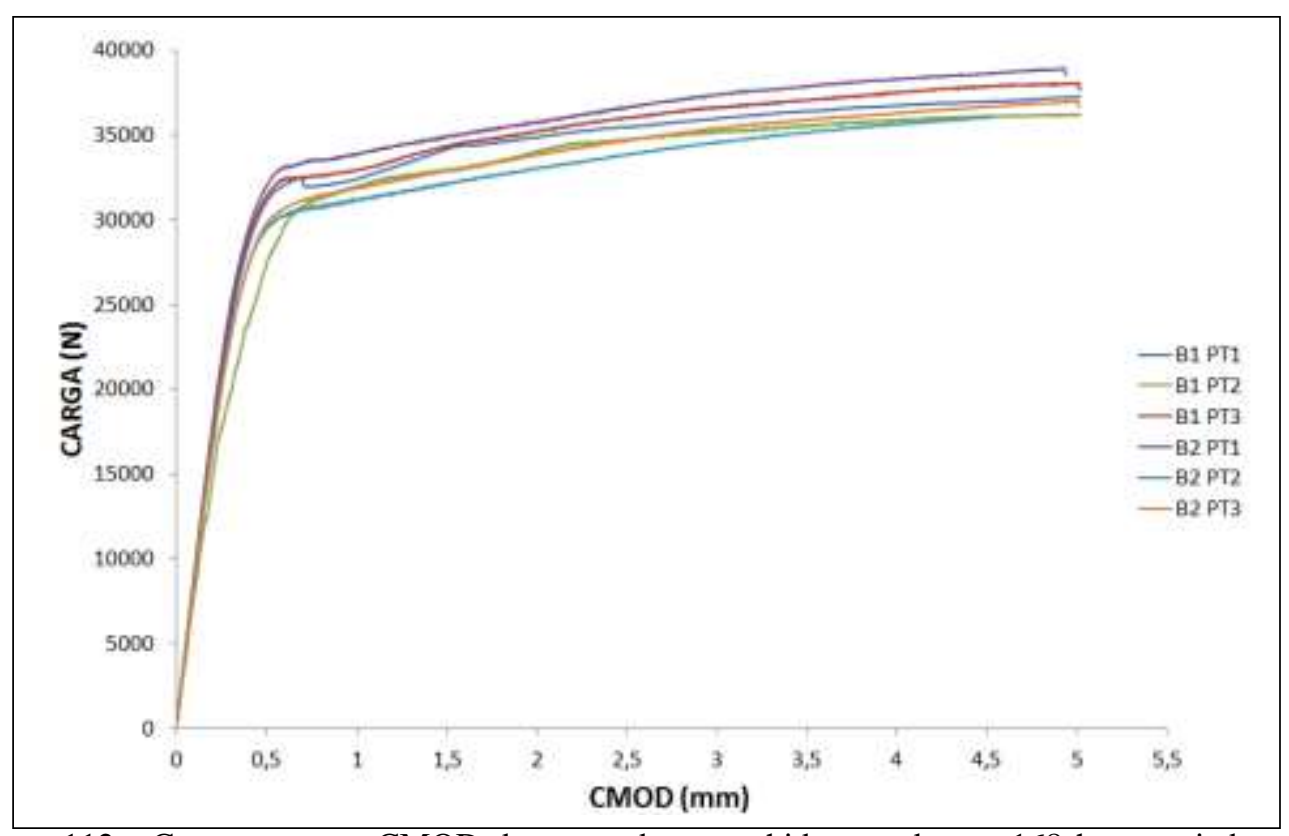

Figura 112 - Curva carga $v s$ CMOD de corpo de prova hidrogenado por $168 \mathrm{~h}$ e ensaiado a 0,5 $\mathrm{mm} / \mathrm{min}$. 
Os resultados de CTOD e Integral J obtidos para a condição em questão, estão apresentados nas Tabelas 24 e 25, conforme explicado na Tabela 19 e 20.

Tabela 24 - Valores de CTOD para corpos de prova hidrogenados por $168 \mathrm{~h}$.

\begin{tabular}{|c|c|c|c|c|c|c|}
\hline CP & $\begin{array}{c}\mathrm{P} \\
(\mathrm{N})\end{array}$ & $\begin{array}{c}\mathrm{a}_{\mathrm{r}} \\
(\mathrm{mm})\end{array}$ & $\begin{array}{c}\mathrm{V}_{\mathrm{p}} \\
(\mathrm{mm})\end{array}$ & $\begin{array}{c}\text { CTOD }^{(1)} \\
(\mathrm{mm})\end{array}$ & $\begin{array}{c}\mathrm{CTOD}^{(2)} \\
(\mathrm{mm})\end{array}$ & $\begin{array}{c}\mathrm{CTOD}^{(3)} \\
(\mathrm{mm})\end{array}$ \\
\hline B1 PT1 & 37270 & 20,50 & 4,58 & 1,25 & 1,25 & 0,89 \\
\hline B1 PT2 & 36370 & 21,02 & 4,40 & 1,16 & 1,15 & 0,87 \\
\hline B1 PT3 & 38090 & 20,48 & 4,44 & 1,21 & 1,21 & 0,88 \\
\hline B2 PT1 & 38970 & 20,28 & 4,50 & 1,24 & 1,25 & 0,90 \\
\hline B2 PT2 & 36370 & 21,07 & 4,55 & 1,19 & 1,19 & 0,88 \\
\hline B2 PT3 & 37040 & 20,90 & 4,50 & 1,20 & 1,19 & 0,88 \\
\hline $\begin{array}{c}\text { Média } \pm \\
\text { DP }\end{array}$ & $\begin{array}{c}37352 \pm \\
1081,13\end{array}$ & $\begin{array}{c}20,71 \pm \\
0,33\end{array}$ & $\begin{array}{c}4,50 \pm \\
0,07\end{array}$ & $\begin{array}{c}1,21 \pm \\
0,03\end{array}$ & $\begin{array}{c}1,21 \pm \\
0,04\end{array}$ & $\begin{array}{c}0,88 \pm \\
0,03\end{array}$ \\
\hline
\end{tabular}

Tabela 25-Valores de Integral J para corpos de prova hidrogenados por $168 \mathrm{~h}$.

\begin{tabular}{|c|c|c|c|}
\hline & \multicolumn{3}{|c|}{ Integral J $\left(\mathrm{J} / \mathrm{mm}^{2}\right)$} \\
\hline $\begin{array}{c}\text { Identificação } \\
\text { corpo de prova }\end{array}$ & $\mathbf{J}^{(1)}$ & $\mathbf{J}^{(2)}$ & $\mathbf{J}^{(3)}$ \\
\hline B1 PT1 & 0,86 & 0,84 & 0,83 \\
\hline B1 PT2 & 0,85 & 0,85 & 0,81 \\
\hline B1 PT3 & 0,85 & 0,86 & 0,82 \\
\hline B2 PT1 & 0,87 & 0,88 & 0,83 \\
\hline B2 PT2 & 0,85 & 0,85 & 0,81 \\
\hline B2 PT3 & 0,86 & 0,86 & 0,82 \\
\hline Média \pm DP & $0,86 \pm 0,01$ & $0,86 \pm 0,01$ & $0,82 \pm 0,01$ \\
\hline
\end{tabular}

Os resultados obtidos mostram que a presença do hidrogênio nos corpos de prova ensaiados não interferiu significativamente no valor de $\mathrm{CTOD}^{(1)}$. Como na condição não hidrogenada, não se obteve valor de CTOD correspondente a um evento físico relevante para a tenacidade do material, o valor de CTOD medido 
foi o correspondente a máxima abertura do clip gage posicionado no entalhe do corpo de prova, conforme já foi esclarecido no item 3.5.

A partir dos valores obtidos se verifica que os mesmos são similares aos encontrados para a condição não hidrogenada. Este fato pode ser comprovado pela ferramenta estatística Mann-Whitney onde se pode ver que tais valores não são diferentes mesmo com a influência do hidrogênio com um nível de confiança de $95 \%$.

Ensaios de CTOD realizados por Souza (2011) em corpos de prova de mesmo material e mesma dimensão, porém a uma taxa de deformação maior $(1,7$ x $10^{-3} / \mathrm{s}$ ) indicaram uma redução no parâmetro encontrado em relação ao obtido para os corpos de prova sem hidrogênio. Este fato não foi observado nos ensaios atuais, porém os resultados encontrados são condizentes com relatos feitos por Hagiwara(1999), que verificou que o valor de CTOD obtidos ao ar e em atmosfera hidrogenada são iguais para uma velocidade de $0,25 \mathrm{~mm} / \mathrm{min}$, o que corresponde a uma taxa de deformação de $4,2 \times 10^{-3} / \mathrm{s}$.

A diferença encontrada nos ensaios realizados neste trabalho está associado a redução da taxa de deformação aplicada, em relação ao estudo mencionado de 2011. Taxas de deformação mais baixas facilitam a formação de uma atmosfera ao redor das discordâncias existentes na ponta da trinca pelos átomos de hidrogênio (efeito shielding), reduzindo a tensão de cisalhamento crítica para o deslizamento das discordâncias, aumentando a deformação local e contribuindo para os valores de CTOD alcançados nesta condição de teste. Este efeito localizado ao redor da ponta da trinca evidencia o efeito de amaciamento (softening) do material, e consequentemente a atuação do mecanismo HELP de atuação do hidrogênio.

\subsection{Corpos de Prova Hidrogenados por 168 h - Grupo C}

Semelhante aos corpos de prova do grupo B, a hidrogenação foi feita conforme norma NACE TM 0177 - 2005 (2005) em solução A e os parâmetros de concentração de $\mathrm{H}_{2} \mathrm{~S}$ e valores de pH são apresentados na Tabela 26 e estão de acordo com os requisitos da norma citada. 
Tabela 26 - Especificação da solução de hidrogenação para tempo de 168 h.

\begin{tabular}{|c|c|}
\hline \multicolumn{2}{|c|}{ Especificação Solução A } \\
\hline $\mathrm{pH}$ antes da saturação & 2,70 \\
\hline $\mathrm{pH}$ após o ensaio & 3,60 \\
\hline Concentração $\mathrm{H}_{2} \mathrm{~S}$ inicial (antes do teste) & $2550 \mathrm{ppm}$ \\
\hline Concentração $\mathrm{H}_{2} \mathrm{~S}$ final (após do teste) & $2567 \mathrm{ppm}$ \\
\hline
\end{tabular}

A Figura 113 apresenta as curvas carga vs CMOD para os 6 corpos de prova ensaiados. Nesta etapa, este grupo foi dividido em 2 subgrupos (C1 e C2) com 3 corpos de prova para cada ensaio com velocidade de $0,25 \mathrm{~mm} / \mathrm{min}$ e $1,0 \mathrm{~mm} / \mathrm{min}$, o que corresponde a uma taxa de deformação $4,2 \times 10^{-3} / \mathrm{s}$ e $1,67 \times 10^{-2} / \mathrm{s}$, respectivamente.

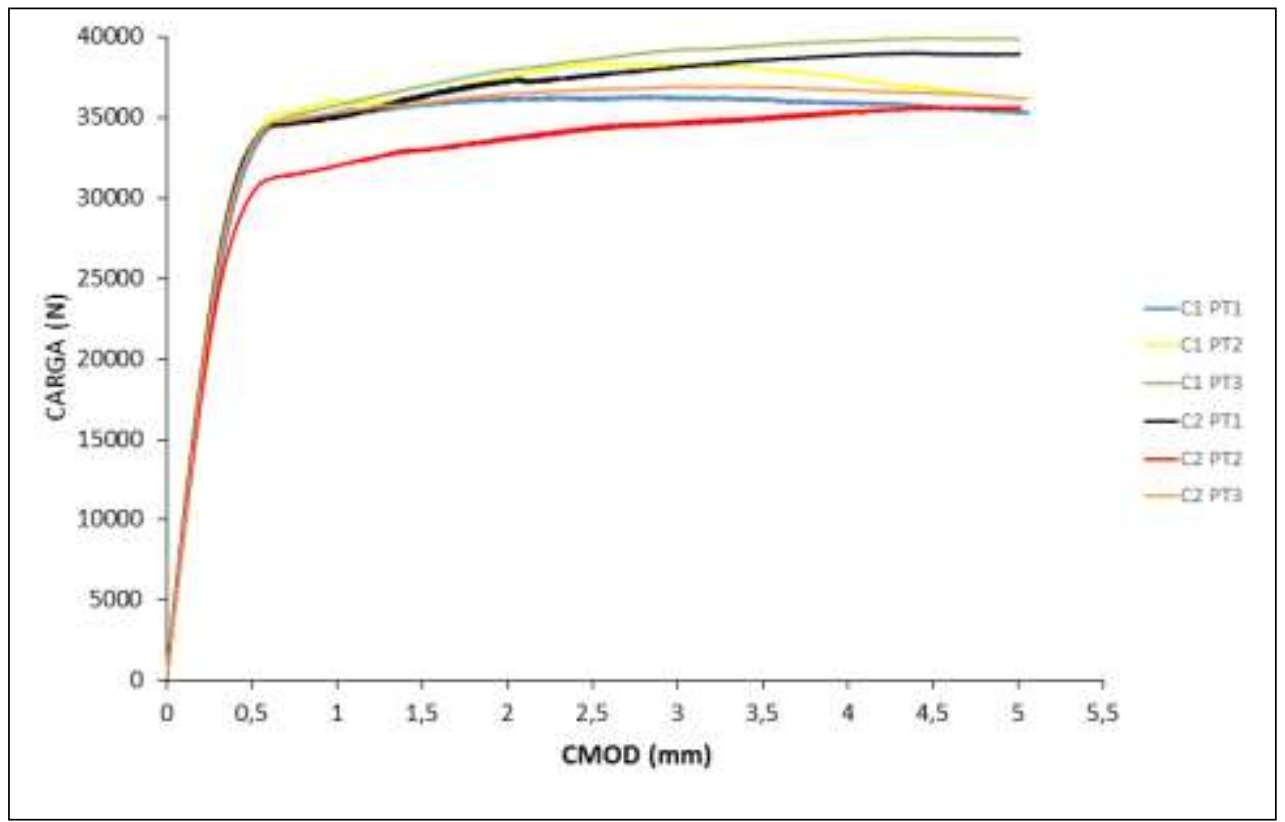

Figura 113 - Curva carga vs CMOD de corpo de prova hidrogenado por $168 \mathrm{~h}$.

Os resultados de CTOD e Integral J obtidos para a condição em questão, estão apresentados nas Tabelas 27 e 28, conforme explicado na Tabela 19 e 20, em função da velocidade de ensaio. 
Tabela 27 - Valores de CTOD para corpos de prova hidrogenados por $168 \mathrm{~h}$ para velocidade de $0,25 \mathrm{~mm} / \mathrm{min}$ e $1,0 \mathrm{~mm} / \mathrm{min}$.

\begin{tabular}{|c|c|c|c|c|c|c|c|}
\hline $\mathrm{CP}$ & $\begin{array}{c}\mathrm{v} \\
(\mathrm{mm} / \mathrm{min})\end{array}$ & $\begin{array}{c}P \\
(\mathrm{~N})\end{array}$ & $\begin{array}{c}\mathrm{a}_{\mathrm{r}} \\
(\mathrm{mm})\end{array}$ & $\begin{array}{c}\mathrm{V}_{\mathrm{p}} \\
(\mathrm{mm})\end{array}$ & $\begin{array}{c}\text { CTOD }^{(1)} \\
(\mathrm{mm})\end{array}$ & $\begin{array}{c}\text { CTOD }^{(2)} \\
(\mathrm{mm})\end{array}$ & $\begin{array}{c}\text { CTOD }^{(3)} \\
(\mathrm{mm})\end{array}$ \\
\hline C1PT1 & \multirow{4}{*}{0,25} & 36400 & 20,48 & 4,70 & 1,28 & 1,28 & 0,92 \\
\hline C1PT2 & & 38370 & 20,05 & 4,70 & 1,32 & 1,30 & 0,93 \\
\hline C2PT3 & & 36990 & 20,05 & 4,65 & 1,31 & 1,30 & 0,92 \\
\hline $\begin{array}{l}\text { Média } \\
\pm \text { DP }\end{array}$ & & $\begin{array}{l}37253 \pm \\
1011,06\end{array}$ & $\begin{array}{c}20,19 \pm \\
0,25\end{array}$ & $\begin{array}{c}4,68 \pm \\
0,03\end{array}$ & $\begin{array}{c}1,30 \pm \\
0,02\end{array}$ & $\begin{array}{c}1,29 \pm \\
0,01\end{array}$ & $\begin{array}{c}0,92 \pm \\
0,01\end{array}$ \\
\hline$\overline{\mathrm{C} 2 \mathrm{PT} 1}$ & \multirow{4}{*}{1,0} & 39080 & 20,02 & 4,50 & 1,27 & 1,26 & 0,93 \\
\hline C2PT2 & & 35699 & 20,47 & 4,60 & 1,25 & 1,24 & 0,86 \\
\hline C1PT3 & & 39983 & 20,02 & 4,52 & 1,27 & 1,27 & 0,94 \\
\hline $\begin{array}{l}\text { Média } \\
\pm \mathrm{DP}\end{array}$ & & $\begin{array}{l}38254 \pm \\
2258,29 \\
\end{array}$ & $\begin{array}{c}20,17 \pm \\
0,26\end{array}$ & $\begin{array}{c}4,54 \pm \\
0,05 \\
\end{array}$ & $\begin{array}{c}1,26 \pm \\
0,01\end{array}$ & $\begin{array}{c}1,26 \pm \\
0,02 \\
\end{array}$ & $\begin{array}{c}0,91 \pm \\
0,04\end{array}$ \\
\hline
\end{tabular}

Tabela 28 - Valores de Integral $\mathrm{J}$ para corpos de prova hidrogenados por $168 \mathrm{~h}$ para velocidade de $0,25 \mathrm{~mm} / \mathrm{min}$ e $1,0 \mathrm{~mm} / \mathrm{min}$.

\begin{tabular}{|c|c|c|c|c|}
\hline \multirow{2}{*}{$\mathrm{CP}$} & \multirow{2}{*}{$\begin{array}{c}\mathrm{v} \\
(\mathrm{mm} / \mathrm{min})\end{array}$} & \multicolumn{3}{|c|}{ Integral $\mathrm{J}\left(\mathrm{J} / \mathrm{mm}^{2}\right)$} \\
\hline & & $\mathbf{J}^{(1)}$ & $\mathbf{J}^{(2)}$ & $\mathbf{J}^{(3)}$ \\
\hline C1PT1 & \multirow{4}{*}{0,25} & 0,89 & 0,90 & 0,85 \\
\hline C1PT2 & & 0,90 & 0,91 & 0,86 \\
\hline C2PT3 & & 0,90 & 0,90 & 0,85 \\
\hline Média \pm DP & & $\begin{array}{c}0,90 \pm \\
0,01\end{array}$ & $\begin{array}{c}0,90 \pm \\
0,01\end{array}$ & $\begin{array}{c}0,85 \pm \\
0,01\end{array}$ \\
\hline C2PT1 & \multirow{4}{*}{1,0} & 0,88 & 0,90 & 0,85 \\
\hline C2PT2 & & 0,83 & 0,84 & 0,80 \\
\hline C1PT3 & & 0,91 & 0,92 & 0,87 \\
\hline Média \pm DP & & $\begin{array}{c}0,87 \pm \\
0,04\end{array}$ & $\begin{array}{c}0,89 \pm \\
0,04\end{array}$ & $\begin{array}{c}0,84 \pm \\
0,04\end{array}$ \\
\hline
\end{tabular}

A análise dos valores de CTOD $^{(1)}$ para as velocidades testadas mostra que a carga de hidrogênio é responsável pelos valores significativos de CTOD mesmo com o aumento da velocidade de ensaio. Os resultados obtidos na condição de ensaio com velocidade de $1,0 \mathrm{~mm} / \mathrm{min}$ demonstra a boa ductilidade do material e condiz com os resultados obtidos por Souza (2011) em pesquisa realizada com material de mesma especificação adotada neste trabalho e com a mesma condição experimental, ou seja, mesmo tempo de hidrogenação e velocidade de ensaio. Nesta etapa também se pode verificar que taxas de deformação menores 
proporcionam maiores valores de CTOD, já que os valores de CTOD $^{(1)}$ obtidos na velocidade de $0,25 \mathrm{~mm} / \mathrm{min}$ são superiores aos obtidos no ensaio com velocidade de $0,5 \mathrm{~mm} / \mathrm{min}$. Tal fato mostra a atuação do mecanismo de plasticidade localizada.

\subsubsection{Corpos de Prova Hidrogenados por 96 h - Grupo D}

A Tabela 29 indica os valores de concentração de $\mathrm{H}_{2} \mathrm{~S}$ e de $\mathrm{pH}$ encontrados na solução A da norma NACE TM0177-2005 (2005) em acordo com especificação exigida.

Tabela 29 - Especificação da solução de hidrogenação para tempo de 168 h.

\begin{tabular}{|c|c|}
\hline \multicolumn{2}{|c|}{ Especificação Solução A } \\
\hline $\mathrm{pH}$ antes da saturação & 2,70 \\
\hline $\mathrm{pH}$ após o ensaio & 3,59 \\
\hline Concentração $\mathrm{H}_{2} \mathrm{~S}$ inicial (antes do teste) & $2550 \mathrm{ppm}$ \\
\hline Concentração $\mathrm{H}_{2} \mathrm{~S}$ final (após do teste) & $2499 \mathrm{ppm}$ \\
\hline
\end{tabular}

A Figura 114 apresenta as curvas carga vs CMOD para os 6 corpos de prova ensaiados com velocidade de 1,0 $\mathrm{mm} / \mathrm{min}$, o que corresponde a um taxa de deformação $1,67 \times 10^{-2} / \mathrm{s}$ na condição de hidrogenação em questão.

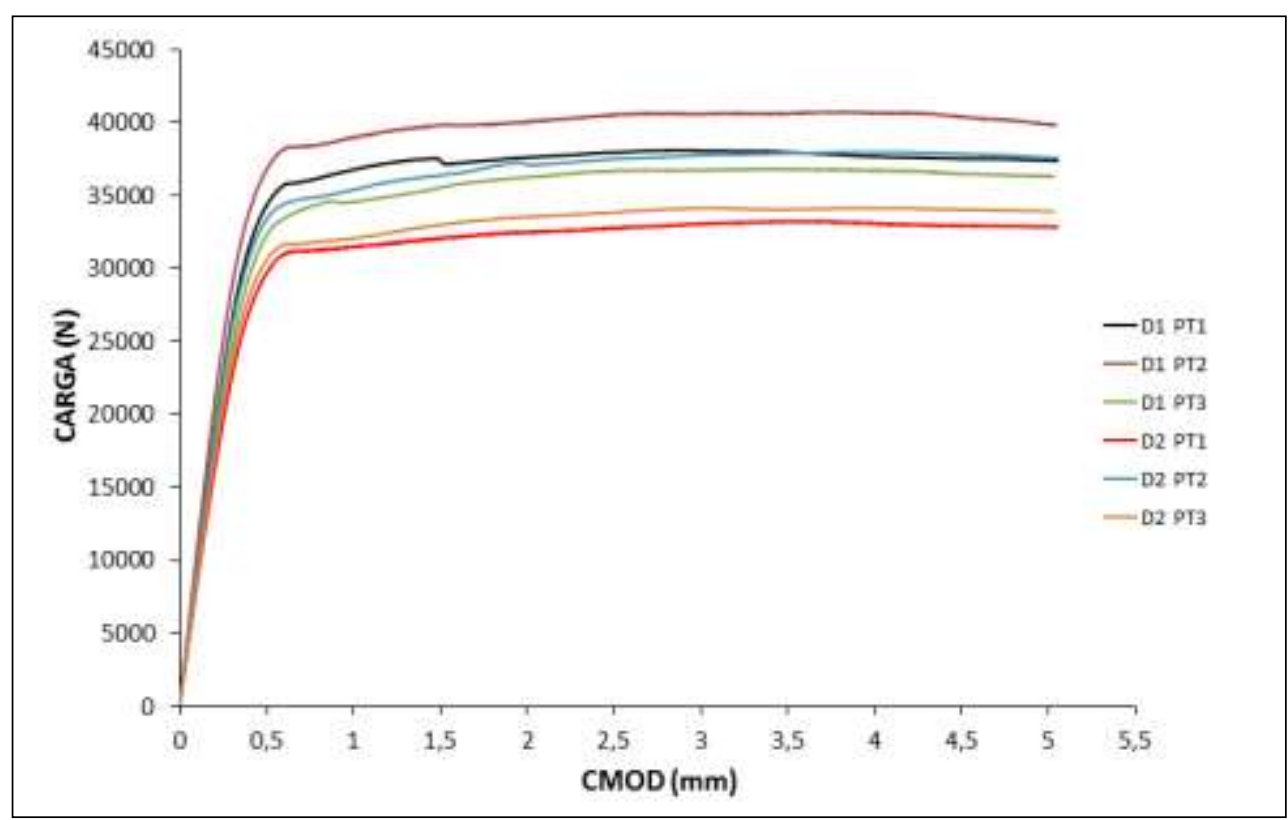

Figura 114 - Curva carga vs CMOD de corpo de prova hidrogenado por $96 \mathrm{~h}$ e ensaiado a 1,0 $\mathrm{mm} / \mathrm{min}$. 
Os resultados de CTOD e Integral $\mathbf{J}$ obtidos para a condição em questão, estão apresentados nas Tabelas 30 e 31, de acordo com descrição explicada no item 4.3.4, Tabela 19 e 20.

Tabela 30 - Valores de CTOD para condição hidrogenada por $96 \mathrm{~h}$.

\begin{tabular}{|c|c|c|c|c|c|c|}
\hline CP & $\begin{array}{c}\mathrm{P} \\
(\mathrm{N})\end{array}$ & $\begin{array}{c}\mathrm{a}_{\mathrm{r}} \\
(\mathrm{mm})\end{array}$ & $\begin{array}{c}\mathrm{V}_{\mathrm{p}} \\
(\mathrm{mm})\end{array}$ & $\begin{array}{c}\mathrm{CTOD}^{(1)} \\
(\mathrm{mm})\end{array}$ & $\begin{array}{c}\mathrm{CTOD}^{(2)} \\
(\mathrm{mm})\end{array}$ & $\begin{array}{c}\mathrm{CTOD}^{(3)} \\
(\mathrm{mm})\end{array}$ \\
\hline D1 PT1 & 38015 & 19,83 & 4,40 & 1,24 & 1,24 & 0,93 \\
\hline D1 PT2 & 40624 & 19,07 & 4,50 & 1,34 & 1,34 & 0,97 \\
\hline D1 PT3 & 36755 & 20,35 & 4,52 & 1,20 & 1,19 & 0,92 \\
\hline D2 PT1 & 33162 & 21,26 & 4,50 & 1,25 & 1,24 & 0,87 \\
\hline D2 PT2 & 37799 & 20,03 & 4,55 & 1,27 & 1,27 & 0,94 \\
\hline D2 PT3 & 34026 & 20,76 & 4,55 & 1,14 & 1,13 & 0,87 \\
\hline $\begin{array}{c}\text { Média } \pm \\
\text { DP }\end{array}$ & $36730 \pm$ & $20,22 \pm$ & $4,50 \pm$ & $1,24 \pm$ & $1,24 \pm$ & $0,92 \pm$ \\
0,06 & 0,07 & 0,07 & 0,04 \\
\hline
\end{tabular}

Tabela 31- Valores de Integral J para corpos de prova hidrogenados por $96 \mathrm{~h}$.

\begin{tabular}{|c|c|c|c|}
\hline \multirow{2}{*}{ CP } & \multicolumn{3}{|c|}{ Integral $\mathbf{J}\left(\mathbf{J} / \mathrm{mm}^{2}\right)$} \\
\cline { 2 - 4 } & $\mathbf{J}^{(1)}$ & $\mathbf{J}^{(2)}$ & $\mathbf{J}^{(3)}$ \\
\hline D1 PT1 & 0,90 & 0,91 & 0,86 \\
\hline D1 PT2 & 0,93 & 0,94 & 0,93 \\
\hline D1 PT3 & 0,89 & 0,89 & 0,89 \\
\hline D2 PT1 & 0,84 & 0,84 & 0,84 \\
\hline D2 PT2 & 0,92 & 0,92 & 0,91 \\
\hline 2 PT3 & 0,83 & 0,84 & 0,84 \\
\hline Média \pm DP & $0,89 \pm 0,04$ & $0,89 \pm 0,04$ & $0,88 \pm 0,04$ \\
\hline
\end{tabular}

Os resultados obtidos mostram uma pequena tendência de redução dos valores de CTOD e Integral J em relação a condição de hidrogenação anterior (168 h). Tal redução está associada ao aumento da velocidade de ensaio que diminuiu o tempo para atuação da atmosfera de hidrogênio ao redor das das discordâncias (mecanismo de plasticidade localizada). Vale ressaltar que apesar 
desta pequena redução nos parâmetros de tenacidade à fratura, tais valores ainda permanecem elevados mostrando a boa ductilidade do material.

\subsubsection{Corpos de prova hidrogenados por 48 h - Grupo E}

A Tabela 32 indica os valores de concentração de $\mathrm{H}_{2} \mathrm{~S}$ e valores de $\mathrm{pH}$ da solução especificada pela norma NACE TM0177-2005 (2005).

Tabela 32 - Especificação da solução de hidrogenação para tempo de 48 h.

\begin{tabular}{|c|c|}
\hline \multicolumn{2}{|c|}{ Especificação Solução A } \\
\hline $\mathrm{pH}$ antes da saturação & 2,70 \\
\hline $\mathrm{pH}$ após o ensaio & 3,28 \\
\hline Concentração $\mathrm{H}_{2} \mathrm{~S}$ inicial (antes do teste) & $2618 \mathrm{ppm}$ \\
\hline Concentração $\mathrm{H}_{2} \mathrm{~S}$ final (após do teste) & $2652 \mathrm{ppm}$ \\
\hline
\end{tabular}

Os resultados encontrados mostram que a solução utilizada para a hidrogenação do material estava de acordo com o especificado pela norma NACE TM0177-2003 (2003).

A Figura 115 apresenta as curvas carga $v s$ CMOD para os 6 corpos de prova ensaiados com velocidade de 0,5 mm/min, o que corresponde a um taxa de deformação $8,3 \times 10^{-3} / \mathrm{s}$ na condição não hidrogenados por $48 \mathrm{~h}$.

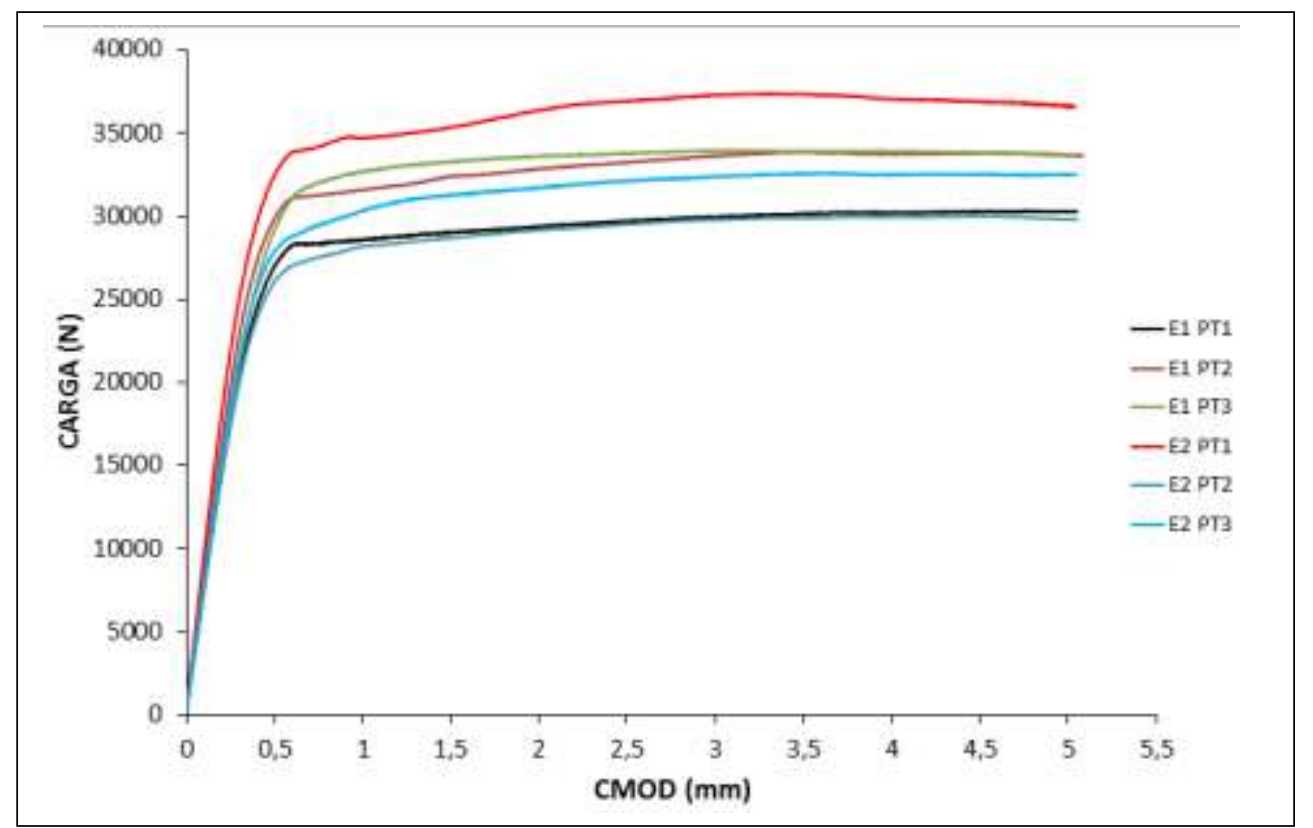

Figura 115 - Curva P vs CMOD de corpo de prova hidrogenado por $48 \mathrm{~h}$ e ensaiado a 1,0 $\mathrm{mm} / \mathrm{min}$. 
Os resultados de CTOD e Integral $\mathbf{J}$ alcançados para a condição em questão, estão apresentados nas Tabela 33 e 34, conforme descrição apresentada na Tabela 19 e 20.

Tabela 33- Valores de CTOD para condição hidrogenada por $48 \mathrm{~h}$.

\begin{tabular}{|c|c|c|c|c|c|c|c|}
\hline $\mathrm{CP}$ & $\begin{array}{c}\mathrm{v} \\
(\mathrm{mm} / \mathrm{min})\end{array}$ & $\begin{array}{c}P \\
(N)\end{array}$ & $\begin{array}{c}\mathrm{a}_{\mathrm{r}} \\
(\mathrm{mm})\end{array}$ & $\begin{array}{c}\mathrm{V}_{\mathrm{p}} \\
(\mathrm{mm})\end{array}$ & $\begin{array}{c}\text { CTOD }^{(1)} \\
(\mathrm{mm})\end{array}$ & $\begin{array}{c}\text { CTOD }^{(2)} \\
(\mathrm{mm})\end{array}$ & $\begin{array}{c}\mathrm{CTOD}^{(3)} \\
(\mathrm{mm})\end{array}$ \\
\hline E1 PT1 & \multirow{4}{*}{1,5} & 30367 & 22,33 & 4,62 & 1,07 & 1,06 & 0,81 \\
\hline E1 PT2 & & 33904 & 21,41 & 4,50 & 1,13 & 1,13 & 0,88 \\
\hline E2 PT2 & & 30036 & 22,23 & 4,62 & 1,08 & 1,08 & 0,81 \\
\hline $\begin{array}{l}\text { Média } \\
\pm \text { DP }\end{array}$ & & $\begin{array}{l}31435 \pm \\
2144,04\end{array}$ & $\begin{array}{l}21,99 \\
\pm 0,50\end{array}$ & $\begin{array}{c}4,58 \pm \\
0,07\end{array}$ & $\begin{array}{c}1,09 \pm \\
0,03\end{array}$ & $\begin{array}{c}1,09 \pm \\
0,04\end{array}$ & $\begin{array}{c}0,83 \pm \\
0,04\end{array}$ \\
\hline E1 PT3 & \multirow{4}{*}{1,0} & 34015 & 21,74 & 4,50 & 1,10 & 1,09 & 0,90 \\
\hline E2 PT1 & & 37431 & 20,34 & 4,45 & 1,22 & 1,21 & 0,91 \\
\hline E2 PT3 & & 32635 & 21,57 & 4,50 & 1,13 & 1,13 & 0,84 \\
\hline $\begin{array}{c}\text { Média } \\
\pm \text { DP }\end{array}$ & & $\begin{array}{l}34694 \pm \\
2468,98\end{array}$ & $\begin{array}{l}21,22 \\
\pm 0,76 \\
\end{array}$ & $\begin{array}{c}4,48 \pm \\
0,03 \\
\end{array}$ & $\begin{array}{c}1,15 \pm \\
0,06\end{array}$ & $\begin{array}{c}1,14 \pm \\
0,06\end{array}$ & $\begin{array}{c}0,88 \pm \\
0,04 \\
\end{array}$ \\
\hline
\end{tabular}

Tabela 34 - Valores de Integral J para corpos de prova hidrogenados por $48 \mathrm{~h}$.

\begin{tabular}{|c|c|c|c|c|}
\hline \multirow{2}{*}{$\mathrm{CP}$} & \multirow{2}{*}{$\begin{array}{c}\mathrm{v} \\
(\mathrm{mm} / \mathrm{min})\end{array}$} & \multicolumn{3}{|c|}{ Integral $\mathrm{J}\left(\mathrm{J} / \mathrm{mm}^{2}\right)$} \\
\hline & & $\mathbf{J}^{(1)}$ & $\mathbf{J}^{(2)}$ & $\mathbf{J}^{(3)}$ \\
\hline E1 PT1 & \multirow{4}{*}{1,5} & 0,80 & 0,79 & 0,76 \\
\hline E1 PT2 & & 0,87 & 0,87 & 0,83 \\
\hline E2 PT2 & & 0,80 & 0,79 & 0,76 \\
\hline Média $\pm \mathrm{DP}$ & & & & \\
\hline E1 PT3 & \multirow{4}{*}{ ' 1,0} & 0,86 & 0,88 & 0,84 \\
\hline E2 PT1 & & 0,89 & 0,90 & 0,85 \\
\hline E2 PT3 & & 0,82 & 0,83 & 0,79 \\
\hline Média \pm DP & & $\begin{array}{c}0,86 \pm \\
0,04\end{array}$ & $\begin{array}{c}0,87 \pm \\
0,04\end{array}$ & $\begin{array}{c}0,83 \pm \\
0,03\end{array}$ \\
\hline
\end{tabular}

Os valores de CTOD mostram uma redução quando confrontados com os alcançados no tempo de hidrogenação anteriores. O resultados estão associados ao menor tempo de hidrogenação insuficiente para proporcionar concentração de 
hidrogênio suficiente na ponta da pré-trinca, já que o tempo nesta condição foi inferior que o especificado pela norma NACE TM-0284-2003 (2003). A maior velocidade de ensaio junto com a menor concentração de hidrogênio contribuíram para os menores valores de $\mathrm{CTOD}^{(1)}$ e Integral $\mathbf{J}^{(1)}$.

\subsubsection{Análise dos Valores de CTOD para as Condições de Ensaio}

\subsubsection{Hidrogenação por $168 \mathrm{~h}$}

A Figura 116 mostra os valores de CTOD $^{(1)}$ obtidos para o tempo de hidrogenação de 168 h em função da velocidade de ensaio realizada com o objetivo de avaliar a influência da velocidade de ensaio sobre a condição mais severa de hidrogenação.

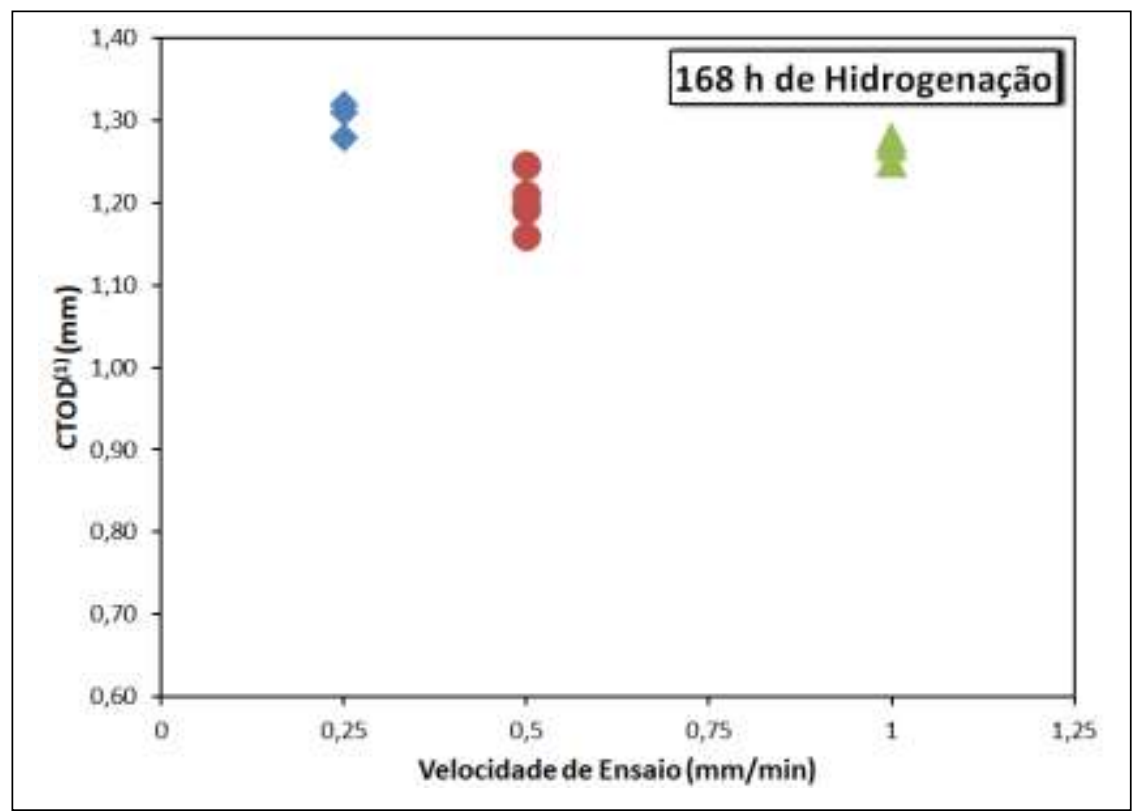

Figura 116 - Valores de CTOD ${ }^{(1)}$ em função da velocidade de ensaio para hidrogenação de 168 h.

Os resultados obtidos nos ensaios realizados com velocidade de $0,25 \mathrm{~mm} /$ min, 0,5 $\mathrm{mm} / \min$ e $1,0 \mathrm{~mm} /$ min são diferentes em um nível de confiança de 95\%. Pelo teste de Mann-Whitney se pode comprovar que há diferença entre os valores de $\mathrm{CTOD}^{(1)}$ encontrados rejeitando-se assim a hipótese $\mathrm{H}_{0}$ de que tais valores são iguais. 
Pela análise dos valores de $\mathrm{CTOD}^{(1)}$ se pode concluir que o fator velocidade interfere nos valores do parâmetro de tenacidade à fratura mencionado. A redução da velocidade de ensaio aumenta o tempo de duração do mesmo, que associado a concentração de hidrogênio na ponta da trinca favorece a atuação da atmosfera de elétrons ao redor das discordâncias, e consequentemente a ação do mecanismo HELP na ponta da trinca para obtenção dos maiores valores de $\operatorname{CTOD}^{(1)}$ na velocidade de ensaio mais baixa, ou seja, $0,25 \mathrm{~mm} / \mathrm{min}$.

Em relação a propagação da trinca defeito durante o ensaio se verifica para as velocidades de $0,25 \mathrm{~mm} / \mathrm{min}$ e $1,0 \mathrm{~mm} / \mathrm{min}$ uma extensa propagação estável. A Tabela 35 apresenta os valores de propagação estável parcial e total dos 6 corpos de prova ensaiados.

Os valores encontrados para a propagação estável da trinca estão de acordo com os valores de CTOD $^{(1)}$ encontrados. Segundo o critério da curva de resistência (Curva-R), quanto maior o valor do CTOD, maior o valor da propagação estável. Desta forma, pode-se verificar que as maiores propagações estáveis estão associados aos maiores valores de CTOD.

Tabela 35- Valores parciais e totais de propagação da trinca das superfícies de fratura hidrogenadas por $168 \mathrm{~h}$.

\begin{tabular}{|c|c|c|c|c|c|c|}
\hline & \multicolumn{3}{|c|}{$0,25 \mathrm{~mm} / \mathrm{min}$} & \multicolumn{3}{c|}{$1,0 \mathrm{~mm} / \mathrm{min}$} \\
\hline$\Delta \mathbf{a}(\mathbf{m m})$ & C1 PT1 & C1 PT2 & C2 PT3 & C2 PT1 & C2 PT2 & C1 PT3 \\
\hline $\mathrm{a} 1$ & 0,63 & 0,35 & 0,00 & 0,33 & 0,21 & 0,25 \\
\hline $\mathrm{a} 2$ & 0,76 & 0,67 & 0,74 & 0,57 & 0,49 & 0,47 \\
\hline $\mathrm{a} 3$ & 2,51 & 1,69 & 2,86 & 1,19 & 1,07 & 1,38 \\
\hline $\mathrm{a} 4$ & 3,33 & 2,59 & 3,54 & 2,24 & 1,91 & 1,96 \\
\hline $\mathrm{a} 5$ & 3,41 & 3,84 & 3,61 & 2,15 & 2,92 & 2,24 \\
\hline $\mathrm{a} 6$ & 2,41 & 3,76 & 3,01 & 2,12 & 2,40 & 1,38 \\
\hline $\mathrm{a} 7$ & 1,79 & 3,13 & 1,56 & 1,52 & 1,80 & 0,64 \\
\hline $\mathrm{a} 8$ & 0,67 & 0,91 & 0,68 & 0,35 & 1,31 & 0,56 \\
\hline $\mathrm{a} 9$ & 0,48 & 0,13 & 0,68 & 0,11 & 0,29 & 0,48 \\
\hline$\Delta \mathbf{a}_{\text {total }}$ & 1,92 & 2,10 & 2,04 & 1,29 & 1,52 & 1,12 \\
\hline $\mathbf{C T O D}^{(\mathbf{1})}$ & 1,28 & 1,32 & 1,31 & 1,27 & 1,25 & 1,27 \\
\hline
\end{tabular}

A propagação estável da trinca ocorreu devido a combinação dos mecanismos de plasticidade localizada e decoesão, HELP e HEDE, 
respectivamente. A presença do hidrogênio provoca efeitos diferentes no plano da trinca. Na ponta da trinca devido a maior nível de tensões existe o efeito de amaciamento provocado pela atmosfera de elétrons oriundo dos átomos de hidrogênio aprisionados pelas discordâncias, favorecendo a deformação e contribuindo para os valores de $\mathrm{CTOD}^{(1)}$ obtidos. Porém após exaustão da ductilidade do material, iniciou-se a propagação estável da trinca devido ao efeito de endurecimento existente nas regiões mais afastadas da ponta da trinca. Com o enfraquecimento das ligações atômicas provocado pelo hidrogênio houve favorecimento a propagação estável da trinca, que contribuiu para sua extensão.

A Figura 117 ilustra a direção da propagação estável da trinca obtida em corpo de prova hidrogenado por $168 \mathrm{~h}$ e ensaiado a $0,25 \mathrm{~mm} / \mathrm{min}$.

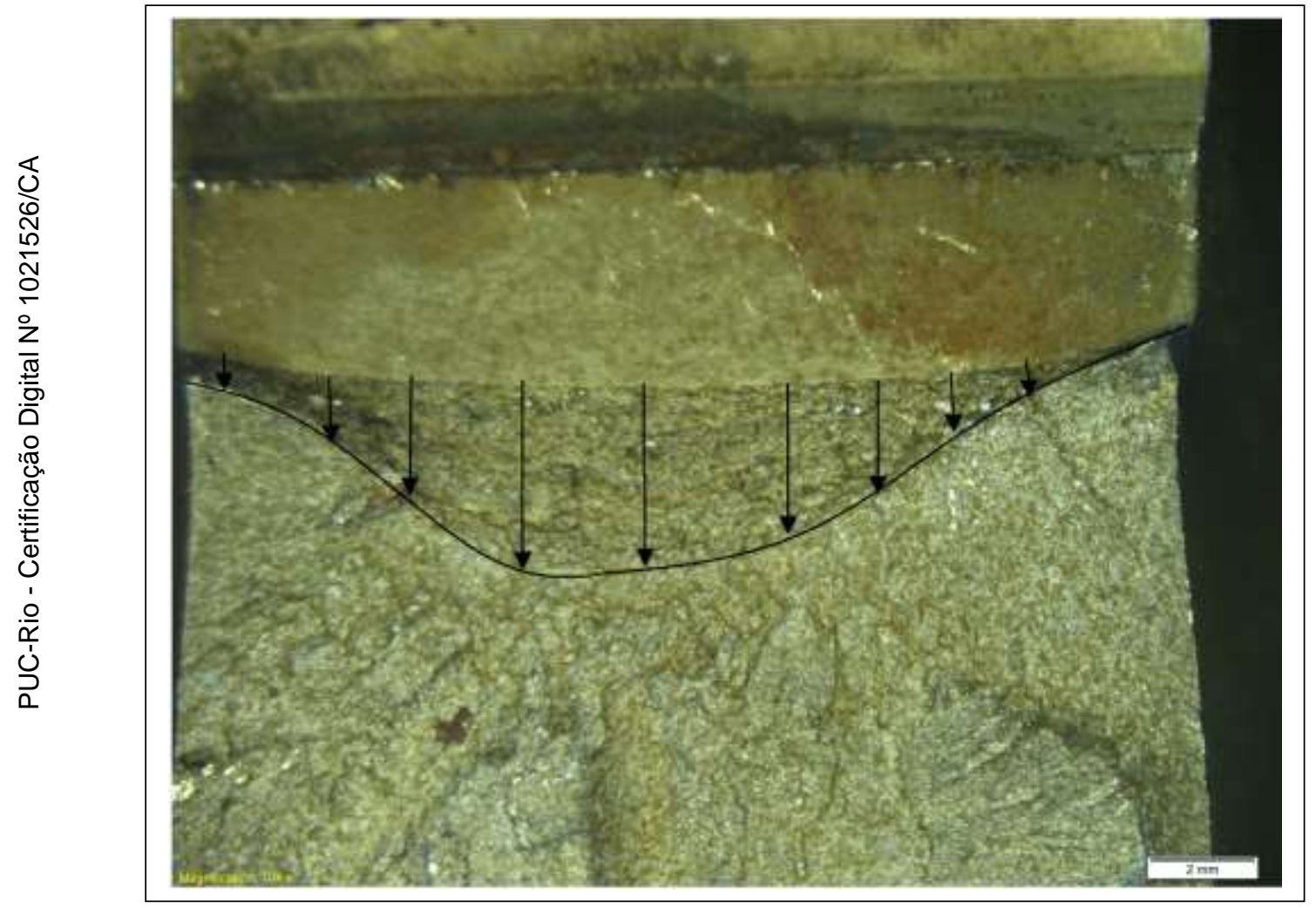

Figura 117 - Propagação estável da trinca após 168 h de hidrogenação. Aumento de 8x.

Tal efeito está de acordo com o verificado por Murakami (2012) em estudos realizados com aços inoxidáveis austeníticos submetidos a exposição ao hidrogênio.

Através de fractografias se observou o efeito do hidrogênio sobre a morfologia da fratura. A partir da pré-trinca se observa uma propagação estável de trinca marcada pela inexistência dimples profundos característicos de fratura 
predominantemente dúctil. Ao invés dos dimples profundos se observa uma morfologia de fratura associada a uma leve mudança no micromecanismo de propagação da trinca.

A Figura 118 mostra a morfologia de propagação de trinca encontrada para a condição de $168 \mathrm{~h}$ de hidrogenação e ensaio a $0,25 \mathrm{~mm} / \mathrm{min}$ e detalhamento indicado por um círculo de região analisada com maior ampliação.

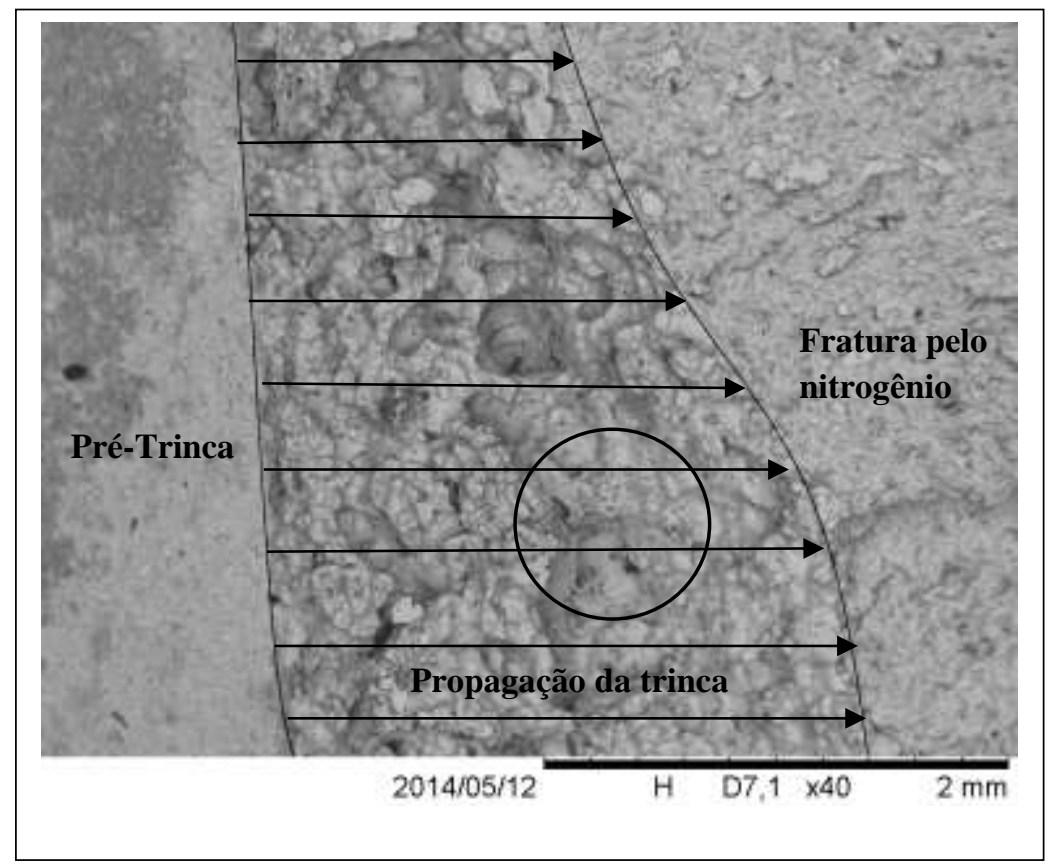

Figura 118- Fractografia de superfície hidrogenada por $168 \mathrm{~h}$ oriunda de ensaio de CTOD a $0,25 \mathrm{~mm} / \mathrm{min}$. Aumento 40x.

A partir do exposto se observa que o micromecanismo de fratura envolvido na propagação da trinca passou de nucleação, crescimento e coalescimento de cavidades para o micromecanismo de quase clivagem. Tal micromecanismo, Figura 119, é assinalado pela presença de cavidades quase planas (“dimples" facetados), ao redor de partículas de 2. ${ }^{a}$ fase, que se assemelham as facetas encontradas no micromecanismo de clivagem pura.

Também se visualiza que as cavidades nas quais se encontram as partículas de 2. ${ }^{\text {a }}$ fase não foram submetidas a grande deformação plástica, sendo assim o ponto de partida para a fratura transgranular. Este fato está indicado na Figura 119 através de um detalhe que pode ser melhor visualizado na Figura 120 que mostra cavidade de partícula de 2. ${ }^{a}$ fase inserida no interior dos falso dimple (dimple facetado). 


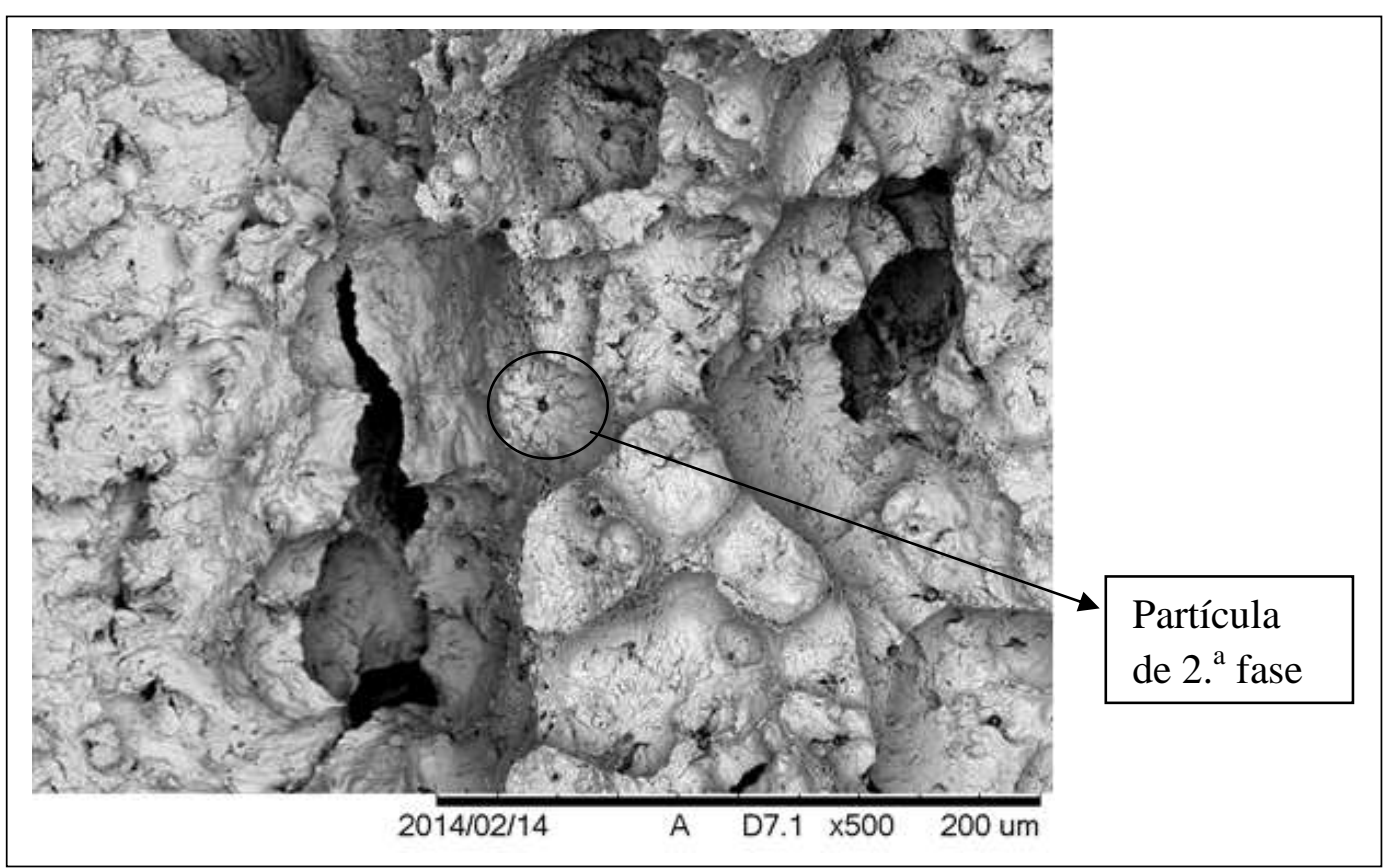

Figura 119- Micromecanismo de quase clivagem na região de propagação estável da pré-trinca. Aumento: 500X.

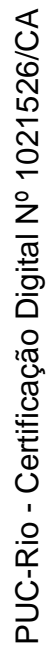

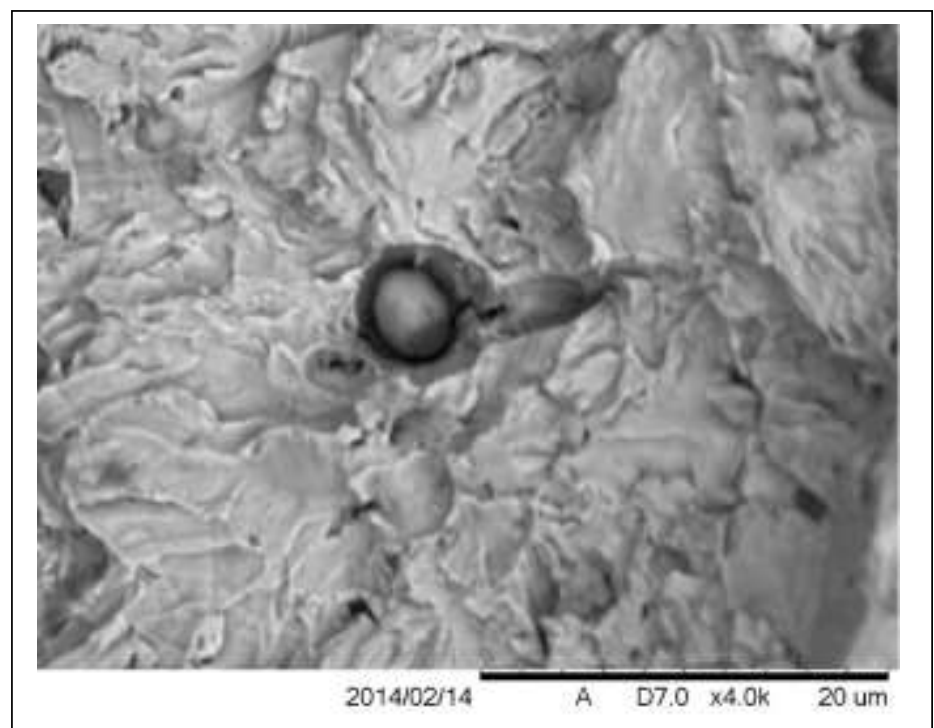

Figura 120- Partícula de $2 .^{\text {a }}$ fase iniciadora da quase clivagem. Aumento: 4000X.

O resultado encontrado está de acordo com o visualisado em estudos realizados com o mesmo material (aço API 5L X65) na condição hidrogenada realizado por Fassina et al. (2012) que verificou a presença dos falsos dimples ao redor das partículas de 2. ${ }^{\mathrm{a}}$ fase, iniciadores do micromecanismo de quase clivagem. 


\subsubsection{Ensaios a Velocidade de $1,0 \mathrm{~mm} / \mathrm{min}$}

A Figura 121 mostra os valores de CTOD $^{(1)}$ obtidos para corpos de prova com diferentes cargas de hidrogenação e ensaiados a $1,0 \mathrm{~mm} / \mathrm{min}$.

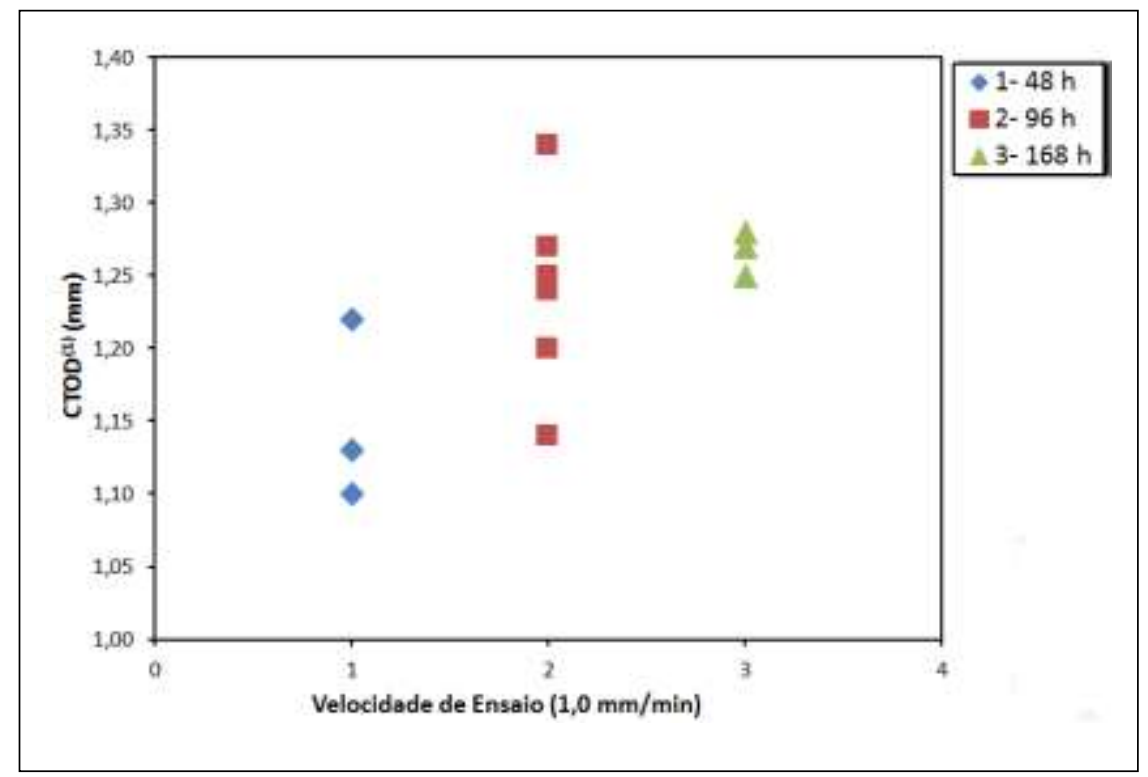

Figura 121- Influência do tempo de hidrogenação para velocidade de ensaio de 1,0 mm/min.

Os valores de CTOD $^{(1)}$ encontrados para a carga de hidrogenação de 48 h, 96 h e 168 h são similares. A análise estatística feita pelo teste de Mann-Whitney mostra que os valores encontrados não são diferentes com um nível de confiança de $95 \%$. Porém, comparando tais valores se percebe uma leve inferioridade para a condição de 48 h. Tal fato está associado a menor concentração de hidrogênio.

Para uma adequada concentração de hidrogênio, a norma NACE TM02842003 (2003) estabelece um tempo mínimo de 96 h. Sendo assim, os resultados de CTOD $^{(1)}$ mais baixos estão condicionados a concentrração de hidrogênio insuficiente na ponta da trinca.

$\mathrm{O}$ aumento dos tempos de hidrogenação proporcionaram valores mais altos de CTOD $^{(1)}$. A maior quantidade de hidrogênio difundida para a ponta da trinca favoreceu o desempenho do mecanismo de plasticidade localizada. Para a condição de hidrogenação de 168 h não se verificou aumento do CTOD $^{(1)}$. Este fato é explicado pelo aumento da velocidade de ensaio que reduziu o tempo para atuação do mecanismo de plasticidade localizada. 
Em relação à propagação estável da trinca, se pode perceber que estas são similares para as condições de ensaio realizadas (Figura 122), o que é de se esperar, já que os resultados do $\mathrm{CTOD}^{(1)}$ obtidos são iguais segundo teste estatístico de Mann-Whitney.

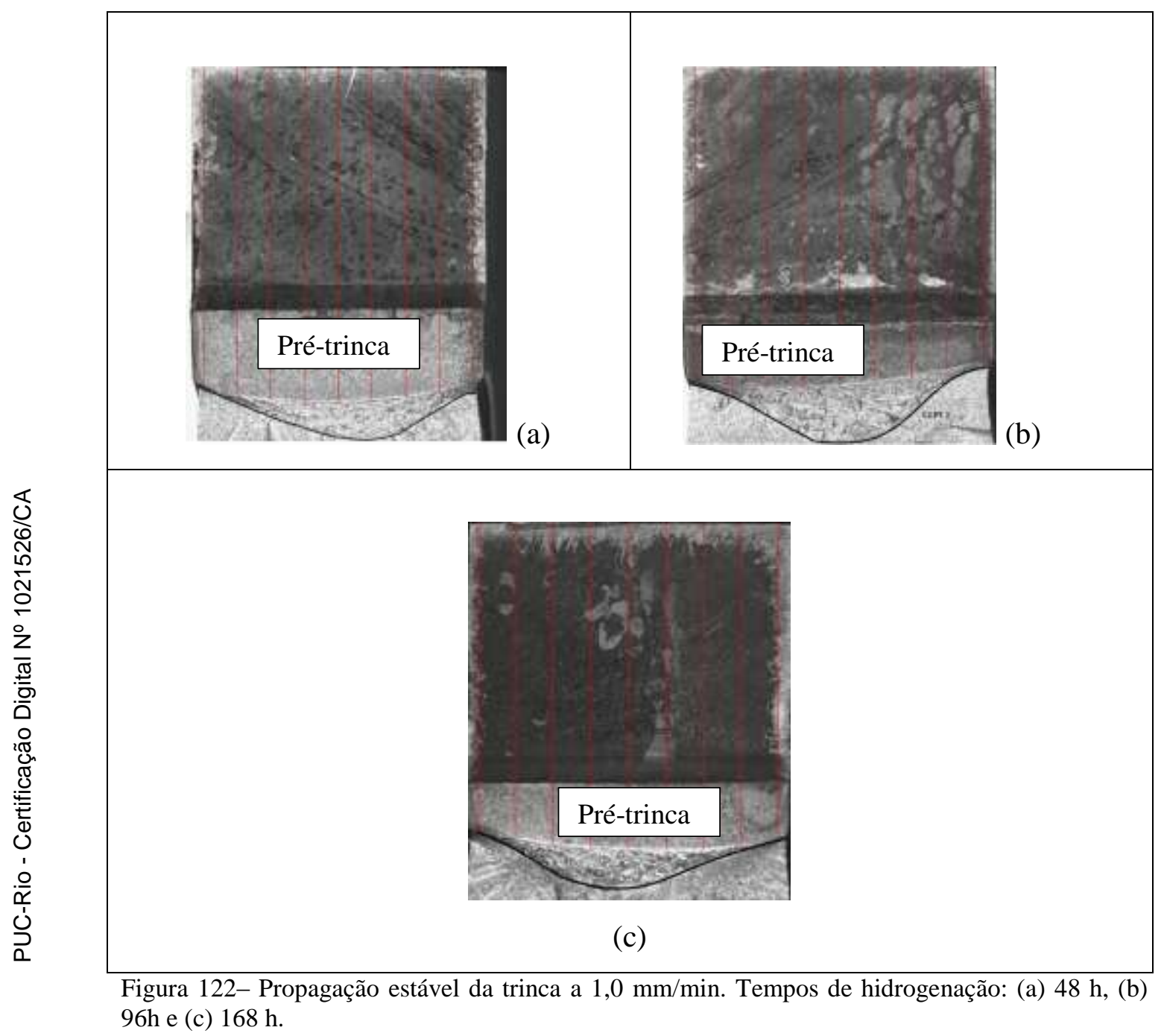

\subsubsection{Ensaios a velocidade de $0,5 \mathrm{~mm} / \mathrm{min}$}

Os resultados de $\mathrm{CTOD}^{(1)}$ obtidos para a velocidade de ensaio de 0,5 mm/min, mostrados na Figura 123, são referentes às condições sem hidrogênio e hidrogenação por $168 \mathrm{~h}$. 


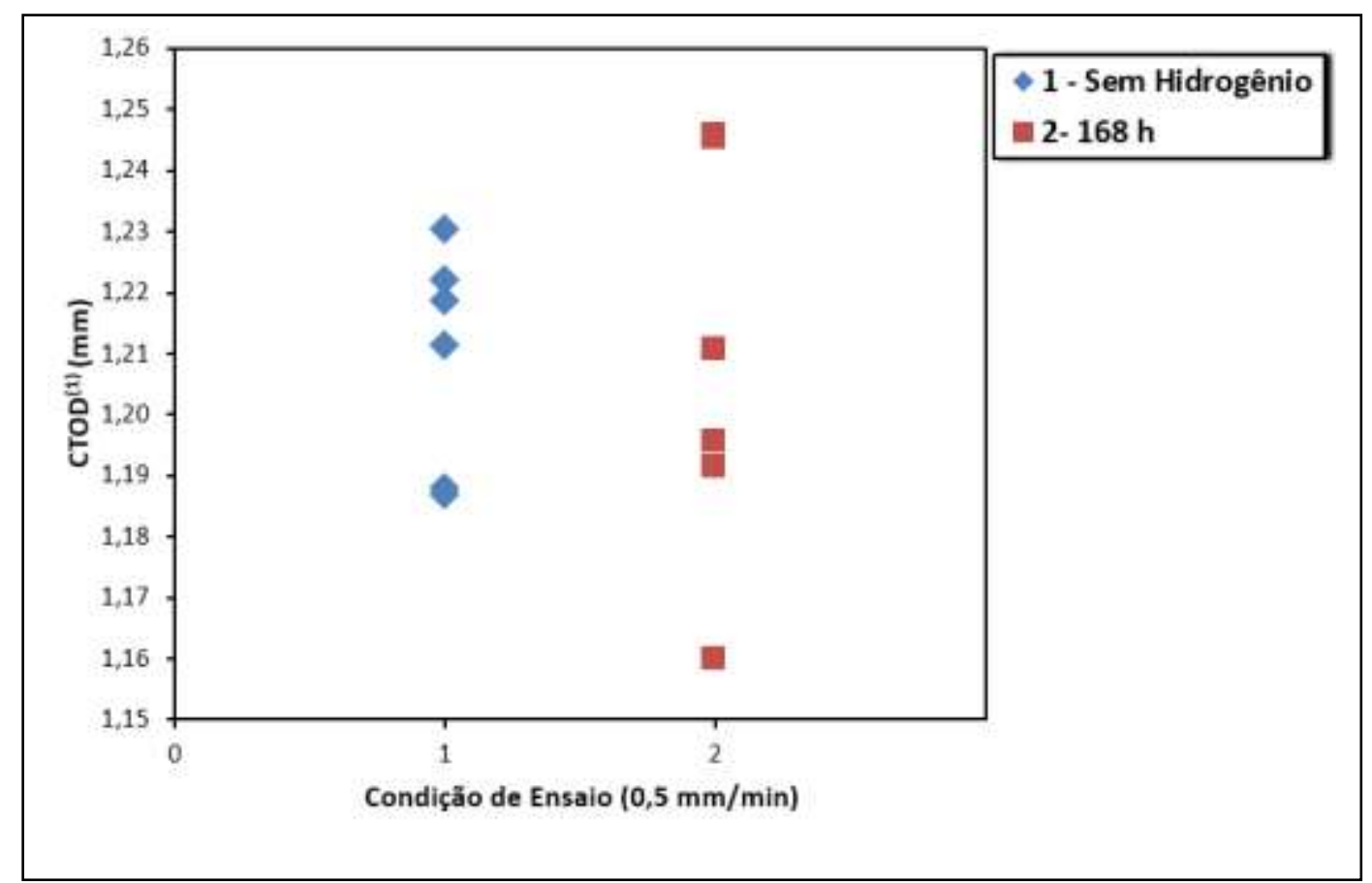

Figura 123- Influência do tempo de hidrogenação na tenacidade à fratura para velocidade de ensaio de $0,5 \mathrm{~mm} / \mathrm{min}$.

Os valores de $\mathrm{CTOD}^{(1)}$ encontrados mostram que o hidrogênio não reduziu a tenacidade do material para a condição testada. Estudo estatístico feito pelo teste de Mann-Whitney mostra que os valores mencionados são iguais para um nível de confiança de $95 \%$.

Mais uma vez verifica-se que velocidades de ensaio mais baixas favorece a atuação do mecanismo de plasticidade localizada pela atmosfera de elétrons ao redor das discordâncias na ponta da trinca, responsável pelo efeito de amaciamento e consequentemente elevados valores de tenacidade à fratura.

O efeito prejudicial causado pelo hidrogênio está no aumento da propagação estável da trinca. Na condição sem hidrogênio os corpos de prova apresentaram uma propagação estável muito pequena, enquanto que para a condição hidrogenada, a propagação estável da trinca foi semelhante ao encontrado para os corpos de prova com a mesma carga de hidrogenação, porém ensaiados a 0,5 $\mathrm{mm} / \mathrm{min}$. A Figura 124 ilustra o comentário acima. 


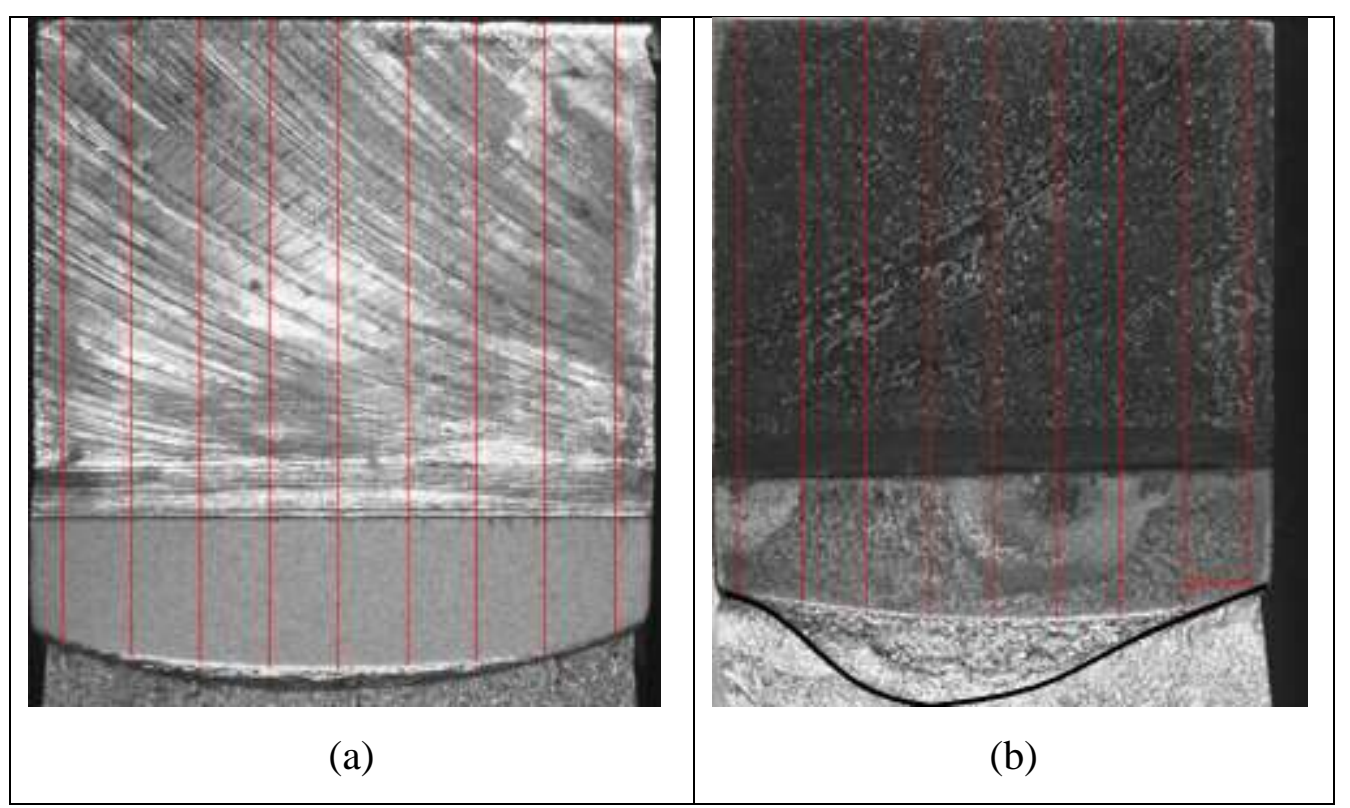

Figura 124- Macroscopia da superfície de fratura de corpos de prova ensaiados a $0,5 \mathrm{~mm} / \mathrm{min}$ não hidrogenados (a) e após 168 h de hidrogenação (b).

A maior propagação estável da trinca na condição hidrogenada é explicada pelo enfraquecimento das ligações atômicas favorecendo a propagação da trinca. Este fato mostra a combinação de de mecanismos de atuação de hidrogênio (HEDE e HELP), o que está de acordo com a literatura como, por exemplo, Gerberich, Stauffer e Sofronis (2008) que afirma os mecanismos de atuação de hidrogênio é dependente da microestrutura e que um único mecanismo não é responsável pelos efeitos observados no material.

A pequena propagação estável dos corpos de prova sem hidrogênio é preveniente do maior consumo da energia armazenada na forma de deformação plástica. Pela fractografia se visualiza que a propagação estável da trinca ocorreu com uma quantidade significativa de deformação plástica. Como esperado o micromecanismo de fratura predominante durante a propagação estável é o micromecanismo dúctil de nucleação, crescimento e coalescimento de cavidades, que pode ser visualizado pela Figura 125, assim como as regiões de interesse A e $\mathrm{B}$ da superfície de fratura. A região A corresponde a pré-trinca e a região $\mathrm{B}$ equivale a propagação estável da trinca durante o ensaio de tenacidade à fratura. 


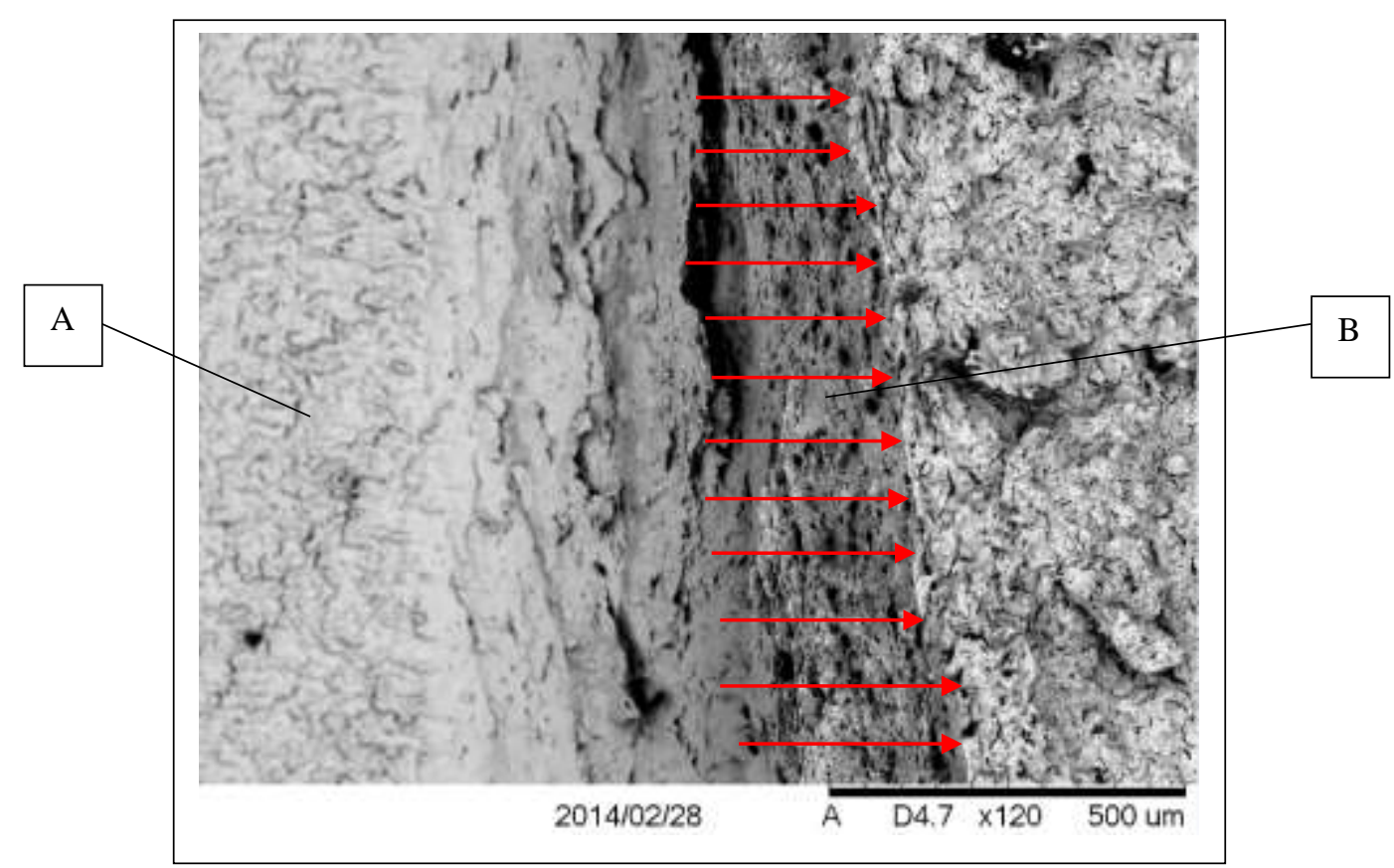

Figura 125 - Regiões da superfície de fratura para a condição não hidrogenada. As setas indicam a direção de propagação da trinca. Aumento: $120 \mathrm{X}$

Detalhando-se a região $\mathrm{B}$ com aumento de 600X, observa-se o micromecanismo dúctil responsável pela fratura, através da presença de dimples (microcavidades) muito pequenos, com diâmetros máximos $0,8 \mathrm{~mm}$, o que é de esperar para um aço de estrutural de boa ductilidade e baixo nível de inclusões (Figura 126). Verifica-se a presença de pequenas partículas de 2. ${ }^{a}$ fase no interior de alguns dimples. A inexistência de partículas de $2 .^{\text {a }}$ fase em grande parte dos dimples está associada a saída das mesmas durante a etapa de exposição da superfície de fratura após ruptura com auxílio do nitrogênio líquido. 


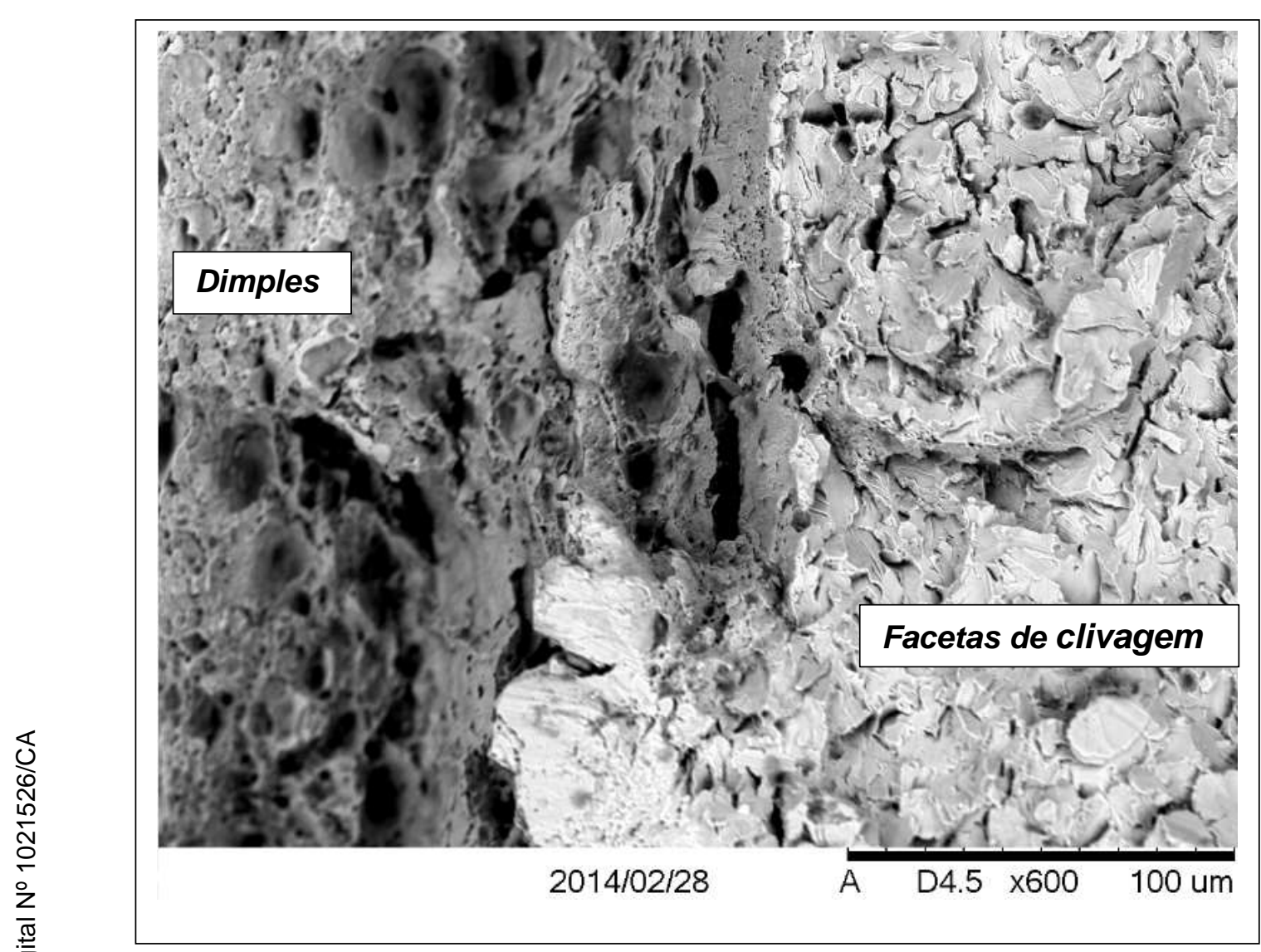

Figura 126 - Fractografia da região de propagação estável da trinca obtida por microscopia eletrônica de varredura de corpo prova não hidrogenado. Aumento: 600X.

\subsubsection{Influência da Velocidade de Ensaio para $168 \mathrm{~h}$ de Hidrogenação}

Como pode ser visualizado na Figura 127, a redução da velocidade favorece a obtenção de maiores valores de $\operatorname{CTOD}^{(1)}$ na condição de 168 h de hidrogenação. A menor velocidade de ensaio aumenta o tempo de duração do mesmo e contribui para ação do mecanismo de plasticidade localizada.

Os valores alcançados para corpos de prova submetidos a $168 \mathrm{~h}$ de hidrogenação a $0,25 \mathrm{~mm} / \mathrm{min}$ e $0,5 \mathrm{~mm} / \min$ são diferentes conforme teste de Mann-Whitney com um nível de confiança de 95\%. Desta forma, se conclui que há influência da velocidade sobre o valor de $\operatorname{CTOD}^{(1)}$ na condição de hidrogenação mencionada. 


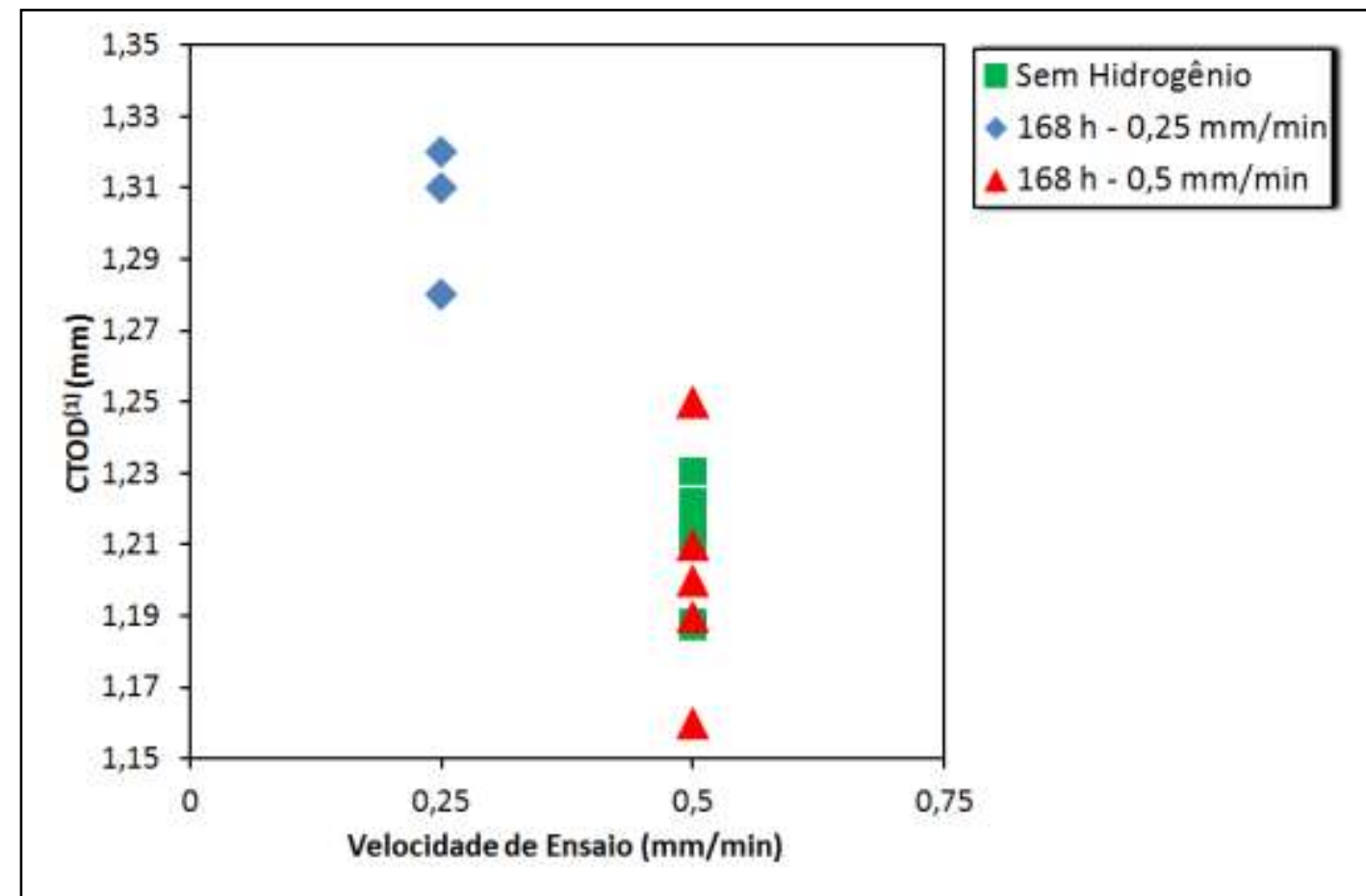

Figura 127 - Influência da velocidade de ensaio na tenacidade a fratura para $168 \mathrm{~h}$ de hidrogenação.

\subsubsection{Influência da Velocidade de Ensaio para $48 \mathrm{~h}$ de Hidrogenação}

Os resultados para a condição de hidrogenação de $48 \mathrm{~h}$ a $1,0 \mathrm{~mm} / \mathrm{min}$ e 1,5 $\mathrm{mm} /$ min são iguais segundo teste de Mann-Whitney com nível de confiança de 95\%. Porém o aumenta da velocidade de ensaio resultou em menores valores de CTOD $^{(1)}$ quando comparados com a condição sem hidrogênio.

Como já mencionado, $48 \mathrm{~h}$ de hidrogenação é inferior ao tempo mínimo especificado pela norma NACE TM0284-2003 (2003). Sendo assim, os menores valores de $\mathrm{CTOD}^{(1)}$ estão associados a baixa concentração de hidrogênio e ao menor tempo para a difusão deste para a ponta da trinca durante o ensaio, impedindo a formação da atmosfera de elétrons ao redor das discordâncias (mecanismo HELP) na ponta da trinca.

$\mathrm{O}$ aumento da velocidade de ensaio de $1,0 \mathrm{~mm} / \min$ para $1,5 \mathrm{~mm} / \mathrm{min}$ reduziu o tempo para difusão do hidrogênio até a ponta da trinca. A menor concentração de hidrogênio junto com menor tempo de difusão resulta em valores 
de CTOD $^{(1)}$ elevados em relação aos valores obtidos para condição não hidrogenada.

A ausência de hidrogênio suficiente na ponta da trinca leva a conclusão que ensaios de CTOD com velocidades menores que 1,0 $\mathrm{mm} / \mathrm{min}$ realizados nos corpos de prova com carga de hidrogênio inferior ao especificado pela norma NACE proporcionariam valores de $\operatorname{CTOD}^{(1)}$ semelhantes a condição sem hidrogênio. Desta forma, tais resultados seriam decorrentes da microestrutura do material e consequentemente da boa ductilidade do aço adotado neste trabalho.

Os valores de $\mathrm{CTOD}^{(1)}$ estão apresentados na Figura 128 junto com os obtido para condição sem hidrogênio para fins de comparação.

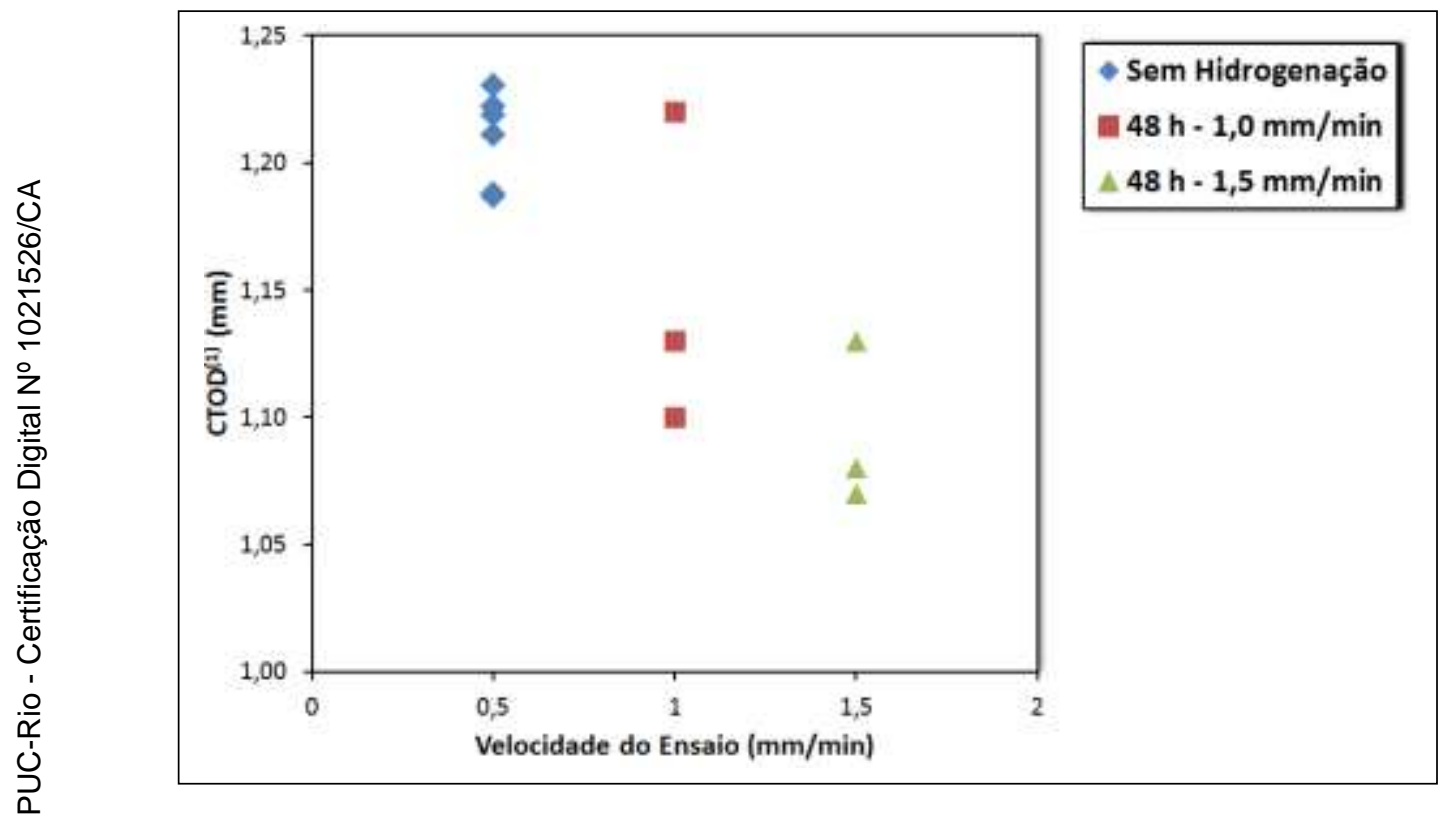

Figura 128- Influência da velocidade de ensaio na tenacidade a fratura para carga de hidrogênio de $48 \mathrm{~h}$.

\subsubsection{Corpos de Prova com Entalhe Lateral}

Os corpos de prova $\mathrm{SG}_{1}$ e $\mathrm{SG}_{2}$, com entalhe lateral de profundidade igual a 2,5 mm e $5 \mathrm{~mm}$, respectivamente, obtiveram as seguintes curvas carga vs CMOD, ilustradas na Figura 129. 


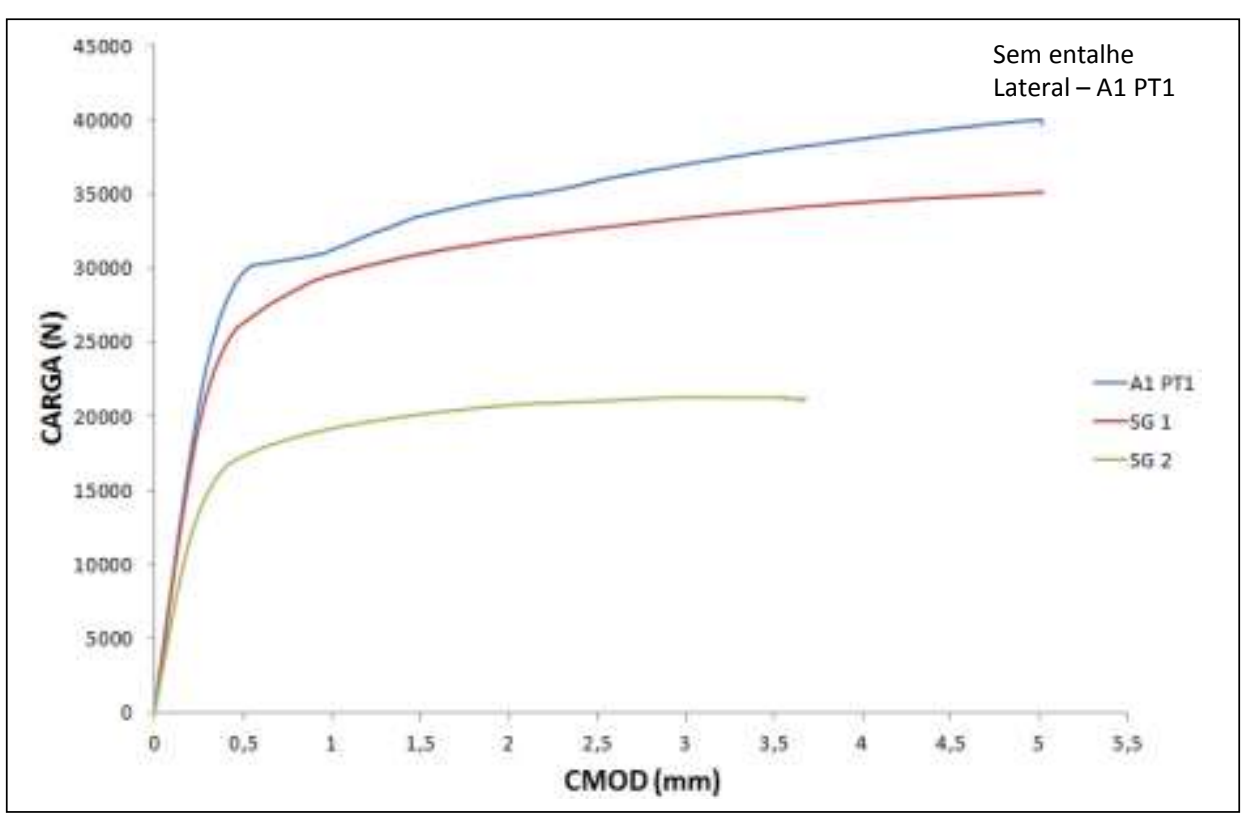

Figura 129- Curvas Carga vs CMOD dos corpos de prova entalhados lateralmente em relação aos sem entalhe a $0,5 \mathrm{~mm} / \mathrm{min}$.

Os resultados de CTOD e Integral $\mathbf{J}$ alcançados para a condição em questão, estão apresentados nas Tabelas 36 e 37, conforme descrição apresentada na Tabela 19 e 20.

Tabela 36 - Valores de CTOD para condição não hidrogenada.

\begin{tabular}{|c|c|c|c|c|c|c|}
\hline $\mathrm{CP}$ & $\begin{array}{c}\mathrm{P} \\
(\mathrm{N})\end{array}$ & $\begin{array}{c}\mathrm{a}_{\mathrm{r}} \\
(\mathrm{mm})\end{array}$ & $\begin{array}{c}\mathrm{V}_{\mathrm{p}} \\
(\mathrm{mm})\end{array}$ & $\begin{array}{c}\mathrm{CTOD}^{(1)} \\
(\mathrm{mm})\end{array}$ & $\begin{array}{c}\mathrm{CTOD}^{(2)} \\
(\mathrm{mm})\end{array}$ & $\begin{array}{c}\mathrm{CTOD}^{(3)} \\
(\mathrm{mm})\end{array}$ \\
\hline $\mathrm{SG}_{1}$ & 33750 & 20,80 & 4,60 & 1,24 & 1,22 & 1,13 \\
\hline $\mathrm{SG}_{2}$ & 21290 & 21,18 & 3,10 & 1,15 & 1,17 & 0,67 \\
\hline $\begin{array}{c}\text { Média } \pm \\
\mathrm{DP}\end{array}$ & $\begin{array}{c}27520 \\
\pm 8810\end{array}$ & $\begin{array}{c}20,99 \pm \\
0,27\end{array}$ & $\begin{array}{c}3,85 \pm \\
1,06\end{array}$ & $\begin{array}{c}1,20 \pm \\
0,06\end{array}$ & $\begin{array}{c}1,20 \pm \\
0,04\end{array}$ & $\begin{array}{c}0,90 \pm \\
0,33\end{array}$ \\
\hline
\end{tabular}

Tabela 37- Valores de Integral $\mathbf{J}$ para corpos de prova com entalhe lateral para condição não hidrogenada.

\begin{tabular}{|c|c|c|c|}
\hline & \multicolumn{3}{|c|}{ Integral $\mathbf{J}\left(\mathrm{J} / \mathrm{mm}^{2}\right)$} \\
\hline $\mathrm{CP}$ & $\mathbf{J}^{(1)}$ & $\mathbf{J}^{(2)}$ & $\mathbf{J}^{(3)}$ \\
\hline $\mathrm{SG}_{1}$ & 1,13 & 1,10 & 1,05 \\
\hline $\mathrm{SG}_{2}$ & 0,65 & 0,64 & 0,62 \\
\hline Média \pm DP & $0,89 \pm 0,34$ & $0,87 \pm 0,33$ & $0,84 \pm 0,30$ \\
\hline
\end{tabular}


Através da análise das curvas obtidas durante o ensaio se pode verificar a interferência no comportamento à fratura provocada pelo entalhe lateral (side groove). O side groove altera o estado de tensão no centro do corpo de prova, aumentando a triaxilidade de tensões neste local.

Como o nível de restrição próximo as extremidades é significativamente elevado com a existência do side groove, se tem uma propagação de trinca mais uniforme, ou seja, com menos deformação nas laterais do corpo de prova.

Devido ao aumento do nível de restrição pelo side groove, a propagação da trinca é facilitada e ocorre de maneira uniforme e com menos deformação (tunneling) nas laterais do corpo de prova, resultando na redução da capacidade de resistência a carregamentos. Isto pode ser visualizado na curva carga x CMOD, onde a carga de desvio da linearidade, indicativo de deformação significativa no ligamento do corpo de prova, é da ordem de $30 \mathrm{kN}$ para o corpo de prova sem entalhe lateral enquanto que para o entalhado lateralmente é da ordem de $25 \mathrm{kN}$. $\mathrm{O}$ efeito da profundidade do side groove no comportamento à fratura do aço API 5L X65 pode ser verificado com o alcance de um CTOD representativo de um evento físico relevante para o material, ou seja, CTOD de carga máxima $\left(\delta_{\mathrm{m}}\right)$ para a profundidade de entalhe lateral de $5 \mathrm{~mm}$, o que correspondeu a uma redução de espessura de $50 \%$ do corpo de prova $\mathrm{SG}_{2}$.

A seguir estão apresentados os resultados obtidos com as outras baterias de corpos de prova entalhados lateralmente, conforme descrito no item 3.5.2. Vale ressaltar que os corpos de prova nesta etapa foram expostos a hidrogenação por $168 \mathrm{~h}$ e ensaiados a velocidade de $0,5 \mathrm{~mm} / \mathrm{min}$, o que corresponde a um taxa de deformação $8,3 \times 10^{-3} / \mathrm{s}$.

\subsubsection{Corpos de Prova com $50 \%$ de Redução de Espessura Hidrogenados por $168 \mathrm{~h}$}

A Figura 130 apresenta as curvas carga $v s$ CMOD para os 5 corpos de prova entalhados lateralmente ensaiados com velocidade de $0,5 \mathrm{~mm} / \mathrm{min}$, na condição hidrogenada por $168 \mathrm{~h}$. 


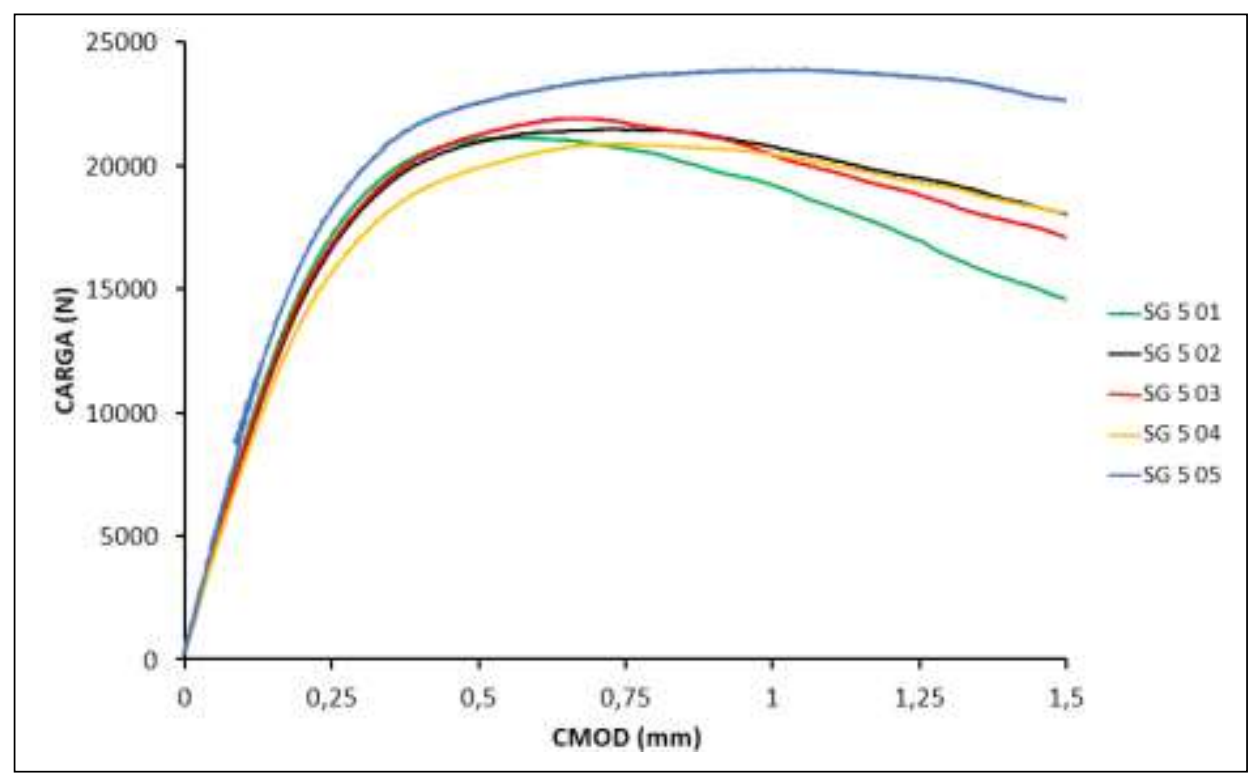

Figura 130- Carga vs CMOD para corpos de prova com 50\% de redução lateral na espessura ensaiados a $0,5 \mathrm{~mm} / \mathrm{min}$.

Os resultados de $\mathrm{CTOD}^{(1)}$ e $\mathbf{J}^{(1)}$ de carga máxima $\left(\delta_{\mathrm{m}}\right.$ e $\left.\mathrm{J}_{\mathrm{m}}\right)$ alcançados para

a condição em questão, estão apresentados nas Tabelas 38 e 39, conforme descrição apresentada na Tabela 19 e 20. Como já foi verificado que os resultados fornecidos pelo software controlador da máquina são confiáveis, nesta etapa decidiu-se em omitir os resultados de CTOD calculados pela autora.

Tabela 38- Valores de CTOD de carga máxima para condição de 168 h de hidrogenação para corpos de prova com $50 \%$ de redução de espessura.

\begin{tabular}{|c|c|c|c|c|c|}
\hline CP & $\begin{array}{c}\mathrm{P} \\
(\mathrm{N})\end{array}$ & $\begin{array}{c}\mathrm{a}_{\mathrm{r}} \\
(\mathrm{mm})\end{array}$ & $\begin{array}{c}\mathrm{V}_{\mathrm{p}} \\
(\mathrm{mm})\end{array}$ & $\begin{array}{c}\mathrm{CTOD}^{(1)} \\
(\mathrm{mm})\end{array}$ & $\begin{array}{c}\mathrm{CTOD}^{(3)} \\
(\mathrm{mm})\end{array}$ \\
\hline SG 5 01 & 21119 & 20,19 & 0,25 & 0,14 & 0,13 \\
\hline SG 5 02 & 21474 & 20,56 & 0,38 & 0,18 & 0,17 \\
\hline SG 5 03 & 21897 & 20,34 & 0,38 & 0,18 & 0,15 \\
\hline SG 5 04 & 20866 & 20,93 & 0,43 & 0,19 & 0,17 \\
\hline SG 5 05 & 23891 & 19,83 & 0,70 & 0,30 & 0,26 \\
\hline $\begin{array}{c}\text { Média } \pm \\
\text { DP }\end{array}$ & $\begin{array}{c}21849 \pm \\
1205,39\end{array}$ & $\begin{array}{c}20,37 \\
\pm 0,41\end{array}$ & $\begin{array}{c}0,43 \pm \\
0,17\end{array}$ & $\begin{array}{c}0,20 \pm \\
0,06\end{array}$ & $\begin{array}{c}0,18 \pm \\
0,05\end{array}$ \\
\hline
\end{tabular}


Tabela 39- Valores da Integral J de carga máxima para condição de 168 h de hidrogenação para corpos de prova com $50 \%$ de redução de espessura.

\begin{tabular}{|c|c|c|}
\hline \multirow{2}{*}{ CP } & \multicolumn{2}{|c|}{ Integral $\mathbf{~}\left(\mathrm{J} / \mathrm{mm}^{2}\right)$} \\
\cline { 2 - 3 } & $\mathbf{J}^{(1)}$ & $\mathbf{J}^{(3)}$ \\
\hline SG 5 01 & 0,13 & 0,12 \\
\hline SG 5 02 & 0,16 & 0,16 \\
\hline SG 5 03 & 0,15 & 0,14 \\
\hline SG 5 04 & 0,16 & 0,16 \\
\hline SG 5 05 & 0,26 & 0,23 \\
\hline Média \pm DP & $0,17 \pm 0,05$ & $0,16 \pm 0,04$ \\
\hline
\end{tabular}

Como esperado, os valores de $\mathrm{CTOD}^{(1)}$ e Integral $\mathbf{J}^{(1)}$ apresentados na Tabela 38 e 39 são correspondentes ao CTOD e Integral $\mathbf{J}$ associado a evento físico relevante ao material (carga máxima), antes não visualizado nos resultados apresentados no item 4.3.4.

A presença dos entalhes laterais de $5 \mathrm{~mm}$ de profundidade cada um, aumenta da severidade do nível de restrição plástica devido ao alcance da condição de deformação plana em porções do corpo de prova onde normalmente se há uma relaxação das tensões através da deformação plástica (estado plano de tensão). Devido a isso houve um adiantamento da máxima carga suportada pelo material, indicado pelo patamar de carga da curva carga vs CMOD, resultando no CTOD de carga máxima do material.

\subsubsection{Corpos de Prova com $70 \%$ de Redução de Espessura Hidrogenados por $168 \mathrm{~h}$}

A Figura 131 apresenta as curvas carga vs CMOD para os 5 corpos de prova ensaiados entalhados lateralmente com velocidade de $0,5 \mathrm{~mm} / \mathrm{min}$, na condição hidrogenada em questão. 


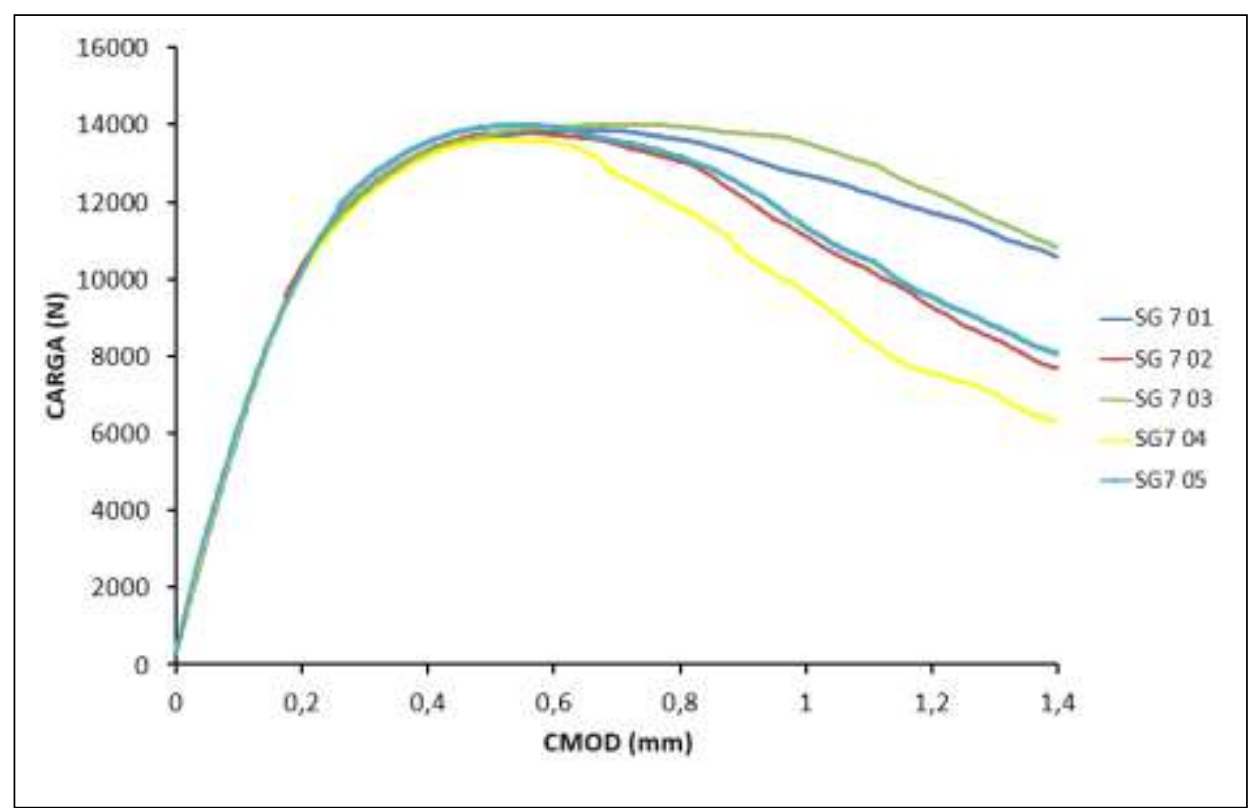

Figura 131 - Carga vs CMOD para corpos de prova com $70 \%$ de redução lateral na espessura ensaiados a $0,5 \mathrm{~mm} / \mathrm{min}$.

Os resultados de $\operatorname{CTOD}^{(1)}$, ambos na condição de carga máxima $\left(\delta_{\mathrm{m}}\right.$ e $\left.\mathrm{J}_{\mathrm{m}}\right)$ alcançados para a condição em questão, estão apresentados nas Tabelas 40 e 41, conforme descrição apresentada na Tabela 19 e 20.

Tabela 40- Valores de CTOD de carga máxima para condição de 168 h de hidrogenação para corpos de prova com $50 \%$ de redução de espessura.

\begin{tabular}{|c|c|c|c|c|c|}
\hline $\begin{array}{c}\text { Corpo } \\
\text { de prova }\end{array}$ & $\begin{array}{c}\mathrm{P} \\
(\mathrm{N})\end{array}$ & $\begin{array}{c}\mathrm{a}_{\mathrm{r}} \\
(\mathrm{mm})\end{array}$ & $\begin{array}{c}\mathrm{V}_{\mathrm{p}} \\
(\mathrm{mm})\end{array}$ & $\begin{array}{c}\text { CTOD }^{(1)} \\
(\mathrm{mm})\end{array}$ & $\begin{array}{c}\text { CTOD }^{(3)} \\
(\mathrm{mm})\end{array}$ \\
\hline SG 7 01 & 13878 & 21,13 & 0,36 & 0,18 & 0,19 \\
\hline SG 7 02 & 13817 & 20,48 & 0,28 & 0,17 & 0,16 \\
\hline SG 7 03 & 14018 & 20,61 & 0,36 & 0,19 & 0,21 \\
\hline SG 7 04 & 13622 & 20,47 & 0,26 & 0,16 & 0,15 \\
\hline SG 7 05 & 14012 & 20,50 & 0,28 & 0,16 & 0,13 \\
\hline $\begin{array}{c}\text { Média } \pm \\
\text { DP }\end{array}$ & $\begin{array}{c}13869 \pm \\
163,13\end{array}$ & $\begin{array}{c}20,64 \\
\pm 0,28\end{array}$ & $\begin{array}{c}0,31 \pm \\
0,05\end{array}$ & $\begin{array}{c}0,17 \pm \\
0,03\end{array}$ & $\begin{array}{c}0,17 \pm \\
0,03\end{array}$ \\
\hline
\end{tabular}


Tabela 41- Valores de Integral J de carga máxima para condição de 168 h de hidrogenação para corpos de prova com $70 \%$ de redução de espessura.

\begin{tabular}{|c|c|c|}
\hline \multirow{2}{*}{ CP } & \multicolumn{2}{|c|}{ Integral $\mathbf{J}\left(\mathrm{J} / \mathrm{mm}^{2}\right)$} \\
\cline { 2 - 3 } & $\mathbf{J}^{(1)}$ & $\mathbf{J}^{(3)}$ \\
\hline SG 7 01 & 0,18 & 0,18 \\
\hline SG 7 02 & 0,15 & 0,15 \\
\hline SG 7 03 & 0,20 & 0,20 \\
\hline SG 7 04 & 0,15 & 0,14 \\
\hline SG 7 05 & 0,13 & 0,12 \\
\hline
\end{tabular}

O alcance do CTOD de carga máxima nesta bateria de ensaios está condicionada a presença de entalhes laterais de profundidade adequada confirmando estudos de Green e Knott (1975) e Zhang e Shi (1992).

De acordo com os estudos mencionados a existência dos entalhes laterais representa um aumento virtual da espessura do corpo de prova e aumenta a severidade da restrição plástica ao longo da espessura remanescente do corpo de prova. Tal fato pode ser verificado com o alcance do CTOD / Integral J relevantes a o material ( $\delta_{\mathrm{i}} / \mathrm{J}_{\mathrm{i}}, \delta_{\mathrm{c}} / \mathrm{J}_{\mathrm{c}}, \delta_{\mathrm{u}} / \mathrm{J}_{\mathrm{u}}$ e $\delta_{\mathrm{m}} / \mathrm{J}_{\mathrm{m}}$ ) antes não alcançados com corpos de prova de espessura total, ou seja, sem entalhes laterais.

Nos resultados obtidos neste trabalho, o alcance do CTOD de carga máxima com entalhes laterais é explicado pela imposição de um maior nível de restrição plástica ao ligamento lateral do corpo de prova e uma redistribuição de tensão ao longo da espessura do corpo de prova

O centro do corpo de prova é a região de maior restrição plástica, o que pode ser considerado como a região em estado plano de deformação quando se tem corpos de prova espessos o suficiente.

Caso contrario, o uso de entalhes laterais em corpos de prova com espessura insuficiente para garantir o estado plano de deformação pode reduzir a extensão de regiões do corpo de prova em estado plano de tensão (extremidade na direção da espessura), aumentando assim a extensão da região de deformação plana.

Segundo Knott e Green (1975), na presença de entalhes laterais, as regiões do corpo de prova em estado plano de tensão com uma extensão de 4 r, onde $r$ é igual ao raio do entalhe, é menor que a mesma região em corpos de prova sem 
entalhes. A Figura 132 ilustra a redução da região de deformação plana em função da redistribuição das tensões principais.

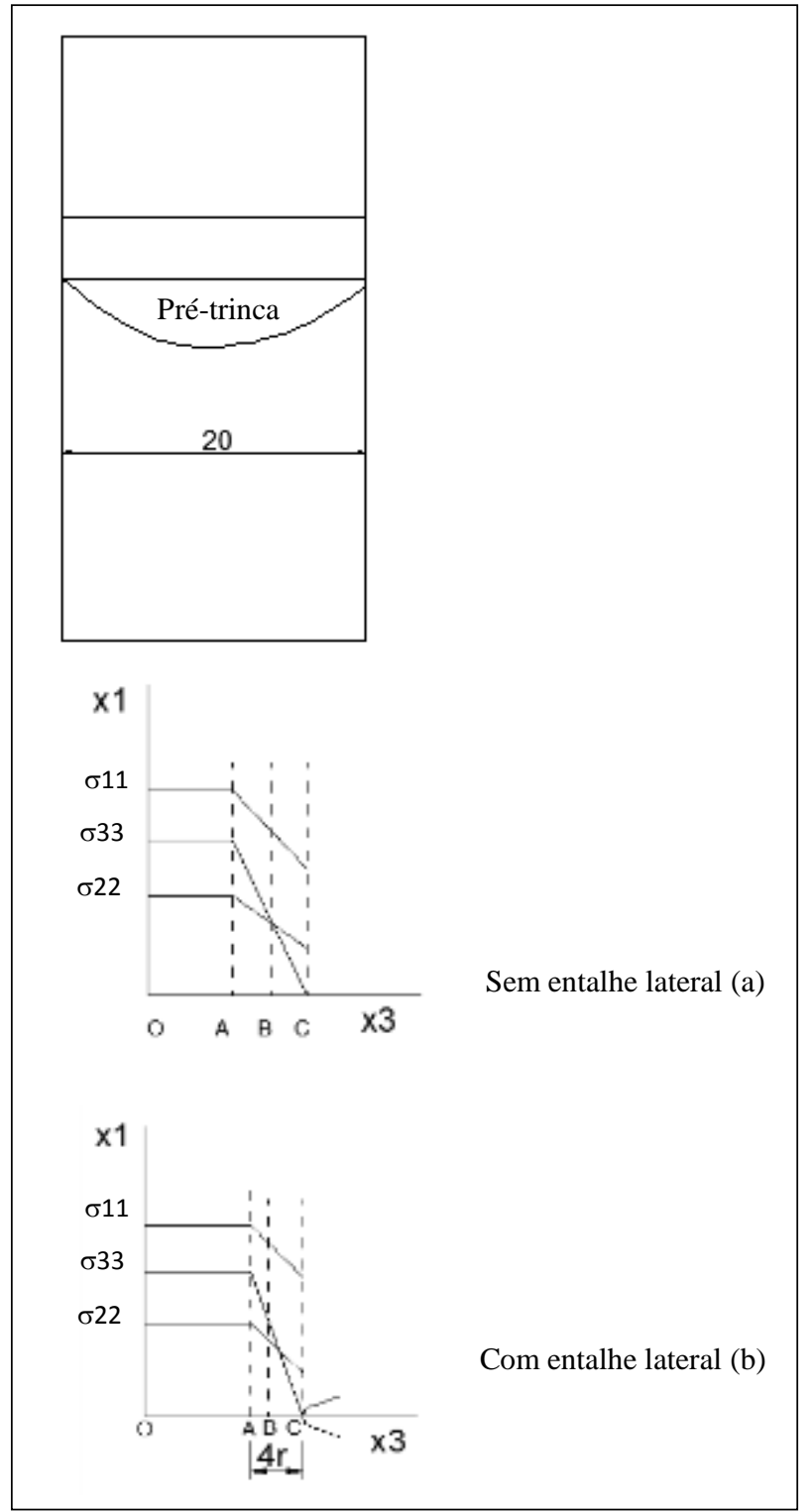

Figura 132- Distribuição de tensões na espessura em corpos de prova sem entalhe lateral (a) e com entalhe lateral (b). Adaptado de (Knott e Green ,1975)

\subsection{Análise dos métodos usados na determinação da tenacidade à} fratura.

Apesar dos valores de Integral $\mathbf{J}$ terem sido apresentados, a discussão dos diferentes valores é apresentada em função dos valores de CTOD descritos no item 4.3.4. 
A análise dos valores de CTOD encontrados para todas as condições de ensaio mostra a equivalência existente entre os resultados obtidos diretamente do ensaio através do software controlador do ensaio $\left(\mathrm{CTOD}^{(1)}\right)$ e os calculados pela autora pela Equação (45) da norma BS 7448:1 (1991) descrita no item 2.4.1. Essa verificação mostra a confiabilidade do procedimento experimental adotado neste estudo.

Os valores de CTOD calculados pelo método da ASTM 1820-11 (2011), ou seja, $\mathrm{CTOD}^{(3)}$ são menores que os obtidos pela BS $7448\left(\mathrm{CTOD}^{(1)}\right.$ ou $\mathrm{CTOD}^{(2)}$, o que implica em análises de tenacidade a fratura mais conservadoras pela norma americana. Tal conservadorismo está de acordo com estudos feitos por Tagawa(2010).

Atualmente a norma ASTM 1820-11 (2011) estabelece que o CTOD deve ser obtido pela Integral J, através da Equação(49) descrita no item 2.4.2.

A razão para a diferença nos valores de $\operatorname{CTOD}^{(3)}$ está preliminarmente associada a incompatilidade entre a forma de cálculo do parâmetro mencionado. Através da análise da Equaçãopara cálculo do CTOD, se verifica que a ASTM (1820-11) considera o comportamento elasto-plástico do material com a inserção do fator de restrição plástica $(\mathrm{m})$, descrito no item 2.4.2, e o efeito do limite de escoamento e da resistência mecânica do material.

A redução do CTOD obtido pela norma americana está relacionado com a presença do fator de restrição plástica (m) na Equaçãodo determinação do CTOD, descrita no item 2.4.2.

A influência da restrição plástica é claramente verificada através da relação $2 \sigma_{\mathrm{ys}} / \mathrm{m}_{\mathrm{f}}$, na qual $\sigma_{\mathrm{ys}}$ e $\sigma_{\mathrm{f}}$ são respectivamente o limite de escoamento (462 $\mathrm{MPa})$ e a tensão de escoamento do material (508,5 MPa), respectivamente. Com a incorporação de $(\mathrm{m})$, o termo $m \sigma_{\mathrm{y}}$ é maior que $2 \sigma_{\mathrm{ys}}$ e consequentemente a relação $2 \sigma_{\mathrm{ys}} / \mathrm{m \sigma}_{\mathrm{f}}$, correspondente a $\delta_{\mathrm{el}: \mathrm{ASTM}} / \delta_{\mathrm{el}: \mathrm{BS}}$, assume valores menores que a unidade. A Figura 133 mostra os dois termos citados $\left(\sigma_{\mathrm{ys}}\right.$ e $\left.\sigma_{\mathrm{y}}\right)$ para todas as condições de ensaio. 


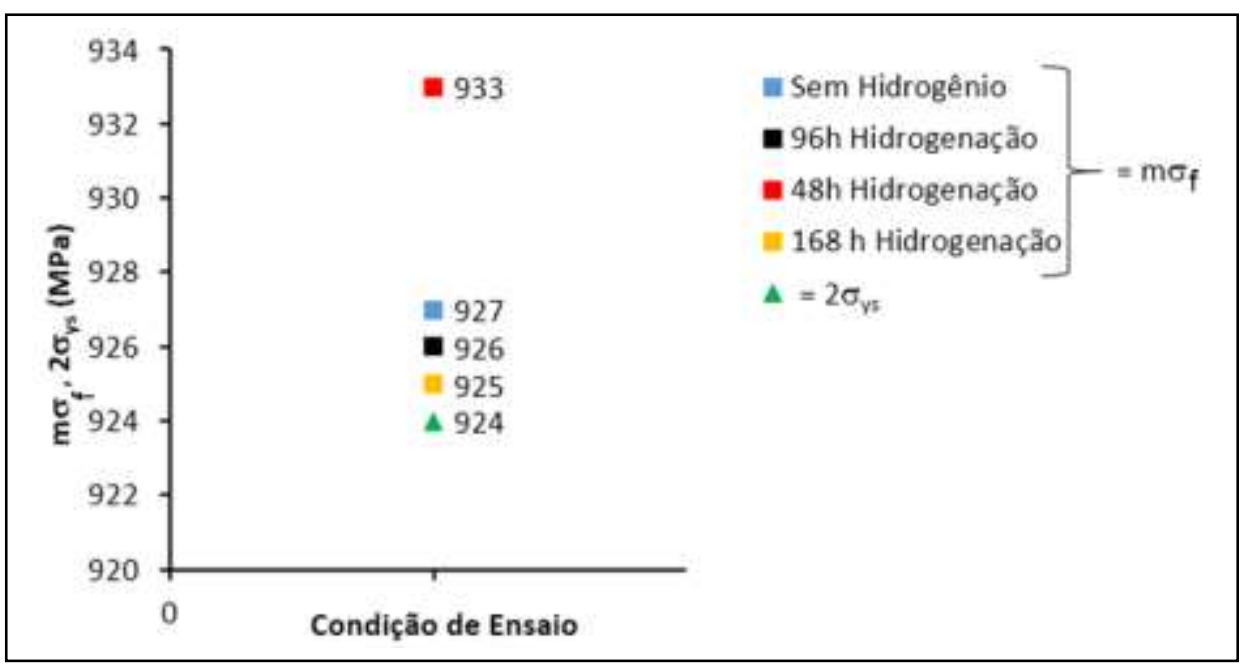

Figura 133-Relação entre termos $2 \sigma_{\mathrm{ys}}$ e $m \sigma_{\mathrm{f}}$ para as condições de ensaio realizadas.

Sabe-se que $\mathrm{m}=1$ para corpos de prova no estado plano de tensão e $\mathrm{m}=2$ para a condição de deformação plana, porém Tagawa (2010) e Pereira, Darwish e Campelo (2013) comprovaram que o nível de restrição plástica imposta ao corpo de prova e dependente de propriedades mecânicas como limite de resistência mecânica e coeficiente de encruamento do material. Pereira, Darwish e Campelo (2013) compravaram a possibilidade de se obter fatores de restrição plástica maiores que 2 em função do coeficiente de encruamento. Consequentemente pode-se alcançar maiores termos $m \sigma_{\mathrm{y}} \mathrm{e}$ consequentemente menores valores de tenacidade à fratura quando avaliados pela norma ASTM 1820-11(2011). 


\section{Conclusões e Sugestões de Trabalhos Futuros}

Este trabalhou estudou o comportamento em fratura do aço estrutural API 5L X65 após exposição a diferentes carregamentos de hidrogênio. De acordo com os resultados obtidos no Capítulo 4, se pode concluir que:

O aço de grau API 5L X65 possui boa ductilidade, preliminarmente determinada no ensaio de impacto, onde se observou altos valores de energia absorvida em baixas temperaturas, incluindo nestas baixas temperaturas, aquela na qual se realizou os ensaios de CTOD. Tal comportamento dúctil, associado com a limitação operacional do clip gage, contribuiu para que os resultados de tenacidade à fratura da primeira bateria de ensaios não fossem representativos de qualquer evento físico relevante do material, mesmo em condições de carga de hidrogênio.

Em relação aos ensaios feitos com maior tempo de hidrogenação (168 h) e diferentes velocidades de ensaio $(0,25 \mathrm{~mm} / \mathrm{min}$ e $0,50 \mathrm{~mm} / \mathrm{min})$, se observou diferença na tenacidade à fratura do material medida por CTOD e Integral J.

Pela análise dos valores de CTOD se pode concluir que o fator velocidade interfere nos parâmetros de tenacidade à fratura do material estudado. A redução na velocidade de ensaio para condição de 168 h aumenta o tempo de duração do mesmo e favorecendo a difusão do hidrogênio na estrutura cristalina. $O$ maior tempo de duração do ensaio associado a concentração de hidrogênio beneficia a atuação do hidrogênio sobre as discordâncias (mecanismo HELP) e, consequentemente o alcance de maiores valores de CTOD na velocidade de ensaio mais baixa, ou seja, 0,25 $\mathrm{mm} / \mathrm{min}$.

Para a condição de hidrogenação de 96 h e velocidade de ensaio de 1,0 mm / min se obteve valores de tenacidade à fratura semelhantes aos obtidos para condição de hidrogenação de 168 h e mesma velocidade. Ambos os resultados de $96 \mathrm{~h}$ e $168 \mathrm{~h}$ para velocidade de ensaio de $1,0 \mathrm{~mm} / \mathrm{min}$ são similares que os obtidos para carga de hidrogênio anterior $(168 \mathrm{~h}$ ) na velocidade de teste de 0,5 $\mathrm{mm} / \mathrm{min}$. Tal fato mostra que o tempo de hidrogenação acima do mínimo de $96 \mathrm{~h}$ 
especificado pela norma influencia a comportamento à fratura do material. Este tempo de hidrogenação mesmo com o aumento da velocidade de ensaio favorece a atuação do mecanismo de plasticidade localizada na ponta da trinca provocado pelo hidrogênio e, consequentemente a obtenção de elevados valores de CTOD.

Os resultados de tenacidade à fratura para a menor carga de hidrogênio (48 h) aliado a velocidade de teste de $1,0 \mathrm{~mm} / \mathrm{min}$ são levemente inferiores aos obtidos com carga de 96 h na mesma velocidade.

A velocidade de ensaio influencia a tenacidade à fratura, como já concluído nas condições de hidrogenação de 168 h. Tal evidência também foi verificada nos ensaios realizados com velocidade de 1,5 mm / min após 48 h de hidrogenação. Em relação aos resultados anteriores para esta condição de hidrogenação na velocidade de 1,0 mm / min, o tempo para a difusão do hidrogênio em direção a ponta da trinca foi menor. Este fato associado a menor concentração de hidrogênio inferior ao especificado pela norma NACE 0284-2003 (2003) acarreta quantidade de hidrogênio insuficiente na ponta da trinca não favorecendo o mecanismo de atuação HELP pelo hidrogênio. Tal fato é responsável pela redução dos valores de CTOD.

Com base no exposto, se conclui que houve interferência do hidrogênio e da taxa de deformação imposta aos corpos de prova no comportamento à fratura do aço estudado, e tais interferências foram função de fatores relacionados a concentração (tempo de hidrogenação) e velocidade de teste.

Em se tratando de efeitos prejudiciais provocados pelo hidrogênio, estes não foram verificados nos valores de CTOD para a condição máxima de hidrogenação (168 h e velocidade de ensaio de $0,5 \mathrm{~mm} / \mathrm{min}$ ) em relação a condição não hidrogenada. Porém, se observou aumento da propagação estável da trinca conforme demonstrado no item 4.3.5.3. Quanto ao micromecanismo de fratura, observou-se uma leve mudança na condição hidrogenada por 168 h. Este passou de nucleação, crescimento e coalescimento de cavidades na condição sem hidrogênio para micromecanismo de quase clivagem (dimples facetados).

A segunda bateria de ensaios com corpos de prova entalhados lateralmente permitiu concluir que a severidade do nível de tensões tem importância fundamental no comportamento à fratura do aço frente a exposição ao hidrogênio.

A análise dos resultados obtidos na condição de hidrogenação de 168 h e velocidade de ensaio de $0,5 \mathrm{~mm} / \mathrm{min}$ evidenciou que a presença de entalhes 
laterais diminuiu a capacidade do material em suportar carregamentos. Tal fato foi verificado pelos menores valores de carga alcançados durante o ensaio.

Os valores reduzidos de tenacidade à fratura correspondentes a condição de carga máxima, antes não alcançados na primeira bateria de ensaios, se deve a redução da carga portante do material e a antecipação do instante (abertura do clip gage) onde as cargas máximas aconteceram durante os ensaios.

Para a continuidade da avaliação da susceptibilidade dos aços grau API 5L X65, a ação do hidrogênio, se sugere os seguintes itens:

- realizar ensaios de tenacidade à fratura simultâneo a exposição a fonte de hidrogenação;

- avaliar quantitativamente a concentração de hidrogênio existente (ppm) no aço submetido a exposição ao método de hidrogenação para análise da influência sobre a tenacidade a fratura e determinação da concentração crítica de hidrogênio;

- Ensaiar maior número de corpos de prova nas velocidades estudadas, com o objetivo de obter melhor avaliação da influência de tal parâmetro de ensaio no comportamento à fratura do material;

- efetuar ensaios em corpos de prova com entalhes laterais profundos expostos a diferentes cargas de hidrogenação (168 h, 96 h) para avaliar a interferência do hidrogênio sobre o comportamento à fratura em condições de maior severidade de tensões;

- realizar observações dos corpos de prova expostos a hidrogenação através da técnica de microscopia eletrônica de transmissão (MET) para avaliar comportamento das discordâncias e consequentemente sua contribuição para o deslizamento dos planos cristalográficos no material (deformação plástica). 


\section{Referência Bibliográfica}

AGENCE FRANCE PRESSE. AIE mantém previsão de demanda de petróleo em 2015. G1, Rio de Janeiro, jan. 2015. Seção Economia. Disponível em: <http: //g1.globo.com/economia/noticia/2015/01/aie-mantem-previsao-de-demanda-depetroleo-em-201.html>. Acesso em: fev 2015.

AL-MANSOUR, M; ALFANTAZI, A.M.; EL-BOUDJDAINI, M. Sulfide stress cracking resistance of API X-100 high strength low alloy steel. Materials and Design, USA, v. 30, n. 10, p. 4088-4094, dez, 2009.

AMERICAN PETROLEUM INSTITUTE. API Specification 5L. Specification for line pipe, $44^{\mathrm{a}}$ ed. USA: National adoption.2007. $154 \mathrm{p}$.

AMERICAN SOCIETY FOR TESTING AND MATERIALS. ASTM E 1820-11. Standard Test Method for Measurement of Fracture Toughness, USA, 2011.

ASTM E45-11. Standard Test Methods for Determining the Inclusion Content of Steel, USA, 2011.

ASTM E E407-07e1. Standard Test Methods for Microetching Metals and Alloys, USA, 2007.

ASTM E23-12c. Standard Test Methods for Notched bar Impact Testing of Metallic Materials, USA, 2012.

ASTM A 370-12a. Standard Test Methods and Definitions for Mechanical Testing of Steel Products, USA, 2012 
ASTM E92. Standard Test Method for Vickers Hardness of Metallic Materials, USA, 2003.

ASTM F519-13. Standard Test Method for Mechanical Hydrogen Embrittlement Evaluation of Plating/Coating Processes and Service Environment, USA, 2013. ASTM F1459-06. Standard Test Method for of the Susceptibility of Metallic Materials to Hydrogen Gas Embrittlement (HE), USA, 2012.

ASTM F1624-12. Standard Test Method for Measurement of Hydrogen Embrittlement Threshold in Steel by the Incremental Step Loading Technique, USA, 2012.

ASTM F1940-07a. Standard Test Method for Process Control Verification to Prevent Hydrogen Embrittlement in Plated or Coated Fasteners, USA, 2014.

ASTM G129-00. Standard for Slow Strain Rate Testing to Evaluate the Susceptibility of Metallic Materials to Environment Assisted Cracking, USA, 2013.

ASTM G142-98. Standard Test Method for Pressure, High Temperature. Or Both, USA, 2011.

ANDERSON, T. L. Fracture Mechanics: Fundamentals and Applications. 3.ed. Oxford: CRC Press, 2005. 640p.

ANDREWS, P .; MCQUEEN, M; MILLWOOD, N. Fracture Toughness of Line Pipe Under Cathodic Protection Using Crack Tip Opening Displacement Tests. Corrosion Engineering, USA, v. 57, n. 8, p. 721-729, ago, 2001. 
ARAFIN, M.A; SZPUNAR, J.A. Effect of bainitic microstructure on the susceptibility of pipeline steels to hydrogen induced cracking. Materials Science and Engineering A. USA, v. 528, p. 4927-4940, jun, 2011.

ASAHI, H. Effect of the microstructure and non metallic inclusions on the susceptibility of low alloy steels to sulfide stress corrosion cracking. Materials Science. Moscow, v. 27, n.6, p. 580-585, dec, 1989

ASAHI, H; HIRAMAKI, D; YAMASAKI, S. Hydrogen Trapping Behavior in Vanadium-added Steel. ISIJ International, v. 43, n.4, p. 527-533, Japão, 2003

ASKELAND, D; FULAY, P; WRIGHT, W. The Science and Engineering of Materials. Cengage Learning, 2010. 896 p.

ASM. ASM Handbook Volume 12: Fractography. USA. ASM International, 1987. 517p.

BARNOUSH, A. Hydrogen Embrittlement. Saarland University Journal, 2011. Disponível em: <http: //www.unisaarland.de/fak8/wwm/research/phd_barnoush/hydrogen.pdf>. Acesso em: mai 2013

BEACHEM, C.D. A new model for hydrogen-assisted cracking (Hydrogen “Embrittlement”). Metallurgical Transactions, v. 3, n.2, p. 441-455, fev. 1972.

BEIDOKHTI, B; DOLATI, A; KOUKABI, A.H. Effects of alloying elements and microstructure on the susceptibility of the welded HSLA steel to hydrogeninduced cracking and sulphide stress cracking. Materials Science and Engineering: A, v. 507, p. 167-173, may. 2009.

BEREJENOI, C; PEREZ IPIÑA, J.E.; LLORENTE, C.L. Reproducibility of popins in laboratory testing of welded joints. Materials Research, v. 3, n. 4, p. 139$146,2000$. 
BIRNBAUM, H.K; SOFRONIS, P. Hydrogen-enhanced localized plasticity - a mechanism for hydrogen-related fracture. Materials Science and Engineering: A. USA, v. 176, n. 1-2, p. 191-202, mar.1994.

BONORA, N. et al. Ductile damage evolution under triaxial state of stress: theory and experiments. International Journal of Plasticity. USA, v.21, n. 5, p. 9811007, mai. 2005

BRITISH STANDARD (BS). BS 7448 - Fracture mechanics toughness tests: PART I: Method for determination of $\mathrm{K}_{\mathrm{Ic}}$, critical CTOD and critical $\mathbf{J}$ values of metallic materials. United Kingdom: BSI, dez.1991. 42 p.

BROEK, D. Elementary Engineering Fracture Mechanics. 4. ed. Springer, $1982,540 \mathrm{p}$.

The Practical Use of Fracture Mechanics. 1. ed. Kluwer Academic, 1988,522 p.

CARNEIRO, R.A; RATNAPULI, R.C; LINS, V.F.C. The influence of chemical composition and microstructure of API linepipe steels on hydrogen induced cracking and sulfide stress corrosion cracking. Materials Science \& Engineering, USA, v. 357, n.1-2, p.104-110, set, 2003.

CHATEAU, J.P; DELAFOSSE, D; MAGNING, T. Numerical simulations of hydrogen-dislocation interactions in $f c c$ stainless steels.: part I: hydrogendislocation interactions in bulk crystals. Acta Materialia. França, v.50, n. 5, p. 1507 a 1522, abr.2002.

CHATZIDOUROS, E.V. et al. Hydrogen effect on fracture toughness of pipeline steel welds, with in situ hydrogen charging. International Journal of Hydrogen Energy, USA, v. 36, p.12626-12643, jul. 2011. 
CHEN, Z; BUTCHER, C. Micromechanics Modelling of Ductile Fracture. Canada. Springer, 2013, 358p.

CHICOT, D.; VIANNA, C.S.; MIRANDA, P.E.V. Difusão do hidrogênio em martensita. In: Actas del Congresso/CONAMET/SAM.2002. Santiago. Simpósio Matéria. Difusão do hidrogênio em martensita. Rio de Janeiro: UFRJ, 2002, v.1, p.1-12.

CHOO, L.Y.; LEE, W.Y. Thermal Analysis of Trapped Hydrogen in Pure Iron. Metallurgical Transactions A, USA, v. 13, p. 135-140, jan. 1982.

COLEMAN, K.; LIU, K. Stress corrosion cracking of grade 91 materials. Palo Alto (CA): EPRI; 2007, report n. 1013360.

COTTERELL, B. The past, present and future of fracture mechanics. Engineering Fracture Mechanics, USA, v. 69, n.5, p. 533-553, mar. 2002.

CRANK, J. The Mathematics of Diffusion. 2. ed. Oxford Univerty Press, 1980. $424 \mathrm{p}$.

DAYAL, R.K; PARVATHAVARTHINI, N. Hydrogen embrittlement in power plant steels. Sadhana, India, v. 28, p. 431-451, 2003.

DE CASTRO, J.F.R. Desenvolvimento de Nanocompósitos à Base de $\mathbf{M g}$ Armazenadores de Hidrogênio Processados por Moagem de Alta Energia. 2003. Tese. Doutorado em Ciência e Engenharia de Materiais - Universidade Federal de São Carlos, São Paulo 2003.

DOMIZZI, G.; ANTERI, G.; OVEREJO-GARCIA, J. Influence of sulphur content and inclusion distribution on the hydrogen induced blister cracking in pressure vessel and pipeline steels. Corrosion Science, USA, v. 43, n. 2, p. 325339, fev, 2001. 
DONATO, G. H. B. Efeito de Heterogeneidades Mecânicas sobre Forças Motrizes de Trincas em Juntas Soldadas: Determinação Experimental de Tenacidade e Extensão de Metodologia de Avaliação de Criticidade de Defeitos. 2009. Tese. Doutorado em Engenharia Naval e Oceânica - Escola Politécnica da Universidade de São Paulo, São Paulo 2009.

DONG, C. F. et al. Effects of hydrogen-charging on the susceptibility of X100 pipeline steel to hydrogen-induced cracking. International Journal of Hydrogen Energy, USA, v. 34, p.9879-9884, out. 2009.

DONG, X; ZENG, Z.; ZHENG, Q. Electronic structure of light impurities in alpha -Fe and V. Journal of Physics: Condensed Matter, v.1, n.41, United Kingdom, p.7577-7582, 1989.

ELIEZER, D.; TAL-GUTELMACHER, E.; BOELLINGHAUS, TH. Hydrogen embrittlement in Hydride and non hydride formimg systems - microstructural / phase changes and cracking mechanisms. $1^{\text {th }}$ International Conference on Fracture, Italy, p. 123-130, 2005

FALLAHMOHAMMADI, F; BOLZONI, F; LAZZARI, L. Measurement of lattice and apparent diffusion coefficient of hydrogen in X65 and F22 pipeline steels. International Journal of Hydrogen Energy, USA, v.38, n.5, p. 25312543, 2013.

FASSINA et al. Influence of hydrogen and low temperature on mechanical behavior of two pipeline steels. Engineering Fracture Mechanics, USA, v. 81, p. 43-55, fev. 2012.

FERREIRA, G.L.M. Estudo da Susceptibilidade à Corrosão sob Tensão e à Corrosão - Fadiga do Aço API 5L X65 Aspergido Termicamente Utilizado Em Componentes Offshore. Tese. 2003. Universidade Federal do Rio Grande do Sul UFRGS. Porto Alegre. 
FERREIRA, P.J.; ROBERTSON, I.M.; BIRNBAUM, H.K. hydrogen effects on the interaction between dislocations. Acta Materialia, USA, v.46, n.5, p. 17491757, 1998.

GARRIDO, E. China compra parte de campo de petróleo no Cazaquistão. Exame.com. <http://exame.abril.com.br/mundo/noticias/china-compra-parte-degrande-campo-de-petroleo-no-cazaquistao> Acesso em: 08 set. 2013.

GAVRILJUK, V. G.; SHIVANYUK, V.N.; SHANINA, B.D. Change in the electron structure caused by $\mathrm{C}, \mathrm{N}$ and $\mathrm{H}$ atoms in iron and its effect on their interaction with dislocation. Acta Materialia, USA, v. 53, n. 19, p. 5017-5024, nov. 2005.

GEELS, K. Metallographic and Materialographic Specimen Preparation, Light Microscopy, Image Analysis and Hardness Testing. USA: ASTM international, 2007. p. 698.

GERBERICH, W.W.; STAUFFER, D.D.; SOFRONIS, P. A Coexistent View of Hydrogen Effects on Mechanical Behavior of Crystals: HELP and HEDE. In: Effects of Hydrogen on Materials, USA, p. 38-45, 2008.

GORDON, J.R.; NEALE, B.K.; WANG, Y.Y. A comparison of J and CTOD as elastic-plastic fracture characterizing parameters. In: KIRK, M; BAKKER, A. Constraint Effect in Fracture: Theory and Applications. USA, American Society for Testing and Materials, 1995. p. 425-444.

GOTO, D.M; KOSS, D.A. An experimental model of the growth of neighboring voids during ductile fracture. Scripta Materialia, USA, v.35, n.3, p. 459-463, ago, 1996.

GREEN, G.; KNOTT, J. F. Effects of side grooves on initiation and propagation of ductile fracture. Metals Tecnology, USA, v.2, n.1, p. 422-427, jan, 1975. 
GROSS, D; SEELIC, T. Fracture Mechanics: With a Introduction to Micromechanics. 2. ed. Springer, 2011. 340 p.

GUO et al. Effects of strain rate on Fracture Toughness in Sour Environmet. 29th International Conference on Ocean, Offshore and Arctic Engineering, China, v. 6, p. $57-61,2010$.

HAGIWARA, N.; OGUCHI, N. Fracture Toughness of Line Pipe Under Cathodic Protection Using Crack Tip Opening Displacement Tests. Corrosion Engineering, USA, v. 55, n. 5, p. 503-511, mai, 1999.

HALLEN, J.M.; GONZÁLEZ, J.L; HERNÁNDEZ, J.; HERNANDEZ-LAGO, F. Effect of Inclusions and Dissolved Hydrogen on the Fracture Toughness of

Pipeline Steels. Disponível em: http://www.gruppofrattura.it/ocs/index.php/esis/ECF13/paper/viewFile/8451/4895 >. Acesso em jul. 2013.

HARDIANFARD, M.J. Failure in a high pressure feeding line of an oil refinery due to hydrogen effect. Engineering Failure Analysis, USA, v. 17, p.873-881, nov. 2009.

HARDIE, D; CHARLES, E.A; LOPEZ, A.H Hydrogen embrittlement of high strength pipeline steels. Corrosion Science, USA, v. 48, p. 4378-4385, mai. 2006.

HEARN, E. J. Mechanical of Materials 1: An Introduction to the Mechanics of Elastic and Plastic Deformation of Solids and Structural Materials. 3.ed. Oxford: Butterworth-Heinemann, 1997. 450p.

HUANG, et al. Effect of microstructure and inclusions on hydrogen induced cracking susceptibility and hydrogen trapping efficiency of X120 pipeline steel. Materials Science and Engineering, v.527, USA, p. 6997-7001, july 2010 
HULKA, K. Metallurgical Concept and Full-Scale Testing of High Toughness, $\mathrm{H}_{2} \mathrm{~S}$ Resistant 0,03\%C-0,10\%Nb Steel. Niobium Technical Report. CBMM.2001.

HULL, D.; BACON, D. J. Introduction to Dislocations. New York. Elsevier, 2011. 268p.

HÜTTER, G; ZYBELL, L; KUNA, M. Micromechanical Modeling of Crack Propagation with Competing Ductile and Cleavage Failure. Procedia Materials Science, USA, v, 3, p. 428-433, 2014.

IMAI, Y.; MATAKE, T. Effect of side grooves on the elastic-plastic stress state of fracture toughness specimens - three dimensional finite element analysis. Engineering Fracture Mechanics, USA, v.16, n.5, p. 659-668, 1982.

ISACSSON, M; NARSMTRÖN, T. Microscopic examination of crack growth in a pressure vessel steel. Materials Science and Engineering, USA, v. 241, n. 1-2, p. 169-178, jan, 1998.

INTERNATIONAL ORGANIZATION FOR STANDARDIZATION. ISO 11114-4. Test Methods for Selecting Metallic Materials Resistant to hydrogen Embrittlement, USA, 2005.

INTERNATIONAL ORGANIZATION FOR STANDARDIZATION. ISO 17081-2004. Method of Measurement of Hydrogen Permeation and Determination of Hydrogen Uptake and Transport in Metals by an Electrochemical Technique, USA, 2004.

JANSSEN, M.; ZUIDEMA, J; WANHILL, R. Fracture Mechanics. 2.ed. USA. VSSD, 2006. 378p.

JANSSON, J.; HULT, J. Fracture mechanics and damage mechanics: a combined approach. Journal of Applied Mechanics. USA, v. 1, n.1 p. 69-84, 1977. 
JHA et al. Failure analysis of high strength low alloy $0,15 \mathrm{C}-1,25 \mathrm{Cr}-1 \mathrm{Mo}-$ $0,25 \mathrm{~V}$ steel pressure vessel. Case Studies in Engineering Failure Analysis, China, v.1, n.4, p. 265 a 272. out.2013.

JIANG, D.E.; CARTER, E.A. Diffusion of interstitial hydrogen into and through bcc Fe from first principles. Physical Review B, v.70, USA, p. 1-9, 2004.

JOHNSON, W.H. On some remarkable changes produced in iron and steel by the action of hydrogen and acid. Disponível em: < rspl.royalsocietypublishing.org>. Acesso em nov. 2013.

KIM, J; GAO, X; SRIVATSAN, T.S. Modeling of void growth in ductile solids: effects of stress triaxiality and initial porosity. Engineering Fracture Mechanics. USA, v. 71, n.3, p. 379-400, fev. 2004.

KOZAK, D.; IVANDIĆ, Ž. Stress triaxility as a measure of the constraint by fracture mechanics specimens. In: Symposium on Experimental Solid Mechanics, Zagreb, 2002, Croacia. Disponível em: <https://bib.irb.hr/datoteka/83876.bertinoro.doc>. Acesso em jul. 2013.

LANCASTER, J. F. Metallurgy of Welding. 6.ed. Woodhead Publishing Limited, 1999. 446p.

LANDES, J.D; BEGLEY, J.A. Recent developments in $\mathrm{J}_{\text {Ic }}$ testings. In: BROWN, W.F. Developments in Fracture Mechanics Test Methods Standardizations. USA: 1977. ASTM, p. 57-81

LEAL, F.C. Influência do tamanho de grão austenítico na resistência à corrosão sob tensão de aços para aplicação sour service. 2007. Dissertação. Mestrado em Engenharia Metalúrgica - Universidade Federal de Minas Gerais UFMG, Belo Horizonte.

LEE, H.G.; LEE, J-Y. Hydrogen Trapping by TiC Particles in Iron. Acta Metallurgica, v. 32, n.1, p. 131-136, jan. 1984. 
LI et al. A failure study of the railway rail serviced for heavy cargo train. Case Studies in Engineering Failure Analysis, China, v.1, n.4, p.243 a 248, out.2013.

LIU, A. Mechanics and Mechanisms of Fracture: An Introduction. USA. ASM International, 2005. 458p.

LOUTHAN JR., M. R. Hydrogen embrittlement of metals: A primer for the failure analyst. Journal Failure Analysis and Prevention. USA, v.8, p.289-307, mai. 2008.

MALCHER, L; ANDRADE PIRES, F.M; CÉSAR DE SÁ, J.M.A. An assessment of isotropic constitutive models for ductile fracture under high and low stress triaxiality. International Journal of Plasticity. USA. v. 30-31, p. 81-115, mar. 2012.

MATSUI, H.; KIMURA, H.; MORIYA,S. The effect of hydrogen on the mechanical properties of high purity iron by hydrogen charging during tensile deformation. Materials Science and Engineering, USA, v. 40, n. 2, p. 207-216, out. 1979.

McMAHON JR., C.J. Hydrogen-induced intergranular fracture steels. Engineering Fracture Mechanics, USA, v. 68, n.6, p. 773-788, abr. 2001

McMEEKING, R.M. Finite deformations analysis of crack tip opening displacement in elastic-plastic materials and implications for fracture. Journal of Mechanics and Physics of Solids. USA, v. 25, p. 357-381, 1977

MEHRER, H. Diffusion in Solids: Fundamentals, Methods, Materials, Diffusion-Controled Processes. 2. ed. Springer, 2007. 645 p.

MENEZES, C.W.S. Caracterização de Dano Por Hidrogênio em Aços API 5CT L80 13Cr por Meio de Ondas Ultra-Sônicas. Dissertação. 2006. Mestrado em 
Engenharia Metalúrgica e de Materiais - Universidade Federal do Rio de Janeiro - UFRJ, Rio de Janeiro.

MEYERS, M. A; CHAWLA, K. Mechanical Behavior of Materials. 2. ed. Cambridge University Press, 2008. 882 p.

MICHLER, T; BALOGH, M.P. Hydrogen environment embrittlement of an ODS RAF steel - Role of irreversible hydrogen trap sites. International Journal of Hydrogen Energy, USA, v. 35, p.9746-9754, sep. 2010.

MICHLER, T; NAUMANN, J. Microstructural aspects upon hydrogen environment embrittlement of various bcc steels. International Journal of Hydrogen Energy, USA, v. 35, p.821-832, jan. 2010.

MILLS, K. ASM Handbook - Fractography. USA: ASM International, v. 12, 1987. 517p.

MIRANDA, P. E.V; RODRIGUES, J.A. Gases em metais e ligas - Fundamentos e aplicações na engenharia. Rio de Janeiro: Editora Didática e Científica Ltda, 1994.

MOORE, P; PISARSKI, H. CTOD and pipelines: the past, present and future. Journal of Pipeline Engineering, USA, v. 12, n.3, p.237-244, set. 2013.

MORO, et al. Hydrogen embrittlement susceptibility of a high strength steel X80. Materials Science and Engineering A, USA, v. 527, p.7252-7260, jul. 2010.

MORO, I. Fragilisation par l'hydrogène gazeux d'un acier ferrito-perlitique de grade API X80. 2009. Tese. Doutorado em Ciências dos Materiais e Engenharia - L' Université de Toulouse, Toulose 2009.

MURAKAMI, Y. KANEKASI, T. MINE, Y. Hydrogen Effect against Hydrogen Embrittlement. Metallurgical and Materials Transactions A, USA, v.39, n.6, p. 
1327-1339. Disponível em: < http://link.springer.com/article/10.1007\%2Fs11661008-9506-5>. Acesso em jul. 2013.

MURAKAMI, Y. Hydrogen embrittlement mechanism in fatigue and fracture. Disponível em:

http://www.gruppofrattura.it/ocs/index.php/esis/ECF19/paper/viewFile/9008/5781 >. Acesso em jun. 2013.

NACE INTERNATIONAL. NACE MR 0103. Materials Resistant to Sulfide Stress Cracking in Corrosive Petroleum Refining Environments, USA, 2003.

NACE INTERNATIONAL. NACE MR 0175. Petroleum and Natural Gas Industries - Materials for Use in $\mathrm{H}_{2} \mathrm{~S}$-Containing Environments in Oil and Gas Production, USA, 2009.

NACE INTERNATIONAL. NACE TM 0177. Laboratory Testing of Metals for Resistance to Sulfide Stress Cracking and Stress Corrosion Cracking $\mathrm{H}_{2} \mathrm{~S}$ Environments, USA, 2005.

NACE INTERNATIONAL. NACE TM 0284. Evaluation of Pipeline and a Pressure Vessels for Resistance to Hydrogen-Induced Cracking, USA, 2003.

NORSKOV, J.K. Covalent effects in the effective-medium theory of chemical binding: Hydrogen heats of solution in 3d metals. Physical Reviews B, USA, v. 26, n. 6, p. 2875-2885, set. 1982. Disponível em: <http: //www.journals.aps.org/prb/pdf/10.1103/PhysRevB.26.2875>. Acesso em mai. 2014.

OFFERMAN, et al. Ferrite/pearlite band formation in hot rolled medium carbon steel. Materials Science and Technology, USA, v. 18, p.297-303, mar. 2002.

ORIANI, R. The diffusion and trapping of hydrogen in steel. Acta Metallurgical, USA, v. 18, n.1, p. 147-157, jan. 1970. 
ORIANI, R. apud BARNOUSH, A. Hydrogen Embrittlement. Saarland University Journal, 2011. Disponível em: <http: //www.unisaarland.de/fak8/wwm/research/phd_barnoush/hydrogen.pdf $>$. Acesso em: mai 2013.

ORIANI, R. apud STROE, M.E. Hydrogen Embrittlement of Ferrous Materials. 2006. Tese. Doutorado em Ciência dos Materiais - Universidade de Bruxelas - Faculdade de Ciências Aplicadas de Bruxelas, Bélgica 2006. Disponível em: <http://theses.ulb.ac.be/ETD-db/collection/available/ULBetd03312006-122217/unrestricted/HydrogenEmbrittlementofFerrousMaterials.pdf Acesso em: mai 2013.

PARK, G.T. et al. Effect of Microstructure on the Hydrogen Trapping Efficiency and Hydrogen Induced Cracking of Linepipe Steel. Corrosion Science, USA, v. 50, p.1865-1871, may. 2008.

PEREIRA, M. V.; DARWISH, F. A.; CAMPELO, E. On the relationship between J-Integral and crack tip opening displacement in elastic-plastic fracture mechanics. Journal of Materials Engineering and Performance. USA, ASM International, v. 22, n.8, p. 271 - 276, ago. 2013.

PEREZ, N. Fracture Mechanics. Kluwer Academic Publishers, 2004, 284 p.

PERNG, T. P; WU, J. K. A brief review note on mechanism of hydrogen entry into metals. Materials Letters, USA, v. 57, n. 22-23, p. 3437-3438, jul. 2003.

PETCH, N.J; STABLES, P. Delayed fracture of metals under static load. Nature. USA, v. 169, p. 842-851, mai. 1952.

POKLUDA, J.; SANDERA, P. Micromechanism of Fracture and Fatigue: in a Multi-scale Context. 1.ed. Springer, 2012, 293 p. 
PRESSOUYRE, G. M. Trap theory of hydrogen embrittlement. Acta Metallurgica, London, v. 28, n. 7, p. 895-911, jul. 1980.

RAMÍREZ, et al. Effect of Microstructure on the Sulphide Stress Cracking Susceptibility of a High Strength Pipeline Steel. Corrosion Science, USA, v. 50, p.3534-3541, dec. 2008.

ROBERTSON, I. M.; LILLIG, D.; FERREIRA, P. J. Revealing the Fundamental Processes Controlling Hydrogen Embrittlement. In: Effects of Hydrogen on Materials, USA, p. 22-37, 2009.

ROBERTSON, et al. Hydrogen Embrittlement Understood. Metallurgical and Materials Transactions B. USA, v. 46, n. 3, p. 1085-1103, jun, 2015. Disponível: <http: //http://link.springer.com/article/10.1007\%2Fs11663-015-0325-y>. Acesso em: abr 2015.

ROESLER, J., HARDERS, H., BAEKER, M. Mechanical Behaviour of Engineering Materials: Metals, Ceramics, Polymers and Composites. New York. Springer, 2007. 536p.

ROSADO, D. B. Comparação do Efeito da Fragilização por Hidrogênio em Aços com Resistência à Tração Acima de 1000 MPa. 2011. Dissertação. Mestrado em Engenharia e Ciência dos Materiais - Universidade Federal do Rio Grande do Sul - UFRGS, Porto Alegre 2011.

ROYLANCE, D. Introduction to Fracture Mechanics. Massachusetts Institute of Technology, 2001. Disponível em: <http: http://ocw.mit.edu/courses/materialsscience-and-engineering/3-11-mechanics-of-materials-fall-1999/modules/frac.pdf >. Acesso em: mar 2015. 
SAKIR BOR, A. Effect of Pearlite Banding on Mechanical Properties of Hotrolled Steel Plates. ISIJ International, v. 31, n.12, p. 1445-1446, Ankara, Turquia, 1991.

SANTOS, G. A. Desenvolvimento de sensores eletroquímicos a base de Ni e NiCo eletrodepositados para detecção de processos de fragilização por hidrogênio. 2011. 150 f. Dissertação de Mestrado, Universidade Federal do Paraná, Paraná, 2011.

SCHWALBE et al. Relationships between various definitions of the crack tip opening displacement. The Crack Tip Opening Displacement in Elastic-Plastic Fracture Mechanics, Berlim, p. 133-153, 1986.

SHAN, G. X.; KOLEDNIK, O; FISCHER, F. D. A numerical investigation on the geometry dependence of the crack growth resistance in CT specimens. Int. Journal of Fracture, USA, v. 66, pp. 173-187, 1994.

SHIH, C. F. Relationship between the J-Integral and the crack opening displacement for stationary and extending cracks. Journal of the Mechanics and Physics of Solids, USA, v.29, p. 305-326, 1981.

SHUKLA, A. Practical Fracture Mechanics in Design. 2. ed. USA. CRC Press, 2004. 522p.

SOUZA, F. H. L. Avaliação da Tenacidade à Fratura pela Técnica de CTOD para o Tubo de Aço X65Q API 5L Hidrogenado em Ambiente com $\mathrm{H}_{2} \mathrm{~S}$. Dissertação. 2011. Pontifícia Universidade Católica de Minas Gerais - PUC-Minas. Belo Horizonte.

SRINIVASAN, R; NEERAJ, T. Hydrogen embrittlement of Ferritic Steels: Deformation and Failure Mechanism and Challenges in the Oil and Gas Industry. The Minerals, Metals \& Materials Society, jul. 2014. 
STROE, M. E. Hydrogen Embrittlement of Ferrous Materials. 2006. Tese. Doutorado em Ciência dos Materiais - Universidade de Bruxelas - Faculdade de Ciências Aplicadas de Bruxelas, Bélgica 2006.

STROHAECKER, T. R . Comportamento à Fratura de Aços Estruturais de Alta Resistência Mecânica Frente a Ambientes Agressivos. 1989. Tese. Doutorado em Engenharia Metalúrgica e de Materiais - Universidade Federal do Rio de Janeiro - UFRJ, Rio de Janeiro.

SUN, C. T; JIN Z. H. Fracture Mechanics. 1.ed. Elsevier, 2012. 295 p.

TAGAWA, T. et al. Comparison of CTOD Standards: BS 7448-Part 1 and revised ASTM 1290. Engineering Fracture Mechanics, USA, v. 77, n. 2. p. 327-336, jan. 2010.

TAWANCY, H. N.; UL-HAMIG, A.; ABBAS, N. M. Practical Engineering Failure Analysis. CRC Press. USA, 2004.

TETER, D. F; ROBERTSON, I. M; BIRNBAUM, H. K. The effects of hydrogen on the deformation and fracture of $\boldsymbol{\beta}$-titanium. Acta Materialia, USA, v. 49, n. 20, p. 4313-4323, dez. 2001.

TIWARI, G. P. et al. A study of internal hydrogen embrittlement of steels. Materials Science and Enginnering, USA, p. 269-281, fev. 2000.

THOMPSON, A. W. apud STROHAECKER, T. R. Comportamento à Fratura de Aços Estruturais de Alta Resistência Mecânica Frente a Ambientes Agressivos. 1989. Tese. Doutorado em Engenharia Metalúrgica e de Materiais Universidade Federal do Rio de Janeiro - UFRJ, Rio de Janeiro.

TRACEY, D. M. On the Fracture Mechanics Analysis of Elastic-Plastic Materials Using the Finite Element Method. 1973. Tese. Universidade de Brown, USA, 1973. 
TROIANO, A. The role of hydrogen and intersticials in the mechanical behavior of metals. Trans. ASM, USA, v. 52, p. 54-80, 1960.

VEHOFF, H.; ROTHE, W. Gaseous hydrogen embrittlement in FeSi and $\mathrm{Ni}$ single crystals, Acta Metallurgica, USA, v.31, n. 11, p. 1781-1793, nov. 1983.

VERGANI, L. et al. Hydrogen effect on fatigue behavior of a quenched\&tempered steel, Procedia Engineering, USA, v. 74, p. 468-471, 2014.

VIEIRA, P. R. M. Caracterização de juntas de aço-carbono soldadas por “dupla camada" submetidas à ação do $\mathbf{H}_{2}$ S. 2004. Tese. Departamento de Ciência de Materiais e Metalurgia. Pontifícia Universidade Católica do Rio de Janeiro - PUC-Rio, Rio de Janeiro.

VIANNA, C. S. Comportamento Mecânico do Aço API 5L X60 Com e Sem Hidrogênio. 2005. Dissertação. Mestrado em Ciências e Engenharia Metalúrgica e de Materiais - Universidade Federal do Rio de Janeiro - UFRJ, Rio de Janeiro 2005 .

WANG, R. Effects of hydrogen on the fracture toughness of a X70 pipeline steel. Corrosion Science, USA, v. 51, p. 2803-2810, ago. 2009.

WANG, M.; AKYYAMA, E.; TSUZAKI, K. Effect of hydrogen on te fracture behavior of high strength steel during low strain rate. Corrosion Science, USA, v. 49, n. 11, p. 4081-4097, nov, 2007.

WELLS, A. A. Unstable crack propagation in metals: cleavage and fast fracture. In: Crack Propagation Symposium Proceedings. United Kingdom: Cranfield College of Aeronautics 1961. p 210. 
WILLIAMS, J. G. Advances in steels for high strength ERW linepipe applications in Australia. Materials Forum, Canada, v.31, p.1-10, 2007.

ZHANG, X. P; SHIH, Y. W. Constraint os side-groove and its influence on fracture toughness parameter in Charpy-size specimens. Engineering Fracture Mechanics, USA, v. 43, n.5, p. 863-867, nov. 1992.

ZERBST et al. Fitness-for-Service Fracture Assessment of Structures Containing Cracks: A Workshop Based on the European SINTAP/FITNET Procedure. 1.ed. USA, 2007. 320p. 